\title{
IntechOpen
}

\section{Advances in Customer Relationship Management}

Edited by Daniel Catalán-Matamoros 



\section{ADVANCES IN \\ CUSTOMER RELATIONSHIP MANAGEMENT}

Edited by Daniel Catalán-Matamoros 


\section{Advances in Customer Relationship Management}

http://dx.doi.org/10.5772/1795

Edited by Daniel Catalan-Matamoros

\section{Contributors}

Aida Habul, Amila Pilav-Velic, Nichaya Suntornpithug, Pasu Suntornpithug, Namita Bhatnagar, Shiow-Luan Wang, Dzulijana Popovic, Tanko Ishaya, Daniel Catalan-Matamoros

\section{(c) The Editor(s) and the Author(s) 2012}

The moral rights of the and the author(s) have been asserted.

All rights to the book as a whole are reserved by INTECH. The book as a whole (compilation) cannot be reproduced, distributed or used for commercial or non-commercial purposes without INTECH's written permission.

Enquiries concerning the use of the book should be directed to INTECH rights and permissions department (permissions@intechopen.com).

Violations are liable to prosecution under the governing Copyright Law.

\section{(cc) BY}

Individual chapters of this publication are distributed under the terms of the Creative Commons Attribution 3.0 Unported License which permits commercial use, distribution and reproduction of the individual chapters, provided the original author(s) and source publication are appropriately acknowledged. If so indicated, certain images may not be included under the Creative Commons license. In such cases users will need to obtain permission from the license holder to reproduce the material. More details and guidelines concerning content reuse and adaptation can be foundat http://www.intechopen.com/copyright-policy.html.

\section{Notice}

Statements and opinions expressed in the chapters are these of the individual contributors and not necessarily those of the editors or publisher. No responsibility is accepted for the accuracy of information contained in the published chapters. The publisher assumes no responsibility for any damage or injury to persons or property arising out of the use of any materials, instructions, methods or ideas contained in the book.

First published in Croatia, 2012 by INTECH d.o.o.

eBook (PDF) Published by IN TECH d.o.o.

Place and year of publication of eBook (PDF): Rijeka, 2019.

IntechOpen is the global imprint of IN TECH d.o.o.

Printed in Croatia

Legal deposit, Croatia: National and University Library in Zagreb

Additional hard and PDF copies can be obtained from orders@intechopen.com

Advances in Customer Relationship Management

Edited by Daniel Catalan-Matamoros

p. $\mathrm{cm}$.

ISBN 978-953-51-0516-9

eBook (PDF) ISBN 978-953-51-5110-4 


\section{We are IntechOpen, \\ the world's leading publisher of Open Access books}

Built by scientists, for scientists

\section{$4,100+$}

Open access books available

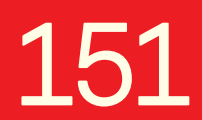

Countries delivered to
$116,000+$

International authors and editors
$120 \mathrm{M}+$

Downloads

Our authors are among the

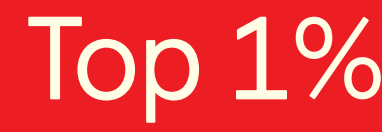

most cited scientists

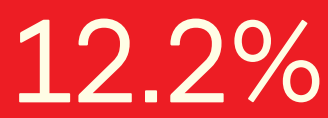

Contributors from top 500 universities

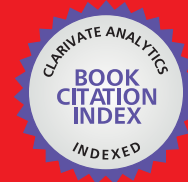

WEB OF SCIENCE ${ }^{\mathrm{TM}}$

Selection of our books indexed in the Book Citation Index in Web of Science ${ }^{\mathrm{TM}}$ Core Collection (BKCI)

Interested in publishing with us?

Contact book.department@intechopen.com

Numbers displayed above are based on latest data collected.

For more information visit www.intechopen.com

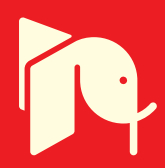





\section{Meet the editor}

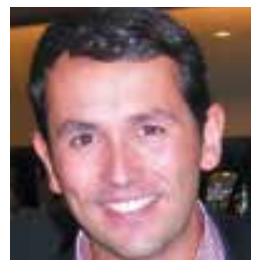

Dr Daniel Catalán-Matamoros was born in Spain, but he has been living in many other countries such as Sweden, Norway and Denmark. He is a PhD, holding a Msc in Mass Communication with expertise in Public Relations. Daniel got a wide experience by working in public administrations being responsible for institutional relations and users satisfaction. His main professional activity has always been dealing with how to promote good relationships with partners and stakeholders. CRM has been always a philosophy in his work which has practiced in many public organisations such as the European Centre for Disease Prevention and Control where he was responsible for the CRM project. Daniel Catalán-Matamoros is convinced that managing good customer relationships is a key element for the success of any organization. 



\section{Contents}

Preface XI

Chapter 1 An Overview to

Customer Relationship Management 1

Daniel Catalán-Matamoros

Chapter 2 Customer Relationship

Management and Business Intelligence 13

Aida Habul and Amila Pilav-Velić

Chapter 3 Investigating Customers' Perceptions

Towards Text Messaging Services as a CRM Medium 31

Nichaya Suntornpithug and Pasu Suntornpithug

Chapter 4 Customer Relationship Marketing:

Customer-Centric Processes for Engendering Customer-

Firm Bonds and Optimizing Long-Term Customer Value 47

Namita Bhatnagar

Chapter 5 Business Intelligence Through

Personalised Location-Aware Service Delivery $\quad 57$

Tanko Ishaya

Chapter 6 Development of a Service Framework for Library Users from Customer Relationship Management Perspective 79

Shiow-Luan Wang

Chapter 7 Dual Approach to the Modelling Single Product

Demand Curves in the Next Best Offer CRM Problem 101

Džulijana Popović

Chapter 8 Business Intelligence in

Telecoms Industry: A Service Oriented Approach 125

Tanko Ishaya and Musiliudeen Folarin 



\section{Preface}

Customer relationship management (CRM) strategies have become increasingly important worldwide due to changes in expectations from customers as well as changes in the nature of markets. This book puts forth a conceptualization that attempts to not only outline CRM's domain but also to reconcile the divergent perspectives found in the academic and popular literature. Readers can see through measurable data-containing examples how the theory is applied with great success by various real-life examples.

This book presents innovative proven methods for determining whether a CRM strategy for changing the way a company provides service (by adding new technology, processes, and procedures) will realize the return on the investment projected. The chapters of the book define important terms, identify the main vendors and actors, and set out the benefits CRM users can expect to experience and the functionality that is available.

KEY TOPICS: Top strategies and tactics for managing customers. Resource allocation decisions, loyalty, and emotions in optimizing customer interactions. Business Intelligence in CRM. Influential factors of CRM performance in electronic services. Customer perceptions towards text messaging services using CRM. Development of a service framework for library users. Modelling single product demand curves in the next best offer in CRM. Book business intelligence in Telecoms Industry: a service oriented approach. Business intelligence through personalised location-aware service delivery.

This book provides the best overall treatment of the subject for anyone interested in understanding and applying customer relationship management concepts in the real world. I believe that this book could be a great help to CRM personnel, student, managers and any one that works directly or indirectly with customers. The way the authors explain the topics is very simple and every step to develop a CRM strategy just makes sense. In addition, the book includes examples of CRM in practice so the readers can learn how CRM is implemented.

I would like personally to congratulate all authors of this book for sharing their experiences in an excellent manner and good methodology. Thanks to their great efforts, this book will be undoubtedly a known reference in the CRM field.

Daniel Catalán-Matamoros

The University of Almeria Spain 



\title{
An Overview to Customer Relationship Management
}

\author{
Daniel Catalán-Matamoros \\ The University of Almeria \\ Spain
}

\section{Introduction}

"[CRM]...isn't a technology. As you will see, that's true, but not strictly. I also heard that it was a 'customerfacing' system. That it is a strategy and/or a set of business processes. A methodology. It is all of the above or whichever you choose" (Greenberg, 2001, p. 4).

Marketing historically has undergone various shifts in emphasis from production through sales to marketing orientation. However, the various orientations have failed to engage customers in meaningful relationship mutually beneficial to organisations and customers, with all forms of the shift still exhibiting the transactional approach inherit in traditional marketing (Kubil \& Doku, 2010). However, Coltman (2006) indicates that in strategy and marketing literature, scholars have long suggested that a customer centred strategy is fundamental to competitive advantage and that customer relationship management (CRM) programmes are increasingly being used by organisations to support the type of customer understanding and interdepartmental connectedness required to effectively execute a customer strategy.

Customer relationship management (CRM) is a combination of people, processes and technology that seeks to understand a company's customers. It is an integrated approach to managing relationships by focusing on customer retention and relationship development. CRM has evolved from advances in information technology and organizational changes in customer-centric processes. Companies that successfully implement CRM will reap the rewards in customer loyalty and long run profitability. However, successful implementation is elusive to many companies, mostly because they do not understand that CRM requires company-wide, cross-functional, customer-focused business process re-engineering. Although a large portion of CRM is technology, viewing CRM as a technology-only solution is likely to fail. Managing a successful CRM implementation requires an integrated and balanced approach to technology, process, and people (Injazz et al, 2003).

The marketing community has been more conscious of the need to manage customer relationships in the long term as well as prior to the first sale. The argument has been further strengthened by data on the low cost of better retention as compared with better acquisition (Blattberg and Deighton 1996, Filiatrault and Lapierre 1997) and the increasing profitability of customers the longer the relationship lasts (Reichheld 1996). CRM has come to represent this more balanced emphasis on continuing relationships rather than simply individual transactions. 
While some suggest that it is a specialized collection of technological tools, others stress it is a set of business processes that focus on managing the customer experience, and still, others propose that it is best conceptualized as a comprehensive strategy for customer retention. Unfortunately, the ambiguity surrounding CRM's nature has also permeated the academic literature and, as a consequence, has generated research streams that address CRM from seemingly incongruent perspectives.

\section{The concept of CRM}

As a review of the literature is likely to reveal, numerous definitions of CRM have been proposed by marketing practitioners and scholars alike. While some of these conceptualizations are similar, there is definitely a lack of consensus as to the most appropriate way in which this emerging phenomenon should be defined.

CRM has been defined from different perspectives (Zablah et al., 2004):

1. as a process,

2. as a strategy,

3. as a philosophy,

4. as a capability

5. and/or as a technological tool.

Table 1 provides a description and representative conceptualization of each of the five major perspectives on CRM. Moreover, the table outlines implications for CRM success (i.e., a firm's ability to build profitable customer relationships) that become particularly salient when CRM is defined in terms of one of the individual perspectives.

There could be other views and functionalities of CRM. For example, according to one industry view, CRM may consist of:

- Helping an enterprise to enable its marketing departments to identify and target their best customers, manage marketing campaigns and generate quality leads for the sales team.

- Assisting the organization to improve telesales, account, and sales management by optimizing information shared by multiple employees, and streamlining existing processes (for example, taking orders using mobile devices)

- Allowing the formation of individualized relationships with customers, with the aim of improving customer satisfaction and maximizing profits; identifying the most profitable customers and providing them the highest level of service.

- Providing employees with the information and processes necessary to know their customers, understand and identify customer needs and effectively build relationships between the company, its customer base, and distribution partners.

\section{Benefits of CRM}

The following lists of desired CRM benefits were collected and summarized from an extensive survey of recent CRM studies (Keith et al., 2008):

1. improved ability to target profitable customers;

2. integrated offerings across channels;

3. improved sales force efficiency and effectiveness; 


\begin{tabular}{|c|c|c|c|}
\hline Perspective & Description & \begin{tabular}{|c|}
$\begin{array}{c}\text { Implications for CRM } \\
\text { success }\end{array}$ \\
\end{tabular} & $\begin{array}{c}\text { Representative } \\
\text { conceptualization }\end{array}$ \\
\hline Process & $\begin{array}{c}\text { Buyer - seller } \\
\text { relationships develop } \\
\text { over time and must } \\
\text { evolve to perdure. }\end{array}$ & $\begin{array}{c}\text { CRM success is } \\
\text { contingent upon a } \\
\text { firm's ability to detect } \\
\text { and respond to } \\
\text { evolving customer } \\
\text { needs and preferences. }\end{array}$ & $\begin{array}{c}\text { [CRM is concerned } \\
\text { with] the creation and } \\
\text { leveraging of linkages } \\
\text { and relationships with } \\
\text { external marketplace } \\
\text { entities, especially } \\
\text { channels and end } \\
\text { users. }\end{array}$ \\
\hline Strategy & $\begin{array}{l}\text { A customer's lifetime } \\
\text { value determines the } \\
\text { amount and kinds of } \\
\text { resources that a firm } \\
\text { invests in a particular } \\
\text { relationship. }\end{array}$ & $\begin{array}{l}\text { CRM success requires } \\
\text { that firms continually } \\
\text { assess and prioritize } \\
\text { customer relationships } \\
\text { based on their relative } \\
\text { lifetime profitability. }\end{array}$ & \begin{tabular}{|c|} 
[CRM enables \\
companies to] invest in \\
the customers that are \\
(potentially) valuable \\
for the company, but \\
also minimize their \\
investments in \\
nonvaluable \\
customers \\
\end{tabular} \\
\hline Philosophy & $\begin{array}{c}\text { Customer retention } \\
\text { (and hence } \\
\text { profitability) is best } \\
\text { achieved through a } \\
\text { focus on relationship } \\
\text { building and } \\
\text { maintenance. }\end{array}$ & $\begin{array}{c}\text { CRM success requires } \\
\text { that firms be } \\
\text { customer-centric and } \\
\text { driven by an } \\
\text { understanding of } \\
\text { customers' changing } \\
\text { needs. }\end{array}$ & $\begin{array}{c}\text { CRM is not a discrete } \\
\text { project - it is a } \\
\text { business philosophy } \\
\text { aimed at achieving } \\
\text { customer centricity for } \\
\text { the company }\end{array}$ \\
\hline Capability & $\begin{array}{l}\text { Long-term, profitable } \\
\text { relationships result } \\
\text { only when firms are } \\
\text { able to continuously } \\
\text { adapt their behavior } \\
\text { towards individual } \\
\text { customers. }\end{array}$ & $\begin{array}{c}\text { CRM success is } \\
\text { contingent upon a } \\
\text { firm's possession of a } \\
\text { set of tangible and } \\
\text { intangible resources } \\
\text { that afford it the } \\
\text { flexibility to change its } \\
\text { behavior towards } \\
\text { individual customers } \\
\text { on an ongoing basis. }\end{array}$ & $\begin{array}{c}\text { [CRM] means being } \\
\text { willing and able to } \\
\text { change your behavior } \\
\text { toward an individual } \\
\text { customer based on } \\
\text { what the customer } \\
\text { tells you and what } \\
\text { else you know about } \\
\text { that customer. }\end{array}$ \\
\hline Technology & $\begin{array}{c}\text { Knowledge and } \\
\text { interaction } \\
\text { management } \\
\text { technologies represent } \\
\text { the key resources } \\
\text { firms need to build } \\
\text { long-term, profitable } \\
\text { customer } \\
\text { relationships. }\end{array}$ & $\begin{array}{l}\text { CRM success is } \\
\text { primarily driven by } \\
\text { the functionality and } \\
\text { user acceptance of the } \\
\text { technology firms } \\
\text { implement in an } \\
\text { attempt to build } \\
\text { customer knowledge } \\
\text { and manage } \\
\text { interactions. }\end{array}$ & $\begin{array}{c}\text { CRM is the technology } \\
\text { used to blend sales, } \\
\text { marketing, and service } \\
\text { information systems to } \\
\text { build partnerships } \\
\text { with customers. }\end{array}$ \\
\hline
\end{tabular}

Table 1. Dominant perspectives on CRM. (Zablah et al., 2004) 
4. individualized marketing messages;

5. customized products and services;

6. improved customer service efficiency and effectiveness; and

7. improved pricing.

According to Kubil \& Doku (2010) a number of benefits could be derived from or associated with building customer relations management. Harrison (2000:231) points out some as:

- It allows cross selling opportunities, leading to low customer expenditure over time. For many institutions, the attraction of building customer relationship is the promise of cross selling; selling additional products and services to existing customer base and that it is generally believed that longer term customers will buy more and if satisfied with the company and the company has what the customer wants, the customer will buy from the same financial services.

- Building relationship with customers stops competitors from knowing them. Harrison is of the view that retained and satisfied customers may be less susceptible to competitors appeal and indicates that a satisfied customer may demonstrate immunity to the pull of competition.

- Harrison maintains that sales, marketing and set up cost are amortised over a longer customer life time. Linked to this point is that associated with acquiring a new customer which incurs initial set up cost and can be recouped over time. The ratio of cost to retention is high: it is costing up to five times more to create a customer than to keep one. Customer economics generally improve over time, which is why it is important to take a lifetime value perspective which considers the potential life time income from customer relations to the cost attributed to the customer.

By understanding customers better, firms can provide higher levels of customer service and develop deeper customer relationships and as such CRM can be used to pin point high value customers, target them more effectively, cross sell the company's product and create offers tailored to specific customer requirement (Kotler et al., 2005).

CRM allows firms to develop a robust targeting and enquiry management processes and this help boost new businesses significantly. CRM improves customer retention and loyalty - customer stays longer, buys and buys more often, thus increasing their long term value to the business. Simns (2003) maintains that research has indicated that if a firm aligns the management of customers to their needs, it reduces attrition rate by $25 \%$ and in the long term helps the firm to spend less on recruiting new customers to sustain a steady volume of business while cost of sales is also reduced as existing customers are usually more responsive. Through CRM customers also develop a sense of familiarity and even a social relationship with their service providers which make it less likely to switch even if they learn about a competitor that might have better quality service, product or a lower price and in the long run the service provider becomes part of the customer social support system.

Donaldson and O'Toole (2002) highlight one of the benefits of CRM as its ability to identify individual customer's profitability and the identification of customer needs so as to tailor products to individual customer requirements to help retain customer longer. However the purpose of understanding profitability of customers is not to eliminate unprofitable 
customers but to make them profitable as their circumstances changed and their needs are met (Fitzgibbon \& White, 2004).

In spite of these benefits of CRM in building business value, most organizations have failed to mainstream the benefits of the concept into their activities to enable them develop closer relationship with customers (Kubil \& Doku, 2010).

\section{Managing CRM to mainstream the benefits}

For firms to effectively practice CRM or be able to diagnose the root cause of failed initiatives, a clear under-standing of what the phenomenon entails is needed. Zablah et al. (2004) has taken that first step by proposing what is (hope-fully) an adequate, representative conceptualization of CRM and providing a brief description of the process. As a result, it is now possible to outline a basic framework that identifies the key steps towards CRM success. From a management perspective, it is important to mention that based on the proposed conceptualization, CRM success is defined hereafter as a firm's ability to efficiently build and sustain a profit-maximizing portfolio of customer relationships.

Fig. 1 illustrates the proposed framework for achieving CRM success and indicates that the first step towards this goal is specifying a relationship management strategy. Successful relationship management requires that firms prioritize relationships and allocate resources destined for relationship building and maintenance based on customers' value to the firm. Thus, a firm's relationship management strategy should reflect how it plans to allocate available resources when dealing with customers belonging to different priority levels (Zablah et al. 2004). In other words, the relationship management strategy should specify, exante, how a firm plans to build durable relationships with customers who (potentially) value different things and differ in terms of their profitability to the firm. For instance, a firm might divide its customer base (and classify prospects) into three tiers based on the amount of after-sales support that they require and on their apparent price sensitivity. After defining the different customer groups, the firm can then proceed to define the specific elements of the marketing mix as they pertain to individual customer groups. Hence, in this situation, tier one customers might warrant individualized attention from a key account manager, while tiers two and three customers might primarily be serviced through selfservice technologies.

Moreover, it is also important to highlight that the objective of the relationship management strategy should be to maximize both the value that customers derive from their relationship with the firm as well as long-term corporate profitability. The goal, however, is not to devise a strategy that enables firms to form close, highly collaborative relationships with all customers. Rather, it is to articulate a strategy that enables firms to form mutually beneficial, durable relationships with their customers. For some, this relationship might be based on close collaboration or high levels of service. For others, it might be based on cost savings and no-frills service. The point is that the strategy should help the firm build a loyal, profitmaximizing customer base. Finally, it is worth mentioning that to construct a relationship management strategy, firms must have a profound understanding of the types of customers that they serve, what they value, and how they differ from each other and from other 
customers who do not form part of their target market. Such an understanding is critical to the development of an effective relationship management strategy.

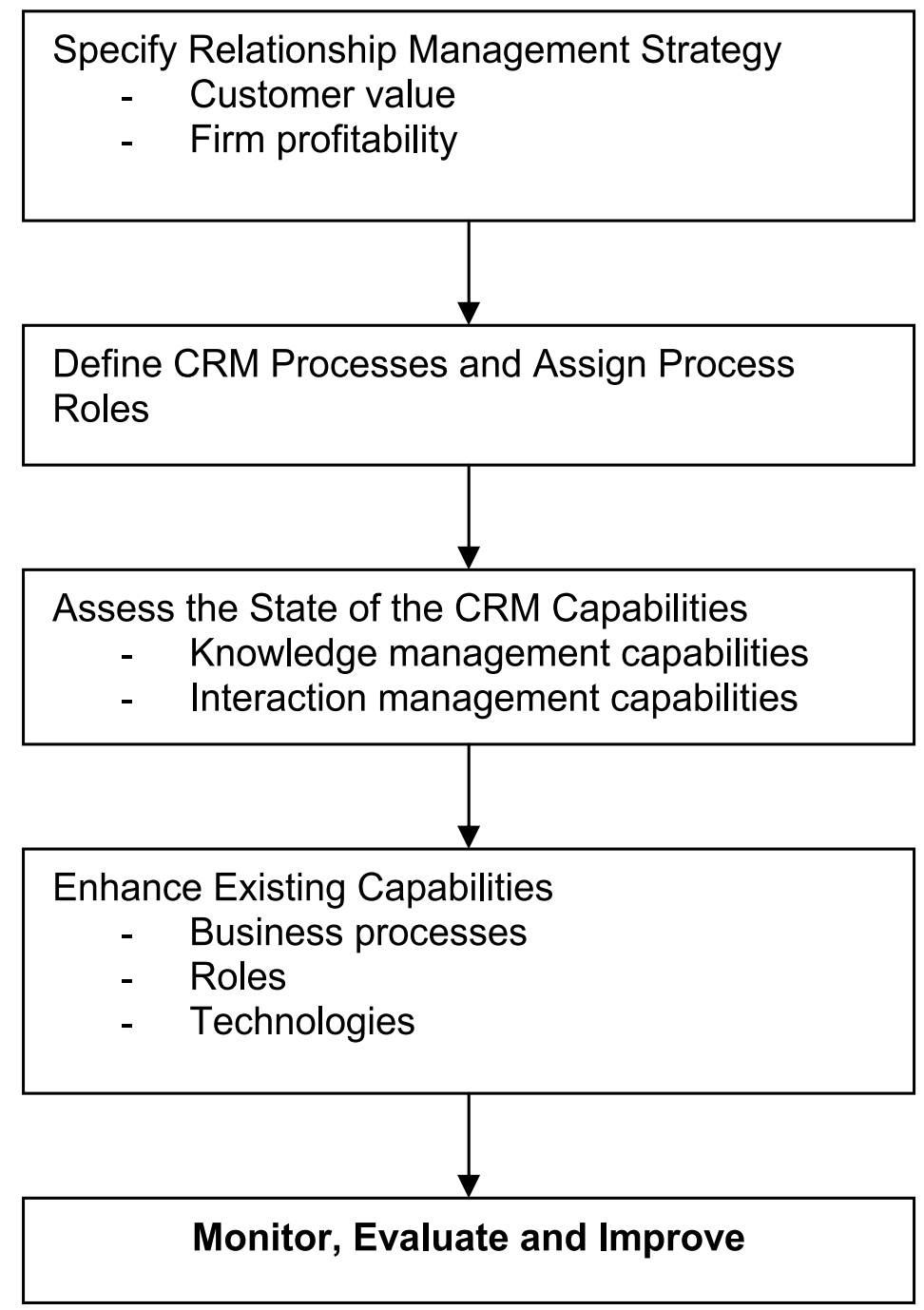

Fig. 1. A framework for achieving CRM success (Zablah et al. 2004)

Having specified a relationship management strategy, firms can proceed to define the relevant CRM processes and process roles. This includes providing a detailed map-ping and description of the relevant processes (knowledge and interaction management) and subprocesses, as well as an allocation of responsibilities for process activities among individuals and groups. The objective here is to ensure that all CRM processes are well defined and that members of the organization have a clear understanding of what they are expected to do. Moreover, a specification of the processes and roles enables managers to specify interfunctional dynamics, including communication flows and coordination patterns. 
Once the CRM processes have been defined and roles assigned, managers must assess the state of their CRM capabilities to ensure that they have the requisite resources to effectively execute the activities related to each of the CRM processes. In general, CRM capabilities refer to the mix of human, physical (including technological), and organizational (e.g., capital) resources that enable firms to execute the knowledge and interaction management pro-cesses. In other words, the management must decide whether the firm can execute the CRM processes - as they have been specified - given the firm's current mix of resources. Following the capability assessment, management can proceed to make enhancements as necessary. For instance, new technologies might have to be adopted and/or processes and process roles might need to be re-specified. The point is to ensure that the appropriate mix of resources is available to execute the CRM process. Upon the completion of this stage, all of the "pieces of the puzzle" needed to achieve CRM success should be in place.

Finally, the last step in the framework involves the continual monitoring, evaluation, and improvement of the process and individual subprocesses. The management's focus here should be on ensuring that the process is delivering the desired outcomes and finding new ways to enhance the productivity of the process. The following are some examples of appropriate measures that can be utilized to assess the firm's level of CRM success: (1) the relative efficiency with which resources destined for acquisition and retention efforts are deployed, (2) the quality of relation-ships in the customer portfolio, (3) the number of crossand up-selling opportunities that are generated, and (4) the share of a customer's business that the firm is able to capture.

Aside from providing the foundations for a CRM success framework, there are several other issues that are of managerial importance. First, implicit in the definition of CRM as a process is the notion that customers derive value from building long-term relationships with their exchange partners. Thus, before embarking on a CRM initiative, managers must really consider if their customers are interested in being "managed." For instance, some customers might resent the fact that a supplier is trying to manage the relationship, and others simply might not see any benefits in forming a long-term relationship with a particular supplier (Zablah et al., 2004). That is, when considering CRM investments, the management needs to address the following question: What is in it for our customers? Careful consideration of this issue might help firms save substantial amounts of money on CRM ventures that are essentially doomed from the start.

A second key implication stemming from this effort is the idea that CRM success is highly dependent on a process management orientation. While the literature has stressed (Zablah et al. 2004) that CRM success cannot be achieved without customer orientation, it has failed to emphasize the importance of a process-oriented culture. More specifically, when attempting to build customer relationships, managers also need to focus on directing and coordinating the cross-functional activities that enable firms to build such relationships . By focusing on the processes themselves, managers can ensure that organizational resources will be effectively utilized to generate the desired outcome (i.e., profitable, long-term relationship).

Third, it was suggested that to effectively manage customer relationships, firms need to develop capabilities related to the knowledge and interaction management processes. 
Judging by the reportedly high failure rate of CRM initiatives, it appears that these capabilities (which involve tangible and intangible resources) are hard to imitate and thus represent a potential source of competitive advantage. Consequently, in industries where competition is intense, firms can achieve superior performance if management focuses its efforts and resources on acquiring and fostering the development of such capabilities.

Finally, a profit-maximizing portfolio of customer relationships was identified as the desired output of the CRM process. This indicates that the customers belonging to this portfolio are likely to change over time and that the strategies used to relate to individual customers are also likely to change as the relationship progresses through the lifecycle. Consequently, managers should demonstrate a willingness not only to change their behaviors towards individual customers over time (e.g., decrease in request turnaround rate) but also to discontinue relationships with those customers who are no longer maximally profitable to the firm (Zablah et al. 2004).

\section{The concept of customer retention in CRM}

Customer retention is a challenge in nowadays organizations. Retained customers are generally more profitable than newly acquired customers. Based on the $2^{\text {nd }}$ edition of Customer Relationship Management (Buttle, 2009), the major strategic purpose of CRM is to manage, for profit, a company's relationships with customers through three stages of the customer lifecycle: customer acquisition, customer retention and customer development. A customer retention strategy aims to keep a high proportion of valuable customers by reducing customer defections (churn), and a customer development strategy aims to increase the value of those retained customers to the company.

Customer retention is the maintenance of continuous trading relationships with customers over the long term. Customer retention is the mirror image of customer defection or churn. High retention is equivalent to low defection.

Companies should focus on retaining customers that contribute value (Buttle, 2009). Sometimes this will mean that the focus is not on retention of customers, per se, but on retention of share of wallet. In the banking industry, for example, it may be more important for companies to focus on managing the overall downward migration of customer spending than managing customer retention. Many customers simply change their buying behaviour rather than defect. Changes in buying behaviour may be responsible for greater changes in customer value than defection. One bank, for example, lost 3 percent of its total balances when 5 percent of checking account customers defected in a year, but lost 24 percent of its total balances when 35 percent of customers reduced the amounts deposited in their checking accounts. The need to manage migration, rather than defection, is particularly important when customers engage in portfolio purchasing by transacting with more than one supplier.

Improving customer retention is an important objective for many CRM implementations. Its definition and measurement need to be sensitive to the sales, profitability and value issues discussed previously. It is important to remember that the fundamental purpose of focusing CRM efforts on customer retention is to ensure that the company maintains relationships 
with value-adding customers. It may not be beneficial to maintain relationships with all customers; some may be too costly to serve, others may be strategic switchers constantly in search of a better deal. These can be value-destroyers, not value-adders.

There is a strong economic argument in favour of customer retention. The argument goes as follows:

1. Increasing purchases as tenure grows: over time, customers come to know their suppliers. Providing the relationship is satisfactory, trust grows while risk and uncertainty are reduced. Therefore, customers commit more of their spending to those suppliers with whom they have a proven and satisfactory relationship. Also, because suppliers develop deeper customer intimacy over time, they can enjoy better yields from their cross-selling efforts.

2. Lower customer management costs over time: the relationship startup costs that are incurred when a customer is acquired can be quite high. It may take several years for enough profit to be earned from the relationship to recover those acquisition costs. For example, it can take six years to recover the costs of winning a new retail bank customer. In the B2B context in particular, ongoing relationship maintenance costs such as selling and service costs can be low relative to the costs of winning the account. Therefore, there is a high probability that the account will become more profitable on a period-by-period basis as tenure lengthens. These relationship maintenance costs may eventually be significantly reduced or even eliminated as the parties become closer over time. In the B2B context, once automated processes are in place, transaction costs are effectively eliminated. Portals largely transfer account service costs to the customer. In the B2C context, especially in retailing, the assertion that acquisition costs generally exceed retention costs is hard to prove. This is in part because it is very difficult to isolate and measure customer acquisition costs.

3. Customer referrals: customers who willingly commit more of their purchases to a preferred supplier are generally more satisfied than customers who do not. They are therefore more likely to utter positive word-of-mouth and influence the beliefs, feelings and behaviours of others. Research shows that customers who are frequent buyers are heavier referrers. For example, online clothing customers who have bought once refer three other people; after ten purchases they will have referred seven. In consumer electronics, the one-time customer refers four; the ten times customer refers. The referred customers spend about 50 to 75 percent of the referrer's spending over the first three years of their relationship. However, it is also likely that newly acquired customers, freshly enthused by their experience, would be powerful word-of-mouth advocates, perhaps more than longer-term customers who are more habituated.

4. Premium prices: customers who are satisfied in their relationship may reward their suppliers by paying higher prices. This is because they get their sense of value from more than price alone. Customers in an established relationship are also likely to be less responsive to price appeals offered by competitors.

These conditions mean that retained customers are generally more profitable than newly acquired customers. Drawing from their consulting experience, Dawkins and Reichheld report that a 5 percent increase in customer retention rate leads to an increase in the net present value of customers by between 25 and 95 percent across a wide range of industries, 
including credit cards, insurance brokerage, automobile services and office building management. In short, customer retention drives up customer lifetime value.

In regards to which customers to retain, according to Buttle (2009), it should be the customers who have greatest strategic value to your company are prime candidates for your retention efforts. These are the customers we defined as having high lifetime value or who are otherwise strategically significant as high volume customers, benchmarks, inspirations or door openers. The cost of customer retention may be considerable. The most valued customers are also likely to be very attractive to competitors. If the costs of retaining customers become too great then they might lose their status as strategically significant. The level of commitment between customers and the company will figure in the decision about which customers to retain. If the customer is highly committed, they will be impervious to the appeals of competitors, and you will not need to invest so much in their retention.

However, if you have highly significant customers who are not committed, you may want to invest considerable sums in their retention. Some companies prefer to focus their retention efforts on their recently acquired customers. They often have greater future lifetime value potential than longer tenure customers. There is some evidence that retention rates rise over time, so if defections can be prevented in the early stages of a relationship, there will be a pay-off in future revenue streams. A further justification for focusing on recently acquired customers comes from research into service failures. When customers experience service failure, they may be more forgiving if they have a history of good service with the service provider. In other words, customers who have been recently acquired and let down are more likely to defect or reduce their spending than customers who have a satisfactory history with the supplier.

Retention efforts where there is portfolio purchasing can be very difficult. Should effort be directed at retaining the high-share customer with whom you have a profitable relationship, the medium-share customer from whom you might lose additional share to competitors or the low-share customer from whom there is considerable lifetime value potential? The answer will depend on the current value of the customer, the potential for growing that value, and the cost of maintaining and developing the relationship (Buttle, 2009).

\section{Conclusions}

The data maintaining and exchanging processes need to be supported by a CRM system, comprising CRM functionality. The Country Information System, through the CRM software facilitates collection and analysis of stakeholders' data, which results in more effectively managed relations and communication between the ECDC and them Consequently, the connection between Microsoft CRM functionality and country information gives a complete view on how a CRM system can be used.

The development of the Country Information System improves the exchange and dissemination of relevant good quality information, and ensures accessibility to the information derived from the system, in particular through networking and partnership. 
Countries increasingly look at the communicable diseases inventory as an effective, efficient and sustainable approach to improve national capacities. In order to assess existing national CD systems, it is essential to constantly compare and review existing strategies and models in the rest of the EU countries. It will allow countries to identify challenges and constraints, as well as lessons learnt to consolidate achievements.

\section{References}

Blattberg, R.C. \& Deighton, J. (1996). Managing Marketing by the Customer Equity Criterion, Harvard Business Review, 74, (August 1996), pp. 136-44.

Buttle, F. (2009). Customer Relationship Management, Burlington, MA: Elsevier.

Coltman, T.R. (2006). Where Are the Benefits in CRM Technology Investment?, Proceedings of 39th Annual Hawaii International Conference on System Science (HICS 06), 4-7.

Donaldson, B. \& O' Toole, T. (2002). Strategic Marketing Relationship, Chichester: John Wiley.

Filiatrault, P. \& Lapierre, J. (1997). Managing Business-To-Business Marketing Relationships in Consulting Engineering Firms. Industrial Marketing Management, 26, 2, pp. 213-22.

Fitzgibbon, C., \& White, L. (2004). The Role of Attitudinal Loyalty in the Development of CRM Strategy within Service Firms. J. of Financial Serv. Mark., 9, 3, pp. 214230.

Greenberg, P. (2001). CRM at the speed of light, Berkeley, McGraw-Hill.

Harrison, T. (2000). Financial Services Marketing, Harlow, Pearson.

Harrison, J.P., Harrison, R.A., Smith, M. (2008). Role of information technology in disaster medical response. Health Care Manag, 27, 4, pp. 307-13.

Injazz, J.C. \& Karen P. (2003). Understanding customer relationship management (CRM): People, process and technology. Business Process Management Journal, 9, 5, 672688.

Injazz, J.C., Popovich K. (2003). Understanding customer relationship management (CRM): People, process and technology. Business Process Management Journal, Vol. 9 Iss: 5, pp.672- 688 .

Keith, R.A. \& Jones, E. (2008). Customer relationship management: Finding value drivers. Industrial Marketing Management. 37, pp. 120-130.

Kotler, W.G., Saunders, J., \& Armstrong, G. (2005). Principles of Marketing (4ed), Harlow, Pearson.

Kubil, B.A. \& Doku, A.K. (2010). Towards a successful customer relationship management: A conceptual framework. African Journal of Marketing Management, 2, 3, (March 2010), pp. 037-043, ISSN 2180-2777.

Parente, S. Using Information Systems for Public Health Administration. Public health informatics and information systems. O'Carroll, P.W.; Yasnoff, W.A.; Ward, M.E.; Ripp, L.H.; Martin, E.L. (Eds.) Springer, 2003. P. 222-226.

Reichheld, F. (1996). The Loyalty Effect. Boston MA, Harvard Business School Press.

Simns, J. (2003). How Can Value of CRM Activity be Measured. Marketing, (June 2003), London, Hypermarket. 
Zablah, A.R., Bellenger, D.N., \& Johnston, W.J. (2004). An evaluation of divergent perspectives on customer relationship management: Towards a common understanding of an emerging phenomenon. Industrial Marketing Management, 33, pp. 475- 489 . 


\title{
Customer Relationship Management and Business Intelligence
}

\author{
Aida Habul and Amila Pilav-Velić \\ University of Sarajevo, \\ Bosnia and Herzegovina
}

\section{Introduction}

The electronic commerce (e-commerce) has significantly made changes in customer relationships. The development of nowadays technologies has enabled customers to rapidly and without difficulty collect information regarding to the supply of various products and services. It will make effortless in finding out the most best with highest quality suppliers. The client is able to choose and to decide who provides the better offer. Therefore, barging power shifts toward the customer, whose performances determine the success of the company. By applying new advanced technology, costs are reduced as well as product prices and services, and this will intensified the competitive market relations. It will affect the unfavorable position of suppliers in the relation to customers. Therefore, we could say: managing customers' needs and achieving their satisfaction has never been more important and more necessary as in the time and terms of global digitalization. However, it does not mean that the achievement of customer satisfaction in the new economy comes down to an online communication and products sales, as well as customer services. Yet, there will exist a company which will provide better update to a content of products on the web and win client's trust which will be based on the justification of who has identified the customer needs better, more effectively versus other competitors companies. Today clients have a high expectation. What they expect is continuous interaction with companies throughout different paths: web, call center, shopping center, e - mail, etc. What they expect to be understood by companies and to recognize needs, interest, preferences and purchasing habits. Direct contact with the customer's allows by Internet has resulted with more personal relations between company and customers, creating the database of consumers to monitor their activities by the company. According to Entrepreneur Magazine, today, customer are receiving 8.000 different marketing messages per day, while in year 1985 that number was 650 messages per day. Customer themselves determines, what kind of messages will receive when and how frequently. Digitalization has enabled more effective targeting and personalization. It means targeting and one to one relations which are tailored to target segments and individual customers. Accordingly, it is possible to build stronger relationships with the relevant segments (consumer digital boards), individual consumers and business partners. This digital economy has brought a new dimension to consumers and faces the company with a big challenge. Companies which do business 
on the Internet must adapt and be prepared to respond to the increasing challenges placed before, by determining to more sophisticated consumers. Those who seek to strengthen its competitive position and differentiate in relation to others, develop strategies based on clients and based on developing relationships with clients to meet their long-term satisfaction. Achieving customer satisfaction and trust does not involve offering the right product or service which will meet expectations, but delivering the "positive experience" that will result enthusiasm. If the consumer is dissatisfied with the service provided and the relationship that it has some digital companies, it can easily switch to a competitor's Web site.

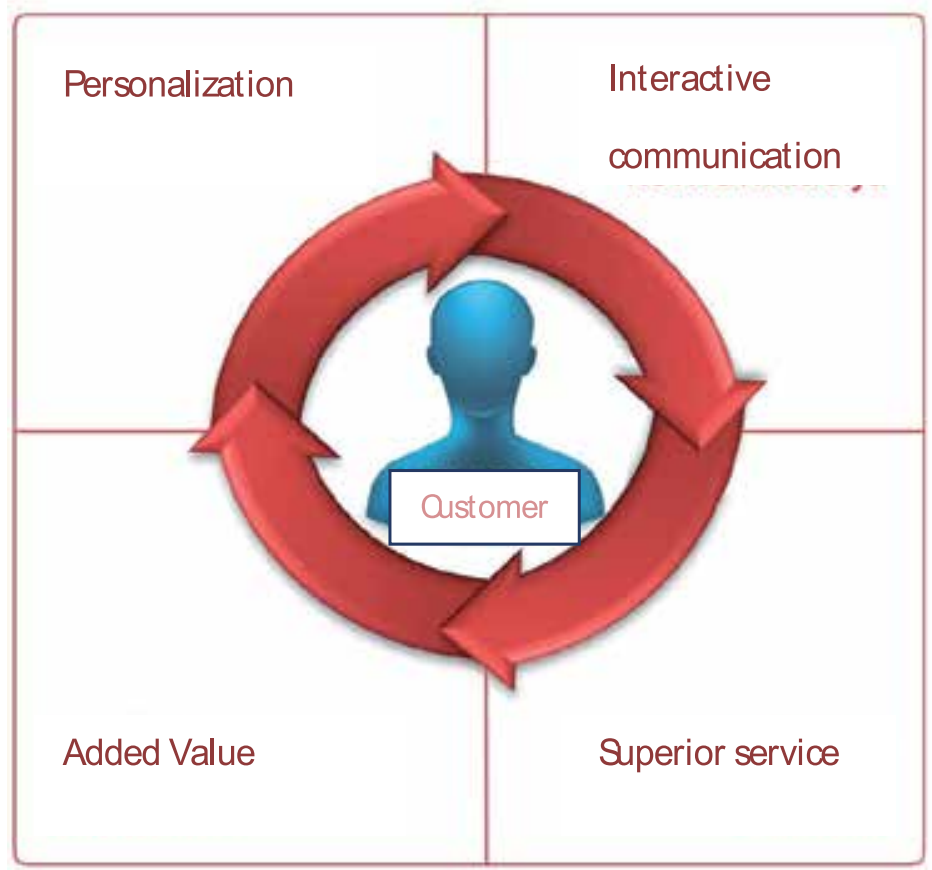

Fig. 1. Customer in focus (Source: Adapted to the definition)

According to the client position in digital enviroment, the online business strategy is concentrated on consumers and it should contain the following elements: ${ }^{1}$

- Off-line promotion through conventional ATL (Above The Line-promotional activities which includes advertising in segments of mass media) and BTL (Bellow The Linepromotional activities involving other types of promotional activities, promotional material, etc.) promotional activities;

- The company's Web site should be simple for use and searching for products information;

- To assure consumers that Web sites are safe to use and the security has met standards for secure data transaction;

${ }^{1}$ Blackwell R.D. \& Stephan K., (2001), Customers rule: why the e-commerce honeymoon is over and where winning businesses go from here, Crown Business, ISBN 0-609-60865-7, pp. 71, 140-148. 
- Identify customers who have trouble for online shopping;

- Develop relationships with customers through e-mail and other communication channels, in accordance with their wishes and preferences;

- To offer customers additional reasons for returning to the web site, for examples with a unique offers and products;

- Enable customers for online bought product to receive it physically at home address, etc.

The requirements posted by today's online customers related to the management about its relations on the web are consisted of: 2

- Unambigously defined the company policy in terms of delivery of ordered products, warnity, payment issues, privacy, etc. Customers would like to know what they can expect from the companies.

- Administration of clients: Consumers would like to contorl their data to be able to access all previous interactions with the company in order to enable them for the future to have easy way of ordering and interactionsRelationships: Consumers would like that companies understand their needs and preferences up to certain level without disturbing clients privacyRead phonetically.

- Searching: Consumers prefer web sites with easy and simple navigation without any kind of confusion. In this way, probability for buying products and/or services is increasing.

- Consumers would like to have cozy shopping atmosphere without compromising on functionalities as (visual merchandising).

- Decision Support: Customers are willing to purchase when they have clear instructions and guidelines.

- Communication: Customers expect an interactive communication and to always being able to have feedback if they "lose" a navigational map, etc.

- Shopping: Customers do not want to give too many information about themselves, they want privacy but as well security and easy way to shop.

- After-sale: Consumers would like to order confirmation, access to order status and to meet delivery dates.

- It is necessary to enable the consumer into an integrated communication, communication through multiple channels of your choice.

Companies that implement e-business strategy need to realize that, although the modern information technology is indispensable in customer relationship management, customers are the power which generates most of the current and future revenues. Consumers are creating value of the company, but not the modern technological solutions. The aim of the new technology is to link technology opportunities with what consumers would like to have. The task of the new technology solutions is aligning technology performances with the needs and wishes of consumers, rather than attempt to change consumer behavior in accordance with these solutions. As we can see, the most of customer requirements are

2Burnett K., (2001), The handbook of key customer relationship management: the definitive guide to winning, managing and developing key account business, (1st edition), Financial Times Prentice Hall, ISBN: 9780273650317, Great Britain, pp. 37. 
based on an effective and interactive communication. Therefore, the provision of appropriate information to clients, but as well to understand their feedback what presents a well defined creation. Quality data and knowledge management enables the company to enhance the created value. Therefore, achieving and enhancing customer satisfaction becomes a mission impossible without the Business Intelligence applications, whose ultimate goal is value creation. In this context, this chapter aims to explore the relationship of Customer Relationship Management (CRM) and Business Intelligence (BI), and the causes and effects of their "flip-flop" connection.

\section{Need for business intelligence in the global competitive environment}

In the modern business, competition becomes more pronounced, and knowledge as a source of success of the company in the market, becomes necessary strategic choice. Information becomes a key resource and the central business function of the company that takes an active part in the virtual market. The problem of finding information has been replaced by the problem of their proper use, or whether the information quality, reliable, and can provide high-quality knowledge. Volume of information has increased, which creates certain difficulties. „Human has only 24 hours a day to deploy their attention to the millions of new effects and features, which falls on him“ (Kelly, 1999). There are many competing and contradictory sources of information, which makes their processing more difficult. In his article "Rationality as a process and product of thought" (1993), american economist G. Simon said that "information is extremely valuable when it is in small quantities, and when there are large amounts of information, it gets a negative role and diverts us from the essence“. In this way, comes to "information-noise“ situations in which rational decision making is difficult, because of increased volume of redundant and incorrect information. The problem is possibility of its high quality treatment, but not the fact how to obtain information. In this regard, the role of Business Intelligence is indispensable. It facilitates the acquisition of knowledge about the factors affecting the company's operations. It is certain that in the future will be successful those organizations which have based their competitive advantage on knowledge. Companies that have specific knowledge can identify market potential and according to this, direct their vision, goals and strategies, allocate and productive use available resources. The greatest challenge of modern business is to provide the right information at the right size and shape, in a way that suits the specific needs of clients. The key to success of the company is consistent communication through all channels of interaction with clients, and a unique image and brand communications business of the company through the Internet, e-mail, electronic and print media, the physical contact center, etc. In this regard, the subject of this work is observed from the perspective of managing relationships with clients to achieve their satisfaction as the maximum value of modern companies. The future of organizations will depend on the ability of individuals, teams and entire organizations to continuously learn and increase their knowledge and inventivity. This is impossible without modern business information systems, including the concept of Business Intelligence as their upgrades, information and communication technologies and electronic networks. These elements are indispensable in building a "learning organization" which can deal with global competition, and will use the BI application as a strategic advantage. 


\subsection{Business intelligence technology}

Business Intelligence is a concept of using information technology as a tool for achieving the competitiveness of businesses, the perception of risk that occurs in the environment within the firm, and the possibility of action. This is a concept that involves the integration of traditional business functions with IT communications technologies and capabilities that are provided. The intent of $\mathrm{BI}$ is the integrated and coordinated application of business information in order to comprehensively improve products, service, profits and the longterm health and growth of a company. Business Intelligence and Competitive Intelligence is the process of collection, treatment, analysis and use of strategic information for a company. So, it's all about information that is important for a company. The definition is also an important segment of the treatment results and information, in case information is not usable for decisionmakers, or even worthless, means there is no difference between data and information. Also, it is useful to mention the difference between Competitive Intelligence and Business Intelligence. The first expression is much broader and includes Business Intelligence, which is more focused on software and IT tools. Effective Business Intelligence system allows data collection from all departments within the company, their analysis, preparation the necessary reports and addressing those users who are most needed. In this sense, each user gets the information that is the subject of interest and which are necessary to carry out its business activities. This aproach avoids the "information chaos" and unnecessary information overloading organizations which could result in making incorrect decisions. BI applications accelerates the process of making business decisions with respect to the quality of data located in one central place, such as Data Warehouse. It can result in useful and high-quality knowledge. On the other hand, a unique reporting system also contributes to higher quality and faster decision making, but also improve all business processes. Specifically, the system of Business Intelligence by its nature, integrates information and knowledge about customers, suppliers, competition, and overall operations. BI improves the strategic and operational planning, control, business indicators, analysis and optimization of business operations, ensuring the successful targeting customers and tracking competitive activity and predicting future trends.

\subsubsection{Business intelligence architecture}

The Business Intelligence architecture consists of three main components: Data extraction and integration, Enterprise reporting systems and Data mining3. This structure can be presented by the following figure:

Namely, in the most important sources of data such as OLAP (Online Analytical Processing), ERP (Enterprise Resources Planning), CRM (Customer Relationships Management), SCM (Supply Chain Management), various databases and documents arising from business processes and activities within the company. These systems are used in the processing and collection of initial data in digital form, and in their construction should strive to achieve high performance processing of data and ensure their continued availability. Transaction and enterprise resourcing planning systems are valuable in automating transactions and capturing

${ }^{3}$ Turban E., \& Volonino L., (2010.), Business Intelligence and Decision Support Systems, Information Technology for Management: Transforming Organizations in the Digital Economy, pp. 445-484, (7th edition ), John Wiley \& Sons, ISBN: 978-0470400326, USA, pp.456. 


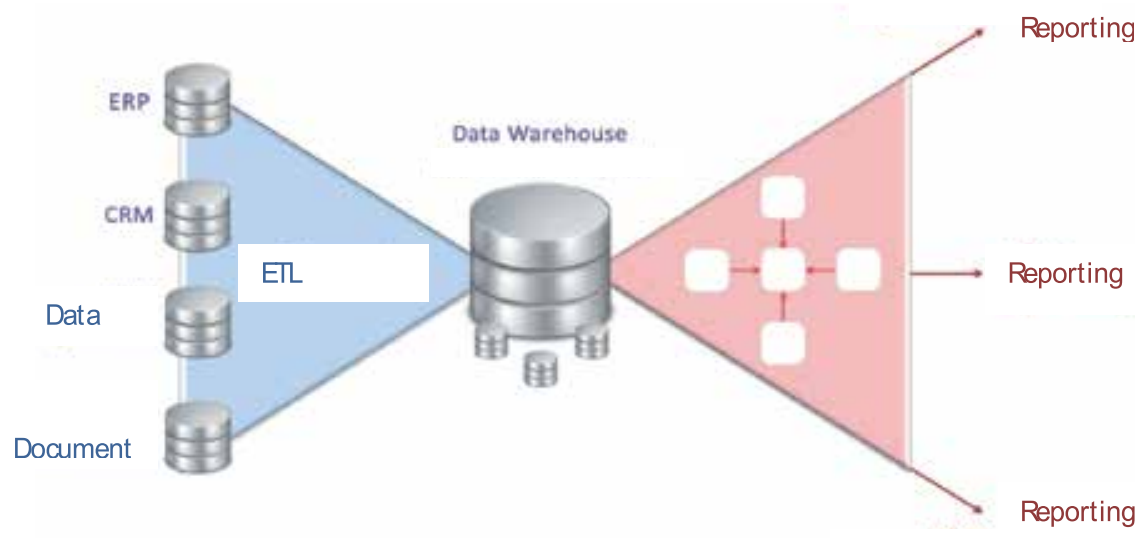

Fig. 2. Business Intelligence (Source: Adapted to the definition)

the data generated. But mostly, they do not provide information suitable for analysis and comparisons. However, these data form multiple systems that can improve companies performances and make profitable decisions. Due to different sources, data are in various formats and not standardized. Therefore, the next step consists of data standardization ETL (Extracting, Transformation, Loading) Processes of data collection and processing for system of Business Intelligence. One of three ETL processes (collection, transformation and loading) steps, for the quality of data and therefore the quality of knowledge, is a critical that the one which contains data transformation that takes the most time. The data can be used for reporting, analysis and so on. Collected and stored data must be available and integrated within the entire organization. In line with this, employees can make better decisions. For example, BI applications enable employees in the customer relations department to get information about all transactions with specific client in a short time period. They can create offer according to customers needs and aspirations. Realization of this goal can be achieved by building a functional Data Warehouse that will produce new knowledge. Therefore, in the 3.3.1. section we discuss Data Warehouse and its role in successful Customer Relationship Management. The next BI component is Enterprise Reporting Systems. It is esential to make data available to external parties but in real time. Reporting systems prepare quantitative data in a report format that might include numbers, charts and/or graphs. They provide standard, ad hoc and summary reports. "Ad hoc" reports are used when the circumstances required current and quick insight into the company's operations, without any previous preparation. Summary reports are presenting the business in a certain time period (month, quarter, year, etc.). Standard reports generated by applications that allow a certain flexibility in their construction. Their contents are the most common spreadsheet with accompanying diagrams and charts. In addition to reporting tools, there are dashboards and scorecards. Dashboards provide easy access to data and support decision making. On the other side, balanced scorecard technology is used for determining, realizing business strategy linking objectives with concrete measures. Third significant BI component are Data Mining, ad hoc and planned queries and analysis tools. These tools enable users to create queries and analyze data. Users investigate data and learn from it. Data Mining is a process that uses statistical, mathematical, artificial intelligence and machine-learning techniques to extract and identify useful information and knowledge from databases and data warehouses. It discovers intelligence from data warehouses that queries 
and reports cannot discover. Considering that better decision making is one of the main goals of BI, it is necessary to disscus Decision Support Systems (DSS) in CRM context, particularly. DSS and its role in CRM is discussed in 3.3.2. section.

\section{Business intelligence and customer relationship management}

\subsection{Importance of customer relationships management in the modern business}

In the modern economy a priority of business activities becomes a two-way communication between the company and its customers. This communication is based on the interests of both sides: companies that seek to profit, survive and grow, and customers who want to achieve added value. The most successful companies today are those that create their business processes in line with customer expectations. New business trends require company's orientation to customers. These are, primarily, grown manufacturing capacities which cause the differentiation of products and services in accordance with different customers aspirations, which brings larger volume of sales. Then, there are new technologies that facilitate the selection of companies that customers will show their confidence. This implies a simple comparison with competitive offers, low cost transition to other suppliers and customers significant time savings through continuous provision of the necessary information and offer personalized products and services. In such circumstances, the achievement of competitive advantage is an extremely difficult job. The value of customers for the company becomes invaluable. Development of information technology significantly improved the mutual relations of the company and customers. Modern information technology is a powerful medium of establishing better contacts between company personnel and clients, but also more efficient management company. Possibility of building direct relationships between companies and consumers leads to their personalization. Multi-channel communication facilitate the establishment of more sophisticated and two-way relationships, but it makes more difficult to integrate data and create unique images of clients. Companies that do not have an integrated information about customers, actually does not know their customers and can't offer personalized products and services. Due the lack of data integration, customers will need at each contact with the company to give back their data, which can cause their dissatisfaction and certain leaving. Customers will feel ignored and irrelevant to that company. For this reason, it is important that information about customers are stored in one place and available to everyone in the organization. This can be achieved by building Customer Data Warehouse. Without functional integration of Data Warehouses as the foundation, there is no successful relationship with customers or acquiring new knowledge in the form of Business Intelligence, which means providing quality information. Therefore, further we discuss importance of integrating customer information in order to achieve customer satisfaction, especially in terms of multi-channel communications and contact centers, and the role of Data Warehouse in creating a distinctive image of them.

\subsection{Contact center concept}

When Internet and new forms of communication have emerged, "Call Centers" and the phone as the primary communication channels, are being replaced by an online services as e-mail, Web, instant messaging, video calls, etc. At first the companies have tried to 
encourage customers to make orders and to purchase products over the phone. Thus, "call centers" were created to provide services for customers based on their calls (inbound calls), perform various transactions, and call the customer (outbound calls) to provide certain information or services. However, with the development of multimedia modes of communication "call centers" evolved into "contact centers", in order to increase the quality of service and achieving customers' satisfaction. The role of "call center" in customer relationship management is in establishing quality relationships with them. In this regard, the Center should be connected with other parts of the organization and other business processes within the company. At the first to clients, the web applications, e-business solutions, BI applications, internal enterprise applications and Data Warehouse as central. Contact centers have become the way of improving relationships with customers. Contact center is providing information to the clients, include deeper relationships with customers, create a better outlook of the company with technical support, suppliers, vendors, after-sale services and etc. This variety of functions requires a highly skilled and trained staff, well organized activities, effective coordination between employees, etc. On the other hand, contact center is characterized by multi-channel communication. Recent research shows that among the technologies of communication within the contact center, the most commons are e-mail, telephone, free info phone, LAN / WAN, interactive Web, VoIP, etc. This multichannel communication facilitates the establishment of bidirectional and sophisticated relationships with clients. But as well it makes difficult to integrate data and to create a unique image of clients. To be successful in "e-environment", company must continuously improve its offer and to magnify the value which is providing to customers. But, it is feasible without reliable and complete image of its customers.

\subsection{Data integration - The root of well defined customer relationship management}

Creating a comprehensive and holistic image of the customer is not possible without integrating an internal business ("back - end") applications as well as Web applications of the company. This would assume management of customer data and their integration. Data management involves the collection and use of high-quality and accurate customer data, which will allow the company to provide a positive experience to their customers. The Data Quality usually implies its applicability and usefulness in building lasting relationships with customers. In fact, many companies have a large amount of incorrect information resulting in a distorted image of the client and additional financial losses. For actual customer perceptions and expectations of their needs companies need to be efficiently integrated with customer data that are obtained from different sources. They should take advantage of every contact with the client made previously as: phone, fax, Web, e-mail, etc., and to collect as much as possible well data on them and store them in a certain "central place" where they will be available to everyone in the company. Only the combination of the most accurate and the most update information from all available sources will enable a holistic approach to clients and winning their loyalty. Due to the lack of integrated data, customers repeatedly give the same information and it could cause their frustration and dissatisfaction. Customers will feel unrecognized, ignored and irrelevant to that company. They will look for other suppliers that will offer them the expected value and where there will not be exposed to such negative experiences. In line with this, during the customer identification, there could be a lot of errors in terms of non-recognition already registered clients. So, the same client will be represented as a number of different clients, and this will prevent the creation of 
clear and comprehensive image of customer and all transactions conducted with this one will be displayed as the transactions carried out with different clients. Such omission will not ensure the establishment of good relations with customers. Lack of adequate integration of customer data will lead to unnecessary costs in the business, storing unnecessary data, sending promotional messages to the same clients, etc. Companies which have not integrated customer data, in fact, do not know their customers, and they can not offer the products and services tailored to them. Collected and stored data must be available and integrated within the entire organization, which is crucial to building quality relationships with clients. Realization of this goal is possible in terms of building a functional data warehouse which will produce a new knowledge about customers.

\subsubsection{Customer data warehouse}

Data Warehouse is the field-oriented, integrated, fixed and timeoriented set of data intended to support decision making4. Field-oriented of Data Warehouse means the data from the different business areas (sales, marketing, finance, etc.), which includes the Data Warehouse, and which are necessary for decision making in relation to that area. Data Warehouse must be integrated, and should include related information arising within the organization and those created in the environment of the organization. Fixity of Data Warehouses means stability in terms of data processing, because they are "loaded" from the operational database and form for analysis. This means that the answer to the same query will always be the same, regardless of the time and frequency of its generation. Data Warehouse is a timeoriented because it contains information that describes the appearance of a longer period of time, allowing comparison and prediction. Namely, the prediction of future events and processes can not be credible and well without understanding their past. Data Warehouse should contain large amounts of detailed data. Success estimation of certain business activities and communications with the environment, established and credible if all the details about them were recorded, and detailed data will enable quick response to changes in market demands. The data in the warehouse must be continuously updated and served to all employees in the company.

Data stored in information systems organizations have no value if it does not analyze, process and transform to information needed to make business decisions. Analytical processing dimensionally organized data in warehouse allows finding answers to questions, transforming data into information necessary for business decision making.It is the most prominent reason for building the data warehouse in order to better manage relationships with customers. In this way, the data warehouse is the core of CRM systems, because of data and their availability in the warehouse determine providing adequate products and/or services to clients. Companies need to implement a data warehouse which will be oriented towards customers and will contain high-quality, complete and update information. This will result in a correct decision regarding the value delivered to customers. In the existing literature, the process of building the data warehouse is determined by three processes: definition and analysis of the warehouse, then its implementation and use which is the ultimate purpose of its construction. Specifically, the process of building the warehouse

${ }^{4}$ Inmon W. H., (1996), Building the Data Warehouse, ( 2nd edition), John Wiley \& Sons, ISBN: 9780471141617, USA, pp.23. 
begins by defining and analyzing the reasons and requirements for data warehouse implementation. These are usually problems for whose solutions the company has no data or owns them but does not know. This latter is known as "data disorientation". Data are lost somewhere in the system, but they are not accessible. At this stage of building the warehouse, the defining the data model is decisive. The method of data storing (network, relational and hierarchical) determines the effectiveness of its use. The next step in the process of building the data warehouse is its implementation. In this process, the most significant activities are such as storing the data, defining procedures of data storage, grouping the data according to certain parameter, etc. Using the data warehouse is the last stage in its construction for the purpose of Customer Relationship Management. This includes reporting, query creation and its application in analytical and forecasting purposes. Data warehouse development influenced the emergence of a wide range of very helpful interrogatory tools, which enable to set the demanding and very complex queries. The role of the warehouses in the integration of data is invaluable. However, the most important use of data warehouses is in the analysis and forecasting which represent the basis for converting information into knowledge and business intelligence, which is of particular importance to the concept of customer relationship management. In this regard, Data Warehouse makes core of Business Intelligence system, because data and their availability in the warehouse determine the quality and effectiveness of business decisions. In addition, we discuss Decision Support Systems (DSS) in the process of achieving customer's satisfaction, with focus on their significance in the analysis and prediction of customer's behavior.

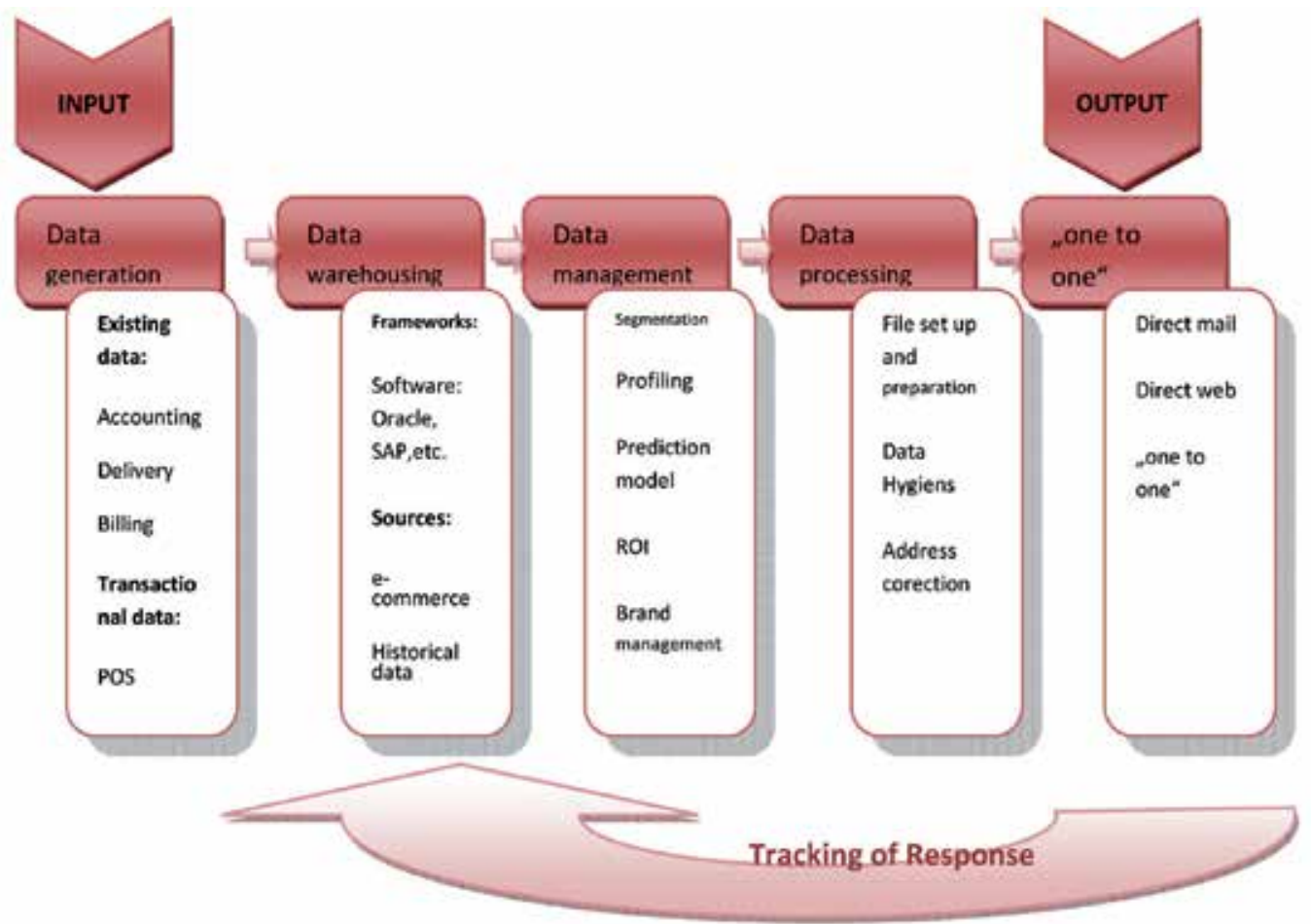

Fig. 3. Data Warehouse and data processing (Source: Adapted to the definition) 


\subsubsection{The role of decision support systems in customer relationship management}

Decision Support Systems processed information from various internal and external sources to gather information needed for decision making. The most important types of these systems are: reporting, analytical and predictive. Reporting systems usually provide answers to questions known in advance. In the CRM context, these questions are mainly related to customers' identification such as demographic characteristics, customers' needs and expectations, their habits, etc. But also, there are queries with focus on type of communication channel, attracting customers across different channels, customers' preferable channels, frequency of communication, customers' experiences with different channels, etc. However, the initial intention of using data warehouse in reporting systems is to facilitate and improve process of establishing the facts. Analytical Systems explains the results displayed in reports generated from the data warehouse. This will enable customers' segmentation and that is grouping of clients around the common features. Unlike Reporting systems, these systems provide answers to more demanding queries such as: reasons for greater costs of using one particular communication or sales channel, why customers prefer some channels, what caused that average revenue per customer declines, etc. The answers to these questions require the different methods and techniques for performing knowledge from data and business intelligence. This requires a deeper analysis that will provide a "fruitful ground" for the next phase of the decision-support system development for forecasting and/or predictive system. Predictive systems are used for the forecasting future events, or processes. Based on projections the company can anticipate certain future trends and customer behavior, and they capitalize and achieve significant competitive advantage. Trying to predict customer behavior, this will contribute superior satisfaction of their expectations, and thereby increase company profits. Therefore, this system in conjunction with data warehouses, answer the questions such as: predictions of customers' buying actions, their choice regarding communication and/or sales channels, their reactions on some new products and/or services, etc. We can notice that the role of a data warehouse is invaluable in retaining existing and attracting new customers, developing new products and services and lowering operational costs. This is the backbone of the entire information infrastructure and associated technologies for decision support. Without a functional data warehouse, there is no data integration as the foundation of successful relationships with customers, or acquiring new knowledge in the form of business intelligence. However, the need for more explicit personalized approach to customers in order to achieve their satisfaction and retention, in the recent time is quite met due to the emergence and increasingly intense use of social networking sites. Therefore, customer relationship management in modern business inevitably involves various aspects of social promotion and advertising. In line with this, the next section is focused on social networking and its advantages in customer relations.

\subsection{Social media and customer relationship management}

The increasing popularity of social networks and similar forms of communication and socializing in a virtual world, but also a large number of users and length of time they spend on these networks, provide new opportunities in business and market positioning of companies. According to the latest research of Nielsen Online company in the June 2009- 
June 2010, the time spent on social networks is $43 \%$ more than in the previous year 5 . Namely, Americans spend nearly a quarter of their time online on social networking sites and blogs. In June 2009, they spent $15.8 \%$ and in June $201022.7 \%$ of their online time on social networks. According to this, monthly time spent on social networks and blogs is 906 millions of hours. The second most popular Internet sector are games with 407 millions of hours, followed by e-mail with 329 millions of hours, portals, instant messaging, etc. Modern companies recognize the potential of social networks in the customer relationship management. Social networks or as often called "social media" have replaced conventional methods of communication such as print media, television, etc. This is because of lower costs, the greater possibility of targeting visitors, as well as direct and two-way communication with target group of users and potential customers. In addition, we must not forget the power of recommendations (word of mouth) what is particulary evident in using social media. The friends and members of the same "group", exchange information and "positive experiences". Companies that provide high value can use this fact as advantage in building better customer service. They can create their own user profiles and group of clients, and thus get feedback and knowledge about the perceptions and experiences of clients, which represents a good basis for creating new and effective CRM strategy and holistic performance in the market. Most important benefits that companies realize using social networks as communication channel with customers are:

- Building a network of followers who promote a company's product or brand. Brand advocates are the best promoters of the company, as they do from their own beliefs. Widgets, surveys or applications on social networks, do not require many resources and when those tools are properly designed users will not even notice that they are exposed to marketing messages or that they participate in market research. These applications users see as recommendations of their friends, what is favorable for achieving confidential customer relationships.

- Search Engine Optimization. Sharing content through social media is, in fact, free advertising, which also increase visibility of companies in the Web browsers, such as Google, Yahoo, Bing and others, and that can result in higher sales volume.

- Social Media Brand Monitoring. Using the analytical tools for brand monitoring and direct communication, companies get feedback about what users think about their product or brand.

- Aqusition. Growing number of users of social networks, enabling company to connect with a large number of organizations and individuals. In that way company expand existing customer base. However, investments in social media are still inadequate, but moving forward. At the beginning of 2009 Forrester Research published a study conducted over a hundred major companies in the world. The results show that $53 \%$ of them intend, regardless of the current economic crisis, to increase investment in "social media". According to a study CMO Survey 2009, $3.5 \%$ of the marketing budget is spent on "social media" and there is prediction that within 12 months, in 2010, will increase to $6.1 \%$ and within five years to $13,7 \%$. Concepts such as "local social advertising," "social

\footnotetext{
${ }^{5}$ Nielsen company, (August 2, 2010), What Americans Do Online: Social Media And Games Dominate Activity, Nielsen Online, 07/15/2011, Available from:

http://blog.nielsen.com/nielsenwire/online_mobile/what-americans-do-online-social-media-andgames-dominate-activity/
} 
search" and "social networks" will become key issues in the future. Using social media company will improve communication with customers. Relationships will become more direct and personalized. A company that recognizes advantages and posibilities of social media in market performance can expect greater customers commitment.

\subsection{With business intelligence to the satisfied customers}

Quality knowledge management improves the quality of products, promotional sales and increases profits and customer satisfaction results. Therefore, we can say that the ultimate goal of knowledge management is to increase customer satisfaction. Business Intelligence is the ultimate purpose of knowledge management and a "way of delivery of the right information in the right format, at the right hand and the right time" (Murfitt, 2001). It does not involve the generation of larger quantities, but the provision of better and quality information. In line with this, data mining techniques have been adopted. These techniques involve alghorithms in order to obtain useful information and knowledge. The discovered knowledge represents a solid base for customers profiling and segmentation according to their habits, attitudes and behaviour. Data mining and machine learning techniques can handle large amounts of data, so they facilitate decision making processes and stimulate automatic generation of customers model. This is extremely significant BI feature considering that information about customers grows and transforms with each customer interaction. Thus, a progressive customer relationship management is enabled by BI applications and solutions which becomes the foundation of a successful customer intimacy strategy. Therefore, the most prominent advantage of Business Intelligence in customer relationship management is its rooting in personalization. Personalization of relations between company and customers is helping company to better understand and respond to the needs of each customer. This ensures that each customer gets exactly what wants and when it wants. BI applications support the implementation of various channels of communication with clients, such as e-mail, Web, telephone, etc. Customers in accordance with their preferences, choose the channel that best suits them and by whom will receive a personalized message. Before we illustrate which of the CRM area represents the strongest link between CRM and BI solutions, we will refresh the knowledge about three main building blocks within CRM. Namely, the CRM solution is based on:

- Operational CRM includes daily communication with clients. It provides support for "front office" business processes, such as sales, marketing and service departments within the company. This system gives employees immediate access to important information about the customer (information about the purchased products, prior contacts and problems, etc.), and eliminates the need for obtaining such information directly from customers.

- Analytical CRM means the collection, storage, extraction, processing, reporting and interpreting customer data. The advantage of these applications is the use of data from multiple sources and their interpretation through appropriate procedures, depending on the needs and purposes which are trying to achieve.

- Collaborative CRM involves all company's interactions with external entities, such as its customers, suppliers and partners. When customers communicate with the company they are able to see only the collaborative CRM, which includes all channels of interaction with them. Those are: offices, telephone contacts, e-mail, web pages, contacts, etc. The established contacts generate operational data that represent the basis of their analysis through analytical CRM. 
As we can notice, connection between BI applications and CRM is the most pronounced within analytical CRM, given that customers related data analysis tools need management support. A consistent and complete image of customer depends of integrated data warehouse called the Customer Data Warehouse. Customer Data Warehouse should contain large amounts of detailed data. It requires adequately designed ETL processes and scalable data warehouse. This integration between CRM and BI is shown at Figure 4.

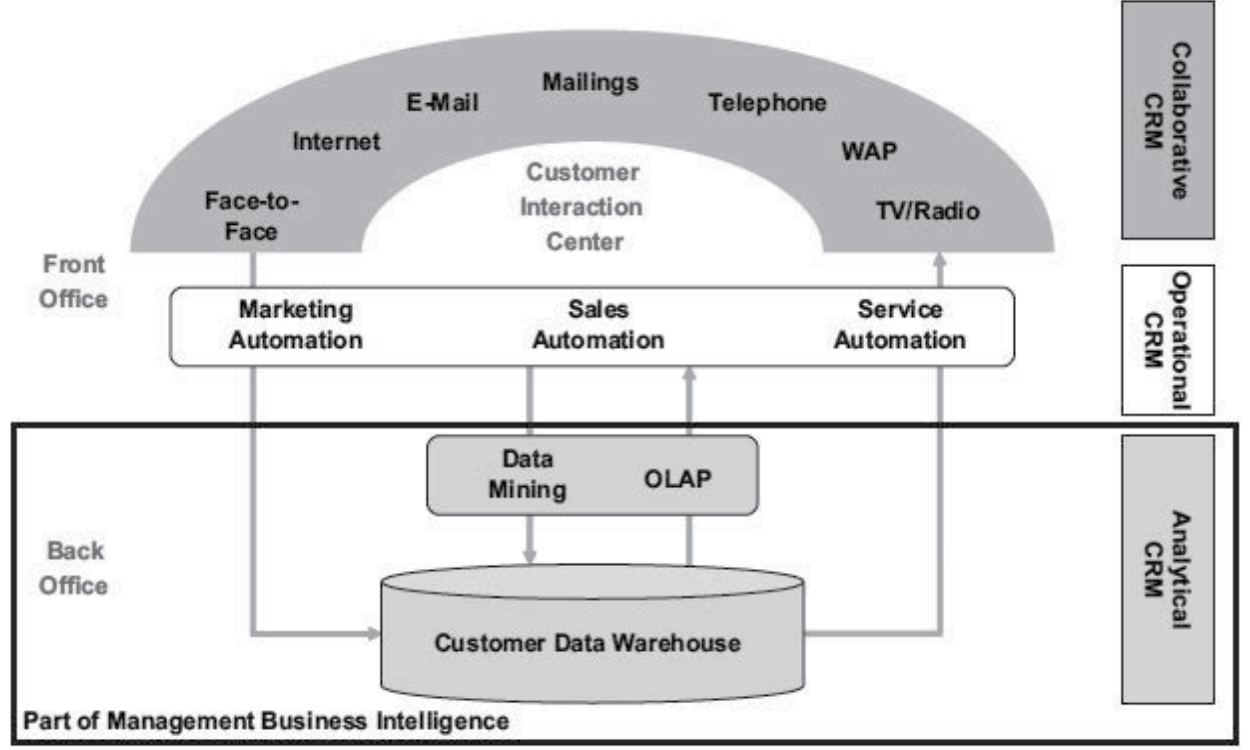

Fig. 4. Customer relationship management and Business intelligence (Source: Baars \& Kemper, 2008; Hippner \& Wilde, 2004.)

However, integration of BI modern technologies and CRM systems, provides the path to customer's loyalty. By possession of full information about all transactions and customer's experience, companies can increase the delivered value. On the other hand, Business Intelligence helps creation of real and complete image that will ensure the customer faster, better and easier decision making. Complementary use of CRM systems and Business Intelligence provides a holistic approach to customers which includes improvements in customer profiling, simpler detection value for customers, measuring the success of the company in satisfying its customers. Use of CRM and BI solutions also create a comprehensive customer relationship management and not just passive response to their requests, and predicting, and shaping their behavior. Business Intelligence can detect various incentives to increase sales and revenue, such as faster conversion of potential into actual clients, reducing the number of outgoing customers and increase sales to existing customers. Therefore, in the modern business, CRM can not be considered separately from Business Intelligence. They constitute a unique model that enables companies forecast customer behavior and make decisions based on these forecasts, and build long-term and profitable customer relationships. 


\section{Potential directions of the customer relationship management's evolution}

Digital economy, or the economy based on electronic data exchange, is definitely something what will represent an increasingly important aspect of modern business. Customer Relationship Management is a concept that has experienced a boom during the exponential growth of the internet. Personalization and direct interaction with customers, which the Internet has provided, have enabled companies for successfully and profitable satisfying their customers. Due to the development of ICT (Information-communication technology), especially Internet technology and increasingly demanding and sophisticated clients, modern companies are integrated with each other working as virtual corporations that perform only what they do best within the supply chain. Companies with an integrated value chain can provide superior service, with their biggest competitive advantage. Clients in these conditions may achieve additional values such as: prompt and accurate delivery, attractive prices, high quality, after-sale services, etc. This requires the electronic communication within the entire business process. This integration of business activities and information flows is achieved by implementing a new business model - a virtual network value. This model can be very effective, but represents a significant risk in terms of choice of partners in the chain. Specifically, the strength of the chain is determined by the strength of its weakest link. For this reason, virtual networks need to manage the company's strongest, namely those who possess the most valuable information and knowledge about customers. Among the partners there should be a great confidence, considering that companies within the same chain of sharing all information about products and services, customers and markets. Managing relationships with customers and partners within the value chain becomes a key to the success of the company in a modern economy. This integration of business activities and information flows is achieved by implementing a new business model - a Virtual Value Network ${ }^{6}$. This model can be very effective, but represents a significant risk in terms of partners' selection in the chain. In fact, the strength of the chain is determined by the strength of its weakest link. Digital economy is based on the technology, but it cannot exist without strong partners' relationships and trust. It erases the boundaries between companies and customers, and integrates customers within the organization, making them part of the value chain. From the previous development of CRM, it is evident that this concept will continue its evolution in the future. It is assumed that the CRM will include managing relationships with partners within the value chain (VCRM-Value Chain Relationship Management) and managing relationships with customer communities (CCRM-Customer Community Relationship Management) ${ }^{7}$. Thereby customer relationship management will involve a broader context, but also a greater role and significance in modern business and the new economy.

\section{Conclusion}

Modern, Internet-based, business requires from the company to find new ways of creating and maintaining relationships with customers. Customer Relationship Management includes an

\footnotetext{
6 Panian Ž., (2002), Izazovi elektroničnog poslovanja, (1st edition), Narodne novine, ISBN: 9536053632, Zagreb, pp.154.

7 Fingar P., \& Aronica R. (2001). The death of "e" and the birth of the real new economy: Business models, technologies and strategies for the 21st century, (1st edition), Meghan-Kiffer Press, ISBN:0929652-20-7, Tampa, Florida, pp.86.
} 
iterative (repetitive) process by which the information collected about customers are converted to positive relationships with them. Establishing direct and two-way communication is especially important in global competitive environment. In terms of stiff competition and global availability of information, products and services, customers expect continuous communication with the company and superior compliance with their requirements. Therefore, every company that is part of "e-story," must strive to offer high quality and customized products and services, and a range of additional benefits that will attract new and retain existing customers. For this reason, companies need to manage relationships with customers to increase their competitiveness and strengthen market position. The development of information technologies has significantly improved the relations between companies and their customers. In fact, modern information technology is a powerful instrument that enhances communication between the company's employees and its customers, but also effectiveness of the management within the company. The most prominent IT feature, in terms of customer relationship management, is enabling the interactive communication. This improves value creation for customers. The possibility of direct and targeted customer relations, leads to their personalization. Multi-channel communication facilitate the establishment of more sophisticated and two-way relationships, but it makes more difficult to integrate data and create unique images of customers. Therefore, the collected and stored data about customers must be available and integrated within the entire organization. This goal can be realized by building the functional customer data warehouse. In this way, the data warehouse represents the information core of Customer Relationship Management system. Data quality and availability in the warehouse enables offering adequate products and/or services to the customers. It is the backbone of the entire information infrastructure and associated technologies for decision support. Without the functional data warehouse, there are no integration of data as the foundation of successful relationships with customers or acquiring new knowledge in the form of business intelligence, which involves the provision of better information. The biggest advantage of business intelligence application in customer relationship management is its foundation in personalization. Personalized relationships with customers provide companies to better understand and satisfy the needs of each customer. This ensures that each customer gets exactly what wants and when it wants. BI applications support the implementation of various channels of communication with clients, such as e-mail, Web, telephone, etc. Customers in accordance with their preferences, choose the channel that best suits them and by whom will receive a personalized message. In addition, by possession of complete information about all performed transactions and customers' experiences, companies can deliver added value and achieve their satisfaction. On the other hand, business intelligence application improves creation a real and complete image of the client, which will provide faster, better and easier decision making. Complementary use of CRM systems and Business Intelligence, provides a holistic approach to customers which includes improvements in customer profiling, simpler detection value for customers, measuring the success of the company in satisfying its customers, and creating a comprehensive customer relationship management. Business Intelligence can detect various incentives to increase sales and revenue, such as faster conversion of potential into actual clientss, reducing the number of outgoing customers and increase sales to existing customers. Therefore, this chapter can be summarized at the main learning objectives. Namely, after completion of this chapter, you will be able to: 
1. Recognize essential value of customers to the enterprise;

2. Identify role of Business Intelligence in long term customer relationships;

3. Define Business Intelligence and explain its architecture;

4. Understand importance of CRM philosophy in the global competitive environment;

5. Describe multidimensional communication with customers;

6. Explain significance of data integration in providing unique experience for customers;

7. Understand social media advantages in advertising and loyalty programs;

8. Identify perspectives of the customer relationship management's evolution.

\section{References}

Baars H., \& Kemper H.G., (2008), Management support with structured and unstructured data - an integrated business intelligence framework, Information Systems Management, Vol.25, Issue 2., March 2008., pp.132-148., ISSN: 1058-0530.

Blackwell R.D., \& Stephan K., (2001), Customers rule: why the e-commerce honeymoon is over and where winning businesses go from here, Crown Business, ISBN 0-609-60865-7, New York.

Boysen M., (2008), Why is a CRM Strategy important?, 01/30/2010, Available from: http:/ / it.toolbox.com/blogs/effectivecrm/why-is-a-crm-strategy-important-26837.

Burnett K., (2001), The handbook of key customer relationship management: the definitive guide to winning, managing and developing key account business, (1st edition), Financial Times Prentice Hall, ISBN: 9780273650317, Great Britain.

CMO Survey, (2009), Marketers Prepare for Better Times Ahead, Duke University, 08/01/2011, Available from: http://news.duke.edu/2009/08/cmo.html

Dyche J., (2002), The CRM Handbook: A business Guide to Customer Relationships Management, (1st edition), Addison-Wesley Professional, ISBN: 978-0201730623, USA.

Fingar P., \& Aronica R. (2001). The death of " $e$ " and the birth of the real new economy: Business models, technologies and strategies for the 21st century, (1st edition), Meghan-Kiffer Press, ISBN:0-929652-20-7, Tampa, Florida.

Greenberg P., CRM at the Speed of Light: Social CRM 2.0 Strategies, Tools, and Techniques for Engaging Your Customers, (4th edition), McGraw-Hill Osborne Media, ISBN: 9780071590457, USA.

Habul A., \& Pilav-Velić A., (2010), Business Intelligence and Customer Relationship Management, Proceedings of 32nd International Conference on Information Technology Interfaces ITI 2010, ISBN 978-953-7138-19-6, Cavtat-Croatia, June 2010.

Inmon W. H., (1996), Building the Data Warehouse, (2nd edition), John Wiley \& Sons, ISBN: 978-0471141617, USA.

Inmon W. H., (2005), Building the Data Warehouse, (4th edition), John Wiley \& Sons, ISBN: 978-0764599446, USA.

Kalakota R., \& Robinson M., (2000), E-Business 2.0: Roadmap for Success, (2nd edition), Addison-Wesley Professional, ISBN: 978-0201721652, London.

Kelly K., (1999), New Rules for the New Economy, (1st edition), Penguin Books, ISBN: 9780140280609, USA.

Kotler P., \& Armstrong G., (2003), "Principles of Marketing“, (10th edition), Prentice Hall, ISBN: 978-0131018617, USA.

Lane N., (1999), Advancing the Digital Economy into 21st Century, Information Systems Frontiers, Vol.1., Issue 3., October 1999., pp.317-320., ISSN:1387-3326. 
Middlebrooks A., \& Craig T., (1999), Market Leadership Strategies for Service Companies: Creating Growth, Profits and Customer Loyalty, (1st edition), McGraw Hill, ISBN: 9780844224411, USA.

Murfitt S., (2001), Using Business Intelligence, 07/05/2010, Available from: www.digitrends/net/scripts

Nielsen company, (August 2, 2010), What Americans Do Online: Social Media And Games Dominate Activity, Nielsen Online, 07/15/2011, Available from: http://blog.nielsen.com/nielsenwire/online_mobile/what-americans-do-onlinesocial-media-and-games-dominate-activity/

Panian Ž., (2003), Odnosi s klijentima u e-poslovanju, (1st edition), Sinergija, ISBN 953-6895-110 , Zagreb.

Panian Ž., (2002), Izazovi elektroničnog poslovanja, (1st edition), Narodne novine, ISBN: 9536053632, Zagreb.

Peppers D., \& Rogers M., (2004), Managing Customer Relationship: a strategic framework, (1st edition), John Wiley \& Sons Inc., ISBN: 978-0471485902, New Jersey.

Prahalad C.K., Ramaswamy P.B., Katzenbach J.R., Lederer Ch., \& Hill S.,(2002), Harvard Business Review on Customer Relationship Management, (1st edition), Harvard Business Press, ISBN: 978-1578516995, USA.

Reynolds G.W., (1995), Information Systems for Managers, (3rd edition), West Publishing Co., ISBN: 0-314-04597-X, USA.

Reynolds J.A., (2002), "Practical Guide to CRM“, (1st edition), CMP Books, ISBN: 9781578201020, New York, USA.

Turban E., \& Volonino L., (2010.), Business Intelligence and Decision Support Systems, Information Technology for Management: Transforming Organizations in the Digital Economy, pp. 445-484, (7th edition ), John Wiley \& Sons, ISBN: 978-0470400326, USA.

Turban E., Sharda R., Delen D., \& King D., (2010), Business Intelligence, (2nd edition), Prentice Hall, ISBN: 978-0136100669, USA.

Vercellis C., (2009), Business Intelligence: Data Mining and Optimization for Decision Making, (1st edition), Wiley, ISBN: 978-0470511398, USA.

Wiliamson D. A., (2009), Social Network Ad Spending: 2010 Outlook, eMarketer Inc, 07/20/2011, Available from:

http://www.emarketer.com/Reports/All/Emarketer_2000621.aspx 


\title{
Investigating Customers' Perceptions Towards Text Messaging Services as a CRM Medium
}

\author{
Nichaya Suntornpithug and Pasu Suntornpithug \\ Indiana University-Purdue University Fort Wayne \\ United States of America
}

\section{Introduction}

Growing interest among consumers towards text messaging creates significant opportunities for brands to connect with customer on a personal level. A recent HipCricket Mobile Marketing Survey (Tsirulnik, 2009), for example, discovered that 73 percent of people use their mobile phone for text messaging their friends more often than for making calls. In the same survey, 34 percent received a marketing offer on their phone as a text message and 37 percent of consumers would participate in a mobile customer loyalty program from a brand they trust (Tsirulnik, 2009). The use of text messaging is increasingly recognized as a valuable CRM medium to improve customer acquisition, customer retention, customer loyalty, and customer profitability (Khurana \& Chaudhary, 2010).

The use of text messaging as a CRM medium not only creates opportunities, but also poses some challenges to companies. Companies need the right information to identify the right messages to be delivered to the right customers at the right time (Shankar et al., 2010). To get the right information, companies need to collect relevant consumer data, such as mobile phone numbers, names and addresses, and preferences as well as permission to deliver messages to them. However, mobile permission is a problem, due to continuing changes in consumer preferences and needs. Even though permission is granted by the customers, the validity of the permission depends on the service provided (Sinisalo et al., 2005), and, hence, permission needs to be updated constantly (Sinisalo et al., 2007).

Previous empirical research in mobile marketing and CRM suggested different values associated with text messaging, yet failed to analyze underlying issues and challenges. This study aims to close this gap by investigating consumers' attitudes on how companies should embrace text messaging services to target consumers and win their trust and loyalty. The results will uncover useful information on whether marketing via mobile devices can be worthwhile for companies. The specific objectives of this research are follows:
a. Investigate consumers' level of interest in various forms of text messaging.
b. Determine what product and service categories are best promoted and received by consumers through various forms of text messaging.
c. Evaluate privacy issues relevant to text messaging as a mCRM medium.
d. Analyze the success of using text messaging as a mCRM medium. 


\section{Literature review}

\subsection{Customer relationship management (CRM) and mobile customer relationship management (mCRM)}

Customer Relationship Management (CRM) is a business approach that incorporates people, process, and technology to create a meaningful dialogue with individual customers (Boulding et al., 2005) to retain customer retention and loyalty (Sinisalo et al., 2007; Khurana \& Chaudhary, 2010; Gebert et al., 2003). It is based on the concept of Relationship Marketing (RM) (Berry, 1983; Bebert et al., 2003; Zablah et al., 2004, as cited in Sinisalo et al. 2007). The advent of novel technology and available data has brought CRM to another level. The Internet has become a popular channel for firms to communicate and manage relationships with their customers (eCRM). eCRM allows customers to access company services from different locations.

Recently, mobile messaging technology has emerged as a relatively new tool for companies to create more unique and personalized one-on-one communication with individual customers (mCRM) (Schultz \& Bailey, 2000). While eCRM has been the subject of extensive investigation by scholars, adequate empirical studies are lacking concerning the emerging phenomenon of mCRM, as a subset of eCRM (Sinisalo et al., 2007; Khurana \& Chaudhary, 2010). Extant research from the customer's perspective includes the effects of mCRM on loyalty (Chan \& Lam, 2004; Liljander et al., 2007, as cited in Sinisalo et al. 2007) and customer satisfaction (Hsu \& Lin 2008). Research also examined the benefits of mCRM and structures required for setting up mCRM from firms' viewpoints (Schierholz et al., 2007; Duran, 2010).

\subsection{Unique characteristic of mCRM}

Mobile Customer Relationship Management (mCRM) was originally defined as "services that aim at nurturing customer relationships, acquiring or maintaining customers, support marketing, sales or services processes, and use wireless networks as the medium of delivery to the customers" (Camponovo et al., as cited in Sinisalo et al., 2007, p 773). Others have argued the importance of communication and redefined $\mathrm{mRCM}$ as "...communication, either one-way or interactive, which is related to sales, marketing, and customer service activities conducted through the mobile medium for the purpose of building and maintaining customer relationships between a company and its customer(s)" (Sinisalo et al., 2007, p. 774).

The concept of mCRM is possible due to the growing use of cellular phone and smart phones, such as Blackberry's, iPhones, and PDAs, that are capable of being used as a cellular device. Companies have used a variety of mobile messaging (such as Instant Messaging (IM), Multimedia Messaging Service (MMS), Short Messaging Services (SMS), Unified Messaging (UM), Messaging Service (EMS), and E-mail) to promote one-to-one communication with their customer. Among different types of mobile messages, the use of SMS (or text messaging) is growing at astounding rates since almost every mobile phone, whether smart or basic, can accept and send text messages. As of December 2010, an estimated 96 percent of Americans were wireless subscribers and an estimated 187.7 billion text messages were sent each month in the US (Martin, 2010). Because of its significance, this paper will focus on text messaging. 


\subsection{Using text messaging as a mCRMmedium}

Companies have used text messaging to deliver mCRM activities, such as coupons, alerts, reminders, contests, or product information, to those who have joined a customer program. The use of text messaging as a mCRM medium is of interest to business because of its unique benefits. First, text messaging services allow personalized communication, given that each mobile device is likely owned by an individual rather than a family (Sinisalo et al. 2007; Schultz \& Bailey, 2000). In addition, text messaging services permit customers to access the firm's services from a mobile phone or PDA with internet access anywhere, anytime, resulting in high flexibility (Balasubramanian et al., 2002). Also, communication via mobile medium could be interactive and immediate when companies are able to establish a direct dialogue with their customers, and at the same time, customers are able to take action quickly using such information (Barnes \& Scornavacca, 2004). Further, the increase in security of wireless network allows customer data be sent over the network with more confidence (Ranjan \& Bhatnagar, 2009).

\subsection{Underlying issues pertaining to using text messaging as a mCRM medium}

The unique characteristics of text messaging services also come with some challenges. First, the use of text messaging service requires customers to opt in for the mCRM program so that marketers could initiate communication with them. Thus, it is a challenging task for marketers to entice consumers to enter into the dialogue over the mobile medium.

Second, while personalized, relevant, timely, and secured communication could result in positive emotional relationship between the companies and their customers (Nysveen et al., 2005), any one irritating or unwanted message could damage this relationship given the intimate nature of mobile devices (Jelassi \& Enders, 2006). Hence, customers' preferences, interests, and needs have to be identified and understood by the company before successful communication can be initiated.

A third challenge involves the price of messages and communications charged by operators, which may pose a barrier to $\mathrm{mCRM}$ because customers may not be willing to pay to receive such messages. This study, therefore, offers different avenues for marketers to understand consumers so that appropriate marketing campaigns can be designed to attract and retain them.

\section{Theoretical background}

There is no exact conceptual framework of mCRM available, since using text messaging to deliver mCRM is a fairly new phenomenon. Previous literature on CRM, eCRM, and mobile advertising streams provide some theoretical background for this study.

\subsection{Consumer's attitudes toward different text messaging services}

Existing literature on mobile advertising focused on the effects of attitudes toward mobile marketing on purchasing behavior (e.g., Ma et al., 2009). More recent literature examined the role of online advertising formats on consumers' attitudes toward advertisements and found that the format plays a significant role and affects the response. This study aims to examine consumer's attitudes toward different formats of text messaging services. 


\subsubsection{Mobile couponing}

A Mobile Coupon is a form of text messaging service that can be sent to consumers via mobile devices that can be exchanged for a financial discount or rebate during a purchase. Different types of coupons include "Buy-one-get-one-free," "free," and "cents-off" or "dollars-off" (Mobile Marketing Association, 2007).The main advantages of using mobile couponing include personalized messages, time immediacy, and convenience (Raslomp, 2001). For example, coupons can be sent to existing consumers via a cell phone while consumers are in a retail shop and its bar-code scanned at the check-out cashier once consumers are ready to pay. However, lack of customer experiences with this service and limited distribution of a universal coupon reader system at the checkpoint could be some barriers for mobile couponing adoption.

\subsubsection{Alerts}

Text messaging can be used to deliver alerts to consumers no matter where they are. Different alerts that consumers may consent to include text messaging services in banking, such as overdraft notifications, bill payment reminders, daily balance notifications, transaction status updates etc. Airlines use text messaging services to inform users of their flight status, including flight arrival, cancellation, and delay. Retail stores send alerts to notify their customers of special sales or events.

\subsubsection{Contests}

Contests are commonly used by marketers to engage consumers with their brands. Major advantages of text messaging contests, compared to other types of contests, include 'immediacy,' 'ease of implementation,' and, particularly, 'fun.' Entertainment services can increase customer loyalty (Dickinger \& Haghirian, 2004); therefore, contests may be a good vehicle for firms to engage their existing customers with their brands.

\subsubsection{Product/service information}

Text messaging can be used to provide related product or service information such as newsletters. This form of text messaging needs to be implemented with caution. Information needs to be relevant to consumers' interest so that it does not irritate them. Since the understanding of consumers' attitudes toward different forms of text messaging is still limited, it is interesting to discover what forms of text messaging are acceptable to consumers?

Q1: What forms of text messaging are acceptable to consumers?

\subsection{Consumers' attitudes toward different text messaging services by industries}

Existing literature identifies a growing list of product and service categories that utilize text messaging services to engage customers. Among them, restaurants (Guo et al., 2007; Terry, 2009), entertainment (Rau et al., 2006; Bruno, 2005), retail stores (Shankar et al., 2010; Dickinger \& Kleijnen 2008), banking (Peevers et al., 2011; Amin \& Ramayah, 2010; Rumpa, 2005; Riivari, 2005), groceries (Kowatsch \& Maass, 2010), and auto sectors (Chattopadhyay et al., 2010) have been widely cited as industries using text messaging services as part of 
their marketing campaign. However, research suggests that not all the product/services categories have the same success rate. Therefore, this study aims to disclose which product/service categories are best promoted with text messaging.

Q2: Which product and service categories will best be promoted to and received by consumers through text messaging?

\subsection{Privacy issue pertaining to text messaging as MCRM medium}

\subsubsection{Consent}

Literature in permission marketing suggested that consumers are likely to refuse to accept messages when consent is not given (Golem, 2002; Tizende et al., 2002), because text messages are considered content that require payment from customers receiving the message. In addition, changing cell phone numbers is not as convenient as changing an email address, so unwanted messages or spam could dramatically irritate consumers when irrelevant messages are sent (Sinisalo et al., 2007; Islam et al., 2011; Sultan, 2005). Therefore, it is proposed that:

$\mathrm{H} 1$ : Consumers consider text messaging without their consent unacceptable.

\subsubsection{Push vs. pull strategies}

Today, marketers use push and pull strategies when delivering text messaging to their clients (Scharl et al., 2005).While push strategy campaign, a predominant method, involves delivering unsolicited messages, pull strategies involve delivering messages based on customers' requests (e.g., based on information they found via mobile applications or on banner ads). A study by Dickinger \& Haghirian (2004) found that 50percent of text messages were in a push mode, 45percent in pull and 5percent in both. Even though push strategies are more economical to companies than that of pull strategies, customers may view the unsolicited contents as intrusive and unwelcome (Yunos et al., 2003). Therefore, to build and maintain relationship with customers, it is proposed that:

$\mathrm{H} 2$ : Consumers prefer pull strategies over push strategies.

\subsection{Success measures of using text messaging services as mCRM medium}

The ultimate outcome of mCRM is to deliver optimal experiences to consumers so that they remain loyal and continue supporting businesses (Khurana \& Chaudhary, 2010). Using text messaging services as a mCRM medium can help companies promote relationships with customers through communications and interactions. This could result in an exchange of goods, services, or information. Therefore, this paper investigates the likelihood of consumers to redeem coupons and the appropriate numbers of text messages that consumers are willing to accept.

Q4: What is the likelihood of consumers to redeem coupons?

Q3: What is the number of text messages consumers prefer to receive per month? 


\section{Methodology}

\subsection{Focus group interview}

The main objective of the focus group interview was to get better understanding of consumers' perceptions towards text messaging services. A group of 12 people who were more than 18 years old and had experience with mobile marking were recruited to participate in the study. The focus group members were asked for their perception, attitudes, and intentions of using mobile marketing.

\subsection{Questionnaire survey}

The questionnaire consists of 30 questions to assess four main constructs: mobile device usage, attitudes toward different $\mathrm{mCRM}$ strategies in different industries, privacy concerns, and intention. The survey was designed to take about five to ten minutes to complete. Mobile device usage was measured using a constant sum scale (Reibstein, 1978), asking respondents to allocate a total of 100 points among different usages of mobile devices (i.e., calling, text messaging, accessing the internet, email, and others). Constant sum scales are appropriate for this study. According to Griffin and Hauser's study (1993), there was no significant difference between direct rating, constant-sum scale, and anchored scale in terms of measures of importance. Constant sum scales, however, provide fine discrimination among stimulus objects. Attitudes toward four text messaging strategies as mCRM (i.e., SMS coupons, SMS alerts, SMS contests, and SMS product information) were measured by four-point interest scales ranging from "not interested" to "very interested" Lastly, privacy was measured using a five-point Likert scale (ranging from "strongly disagree" to "strongly agree"). Intention was measured by asking respondents how many text messages per month are acceptable and how likely they are to redeem a coupon sent via text messaging.

Online consumers who owned mobile devices were targeted for this study. A total of 926 usable responses were returned. The wave analysis method (Armstrong \& Overton, 1977) was used to assess nonresponse bias by comparing early respondents with those of the late respondents. The results showed that there were no differences in the distributions between the early respondents and the late respondents. The characteristics of the respondents to this survey were comparable to recent 2010 text messaging user profiles (Nielsen, 2011).

\section{Data analysis and results}

\subsection{Demographic profile of respondents}

Table 1 shows respondent's demographic profile of this study. The 926 respondents were split between female (62.2percent) and male (37.8percent). Most respondents were fairly young, between the ages of 18 to 24 (64.9percent); were single (73.2percent); had an income between $\$ 5000$ and $\$ 9,999$ (30.1percent); had some college degree (57percent); actively participated in text messaging on their mobile devices (91.1percent); and did not have a data plan that included capabilities for accessing the internet on their mobile devices (57.9percent). 


\begin{tabular}{|c|c|c|c|c|}
\hline Variables & Values & Frequency & Percent & $\begin{array}{c}\text { Cumulative } \\
\text { Percent }\end{array}$ \\
\hline \multirow[t]{2}{*}{ Gender } & Female & 576 & 62.2 & 62.2 \\
\hline & Male & 350 & 37.8 & 100.0 \\
\hline \multirow[t]{5}{*}{ Age } & $18-24$ & 601 & 64.9 & 64.9 \\
\hline & $25-34$ & 200 & 21.6 & 86.5 \\
\hline & $35-44$ & 80 & 8.6 & 5.1 \\
\hline & $45-54$ & 38 & 4.1 & 99.2 \\
\hline & $>55$ & 7 & 0.8 & 100.0 \\
\hline \multirow[t]{3}{*}{ Marital status } & Single & 678 & 73.2 & 73.2 \\
\hline & Married & 204 & 22.0 & 95.2 \\
\hline & Others & 44 & 4.8 & 100.0 \\
\hline \multirow[t]{6}{*}{ Income } & $<\$ 5,000$ & 185 & 20.0 & 20.0 \\
\hline & $\$ 5,000$ to $\$ 9,999$ & 279 & 30.1 & 50.1 \\
\hline & $\$ 10,000$ to $\$ 19,999$ & 170 & 18.4 & 68.5 \\
\hline & $\$ 20,000$ to $\$ 29,999$ & 96 & 10.4 & 78.8 \\
\hline & $\$ 30,000$ to 39,999 & 76 & 8.2 & 87.0 \\
\hline & $>\$ 40,000$ & 120 & 13 & 100.0 \\
\hline \multirow[t]{7}{*}{ Education Level } & Less than high school & 5 & 0.5 & 0.5 \\
\hline & Some high school & 54 & 5.8 & 6.4 \\
\hline & High school graduate & 60 & 6.5 & 12.9 \\
\hline & Some college & 528 & 57.0 & 69.9 \\
\hline & Associates degree & 105 & 11.3 & 81.2 \\
\hline & Bachelors degree & 141 & 15.2 & 96.4 \\
\hline & Masters degree & 33 & 3.6 & 100.0 \\
\hline $\begin{array}{l}\text { Text messaging on } \\
\text { mobile device }\end{array}$ & $\begin{array}{l}\text { Yes } \\
\text { No }\end{array}$ & $\begin{array}{c}844 \\
82\end{array}$ & $\begin{array}{c}91.1 \\
8.9\end{array}$ & $\begin{array}{c}91.1 \\
100.0\end{array}$ \\
\hline \multirow[t]{2}{*}{ Data plan } & Yes & 390 & 42.1 & 42.1 \\
\hline & No & 536 & 57.9 & 100.0 \\
\hline
\end{tabular}

Table 1. Respondent's demographic profile

\subsection{Mobile device usage}

A constant-sum scale (Reibstein, 1978) was used as a measure of importance weights for different usages of mobile devices. As seen in Table 2, text messaging was the most popular usage of mobile device (mean=47.32 with standard deviation of .911), followed by calling (mean $=42.73$ with standard deviation of 42.73 percent). 


\begin{tabular}{cccc}
\hline \multicolumn{2}{c}{$\begin{array}{c}\text { Mobile Usage Importance } \\
\text { (constant-sum scale) }\end{array}$} & $\begin{array}{c}\text { Importance Weight } \\
\text { (percentage of points } \\
\text { assigned) }\end{array}$ & Std. Error \\
Rank & Usages & 47.32 & .911 \\
$\mathbf{1}$ & Text Messaging & 42.73 & .942 \\
$\mathbf{2}$ & Calling & 6.24 & .372 \\
$\mathbf{3}$ & Accessing the internet & 3.55 & .267 \\
$\mathbf{4}$ & Email & 0.17 & .045 \\
$\mathbf{5}$ & Others & & \\
\hline
\end{tabular}

Table 2. Mobile device usage

\subsection{Results}

\subsubsection{What forms of text messaging services are acceptable to consumers? (Q1)}

As shown in Table 3, 28.2 percent of the respondents indicated that they would like to receive coupons on their mobile devices via SMS messaging, but 71.8 percent said they would not. 22.8 percent of the respondents indicated that they would like to receive alerts on their mobile devices, while 77.2 percent would not. 8.1 percent of the respondents indicated that they would like to receive contests on their mobile devices via SMS messaging; 91.9 percent said they would not.

\begin{tabular}{lcccc}
\hline Variables & Values & Frequency & Percent & $\begin{array}{c}\text { Cumulative } \\
\text { Percent }\end{array}$ \\
\hline Interest in receiving coupons & Yes & 261 & 28.2 & 28.2 \\
& No & 665 & 71.8 & 100.0 \\
Interest in receiving alerts & Yes & 211 & 22.8 & 22.8 \\
& No & 715 & 77.2 & 100.0 \\
Interest in receiving contests & Yes & 75 & 8.1 & 8.1 \\
& No & 851 & 91.9 & 100.0 \\
Interest in receiving product & Yes & 75 & 8.1 & 8.1 \\
information & No & 851 & 91.9 & 100.0 \\
\hline
\end{tabular}

Table 3. Consumers' attitudes toward text messaging strategies as mCRM

\subsubsection{Which product and service categories will best be promoted to and received by consumers through text messaging? (Q2)}

As shown in Table 4, using a 4-point interest scale (1=Not Interested, $2=$ Somewhat Interest, $3=$ Interested, $4=$ Very Interested), the results showed that respondents were interested in receiving coupons (mean $\geq 2$ ) and that their interest were in coupons for restaurants (mean=3.15), entertainment (mean=3.11), and retail stores (mean=2.98), respectively. Respondents were somewhat interested in receiving coupons in grocery (mean=2.57) and automotive (mean=2.02) industries, while they had little interest in receiving coupons in banking industry (mean=1.62). In addition, respondents were somewhat interested in receiving alerts in most industries: entertainment (mean=2.43), retail stores (mean=2.25), banking (mean=2.24), restaurants (mean $=2.17$ ), and grocery (mean=2.07), respectively. Respondents were not much interested in receiving alerts in automotive industry (mean=1.83). Results further showed that consumers were somewhat interested in receiving 
contest information in all industries: entertainment (mean=3.37), retail stores (mean=3.01), restaurants $($ mean=2.92), grocery $($ mean=2.43), automotive $($ mean=2.31), banking $($ mean $=2.00)$ industries. Finally, results revealed that consumers were somewhat interested in obtaining product information from firms in all industries: entertainment (mean=2.97), restaurants (mean=2.61), retail stores $($ mean=2.58), automotive $($ mean=2.20), grocery $($ mean=2.18) and banking $($ mean=2.05).

\begin{tabular}{lcccc}
\hline \multirow{2}{*}{ Sectors } & \multicolumn{4}{c}{ Mean Scores (Standard Deviations \& Ranked) } \\
\cline { 2 - 5 } & $\begin{array}{c}\text { Interest in } \\
\text { receiving coupons } \\
(\mathrm{n}=261)\end{array}$ & $\begin{array}{c}\text { Interest in } \\
\text { receiving alerts } \\
(\mathrm{n}=211)\end{array}$ & $\begin{array}{c}\text { Interest in } \\
\text { receiving } \\
\text { contests } \\
(\mathrm{n}=75)\end{array}$ & $\begin{array}{c}\text { Interest in receiving } \\
\text { product information } \\
(\mathrm{n}=75)\end{array}$ \\
\hline Restaurants & $3.15(.835,1)$ & $2.17(1.06,4)$ & $2.92(.846,3)$ & $2.61(1.00,2)$ \\
Entertainment & $3.11(.847,2)$ & $2.43(1.04,1)$ & $3.37(.697,1)$ & $2.97(.844,1)$ \\
Retail Stores & $2.98(.903,3)$ & $2.25(1.05,2)$ & $3.01(.874,2)$ & $2.58(1.04,3)$ \\
Banks & $1.62(.905,6)$ & $2.24(1.10,3)$ & $2.00(1.03,6)$ & $2.05(1.17,6)$ \\
Grocery & $2.57(1.06,4)$ & $2.07(1.07,5)$ & $2.43(1.09,4)$ & $2.18(1.10,5)$ \\
Automotive & $2.02(1.03,5)$ & $1.83(0.99,6)$ & $2.31(1.07,5)$ & $2.20(1.07,4)$ \\
\hline
\end{tabular}

Table 4. Level of consumers' interests in receiving different types of mCRM strategies by industries

\subsubsection{Consumers are likely to consider text messages sent from firms without their consent unacceptable (H1)}

A majority of all respondents (61percent) strongly agreed that text messages without consent are unacceptable, as shown in Table 5. Further exploration using across-tabulation

\begin{tabular}{|c|c|c|c|c|c|c|c|}
\hline & \multirow[t]{2}{*}{ Age } & \multicolumn{5}{|c|}{$\begin{array}{l}\text { It is unacceptable for companies to text me without } \\
\text { my consents }\end{array}$} & \multirow[t]{2}{*}{ Total } \\
\hline & & $\begin{array}{l}\text { Strongly } \\
\text { Disagree }\end{array}$ & Disagree & Neither & Agree & $\begin{array}{l}\text { Strongly } \\
\text { Agree }\end{array}$ & \\
\hline \multirow{2}{*}{$18-24$} & Count & 22 & 28 & 54 & 170 & 327 & 601 \\
\hline & $\%$ within Age & $4 \%$ & $5 \%$ & $9 \%$ & $28 \%$ & $54 \%$ & $100 \%$ \\
\hline \multirow{2}{*}{$25-34$} & Count & 8 & 4 & 12 & 38 & 138 & 200 \\
\hline & $\%$ within Age & $4 \%$ & $2 \%$ & $6 \%$ & $19 \%$ & $69 \%$ & $100 \%$ \\
\hline \multirow{2}{*}{$35-44$} & Count & 4 & 0 & 1 & 12 & 63 & 80 \\
\hline & $\%$ within Age & $5 \%$ & $0 \%$ & $1 \%$ & $15 \%$ & $79 \%$ & $100 \%$ \\
\hline \multirow{2}{*}{$45-54$} & Count & 3 & 0 & 0 & 7 & 28 & 38 \\
\hline & $\%$ within Age & $8 \%$ & $0 \%$ & $0 \%$ & $18 \%$ & $74 \%$ & $100 \%$ \\
\hline \multirow{2}{*}{$\geq 55$} & Count & 0 & 0 & 0 & 0 & 7 & 7 \\
\hline & $\%$ within Age & $0 \%$ & $0 \%$ & $0 \%$ & $0 \%$ & $100 \%$ & $100 \%$ \\
\hline \multirow[t]{2}{*}{ Total } & Count & 37 & 32 & 67 & 227 & 563 & 926 \\
\hline & $\%$ within Age & $4 \%$ & $3 \%$ & $7 \%$ & $25 \%$ & $61 \%$ & $100 \%$ \\
\hline
\end{tabular}

Table 5. Consumers' perceptions of text messaging without consents by age 
analysis revealed an association between age and consumers' perception of text messages without their consent being unacceptable (chi-square $=44.852$, d.f. $=16$, sig $=0.000$ ). The results showed that the older respondents were likely to consider text messages without consent to be unacceptable (e.g., 54 percent of respondents aged 18-24 versus 100 percent of respondents aged over 55).

\subsubsection{It is likely that consumers prefer pull strategies over push strategies (H2)}

Using a 5-point Likert scale (1=strongly disagree, $2=$ disagree, $3=$ neither disagree nor agree, $4=$ agree, $5=$ strongly agree), the results shows that respondents preferred to use mobile applications to seek out offers (mean $=3.53$ ) rather than having a company contact them through text messaging $($ mean $=2.69)$. The mean differences $(0.84)$ were statistically significant (sig=.000). See Table 6.

\begin{tabular}{lccc}
\hline & $\begin{array}{c}\text { Mean } \\
\text { Scores }\end{array}$ & $\begin{array}{c}\text { Standard } \\
\text { Deviation }\end{array}$ & $\begin{array}{c}\text { Mean } \\
\text { Differences }\end{array}$ \\
\hline $\begin{array}{l}\text { It is acceptable for company I shop with } \\
\text { to text me offers. (push strategy) }\end{array}$ & 2.69 & 1.253 & 0.84 \\
$\begin{array}{l}\text { I prefer to use mobile applications to } \\
\text { seek out offers rather than a company } \\
\text { contacting me through text messaging. } \\
\text { (pull strategy) }\end{array}$ & 3.53 & 1.224 & \\
\hline
\end{tabular}

Table 6. Consumers' perceptions toward push strategy versus pull strategy

\subsubsection{What is the number of text messages consumers prefer to receive per month? (Q4)}

As shown in Table 7, a majority of respondents (43.6percent) did not want to receive text messages from companies (mean=1.12 text messages per month, standard deviation = 1.196).

\begin{tabular}{lccc}
\hline \# of Texts & Frequency & Percent & $\begin{array}{c}\text { Cumulative } \\
\text { Percent }\end{array}$ \\
\hline $\mathbf{0}$ & 404 & 43.6 & 43.6 \\
$\mathbf{1}$ & 184 & 19.9 & 63.5 \\
$\mathbf{2}$ & 202 & 21.8 & 85.3 \\
$\mathbf{3}$ & 99 & 10.7 & 96.0 \\
$\mathbf{4}$ & 37 & 4 & 100.0 \\
\hline
\end{tabular}

Table 7. Consumers' perceptions of the appropriate number of texts to be received per month

\subsubsection{What is the likelihood of consumers to redeem coupons? (Q3)}

A majority of respondents (58.7percent) indicated that they were not likely to redeem the coupons that they received via text messaging, as shown in Table 8. Nevertheless, a good proportion indicated that they were somewhat likely to redeem the coupon (mean= 1.48 , standard deviation $=.627$ ). 


\begin{tabular}{lccc}
\hline $\begin{array}{l}\text { Likelihood to } \\
\text { redeem coupon }\end{array}$ & Frequency & Percent & $\begin{array}{c}\text { Cumulative } \\
\text { Percent }\end{array}$ \\
\hline Not likely & 544 & 58.7 & 58.7 \\
Somewhat & 316 & 34.1 & 92.9 \\
Likely & 66 & 7.1 & 100.0 \\
Very Likely & & & \\
\hline
\end{tabular}

Table 8. Likelihood of coupon redemption

\section{Conclusion}

\subsection{Discussion and recommendation}

There is an exponential growth in using text messaging, or SMS, as a $\mathrm{mCRM}$ tool to create a meaningful dialogue with individual customers (Boulding et al., 2005) to build and maintain relationship between firms and their customers (Sinisalo et al., 2007). Evidence shows that there is an enormous failure rate from CRM projects (Saarikoski, 2006). This phenomenon has led to an observation that, while technologies play a significant enabling role for mCRM, they are only one part of the equation (Sinisalo et al., 2007; Crosby \& Johnson, 2001). The key to success is to understand what customers really want over time and to incorporate human processes into the use of the technology. There has been limited empirical research into understanding consumers' attitudes toward using text messaging as a tool for mCRM. This paper fills the research gap in the literature by examining consumer's perceptions toward different forms of text messaging services in different industries and identifying different privacy concerns as well as delineating success measures of text messaging services.

Respondents in this survey indicated that the text messaging abilities of their mobile device were the most popular feature. This finding indicates that delivering $\mathrm{mCRM}$ campaigns via text messaging could be a viable avenue for companies to build a dialogue with their target market, given consumers' familiarity with the use of text messaging.

However, using text messaging as mCRM requires extensive planning. The findings revealed that majority of consumers were still reluctant to receive text messages, from even familiar companies. Further investigation found that consumers were particular about receiving certain forms of message. Although young consumers were relatively more optimistic than older consumers (Mort, 2005), a majority of consumers of all ages viewed unsolicited text messaging without their consent as being unacceptable. Therefore, companies should understand that, while consumers may enjoy text messaging for personal reasons, the majority may still be uncomfortable or simply uninterested in receiving coupons on their mobile devices. Marketers are recommended to launch an awareness campaign about the text messaging campaign and to get customers to opt-in or consent prior to sending messages to them.

In addition, the findings revealed that consumers preferred to initiate the request for text messaging services (pull strategy) than receiving text messaging services from companies without requesting them (push strategy). The findings confirmed that consumers' privacy concerns were the key entry barriers for mCRM text messaging. Marketers must take this concern seriously and thoroughly investigate consumers' wants and needs continuously so 
messages are relevant. In addition, marketers can initiate marketing campaigns on other mobile applications with the link for consumers to request text information (coupons, alerts, contests, product information etc.).

If companies are to send text messaging via a push strategy, the findings showed that the appropriate number of text messages is 1.12 text messages per month. Therefore, it is suggested that companies limit their text messages to current consumers to no more than one per month to maintain a healthy relationship with customers.

Among different forms of mCRM text messaging, coupons received most interests from consumers and a good proportion of consumers indicated that they were likely to redeem the coupons. A study by Jupiter Research estimated that, by the end of 2011, more than $\$ 87$ billion in revenues will be generated by 3 billion mobile coupons.

Consumers indicated interest in receiving coupons from the restaurant, entertainment, and retail industries. Customers were interested in receiving contests information, alerts, and product information from the entertainment industry. Interest was indicated in alerts but only modest interest in product information from the restaurant, retail, banking, and grocery. The automotive industry was somewhat unique, with customers somewhat interested in product information but not in alerts or contests.

\subsection{Managerial implications}

The findings of this study provide insights for firms interested in using text messaging as a mCRM medium. For example, marketers have to be aware that text messaging from companies is still not well received by consumers due to privacy concerns. Marketers must respect these concerns and develop policies and systems to address privacy issues. Companies must not send text messages to consumers before consent is granted. Companies should clearly communicate their opt-in and opt-out policy terms and conditions as well as their guidelines on privacy and customer information sharing. In addition, companies should convince their consumers that the interaction is worthwhile (Lin \& Wang 2006) by launching a marketing campaign to educate customers about their firm's text messaging benefits. To entice consumers to participate in the mCRM text messaging programs, companies could include incentives for the customers to give their personal information, such as a chance to win some prizes in a lottery or discounts on goods and services.

Since permission is not permanent and the validity of consumers' permission relies on the relevancy of services provided, permission to send text messages must be renewed on a regular basis when push (un-requested) messages are used. An analysis of text messaging requests from customers through pull strategies could be analyzed. Then, companies could generate similar structured contents (un-requested content) through push strategies and bundling with other mobile applications to increase acceptance and minimize frustration. For examples, travel providers could deliver alerts about flight status to their customers as a bundle with mobile check-in.

After choosing the content of the messages, marketers should decide what forms of text messaging should be delivered. Consumers indicated interest in receiving coupons from the restaurant, entertainment, and retail industries. Customers were interested in receiving 
contests information, alerts, and product information from the entertainment industry. Interest was indicated in alerts but only modest interest in product information from the restaurant, retail, banking, and grocery. The automotive industry was somewhat unique, with customers somewhat interested in product information but not in alerts or contests.

\subsection{Theoretical implications and future research}

Text messaging as a mCRM medium is new, and this paper represents one of few attempts to empirically investigate an area deficient in empirical research. It offers a conceptualization of mCRM and analyzes consumers' perceptions toward text messaging in maintaining a meaningful dialogue with companies. Different issues such as privacy concerns, age, and types of industries are suggested as potential moderating factors in the success of mCRM.

Our results have some limitations, being exploratory in nature and addressing only four forms of mCRM text messaging in six industries, namely, the restaurant, entertainment, banking, retail, grocery, and automotive industries. The use of an online survey may result in sample bias, since people with certain characteristics may be more likely to respond to online surveys. Nevertheless, the demographic profiles of the respondents to this survey were comparable to mobile user profiles at the time of data collection, and the wave analysis (Armstron \& Overton, 1977) did not detect response bias in the collected data of this study.

Future studies can extend this research by replicating this study in other countries and on a larger scale. Future research can also investigate the role of various forms of text messaging services on different measures of mCRM. Other moderating variables could be further examined, such as consumers' shopping orientation (e.g., recreational, experiential, convenience or economic orientation), mCRM text messaging experiences, and types of industry.

\section{Acknowledgement}

The authors would like to provide credit to Lindsey Hively, Kelsey Hostetler, Preston Kaehr, DaniRosebrock, Katie Spence, and Steve Suddarth for the data collection efforts.

\section{References}

Amin, H. \& Ramayah, T. (2010). SMS banking: explaining the effects of attitude, social norms and perceived security and privacy. The Electronic Journal on Information Systems in Developing Countries. Vol. 41, No. 2, pp. 1-15.

Armstrong, S.J. \& Overton, T.S. (1977).Estimating nonresponse bias in mail surveys. Journal of Marketing Research, Vol. 14. No. 3, pp. 396-402.

Balasubramanian, S., Peterson, R.A., \& Jarvenpaa, S.L. (2002).Exploring the Implications of M-Commerce for Markets and Marketing. Journal of the Academy of Marketing Science. Vol. 30, No. 4, pp. 348-361.

Barnes, S.J. \& Scornavacca, E. (2004). Mobile marketing: the role of permission and acceptance. International Journal of Mobile Communications. Vol. 2. No. 2, pp. 128139. 
Boulding, W., Staelin, R., Ehret, M., \& Johnston, W.J. (2005). A customer relationship management roadmap: What is known, potential pitfalls, and where to go. Journal of Marketing, Vol69, No. 4, pp. 155-167.

Bruno, A. (2005). Acts, Audience connect via text messaging. Billboard. Vol. 117, No. 50, pp. 20.

Crosby, L.A. \& Johnson, S.L. (2001). Technology: friend or foe to customer relationships?. Marketing Management, Vol.10, No.4, pp.10-11.

Dickinger, A. \& Haghirian, P. (2004). An investigation and conceptual model of SMS marketing. Proceedings of the 37th Hawaii International Conference on System Sciences, ISBN 0-7695-2056-1, Big Islands, HI, 5-8 January 2004.

Duran, R.E. (2010). Extending CRM with mobile messaging: a case study. International Journal of Business Innovation and Research. Vol. 4, No. 1/2, pp. 15-29.

Chattopadhyay, T., Dutta, R.N., \& Sivani, S. (2010). An investigation and conceptual model of SMS marketing. IIMB Management Review. Vol.22, No. 4, pp. 173-185.

Dickinger, A. \& Kleijnen, M. (2008). Coupons going wireless: Determinants of consumer intentions to redeem mobile coupons. Journal of Interactive Marketing. Vol. 24, No. 2, pp. 111-120.

Gebert, H., Geib, M., Kolbe, L., \& Brenner, W. (2003). Knowledge-enabled customer relationship management: Integrating customer relationship management and knowledge management concepts. Journal of Knowledge Management, Vol. 7, No. 5, pp. 107-123.

Golem.de (2002). Mobiles Marketing, in: istnocheinWunschtraum, 12 March 2011, Available from: http:/ / www.golem.de/0108/15375.html

Griffin, A. \& Hauser, J.R. (1993). The voice of the customer. Marketing Science, Vol. 12, No. 1, pp. 1-27.

Guo, W., Hu, X. Zhou, \& K., Sun, L. (2007).An intelligent query system based on Chinese short message service for restaurant recommendation.Proceedings of $6^{\text {th }}$ International Conference on the Management of Mobile Business (ICMB 2007), Toronto, Canada, 9-11 July 2007.

Hsu, C.F. \& Lin, S-J.(2008). mCRM's new opportunities of customer satisfaction. International Journal of Social Sciences, Vol. 3, No. 2, pp. 133-137.

Islam, M.A., Ramayah, T., \& Hossain, M.M. (2011). The adoption of mobile commerce service among employed mobile phone users in Bangladesh: Self-efficacy as a moderator. International Business Research, Vol. 4, No. 2, pp. 80-89.

Jelassi, T. \& Enders, A. (2006). Mobile advertising: a European perspective," in Barnes, S. and Scornavacca, E. (Eds), Unwired Business: Cases in Mobile Business, Idea Group Inc., Hershey, PA.

Kowatsch, T. \& Maass, W. (2010). In-store consumer behavior: How mobile recommendation agents influence usage intentions, product purchases, and store preferences. Computers in Human Behavior, Vol. 26, No.4, (July 2010), pp. 697-704, ISSN:0747-5632.

Khuranan, A. \& Chaudhary, V. (2010). Customers' attitudes towards mobile messaging technology in promoting CRM: A study. The IUP Journal of Management Research, Vol. 9, No. 6, pp. 20-28. 
Liljander, V., Polsa, P. \& Forsberg, K. (2007). Do mobile CRM services appeal to loyalty program customers?.International Journal of E-Business Research, Vol. 3, No. 2, pp. $24-40$.

Lin, H.-H. \& Wang, Y.-S. (2006). An examination of the determinants of customer loyalty in mobile commerce contexts. Information and Management, Vol.43, No.3, (April 2006), pp .271-282, ISSN: 0378-7206.

Ma, J., Suntornpithug, N. \& Karaatli, G. (2009). Mobile advertising: Does it work for everyone?. International Journal of Mobile Marketing, Vol. 4, No. 2, pp. 28-35.

Martin, T. (n.d.). Wireless Quick Facts, In: CTIA-The Wireless Association, 6 April 2011, available from: http://www.ctia.org/media/index.cfm/AID/10323

Mobile Marketing Association. (2007). Introduction to Mobile Coupons, Mobile Marketing Association (MMA) version 97, Retrieved from http://www.mmaglobal.com/mobilecoupons.pdf

Mort, G.S. \& Drennan, J. (2005). Marketing m-services: establishing a usage benefit typology related to mobile user characteristics. Database Marketing \& Customer Strategy Management, Vol. 12, No. 4, pp. 327-41.

Nielson Company. (December 2010). Mobile Youth around the World, Nielson Company, Retrieved from http://www.text-board.com/marketing/wp-content/uploads/2011/01/NielsenMobile-Youth-Around-The-World-Dec-2010.pdf

Nysveen, H., Pedersen, P.E., Thorbjornsen, H. \& Berthon, P. (2005).Mobilizing the brand: the Effects of Mobile Services on Brand Relationships and Main Channel Use. Journal of Service Research, Vol. 7, No, 3, pp. 257-276.

Peevers, G., Douglas, G., Marshall, D., \& Jack, M.A. (2011). On the role of SMS for transaction confirmation with IVR telephone banking. International of Bank Marketing, Vol. 29, No. 3, pp. 206-223.

Ranjan, J. \& Bhatnagar, V. (2009). A holistic framework for mCRM - Data mining perspective. Information Management \& Computer Security, Vol.17, No, 2, pp. 151-165, ISSN 0968-5227.

Raskino, M. (2001). Mobile coupons will reach right into your pocket, In: Gartner Group Research Note, 21 April 2011, Available from: http://www.gartner.com/

Rau, P.-L. P. \& Chen, D. (2006). Effects of watermark and music on mobile message advertisements. International Journal of Human-Computer Studies, Vol. 64, No. 9, pp. 905-914.

Reibstein, D.J. (1978). The prediction of individual probabilities of brand choice. Journal of Consumer Research, Vol. 5, No.3, pp. 163-168.

Riivari, J. (2005). Mobile banking: A powerful new marketing and CRM tool for financial services companies all over Europe. Journal of Financial Services Marketing, Vol. 10, No. 1, pp. 11-20, ISSN: 13630539.

Rumpa, G. (6 February 2005). Are you banking more on your mobile?. In: The Times of India, 12 April 2011, Available from: http:/ / timesofindia.indiatimes.com/articleshow/1013140.cms

Saarikoski, V. (2006). The odyssey of the mobile internet, doctoral dissertation, University of Oulu, Oulu.

Scharl, A., Dickinger, A. \& Murphy, J. (2005).Diffusion and success factors of mobile marketing. Electronic Commerce Research and Applications, Vol. 4, No. 2, pp. 159-173. 
Schierholz, R., Kolbe L. \& Brenner, W. (2007). Mobilizing customer relationship management - A journey from strategy to system design. Business Process Management Journal, Vol. 13, No. 6, pp. 830-852.

Schultz, D.E. \& Bailey, S. (2000). Customer/brand loyalty in an interactive marketplace. Journal of Advertising Research, Vol. 40, No. 3, pp. 41-52.

Shankar, V., Venkateshb, A., Hofackerc, C. \& Naikd, P. (2010). Mobile marketing in the retailing environment: Current insights and future research avenues. Journal of Interactive Marketing, Vol. 24, No. 2, pp. 111-120.

Sinisalo, J., Salo, J., Karjaluoto, H. \& Leppa“niemi, M. (2007). Mobile customer relationship management: underlying issues and challenges. Business Process Management, Vol.13, No 6, pp. 771-787.

Sinisalo, J., Salo, J., Leppa“niemi, M. \& Karjaluoto, H. (2005). Building customer database for mobile customer relationship management, Proceedings of the $4^{\text {th }}$ International Conference on Information \& Management Sciences, July 2005.

Sultan, F. \& Roh, A. (2005). The coming era of 'brand in the hand' marketing. MIT Sloan Management Review, Vol. 47, No. 1, pp. 83-90.

Terry, L. (1 March 2009). Restaurants aim to boost sales with mobile apps, In: Nation's Restaurant News, 15 April 2011, Available from: http://www.nrn.com/article/restaurants-aim-boost-sales-mobile-apps

Tizende, T., Smith, B. \& Murphy, J. (2002).Getting permission: Exploring factors affecting permission marketing. Journal of Interactive Marketing, Vol. 16, No. 4, pp. 28-36.

Tsirulnik, G. (4 November 2009). Consumers want more marketing messages: Study, In: Mobile Marketer, 10 April 2011, Available from: http://www.mobilemarketer.com/cms/sectors/marketing/4564.html

Yunos, H.M., Gao, J.Z. \& Shim, S. (2003). Wireless advertising's challenges and opportunities, IEEE Computer, Vol. 36, No. 5, pp. 30-37. 


\title{
Customer Relationship Marketing: Customer-Centric Processes for Engendering Customer-Firm Bonds and Optimizing Long-Term Customer Value
}

\author{
Namita Bhatnagar \\ Department of Marketing, I. H. Asper School of Business, \\ University of Manitoba, Winnipeg, \\ Canada
}

\section{Introduction}

Relationship marketing puts forward that firms' interactions with a variety of agents are part of an ongoing process (akin to a relationship) as opposed to being discrete transactional events (Morgan \& Hunt, 1994). Research within the area has examined interactions with numerous internal and external agents - such as, those that occur internally with employees (e.g., Arndt, 1983), within and across functional areas (e.g., Ruekert \& Walker, 1987) and business units (e.g., Porter, 1987), as well as externally with service providers (e.g., Moorman, Zaltman, \& Deshpande, 1992), suppliers (e.g., Frazier, Spekman, \& O'Neal, 1988), allied companies (e.g., Bucklin \& Sengupta, 1993), and customers (Berry, 1983). While a holistic conceptualization of relationship marketing encompasses a network of all relational exchanges relative to a firm (Morgan \& Hunt, 1994), a focus on profitable relationships with customers has gained traction as well as undergone transformation in recent years (Kumar \& Reinartz, 2006; Thomas, Reinartz, \& Kumar 2004).

Earlier research, particularly in the domain of services marketing, concerned itself with attracting, developing, and retaining customers as a means to creating customer equity (Berry 1983, p. 25; Berry \& Parasuraman 1991, p. 133). Moreover, retaining customers and sustaining long lasting relationships with them was argued as being more beneficial to firms than acquiring new customers (Bendapudi \& Berry, 1997). Many subsequent researchers in the area (e.g., Bhatnagar, Maryott, \& Bejou, 2007; Thomas, Reinartz, \& Kumar, 2004; Zeithaml, Rust, \& Lemon, 2001) have been more nuanced in their approach to customer relationships, and have grappled with: (a) understanding whether some customers are more valuable, and therefore better candidates for developing and maintaining relationships with than others, (b) identifying and developing metrics to help guide customer management decisions, and (c) determining the best methods for incorporating the tenets of customer relationship management (CRM) within marketing decision-making.

Overall, the aim of this chapter is to discuss: (1) what customer relationship management means, the evolution of the CRM concept, and the supporting role of information 
technology; (2) the need for indentifying, prioritizing, and selecting customers, and valuebased metrics for guiding these decisions; and (3) the application of CRM concepts in practice - e.g., with respect to understanding individual needs, and developing customized marketing mixes and loyalty programs that encourage volume and longevity. The need for understanding the role of customer emotions, incorporating hedonic appeals, and addressing privacy concerns that arise as a result of personalized CRM activities will also be discussed.

\section{Customer-centricity and the customer relationship management concept}

Putting customers and their needs at the centre of business thought processes and actions are fundamental aspects of marketing philosophy (Deshpande \& Webster, 1989). At the core of the customer relationship management concept is the related notion that customers are all individuals with unique needs, treating them as such is conducive to fostering long-term customer-firm bonds, and the appropriate development and management of these relationships is profitable to firms. Acting upon the CRM concept, however, can be challenging-especially in terms of understanding the individual needs of diverse customers, and creating customized products and services that meet these needs. As a result, companies often compromise by clustering people on the basis of their similarities on some behavioral, demographic, or psychographic characteristics. Standardized products/services that address the average needs of chosen customer segments are then created and marketed. Some difficulties standing in the way of true customization have been addressed by rapid advances made in the field of information technology since the mid-1990s. The wide availability of powerful IT products, coupled with wide Internet usage, has allowed companies to collect, store, and analyze vast amounts of behavioral and demographic data at the individual customer level, and to interact with customers directly (Moe \& Fader, 2001; Venkatesan \& Kumar, 2003). At the same time, increased flexibility in production processes has made it possible to act upon this customer knowledge by developing individualized products with greater ease.

Companies have utilized information contained within these rich customer databases in different ways as the concept of CRM itself has evolved (Kumar \& Reinartz, 2006; p. 20-22). In the early stages, customer data was used for the purpose of automating sales force processes (e.g., with respect to identifying prospective leads, telemarketing, generating product/service quotations, and placing orders prior to actual sales) and providing customer service and support (e.g., with respect to help desk and field support after a sale). These two processes occurred independently of each other for the most part. In the next phase, data was used cohesively across all customer-oriented activities engaged in by a firm regardless of whether they occurred prior to, during, or after a sales transaction. In the current stage, it is advocated that customer data be used strategically such that all frontfacing customer functions become integrated with the back-end systems of the firm and its' network of suppliers and partners. The end goal is to maximize customer value. This evolution in CRM permits the notion to be embedded again within the broader relationship marketing concept that is holistic in nature, and considers the entire network of ongoing relational exchanges a focal firm is engaged in.

It is also worth mentioning that CRM activities are all too often confused by managers as being mere technological projects that are associated with particular software and 
techniques. Although IT systems play a crucial role in the implementation phase, it must be emphasized that the contemporary notion of CRM is integrative in nature whereby all of a firms' functions and processes are strategically focused on providing customers value and receiving value from them in return. CRM is therefore also defined as "the practice of analyzing and utilizing marketing databases and leveraging communication technologies to determine corporate practices and methods that will maximize the lifetime value of each customer to the firm" (Kumar \& Reinartz, 2006, p.17). The idea of customer lifetime value is of particular importance to contemporary customer management decisions, and will be discussed in greater detail within the context of value-based metrics for customer identification, prioritization, and selection.

\section{Customer identification and prioritization}

Many marketers believe that resources of a company should be invested in developing and maintaining relationships with customers over an extended period of time, and posit a positive association between customer duration and firm performance (Morgan \& Hunt, 1994; Reichheld, Markey, \& Hopton, 2000; Sheth \& Parvatiyar, 1995). The proposed advantages of customer retention and long lasting relationships are contended on several fronts-for example, in terms of (a) generation of recurring business, (b) higher expenditures per period, (c) lower price sensitivity (and the concomitant ability of sellers to charge higher prices), (d) lower costs of servicing, (e) greater dissemination of positive word-of-mouth to other potential prospects, and (f) higher forgiveness for poor service from customers of long standing than newer ones (Bendapudi \& Berry, 1997; Reichheld et al., 2000). In other words, customers' contributions to firm profitability increase as initial acquisition costs are recouped and the ongoing marginal costs of maintaining them are outweighed by the marginal benefits accrued over time.

A consequence of arguments supporting customer longevity has been the proliferation of expensive 'customer loyalty programs' that provide primarily economic/utilitarian incentives for generating patronage and repeat business (e.g., the Air Miles program and other frequency marketing programs). There is scant empirical evidence, however, that backs up the arguments put forth in favor of customer retention as well as for the positive impact of loyalty programs on corporate bottom lines. In fact, Reinartz and Kumar (2000) used a broad-based sample of individual customers across four industries to demonstrate that customers of longer standing who are not bound by a contract don't necessarily pay price premiums, nor are cheaper to service, as compared to shorter term customers.

Researchers such as Dowling and Uncles (1997) have also questioned assertions pertaining to the benefits of customer retention, and called for rigorous testing of the customer longevity-profitability relationship. While it is true that some customers of long standing may display the beneficial characteristics proposed above, this may not always hold true. For instance, patrons that are regulars may also be demanding in terms of the service and support levels sought, as well as the price-points that they consider as acceptable. The cost of supporting such clients may very well exceed the revenue that they bring in, ultimately making them unprofitable to pursue. On the other hand, there may also be customers that are very profitable, but the business generated takes place only for a short period (Thomas et al., 2004). In addition to issues of duration, customers can also be targeted in order to shore up market share and gain a competitive edge-there are segments, however, that 
while boosting market share are unprofitable to serve (Rust, Lemon, \& Zeithaml, 2001; Thomas et al., 2004; Zeithaml et al., 2001). Despite the numerous arguments put forth for increasing customer duration, as well as various strategies suggested for doing so (Bolton \& Lemon, 1999), more recent research recommends the optimization of customer value and profitability regardless of loyalty, duration, or market share concerns (e.g., Kumar \& Reinartz, 2004; Rust et al., 2001; Thomas et al., 2004; Venkatesan \& Kumar, 2003; Zeithaml et al. 2001). A shift has therefore occurred from focusing on customer longevity and developing relationships with all customers to customer value and developing relationships with the right ones - i.e., those that are profitable and are therefore of value to the firm (Thomas et al., 2004; Venkatesan \& Kumar, 2003).

Target marketing usually involves market segmentation on the basis of one or more characteristics (e.g., those that are demographic, behavioural, psychographic, and/or geographic in nature), choosing segments to target by matching the average needs of the various segments with the company's ability and willingness to fulfill them, and creating marketing mixes that satisfy the average needs of the target segments. Also using segment profitability - a variable not typically considered within targeting decisions (Zeithaml et al., 2001) - would allow firms to be more pragmatic about identifying and selecting the most promising customers. Therefore, where the aim earlier was to instigate and manage relationships with all current and potential customers, the aim now is to create typologies of customers on the basis of their profitability to the firm and expend resources on differentially serving and satisfying them. Offering a differentiated mix of products and services is justified by researchers such as Zeithaml et al. (2001) who argue that more valuable customers respond most positively to service quality enhancements and other marketing efforts. The vast amounts of detailed demographic and behavioral customer data amassed by marketers are being used for predicting the potential profitability of individual customers, and are the backbone of direct marketing and database marketing initiatives. A number of metrics have been developed to help categorize customers in terms of their value to the firm. Descriptions of some key metrics - specifically SOW, RFM and CLV techniques, as well as discussions related to their strong points and shortcomings, are provided next

\subsection{Value-based metrics for customer identification, prioritization, and selection}

Marketers use individual response data contained within customer databases within a variety of computations in order to gauge customer value. Popular proxies for customer worth include the SOW, RFM, and CLV scores that are used for ranking customers from most to least valuable. A firm's importance to its customers is often assessed via the share of wallet (SOW) it occupies in relation to its competitors. Customers' SOW scores are simply their expenditures on a particular brand relative to expenditures on all brands within the category. The greater the share of wallet occupied by a brand, the more valuable that customer is deemed within the customer relationship management framework. A weighted combination of transaction recency (i.e., how recently a customer last transacted with a firm), frequency (i.e., how often transactions occur within the pertinent time frame), and monetary value (i.e., the average expenditure during this period) yields a customers' RFM score. Different researchers attach greater or lesser importance to the different facets of customer value. For example, the greatest weightage is typically given to the recency of transactions and the least to the frequency with which they occur (Aaker, Kumar, \& Day, 1998; Kumar, 
Ramani, \& Bohling, 2004). On the other hand, Venkatesan and Kumar (2003) consider frequency as being more important than the average monetary value of transactions.

These customer-valuation techniques, though used often as indicators of relative loyalty and intensity of attachment, have been associated with shortcomings that include the use of average values (that do not adjust for demand fluctuations), and the use of data generated from existing customers (that does not account for prospective customers). The main critique of these approaches, however, centers on their backward-looking historical perspective of buyer behavior. Predictions about future consumption patterns based on extrapolations of past results run into difficulties such as the inability to create distinctions between customers that have transacted heavily in the past but may or may not continue to do so in the future. Consequently, customer lifetime valuation (CLV) techniques that account for differences in purchase and attrition patterns and predict future consumption are often suggested as forward-looking probabilistic alternatives for replacing or augmenting the SOW and RFM metrics (Kumar et al., 2004; Venkatesan \& Kumar, 2003).

Customer lifetime value refers to the net present value of a customer to the firm-i.e., the present value of revenues less expenditures associated with a customer over their lifetime with the firm. While individual CLV aids in customer prioritization and selection decisions (Kumar et al., 2004), CLV is often aggregated (Berger \& Nasr, 1998; Gupta, Lehmann, \& Stuart, 2004) and represents the overall equity inherent within a market segment (Kumar et al., 2004).

\subsection{Managing relative investments in customer acquisition and retention to maximize customer value}

Customer value maximization implies generating the most amount of customer revenue while minimizing associated marketing expenditures (Rust, Moorman, \& Dickson, 2002). Managers must often decide amongst competing resource allocation needs related to all the elements of the marketing mix. For example, Berger and Nasr-Bechwati (2001) and Murthy and Mantrala (2005) examine budget allocation decisions between different types of promotional activities. Along similar lines, investments on customer acquisition must be weighed against investments on customer retention, and vice versa. It is widely assumed that existing customers should be maintained as it is less expensive to retain customers than acquire new ones. Pfeifer (2005) however finds that firms do not necessarily spend more on customer acquisition as compared to retention.

Optimal resource allocation (ORA) models have been developed within marketing in order to provide guidance for an optimal blend of investments across customer acquisition and retention activities such that the value of the customer base is maximized (e.g., Berger, Bolton, Bowman, Briggs, Kumar, Parasuraman, \& Terry, 2002; Blattberg \& Deighton, 1996; Pfeifer, 2005; Thomas et al., 2004). The backward-looking (SOW and RFM) and forwardlooking value metrics (CLV) described previously often guide resource allocation decisions. For instance, Venkatesan and Kumar (2003) modeled data within the high-tech computer industry and recommended reserving the highest level of service for customers high on backward as well as forward measures of value, and the lowest investments for those low on both. They also suggested using strong persuasive tactics for customers with high future potential despite low prior profitability, and interacting with customers that were profitable in the past but are low on forward metrics solely via low-cost means. 
Researchers such as Jain and Singh (2002) and Thomas et al. (2004) caution that optimal resource allocation models should not seek to optimize acquisition and retention costs in an isolated fashion. Rather, they advise incorporating both types of expenditures at the same time in order to assess their joint impact on profitability - an approach reflective of what actually takes place in practice.

\section{Applying the CRM concept}

Companies collect and store detailed data pertaining to existing and prospective customers within vast databases, conduct data analysis in order to better understand each customer, and implement marketing initiatives and CRM programs to pursue individualized profitable relationships with customers. CRM strategies can occur along all dimensions of the marketing mix (Kumar \& Venkatesan, 2005; Murthy \& Mantrala, 2005; Rust et al., 2001). For example, products and services can be tailored, as can pricing, channels of distribution, and promotional methods to suit the unique needs and profile of each customer. CRM strategies are often implemented in the form of customer loyalty programs that are discussed in greater detail here.

Loyalty marketers offer some form of benefits to customers with the goal of instigating greater expenditures and repeat purchases, deeper customer-firm bonds, and lower defection rates (Uncles, Dowling, \& Hammond, 2003). Loyalty programs came about within the travel industry in the 1980s, gained traction in the midst of the information technology boom of the 1990s, and have now attained ubiquity (Capizzi \& Ferguson, 2005). Programs in a variety of formats exist world-wide in consumer-to-business contexts (e.g., airline frequent flier programs, the Canadian Air Miles coalition, grocery store frequent shopper programs, rewards programs associated with credit cards, and so forth) as well as business-to-business settings (e.g., within the technology and telecommunications sectors; Capizzi \& Ferguson, 2005). Berman (2006) reports that the vast majority (90\%) of Americans belong to at least one of more than 2000 such programs that exist within the US (c.f. Mimouni-Chaabane \& Volle, 2010). Kumar and Reinartz (2006) designate loyalty programs as a "CRM tool to identify, reward, and retain profitable customers". Most literature within the area has looked at firms' motivations in terms of creating relational bonds with customers (e.g., Lewis, 2004), and primarily economic gains that customers receive from participating in such programs (Peterson, 1995). More recent research, however, suggests greater variation in customers' motivations for participation (Mimouni-Chaabane \& Volle, 2010) - for example, convenience and cost savings (economic/utilitarian benefits), experiencing enjoyment/entertainment (hedonic benefits), and receiving recognition for intensity of patronage (symbolic benefits). Capizzi and Ferguson (2005) recommend that creativity, innovation, and imagination augment the ubiquitous and largely indistinguishable programs that are developed around financial incentives. Recently, loyalty programs have indeed evolved to include benefits that go well beyond those that are merely economic and utilitarian in nature (e.g., preferential treatment given to Ralph Lauren priority VIP customers, and to frequent fliers within American Airline's AAdvantage program; Mimouni-Chaabane \& Volle, 2010).

Loyalty programs are expensive to run, and questions pertaining to their effectiveness frequently crop up in customer management literature (e.g., Fournier 1998; Kumar \& Reinartz, 2006; Uncles et al. 2003). Uncles et al. (2003) argue that pressures to maintain competitive parity rather than clear cut empirical evidence of a positive relationship with 
profitability often motivate firms to institute and maintain loyalty programs. Fournier (2006) suggests that an inadequate grasp of the true meaning of loyalty itself, and not poor managerial implementation, contributes to the lack of success of loyalty marketing. In the literature, loyalty is conceptualized in several ways: such as, on the basis of attitudes ("a consistently favorable set of stated beliefs towards the brand"; Uncles et al 2003, p. 296), behaviors ("measured by repeat purchase"; p. 297), or a combination thereof (Fournier, 1998). Earlier emphasis by relationship marketers on customer longevity was manifested in a concomitant emphasis on the behavioral notion of loyalty in practice where largely utilitarian incentives (e.g., discounts, cash back, and bonus points) were offered for engaging in repeat purchases. Repeat purchases, however, can be an external expression of inertia and habit, just as much as loyalty which implies a deep emotional connection. Moreover, just as there are many types of transactional and/or emotional relationships that can occur in the interpersonal domain, customer can also have different types of relational bonds with companies (Fournier, 1998). The focus is therefore shifting to engendering not just utilitarian but also a variety of hedonic and symbolic motivations for loyalty program participation.

The reliance on customer-specific data for designing customized loyalty programs also raises the issue of infringements on customer privacy. Selling customer data for the purposes of data-mining and customer profiling is a lucrative revenue stream for many retailers and service providers. For instance, many leading US banks and credit/debit card issuers (e.g., Wells Fargo, Citibank, Discover) sell information related to their customers' shopping habits (e.g., where they shop, how much they spend, the frequency with which this occurs) to merchants that use this data to profile customers and design targeted deals. The financial institutes then act as intermediaries for extending the personalized offerings to customers. Although the banks claim that sensitive customer information such as bank account numbers and Social Security numbers aren't disclosed to the merchants and customers benefit from relevant deals, the automatic opt-in for such loyalty programs (despite the government mandated option to opt out) constitutes an area of deep concern for customers and consumer privacy advocates (Ellis, 2011). The push to provide personalized experiences that rely heavily on past consumption histories can also lead to unintended breaches of privacy and negative consequences in the domain of publicly consumed products and services. Wan, Bhatnagar and Qiu (2008) find that customers whose impression management goals are subverted by disclosures of past consumption patterns respond with feelings of embarrassment, less favorable attitudes toward the service episode, and lowered intentions of future patronage.

Companies as well as customers benefit from fostering emotional connections with each other. This is however subject to caveats wherein hedonic and symbolic benefits and not mere financial benefits are perceived by customers, and private boundaries are not breached in a bid to profile individual customers.

\section{Conclusion}

Conventional customer relationship management wisdom suggested that customers of longer standing provide a number of benefits (such as, lower price sensitivity and cost of serving) that are not as forthcoming from those of shorter tenure. Firms therefore expended resources on creating relational bonds with customers with the intent of retaining them over 
the long-term. This focus on establishing relationships in a generic fashion with all customers has given way to more targeted retention efforts where bonds are sought with higher value (i.e., profitable) customers. The contemporary CRM concept is holistic and encompasses the network of relational exchanges a firm engages in internally as well as externally (with customers, suppliers, and other partners) with the end-goal of maximizing customer value.

Numerous backward (e.g., SOW and RFM scores) and forward looking metrics (e.g., CLV scores) have been developed for gauging customer value, and a combination of both (but especially forward looking CLV metrics) is recommended for identifying and selecting customers with high future potential. Loyalty programs that provide a variety of benefits to customers for intensifying consumption and re-patronage have evolved on two fronts: first, on the basis of providing differential rather than generalized treatment to customers of varying worth, and second, on the basis of the types of benefits offered spanning the spectrum of economic and utilitarian incentives, emotional and experiential incentives, and symbolic incentives that provide recognition and social rewards for greater consumption. Information systems play the essential supporting role of data collection, storage, and analysis required within CRM programs for understanding and interacting with individual customers. At the same time, customer data must be used with care as the access to and use of detailed customer information leaves the relationship marketing industry open to criticisms from customer advocates that fear the loss of privacy.

\section{References}

Aaker, D.A., Kumar V., \& Day, G. S. (1998). Marketing research. New York: John Wiley \& Sons.

Arndt, J. (1983). The political economy paradigm: Foundation for theory building in marketing. Journal of Marketing, 47 (Fall), 44-54.

Bendapudi, N., \& Berry, L.L. (1997). Customers' motivations for maintaining relationships with service providers. Journal of Retailing, 73 (1), 15-37.

Berger, P. D., Bolton, R. N., Bowman, D., Briggs, E., Kumar, V., Parasuraman, A., \& Terry, C. (2002). Marketing actions and the value of customer assets: A framework for customer asset management. Journal of Service Research, 5 (1), 39-54.

\& Nasr, N. I. (1998). Customer lifetime value: Marketing models and applications. Journal of Interactive Marketing, 12 (Winter), 17-30.

, \& Nasr-Bechwati, N. (2001). The allocation of promotion budget to maximize customer equity. The International Journal of Management Science, 29, 49-61.

Berman, B. (2006). Developing an effective customer loyalty program. California Management Review, 49 (1), 123-148.

Berry, L. (1983). Relationship marketing. In Emerging Perspectives on Services Marketing, L. Berry, G. L. Shostack, \& G. D. Upah, eds., Chicago: American Marketing Association, 25-28.

\& Parasuraman, A. (1991). Marketing Services. New York: The Free Press.

Bhatnagar, N., Maryott, K., \& Bejou, D. (2007). Customer selection and prioritization: The optimal resource allocation approach to maximizing customer value. Journal of Relationship Marketing, 6 (3/4), 117-130. 
Blattberg, R. C., \& Deighton, J. (1996). Manage marketing by the customer equity test. Harvard Business Review, (July-August), 136-144.

Bolton, R. N., \& Lemon, K. N. (1999). A dynamic model of customer's usage of services: Usage as an antecedent and consequence of satisfaction. Journal of Marketing Research, 36 (May), 171-186.

Bucklin, L. P., \& Sengupta, S. (1993). Organizing successful co-marketing alliances. Journal of Marketing, 57 (April), 32-46.

Capizzi, M. T., \& Ferguson, R. (2005). Loyalty trends for the twenty-first century. Journal of Consumer Marketing, 22 (2/3), 72-80.

Deshpande, R., \& Webster, Jr., F. E. (1989). Organizational culture and marketing: Defining the research. Journal of Marketing, 53 (1), 3-15.

Dowling, G. R., \& Uncles, M. (1997). Do customer loyalty programs really work?. Sloan Management Review, 38 (Summer), 71-82.

Ellis, B. (2011). Banks' billion-dollar idea: Sell your shopping data. Retrieved from www.CNN.com on July 62011.

Fournier, S. (1998). Consumers and their brands: Developing relationship theory in consumer research. Journal of Consumer Research, 24 (4), 343-373.

Frazier, G. L., Spekman, R. E., \& O'Neal, C. R. (1988). Just-in-time exchange relationships in industrial markets. Journal of Marketing, 52 (October), 52-67.

Gupta, S., Lehmann, D., \& Stuart, J. (2004). Valuing customers. Journal of Marketing Research, 41, 7-18.

Jain, D., \& Singh, S. S. (2002). Customer lifetime value research in marketing: A review and future directions. Journal of Interactive Marketing, 16 (2), 34-46.

Kumar, V., Ramani, G., \& Bohling, T. (2004). Customer lifetime value approaches and best practice applications. Journal of Interactive Marketing, 18 (3), 60-72.

Kumar, V. \& Reinartz, W. J. (2006). Customer Relationship Management: A Databased Approach. John Wiley \& Sons, Inc.

Kumar, V., \& Venkatesan, R. (2005). Who are the multichannel shoppers and how do they perform?: Correlates of multichannel shopping behavior. Journal of Interactive Marketing, 19 (2), 44-62.

Lewis, M. (2004). The influence of loyalty programs and short-term promotions on customer retention. Journal of Marketing Research, 41 (3), 281-292.

Mimouni-Chaabane, A., \& Volle, P. (2010). Perceived benefits of loyalty programs: Scale development and implications for relational strategies. Journal of Business Research, 63, 32-37.

Moe, W. W., \& Fader, P.S. (2001). Uncovering patterns in cyber shopping. California Management Review, 43 (4), 106-117.

Moorman, C., Zaltman, G., \& Deshpande, R. (1992). Relationships between providers and users of marketing research: The dynamics of trust within and between organizations. Journal of Marketing Research, 29 (August), 314-329.

Morgan, R. M., \& Hunt, S. (1994). The commitment-trust theory of relationship marketing. Journal of Marketing, 58 (July), 20-38.

Murthy, P., \& Mantrala. M. K. (2005). Allocating a promotion budget between advertising and sales contest prizes: An integrated marketing communications perspective. Marketing Letters, 16 (1), 19-35. 
Peterson, R. A. (1995). Relationship marketing and the consumer. Journal of the Academy of Marketing Science, 23 (4), 278-281.

Pfeifer, P. E. (2005). The optimal ratio of acquisition and retention costs. Journal of Targeting, Measurement and Analysis for Marketing, 13 (2), 179-188.

Porter, M. E. (1987). From competitive advantage to corporate strategy. Harvard Business Review, 65 (May/June), 43-59.

Reichheld, F. F., Markey Jr., R. G., \& Hopton, C. (2000). The loyalty effect-The relationship between loyalty and profits. European Business Journal, 12 (3), 134.

Ruekert, R., \& Walker, O. (1987). Marketing's interaction with other functional units. Journal of Marketing, 51 (January), 1-19.

Rust, R. T., Lemon, K.N., \& Zeithaml, V.A. (2001). Where should the next marketing dollar go? Marketing Management, 10 (3), 24-28.

, Moorman, C., \& Dickson, P. R. (2002). Getting return on quality: Revenue expansion, cost reduction, or both. Journal of Marketing, 66 (4), 7-24.

Sheth, J. N., \& Parvatiyar, A. (1995). Relationship in consumer markets: Antecedents and consequences. Journal of the Academy of Marketing Science, 23 (4), 255-271.

Thomas, J. S., Reinartz, W., \& Kumar, V. (2004). Getting the most out of all your customers. Harvard Business Review, July-August, 116-123.

Uncles, M. D., Dowling, G. R., \& Hammond, K. (2003). Customer loyalty and customer loyalty programs. The Journal of Consumer Marketing, 20 (4/5), 294-316.

Venkatesan, R., \& Kumar, V. (2003). Using customer lifetime value in customer selection and resource allocation. MSI Reports, Working Paper Series, 3, 3-27.

Wan, F., Bhatnagar, N., \& Qiu, P. (2008). All friendliness Is not created equal: The role of impression management goals and server connectedness in consumer embarrassment and service experience. Competitive Paper, Society for Consumer Psychology Conference, February, New Orleans, LA.

Zeithaml, V. A., Rust, R. T., \& Lemon, K. N. (2001). The customer pyramid: Creating and serving profitable customers. California Management Review, 43 (4), 118-142. 


\title{
Business Intelligence Through Personalised Location-Aware Service Delivery
}

\author{
Tanko Ishaya \\ The University of Hull, Scarborough Campus, Internet Computing, Scarborough, \\ United Kingdom
}

\section{Introduction}

Advances in mobile communication and location-based technologies have presented business and decision-makers (such as marketing managers) with a new paradigm for Business Intelligence (BI). It has created a channel for location-aware advertising - defined as targeted advertising initiatives delivered to a mobile device from an identified service provider that is specific to the location of the consumer (Unni \& Harmon, 2007). With the increasing popularity of the new generation of Global Positioning Systems (GPS)-enabled smartphones (Bellavista et al, 2008) and their ubiquity, marketers and other service providers are able to utilize this emerging technologies to deliver targeted, tailored (Gauntt, 2008) and personalized services (such advertising) based on consumers' geographical locations (W3C, 2009) and prediction of their needs (Barnes, S. \& Scornavacca, 2004), and to reach them through their mobile devices on a geographically targeted basis. As a result, there are now a number of location-aware services that have been classified as - Information and navigations services, emergency assistance, tracking services and network related services (Al-Bayari \& Sadoun, 2007). Location aware services means that the application is aware of the current location and can use this information to present, retrieve or filter the information appropriate to the user at a particular position. For example, current offers at restaurants that are within 10 metres could be shown to a user that is out for a night meal with friends and the device can guide them to the destination. Location-Aware Service (from now on referred to as LAS) revenues are expected to increase to about $\$ 19$ billion by the year 2014 (Kobsa, 2007).

Despite its ubiquity and growing popularity, LAS is yet to be fully utilized from BI perspectives for a number of reasons - one of which is users/consumers resistance / unwilling to accept this new pervasive and intrusive means of service delivery. Whilst there are limitations and concerns over indoor location technology and a fragmented location ecosystem, another impending factor is privacy-related user acceptance (Kobsa, 2007) and security/trust related issues. The potential intrusion of privacy is an important concern for users of location-aware services (Kobsa, 2007; Soroa-Joury \&Yang, 2009). However, there is a clear presuposition that users with different profiles using different access networks and mobile devices require personalized services that meet their needs at specific locations. Therefore, it is important to investigate how users are responding and how BI can be properly utilized for effective location-aware customer relation management. 
The key to successful development of LAS is the ability to provide users with correct, preferred and personalized content. Furthermore, user preferences and profile adjustment is necessary for an acceptable and usable personalised LAS delivery.

This chapter presents an investigation on the development of a LAS delivery framework, by integrating user's personal preferences, profiles, an efficient adjustment algorithms, attributes of their geographical location and the application BI processes in order to provide personalised LAS. The remainder of the chapter is organised as follows: Next section (Section 2) provides a theoretical background by presenting a thorough review of existing LAS applications, systems and enabling technologies including current approaches to user preferences/profiling and recommendations. Section 3 describes the development of a LAS delivery model based on a set of user requirements, which integrates user's personal preferences, profiles, an efficient adjustment algorithms, attributes of their geographical location and the application BI processes. Section 4 describes the development of a personalized Scarborough LAS demonstrable prototype system that is able to respond to user profile adjustments and an evaluation of the approach, effectiveness of the prototype presented in Section 5. Section 6 concludes by discussing some of the lesions learnt, the limitations of the approach and further work being undertaken.

\section{Background}

The availability of existing LAS is a clear indication of its progressive recognition by industry and the gradual maturity of the related platforms and techniques. These services have been and will continue to be adopted for public and commercial activities. Whilst these services are on the increase, the ability to provide users with relevant and contextual content and informaton continues to be a major concern and challenge. This section presents a review of LAS, user profiling and preferences, and personalization of services.

\subsection{Location aware services (LAS)}

LAS system uses mobile and location technologies to exploit knowledge about where an information device user is located and present them with relevant services, such as marketing adverts. Chen (2002) defined this service as the application of which the service and information provided is determined by the user location. This location is normally determined using the mostly recognized global positioning system (GPS1) and other emerging positioning technologies (Sadoun and Al-Bayari, 2007). There are many other positioning technologies that can be used to provide LAS - this includes radiofrequency, ultrasonic, inertial, infrared, magnetic fields - each one with different drawbacks and advantages (Marco el al, 2008; Son and Orten, 2007). These other technologies are network based positioning and typically rely on various means of triangulation of the signal from cell sites serving a mobile phone. In addition, the serving cell site can be used as a fix for location of the user. There is no single positioning

${ }^{1}$ GPS is a navigation technology designed to give instantaneous information about longitude, latitude and altitude anywhere on the globe. 
technology that is suitable for every service or scenario. The availability of low-cost smart phones that are currently shipped with various positioning technologies has significantly increased the ubiquity of LAS. While there have been so many concerns regarding security and privacy issues with these services (Kobsa, 2007; Soroa-Joury \& Yang, 2009), the mutual benefits for both the user and the provider are potentially enormous. In addition to their commercial benefits, these has been extended to provide distinct services and many applications such as vehicle car tracking systems (Al-Bayari \& Sadoun, 2005), emergency rescue services ((Al-Bayari \& Sadoun, 2005), location-aware medical information system for determining a hospital worker's current location from a hospital information system (Rodriguez et al., 2004), and in the entertainment and education fields (Chen, Li, \& Chen, 2007), etc are operating in this context. Steinger et al (2006) identified mobile devices, communication network, positioning component, service and application provider, and data and content provider as the five infrastructural elements for the effective operation of LAS.

LAS applications cover a wide range of services, which can be categorised into two paradigms - pull and push. Clearly, both push and pull services rely on the networks ability to locate a mobile user/device and are further enhanced by user profiles that are normally established and updated either by the subscriber or the LAS system. This help in assuring that the information delivered to each user is truly customised.

\subsubsection{Taxonomy LAS Applications}

Personalised LAS applications are currently on the increase covering a variety of industry services and day-to-day activities of mobile users. The different LAS applications can be categorised from different perspectives as can be seen in Table 1. From table 1, we can see that most of LAS have been design to provide added value by enabling the provision of such services. Different classification scheme exists, but the author have provided a taxonomy that defines three broad categories of LAS and existing principle upon which they have being provided currently.

The Information and navigation services provide data directly to end-users, in particular for destination location and criteria for trip optimization. Most contemporary and modern vehicles are now GPS-equipped that give directions to drivers on display screens and through synthesized voice instructions. Finding someone or something, person by skill (doctor), business directory, navigation, weather, traffic, room schedules, stolen phone, emergency calls

Business and management services provide targeted location aware systems for commercial and management purposes. This includes targeted advertising and promotional services. Some example applications include payments based upon proximity - egg EZ Pass, toll watch. Management services such as resource tracking with dynamic distribution includes taxis, rental equipments, etc. are common profile matching (dating), automatic airport check-in.

Security systems include emergency assistance to provides the location of mobile users in case of distress and need for assistance, such as tracking services. 


\begin{tabular}{|c|c|c|}
\hline LAS Categories & LAS Applications & \begin{tabular}{|l|} 
Type \\
\end{tabular} \\
\hline \multirow{5}{*}{$\begin{array}{l}\text { Information and } \\
\text { Navigational } \\
\text { Systems }\end{array}$} & - locating social events and people & Pull \\
\hline & $\begin{array}{l}\text { - locating essential /nearest services such as } \\
\text { hospitals and medical centres, emergency centres, } \\
\text { stores, police }\end{array}$ & Pull \\
\hline & - receiving alerts - such as Traffic Jam warnings & Pull or Push \\
\hline & $\begin{array}{l}\text { - information requesters -eg. news services, treasure } \\
\text { hunts }\end{array}$ & Pull \\
\hline & - navigational systems - such as Tom-tom & $\begin{array}{l}\text { Pull and } \\
\text { Push }\end{array}$ \\
\hline \multirow{6}{*}{$\begin{array}{l}\text { Business \& } \\
\text { Management } \\
\text { systems }\end{array}$} & - targeted advertising or promotional operations & $\begin{array}{l}\text { Pull and } \\
\text { Push }\end{array}$ \\
\hline & - location sensitive billing -eg toll payments & $\begin{array}{l}\text { Pull and } \\
\text { Push }\end{array}$ \\
\hline & - fleet scheduling - such as taxis & $\begin{array}{l}\text { Pull and } \\
\text { Push }\end{array}$ \\
\hline & - asset / resource tracking and recovery systems & Pull or Push \\
\hline & - common profile matching & Pull \\
\hline & - tracking medical staff and patients care systems & $\begin{array}{l}\text { Pull and } \\
\text { Push }\end{array}$ \\
\hline \multirow{3}{*}{ Security Systems } & $\begin{array}{l}\text { localised parental control - allows parents to know } \\
\text { where their children are }\end{array}$ & $\begin{array}{l}\text { Pull and } \\
\text { Push }\end{array}$ \\
\hline & $\begin{array}{l}\text { - emergency assistance such as calls, stolen phones, } \\
\text { roadside assistance etc }\end{array}$ & Pull \\
\hline & $\begin{array}{l}\text { - home land security systems - such as tracking } \\
\text { criminals }\end{array}$ & Push \\
\hline
\end{tabular}

Table 1. Taxonomy LAS Applications

\subsubsection{A review of positioning techniques}

There are a number of geolocation technologies and more are still in development. However, wireless geolocation technologies have three main common major components as follows:

- the location sensing device that allows determining relative position of the mobile device

- a positioning algorithm that computes the metrics reported by the location sensing device, in order to estimate the position of the mobile device,

- a display system, which displays computed positions of the mobile device

Positioning techniques can be categorized into network-based and handset-based methods. Each technique has its own pros and cons, under a number of constraints. The table 2 below presented an analysis of the strengths and weaknesses of some positioning techniques. Positioning techniques can be categorized into network-based and handset-based methods. Network-based techniques generally utilises the service provider's network infrastructure to identify the location of the handset, while handset-based techniques utilises client software on the handset to determine its location. 


\begin{tabular}{|c|c|c|c|}
\hline Categories & Techniques & Strengths & Limitations \\
\hline \multirow{4}{*}{ 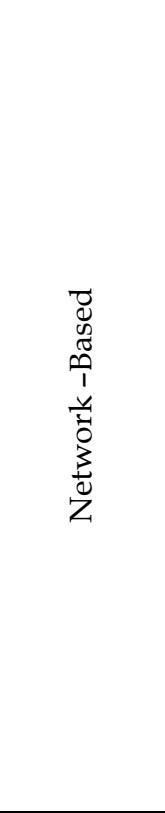 } & Cell ID (CID) & $\begin{array}{l}\text { - low cost of implementation } \\
\text { since it operates in GSM, GPRS } \\
\text { and UMTS networks } \\
\text { - Can work indoors - provided } \\
\text { there is network coverage }\end{array}$ & $\begin{array}{l}\text { - requires a network to } \\
\text { identify the base station for } \\
\text { communication and location } \\
\text { - can only provide an estimate of } \\
\text { the location of a phone device }\end{array}$ \\
\hline & \begin{tabular}{|l|} 
Received \\
Signal \\
Strength \\
(RSS)
\end{tabular} & $\begin{array}{l}\text { - Useful for urban and indoor } \\
\text { geolocation systems } \\
\text { - Already available for cellular } \\
\text { and WLAN networks }\end{array}$ & $\begin{array}{l}\text { - } \text { measurement of the distance } \\
\text { from RSS cannot be reliable } \\
\text { - sensitive to channel } \\
\text { parameter estimation }\end{array}$ \\
\hline & $\begin{array}{l}\text { Angle of } \\
\text { Arrival } \\
(\mathrm{AOA})\end{array}$ & $\begin{array}{l}\text { - usually used to discover the } \\
\text { location of private radio } \\
\text { stations } \\
\text { - delay of arrival of each element } \\
\text { is easily measured directly }\end{array}$ & $\begin{array}{l}\text { - may confuse the location of } \\
\text { the handset } \\
\text { - installing and aligning } \\
\text { antenna arrays on base } \\
\text { stations can be costly }\end{array}$ \\
\hline & $\begin{array}{l}\text { Uplink Time } \\
\text { Difference of } \\
\text { Arrival (U- } \\
\text { TDOA) }\end{array}$ & $\begin{array}{l}\text { - completely network-based and } \\
\text { therefore works very well in } \\
\text { outdoor and indoor } \\
\text { environments } \\
\text { - has a more wider distance } \\
\text { accuracy }\end{array}$ & $\begin{array}{l}\text { - } \text { requires additional network } \\
\text { location measuring unit } \\
\text { (LMU) equipment, and } \\
\text { therefore costly } \\
\text { - limited in rural conditions }\end{array}$ \\
\hline \multirow{3}{*}{ 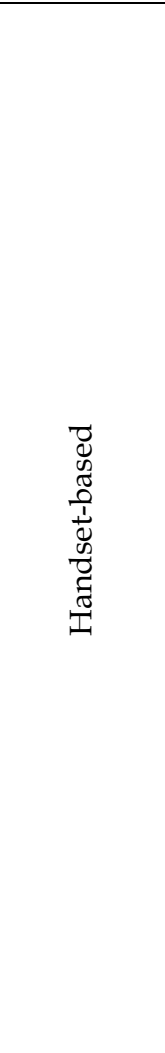 } & GPS & $\begin{array}{l}\text { - } \text { reliable and accurate for } \\
\text { outdoor situations. Although } \\
\text { dependent on clear open sky } \\
\text { - most mobile phones now } \\
\text { shipped with GPS hardware } \\
\text { - lots of development } \\
\text { technologies available } \\
\text { - easy and cheap to use }\end{array}$ & $\begin{array}{l}\text { - limited performance for } \\
\text { indoor situation } \\
\text { - mobile units need special } \\
\text { hardware and software for } \\
\text { receiving GPS signal } \\
\text { - suffers from relatively long } \\
\text { delay to get an initial fix on } \\
\text { the location of a mobile unit }\end{array}$ \\
\hline & $\begin{array}{l}\text { Assisted-GPS } \\
\text { (A-GPS) }\end{array}$ & $\begin{array}{l}\text { - more reliable and accurate for } \\
\text { outdoor situations } \\
\text { - resolves the long delay that can } \\
\text { occurs in locating a mobile unit } \\
\text { when using GPS } \\
\text { - operates on GSM, GPRS, UMTS } \\
\text { networks } \\
\text { - easy and cheap to use }\end{array}$ & $\begin{array}{l}\text { - indoor coverage is still not } \\
\text { ideal and best accuracy is } \\
\text { still in open sky } \\
\text { - requires A-GPS circuitry } \\
\text { inside the phone, legacy } \\
\text { handsets cannot be } \\
\text { supported without } \\
\text { modifications } \\
\text { - suffers in rural environment } \\
\text { where stationary GPS } \\
\text { receivers are more widely } \\
\text { spread } \\
\end{array}$ \\
\hline & $\begin{array}{l}\text { Enhanced- } \\
\text { Observed } \\
\text { Time } \\
\text { Difference } \\
\text { (E-OTD) }\end{array}$ & $\begin{array}{l}\text { - } \text { operates in GSM and GPRS } \\
\text { networks } \\
\text { - takes less time to locate a } \\
\text { mobile unit }\end{array}$ & $\begin{array}{l}\text { - expensive to operate as the } \\
\text { also requires the use of } \\
\text { LMUs } \\
\text { - still vulnerable to accuracy } \\
\text { degradation from multipath } \\
\text { and signal reflections }\end{array}$ \\
\hline
\end{tabular}

Table 2. Strengths and weaknesses of some positioning techniques 
Caffery (2000) clearly describes how conventional positioning techniques rely on the angle of arrival (AOA), received signal strength (RSS), the time of arrival (TOA) and the time difference of arrival (TDOA) measurements. Also note that there are technologies that fall with both the network and handset categories. For example, the Multiple Input Multiple Output (MIMO) that typically includes multiple antennas at both the receiver and transmitting stations and has incorporated Orthogonal Frequency Division Multiplexing in most $4 \mathrm{G}$ wireless networks.

\subsection{User profiling and preferences}

For a system to be able to provide personalized services, it most be able to make inferences about the users' profiles and preferences. Such information as well as information about the users' previous experiences is stored in a user model (Garcia-Cerspo et al., 2009). As discussed in the next section, recommender systems offer guidance based on users' profiles or preferences. Therefore, every recommender system builds and maintains a collection of user profiles and preferences. User profiles contain the subscriber's preferences (e.g., likes/dislikes, schedules, and formats) and permissions (i.e., whether they can be delivered with advertisement content or not). The user's profile and preferences would normally reside in a database maintained by the network provider, which is used to push services to subscribers. For example, if a user likes a particular type of food, the network will see the preference in the user's profile and will push information regarding restaurants that serve that type of food in the general locale of the user. Similarly, the user will be able to request this same information from the network (pull) if he or she chooses not to have this information pushed to the wireless device. There are different approaches to building user profiles. For example, Rich (1983) identified three important dimensions that characterize user models:

1. One model of a single, canonical user vs. a collection of models of individual users.

2. Models specified explicitly either by the system designer or by the users themselves vs. models inferred by the system on the basis of users' behaviour.

3. Models of fairly long-term user characteristics such as areas of interest or expertise vs. models of relatively short-term user characteristics such as the problem that the user is currently trying to solve.

Based on the above categorization of user models, a personalized recommender system may maintain an individual user model or some user models that represent classes of users. These classes are called stereotypes (Kobsa et al., 2001), which are used in user modelling in order to provide default assumptions about individual users belonging to the same category according to a generic classification of users that has previously taken place. This method has the advantage of providing personalized recommendations from the first interaction of the user with the system. However, a main disadvantage of this approach is that users may be similar in some characteristics but differentiate in many others. Furthermore, a user's characteristics and preferences may change over time. Thus defining and maintaining a personal and profile and preferences are fundamental in building an effective and potentially usable personalized recommendation systems.

To offer personalized LAS that are tailored to mobile users' activity contexts, service providers gather user profiles and preferences (including personal location information) 
through mobile communication and positioning systems. This information can be gathered in two ways - covert and overt approaches (Sundars \& Marathe, 2006). In the covert approach, service providers send relevant services to users by covertly observing and capturing their behaviour through tracking physical locations of their mobile devices. With these data, personalization systems tailor LAS services based on the user's known proximity to a data or content provider. Sheng et al (2008) describes a covert-based application that pushes information to customers whenever appearing in the vicinity of a participating store, the customer's mobile phone triggers a system within the application provider that evaluates that customer's purchase history against existing offers from the nearby store. If the system indicates an available will be of interest, it sends a text message to the customer's mobile phone with the rental details on the film. On the other hand, the overt personalization systems only locate users' mobile devices when they initiate the requests. This type of LAS may be seen in some 'on demand' services where the user dials or signals a service provider for specific information/service such as a request for the nearest medical centre. In this approach, location information is ephemeral and useful only to complete the transaction requested (e.g., sending coupons of the nearest Starbucks to the user). One example was a service launched by ZagMe in the United Kingdom. By calling a number or sending a text message to activate location tracking, customers could receive promotional information and coupons through text messages based on their geographical location in a designated mall.

\subsection{Personalization of services}

Research about the provision of personalized services has been carried out within recommender systems since the early 1990s in order to address one of the most challenging problems of today's ever expanding mass of information. It is clear that the selection of the relevant bits of information is becoming more important than the retrieval of data in today's information age. One of the early recommender systems was a mail filtering system (Tapestry) developed by Goldberg et al (1992). Since then, there have been numerous studies on recommender systems have been developed (Hong et al., 2009; Zhang \& Jio, 2007). For example, Sarwar et al (2000) developed a product recommendation system for electronic commerce using user's feedback. Middleton et al.(2004) developed a k-NN-based recommender system that recommends research documentation based on similar users' preferences and uses Ontology to analyze the profiles of users, and "VISCORS' a wall paper recommending system in mobile web coming collaborative filtering with content-based image retrieval was developed by Kim et al. (2004). Singh and Dey (2005) developed a document ranking system based on users' preferences using a filtering agent. Cao and $\mathrm{Li}$ (2007) developed fuzzy-based system for recommendation of product optimized based on customers' needs extracted using interaction between systems, and a personalized eLearning system based on contextualizing multimedia systems suggested in Eze et al.(2007) and a personalized tourism services aim at helping the user finding what they are looking for, easily without spending time and effort described in Kabasi (2010).These system have been classified into two types: ones that develop and test new recommendation methods, and the others that investigate empirically the factors affecting the usefulness of recommendation systems, or the effects of using recommendation systems on consumer purchasing processes (Ahn et al., 2010). 
The purpose of establishing a recommendation system is to solve the problem of information overload. The importance of these systems within the electronic commerce and business industry has since been established and currently being adapted for social and personal services. Recommendation systems are clearly based on the understanding of the user and the recommended products in order to predict the user preferred item or service and thereby recommend an associated item or service. In general, recommendation systems are based on user profiles and preferences, which clearly includes system components for the collection of information to be used to building an initial user profile or preference, processing and analysis of the stored user profiles visa vis existing or potential available products or services to be recommended and then the recommendation. In order to process and provide recommendations, a variety of approaches have been used to perform recommendations in these domains, including content based, collaborative, demographic, knowledge-based or hybrid approaches and many others (Montaner et al., 2003; Sarwar et al., 2000). Content-based and collaborative filtering have been the most popular approaches used in the literature. Content-based filtering refers to recommending items or services based on analysis of the user's previous actions or purchases, while in collaborative or demographic filtering, the items are recommended based on the recommendations of other users (Sarwar et al., 2000). See Kabasi (2010) and Burke (2002), for a detailed description of the recommendation techniques.

The final and important component required for an effective recommendation system is feedback. This provides a means for the system to capture and update user profiles and preferences. The interaction between recommendation system and the user can be divided into explicit (requiring user input on which the system will base its recommendation) as well as implicit (enabling the system to collect or observe user behavior to detect preferences) methods (Leavitt, 2006). The effectiveness of adopting explicit methods for LAS recommender systems requires more empirical investigation given the limited interface display on mobile devices. However, exclusive implicit method would require the system to collect enough user experience before building an appropriate profile and preferences to be used for recommendations. Therefore, there should be a way of integrating both approaches where a user is allowed input.

The challenge with personalised location-aware services is not in the applications but in the implementation. For location services to be of any real value, the network provided must be able to determine the location of subscribers to a high degree of accuracy. Most current LAS have proposed applying global positioning system (GPS) capabilities in handsets to help locate subscribers. However, GPS relies on the ability its receiver to connect to multiple satellites orbiting the Earth. If the receiver has no access to the sky (i.e., it is indoors), no location information can be provided. In addition, to the location, the network provider must be able to determine various other statistics - must be "aware" of the users' availability and propensity. Privacy groups have already expressed concerns regarding the awareness or intrusion of potential users. It is critical that service providers and users manage permissions within an LAS.

To address these issues, this research integrates both explicit and implicit recommendation methods, and designs a model in which the user is allowed to register and conduct preference inputs in the web environment, which will reduce the user input time on the mobile device. In addition, the research proposed a new algorithm that is capable of learning user preferences in order to reduce the burden of the system and to raise the correction rate in recommendation. 


\section{Development of a LAS delivery framework}

This section presents the development of personalised LAS delivery framework, by integrating user's personal preferences, profiles, an efficient adjustment algorithms, attributes of their geographical location and the application BI processes. The framework was based on Scarborough ${ }^{2}$ as a case study. Scarborough (shown in Fig. 1) is often considered as possibly the Britain's first seaside holiday destination, which has operated as a holiday resort for nearly 400 years. It offers a wide range of entertainment, leisure facilities, and shopping facilities. It is a University Campus town attracting over 2500 students each year. The town clearly unique distinction for deploying and trialling a personalised location aware services. The personalised system is expected to utilised data mining and business intelligence to target users with specific adverts and services based on trends related to their account details, profiles (including purchase histories) and tends. The system would use data mined from the users' profiles and preferences to provide personalised location aware product/service recommendations based on current locations of a user. Since most contemporary mobile phones support GPS and a connection to the network, combining these technologies clearly gives us a convenient approach for developing location aware services.

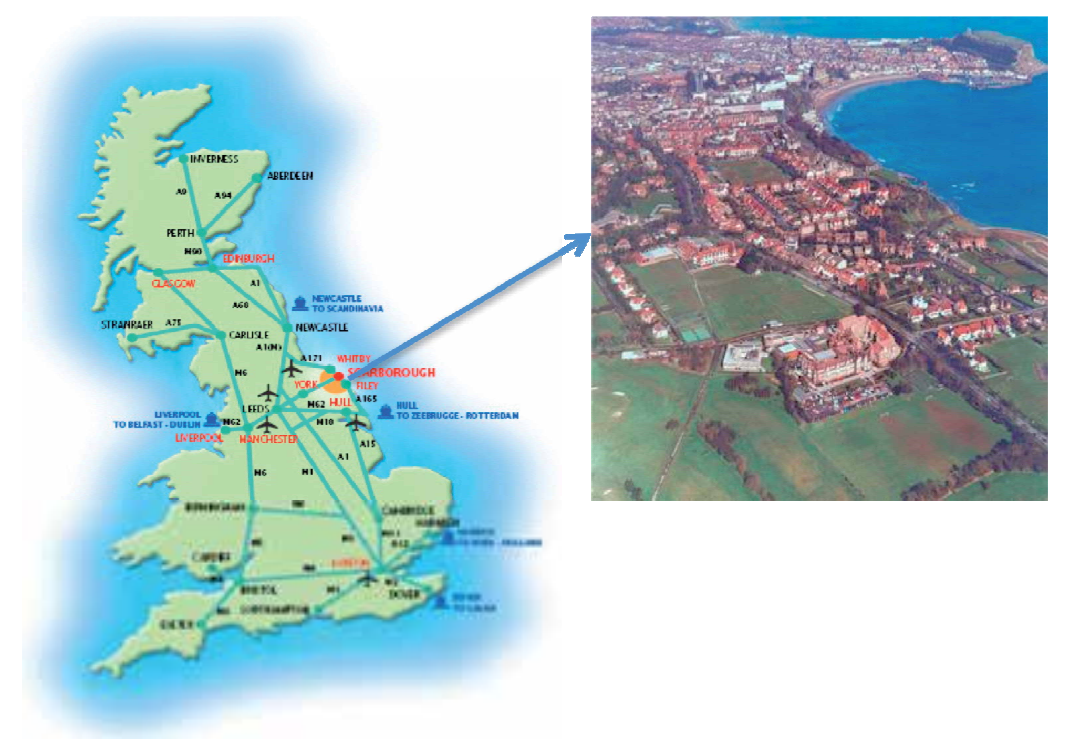

Fig. 1. Scarborough in the United Kingdom

This is a very broad scope that can encompass both commercial and public services, from offering the user deals, price comparisons and alternative shopping options, to helping to plan a day out in at a local theme park, by providing targeted information on the user tastes in rides, queue times and dietary requirements to suggesting available accommodation. The proposed framework (as presented in Fig. 2) consists of a number of components. From a high level perspective, the framework is divided into the 'Internal' - the main application and 'External' - the different systems that interact with users and the internal system.

2Scarborough Borough Council- http:/ / www.scarborough.gov.uk/ 


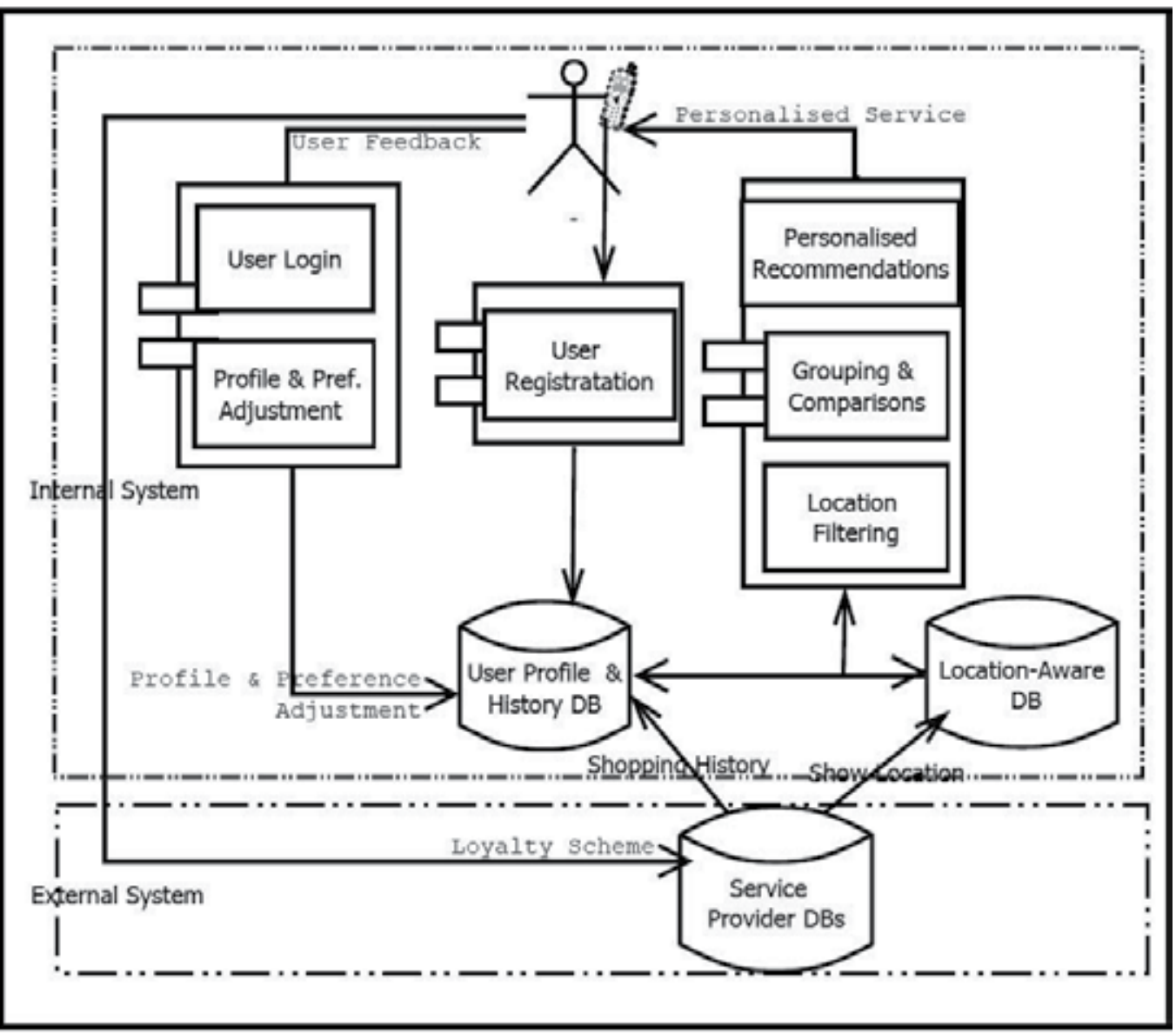

Fig. 2. Personalised Location-Aware Services Model

The model is divided into user registration component, access and feedback component, and the service personalization component, and these components interact with each other through a variety of databases. The description of each of the components have been presented below:

\subsection{Registration component}

The registration component of the system establishes the initial user profile and preference information that is stored on the profile and preference database to be used as the basis of the initial system recommendation. After the registration, the service personalization component checks the location of the mobile user synchronizes their profile with the location databases to present the user with recommendations. At this point, what the system knows about the mobile user is mainly the basic device and user information -such as the device identification, device type, user name and password, personal information including name, age, sex, job, hobby, basic preference and privacy consent to accept push information. 


\subsection{Access and user feedback component}

Although the system is designed to push personalized services to registered users, it is essential to provide a data-gathering component incorporating the login and the user profile and preference adjustment modules. The first, which is the login module, is designed to enable users access to the system in order to provide feedback and to allow them update their profiles and preferences. In addition to user static data such as user name, mobile device identification information that has been captured during the registration process, the design of the access and user feedback component should allow for the capturing of user dynamic data, which could be according to the dynamic attributes of location-aware data items. This is to reflect the change of the user preference. As a result, the effective and efficient system should adopt a learning approach to adjust user preference upon receipt of the user feedback. It is also essential that the user be given certain level of control over their profiles and preferences that has been stored on the system, as such, they should be able to see and update aspects of their currently stored profiles and preferences on the system database. The update profile and preference will be stored in profile and preferences are then stored in the user profile and preference database being used for making personalized recommendations. In order to calculate the probability that a user may prefer certain products and services, it is necessary to calculate the probability of the user profile and preferences towards those products and services. After calculating such a probability, the system would save the results of the predicted product and service preferences in the profiles and preference database, which is to be used for delivering the next personalized products and /or services. The recommendation result will be recorded in the profile and preferences database, and the user preference will be modified through a preference adjustment in order to achieve personalized recommendation process.

This also includes using the GPS module on the user device to receive the GPS signal and calculate the coordinates that would be used in the user profiles and location-aware databases.

\subsection{User profile and history database}

The user profile and history database persistently keeps the record of user profiles and adjusted preferences and historical transactions (including previous purchases and delivered services from all the participating service providers) between the users and recommendations. Clearly, this database serves as the main backbone to the system as it will contain most of the user profiles. It should contain all recommendations made to each user and their response to the recommendations. The logical (recommendation component) requires the information kept on this database to make comparisons against all the different parameters. Note that this database can be implemented as a data warehouse in order to integrate the required information to be mined from a variety of data sources. The benefits of using a data warehouse for this for implementation include scalability, and the ability to classify and organize data around meaningful personalized concepts.

\subsection{Location-aware database}

The location-aware database is designed to keep updated location information about participating service providers - such as stores. The database will store the Global Positioning Systems (GPS) latitude and longitude coordinates of the precise location of each of the participating provider. This coordinates are then used to calculate the proximity of the 
user and nearby service providers to identify potentially relevant personalized products and services to be delivered to users. Service providers can additionally use GSM numbers associated to devices or GPRS to transmit the personalized information via SMS or via GPRS in form of Internet Protocol (IP) packets.

\subsection{Service personalization component}

The service personalization component is considered the "brains" behind the "brown". This is the main recommendation system, which integrates and interacts with other internal and external systems and makes logical reasoning decisions required for personalized recommendation of products and services. It is the component of the system that analysis the relationship between users' profiles and preferences, and services in order to build an appropriate and timely recommendation model for each user. Different data mining techniques including association rules to predict transaction patterns, classification rules such as decision tree algorithm. To provide the real time, proactive and personalized services, the training time is very important, as such the choice of an appropriate datamining algorithm is essential. As shown in Fig.2, the component consists of the location filtering, grouping and comparisons and the recommendation modules. Details of each of the three main modules have been described below:

\subsubsection{Location filtering}

LAS are based on the use of location information, which can be collected in a number of ways. Location information is always attached to some entities that are being tracked. These tracked objects can be people, animals, objects and services. Whatever object in focus, the precision of location information is crucial for many applications, which also depends on the location determination technology used. Two types location information exists - relative and absolute. Absolute - when the actual location is known, for example, the coordinates of the location of a service provider such as a store. Relative - determines what located objects are nearby. There are many approached to location information - including the traditional and the commonly GPS, GSM, GPRS, magnetic or infrared tracking. There are other approaches involving the attachment of both passive markers such as a barcodes and active markers such as infrared transmitters to the environment. The current most widely used is GPS since most mobile phones, PDA's, and even cars are now shipped with in-built GPS technology, making LAS more convenient and of course easy to locate any tracked object (Lee, 2009).

This module is responsible for locating and filtering the relevant information based on the user location in preparation for the main task of personalized recommendations. The module can utilize a number of available location technologies to identify whether a tracked user is in a range of service providers and then utilize relevant data mining and decision support techniques to indentify a recommendation package to be delivered to the a user. It uses the location database and user profiles to achieved the expected task.

\subsubsection{Grouping and comparison}

Upon identifying and filtering the location of a tracked user, the module utilizes relevant techniques to make comparisons. It checks the prices of all possible products or services that the located user is likely to require and makes product by product price comparison with 
other participating service providers in order to identify a better deal. In making these comparisons, other information associated to the user profile -such as user habits, distance between the service providers, etc.

\subsubsection{Personalized recommendations}

The module is the logic system that analyzes trends, patterns, price, and location comparison. The module consists of a number of functionalities including:

- $\quad$ user profile and preference analysis - including an analyses of the previous behaviour of a tracked user with each of the identified location - for example the shopping behaviour of a racked user around Tesco's Shopping Complex on a Saturday afternoons.

- the development of different association rule sets for discovering associations between products, services, location and the tracked user. A user personalized recommendation model is constructed based on users transaction histories, profiles and preference, number of previous recommendations and their responses to such recommendations. This includes a market-basket analysis (studying the composition a shopping basket of products purchased during the single shopping event), to identify user patterns and trends, which will also help in identifying which products tend to be purchased together by the tracked or target user. This information enables stores to make intelligence positioning decisions. Identify what products tend to be purchased together. Clearly, analysing transactional-level data can identify purchase patterns

- a personalized product or service recommendation list for a given tracked user is produced using their specific model. Determining user's likely in recommender systems is very important, since these likelihood should be the basis of personalized recommendations. And a variety of approaches have been used in recommender systems -including content-based, collaborative, knowledge based and a hybrid of those approaches (kabassi, 2010; Zhang et al., 2007), with different methods such as the Bayesian networks or rule-based reasoning (Huang and Bian, 2009) have been used. Other common known techniques used for recommendations include neural networks (Zhang et al., 2007), Bayesian learning (Zhang and Koren, 2007), Markov models (Liu et al., 2007), multi-criteria decision-making theories, fuzzy multi-criteria decision making (Kabassi, 2010) and many others. Content-based filtering can be used to suggests to a user, products or services that are similar to those they bought in the past, by matching the characteristics of the products or service with the characteristics of the user that are maintained in their user model. Content-based filtering is based on facts that involve a particular use and may also capture changes on the user's profile or preferences. While this approach has a number of limitations -especially with the initial cold start approach to building a user model, this may be appropriate for personalized push recommendations.

The focus of this module is to provide the ability to use individual profile and preferences to define a specific dynamic user model that can be used to cluster relevant products and service that the user is highly likely to be interested on. For example, the system should be able to tell a user interested in gigs to build a potentially interesting package of gigs that are on -including prices, nearby venues, times, etc based on the uses needs and then also pass on some alternative artists, which are similar in style that the user likely to be interested on. Various methods for calculating the recommendation score including those described by Yuan \& Tsao (2003) are avalable to be used. 
From the provides point of view, maintaining the a profile of users that might be synchronised with provider databases also provides the providers with market-basket analysis (studying the composition a shopping basket of products purchased during the single shopping event), which helps them to identify which products tend to be purchased together by certain users. This information enables stores to make intelligence positioning decisions. Identify what products tend to be purchased together. Clearly, analysing transactional-level data can identify purchase patterns.

Despite the potential advantages of LAS personalized recommendation, there are increasing concerns about mobile users being tracked and profiled by behavioural advertisers to be able to send them personalized advertising (King \& Jessen, 2010). Clearly, the risk that someone else cannot only know who you are but also where you are, creates an enormous potential for misuse of this data. Furthermore, King and Jessen (2010) have identified potential harms to privacy and personal data related to profiling for behavioural advertising. While, there are evolving legislations, solutions to the privacy issues of LAS application are still unclear. The type of the service also affects the privacy requirements, for example push and pull services have different kind of characteristics. The competition between operators, service providers and other parties also affects the privacy issues. The Legislation is not clear about which laws apply in particular situations. More progress is needed to show how laws will be applied and to decide whether or not new laws are required. Generally, permission from the user is required for using their personal location information but this may impede business and may so be resisted by businesses. Therefore, the development of a prototype described in the next section has being towards evaluating the feasibility and potential usability of the system, which may contribute to the development and or review of regulatory frameworks for protecting privacy and personal data in regards to profiling by behavioural advertisers that targets mobile customers.

\section{Development of a personalised LAS prototype}

There are a variety of positioning systems available for the development of a personalised LAS system. Therefore choosing the best positioning technology is of fundamental importance. The performance (range, accuracy, etc) and ease of use are all key characteristics of consideration. Many technologies exist that are able to provide location information; nevertheless, few of them have a significant impact on final applications and none is perfect for every service (Mazes et al, 2004). The application designer should prioritize the requirements to choose the most appropriate technology. The most obvious considerations should include accuracy, range, refresh frequency, and cost. Other issues are infrastructure and robustness of the chosen infrastructure.

After reviewing various current available positioning technologies presented table 2, a review of development platforms and technologies was further undertaken (see Fig.3) to define an architecture needed for the development of a proof-of -concept prototype.

GPS location technique with Google Map API (for mapping and latitude /longitude translation service) was adopted for the development of a proof of concept prototype. Google Maps API was further integrated with the W3C Geolocation API to provide latitude/longitude information regarding the geographical location of the mobile device. 
Most phones support GPS and a connection to the network, so combining the technologies gives us the convenient location based service. This also includes using the GPS module on the user device to receive the GPS signal and calculate the coordinates that would be used in the user profiles and location-aware databases. Therefore, the prototype was developed for a web browser based interface, enabling compatibility for a range of mobile devices. PHP, HTML 5 and JavaScript was the development tools used to develop the prototype, which is only available for GPS enable mobile devices such as the iPhone, HTC, Blackberry phones. MySQL was used to provide the backend functionality. There is, however, a disadvantage by relying on GPS alone as a location system. The GPS receiver must have a direct line of sight to the satellite, making it almost useless indoors and in dense urban areas.

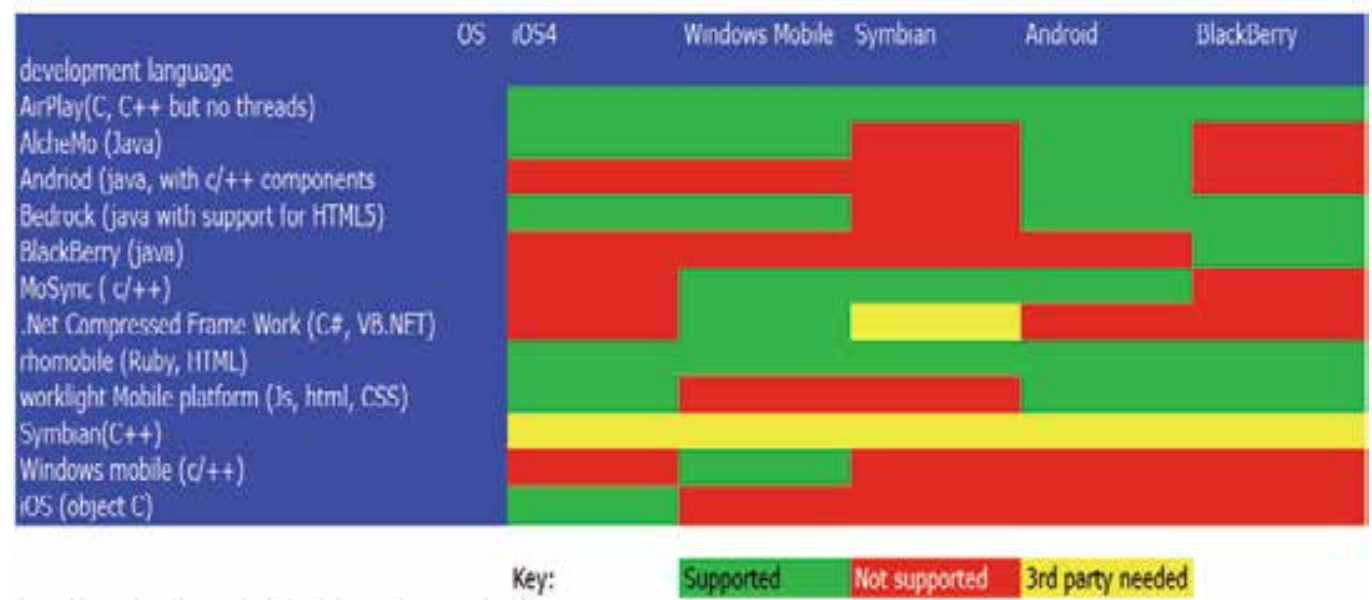

Fig. 3. Location-aware development platform

The development of a LAS prototype system was designed in such a way that is able to track and respond to user profile adjustments. It was was also developed within the Scarborough context as a typical case scenario previously described in section 3 . The prototype - Scarborough Location-aware Advertising project (ScarLaS3) aims to provide a demonstrable prototype that illustrates the feasibility of Location-aware Services in Scarborough. The system adopts the above recommendation model as the design basis of the prototype system, the design of attributes such as location-based information (see Table 1) and user preference. The main components of the prototype are in accordance with the defined framework presented in section 3 (see Fig. 2). In order to allow involvement of a wide variety of mobile users, the first component is the web page for registering user profile, which is provided for the user to conduct service registration and initial preference setting. The second one is the core of system for providing personalized advertisements. Taking into consideration the limited display ability and the convenience in the user operation, the system follows two steps in order to provided this functionality. First, the system will base on the user location to filter the participating shops within the area and determine the appropriate recommendation to deliver to the user. The result is shown to

3http:/ / www.celproject.co.uk/lba/client/ 
the user and they can see the suggested offers. Subsequent recommendations are adjusted based on user feedback from previous recommendations. Brief description of the implemented prototype is presented according to each of the proposed components.

\subsection{Prototype implementation}

The interface of the system can be used without a mobile user having to register to access the system. From the Fig. 4 below any user is assigned a default username and where the service personalization component checks the location of the mobile user synchronizes their profile with the location databases to present them with all offers in the range.

As can be seen in Fig. 4 above, the system the system automatically retrieves all offers within a reasonable geographical range with no user profile to use in personalizing the offers to be presented. The system is also only able to track the user through the device identification and the user number, which information stored in the database. Therefore, in order to provide a personalized recommendation, the registration component allows the user to update their details using the "update" functionality of the system interface (as shown in Fig. 5).

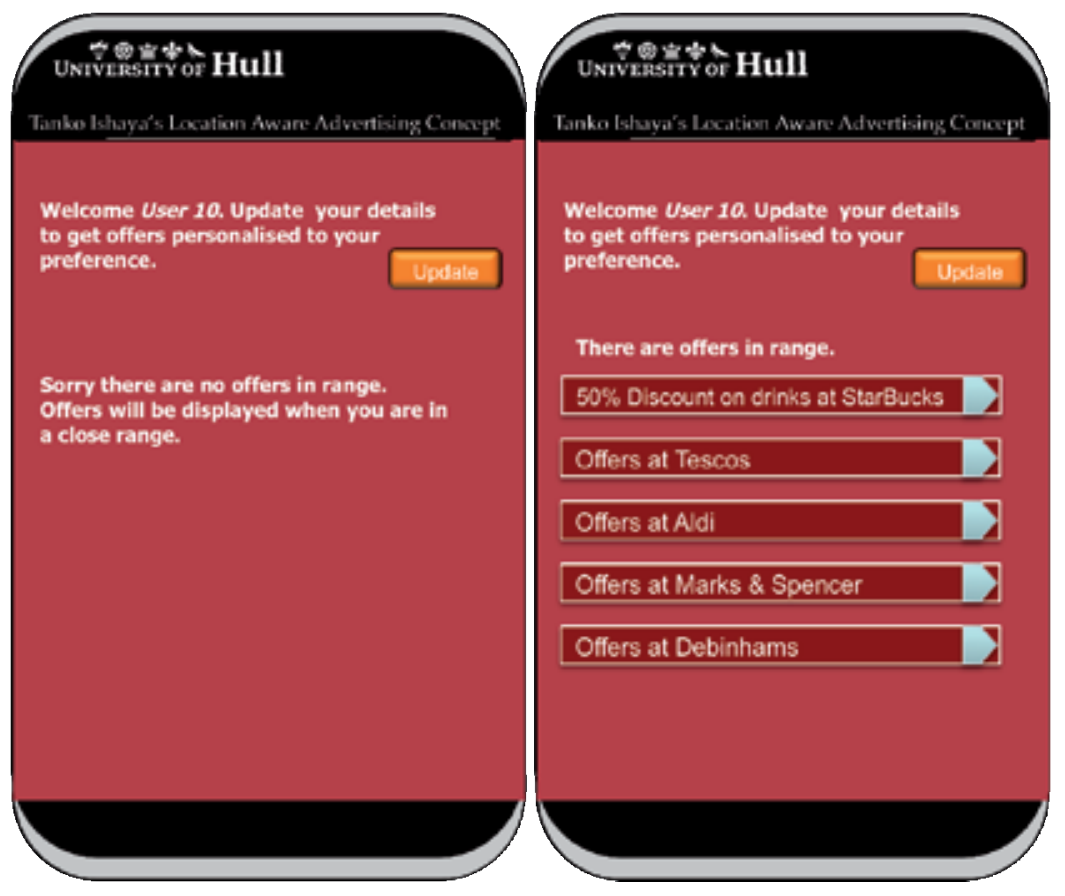

Fig. 4. ScaLaS access interface 


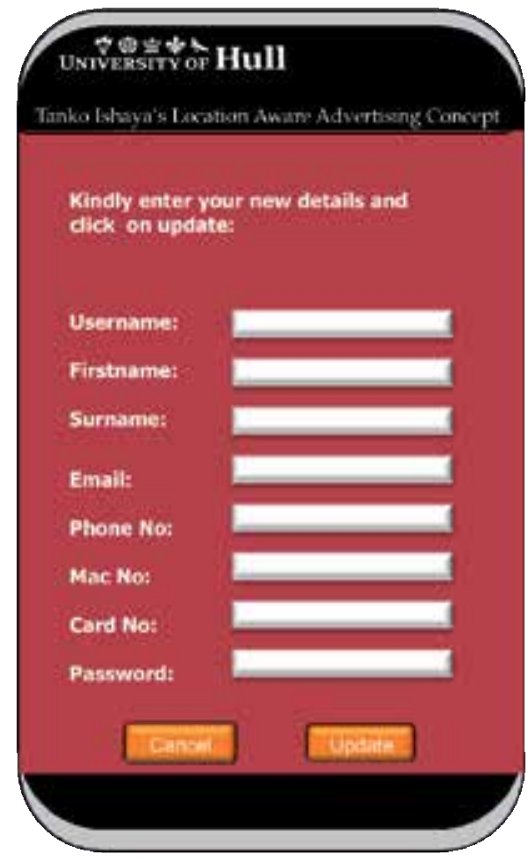

Fig. 5. ScaLaS profile update interface

After updating the user information using the above interface, the system is able to identify a mobile user through the device and user information -such as the device identification, device type, user name and password, personal information -including name, age, sex, job, hobby, basic preferences and privacy consent to accept push information. These user profiles and preferences are then stored in the profile and history database. A location-aware database was implemented to keep updated location information about participating service providers mainly stores at the moment. The database stores the Global Positioning Systems (GPS) latitude and longitude coordinates of the precise location of each of the participating stores. This coordinates are then used to calculate the proximity of the user and nearby service providers to identify potentially relevant personalized products and services to be delivered to users. The registered user is still delivered with all available offers in the range, since the system is yet to have any history of those users transactions. In addition to user static data such as user name, mobile device identification information that has been captured during the registration process, the design of the access and user feedback component needed to allow for the capturing of user feedback. Current interface required the user to manually provide the details of their purchases instead to using QR codes or participating store feedback to provide the learning component. However, the user profile is then adjusted after an initial transaction from any of the participating service provider. The logical (recommendation component) then uses the continually adjusted profile to make personalized recommendations. It is the component of the system that analysis the relationship between users' profiles and preferences, and services in order to build an appropriate and timely recommendation model for each user.

Fig. 6. is a typical delivery to a user with an appropriate profile and their transaction history. The user Mike is known to have previously had some transactions from Starbucks and tesco on a Saturday afternoon, which is when the service was delivered. 


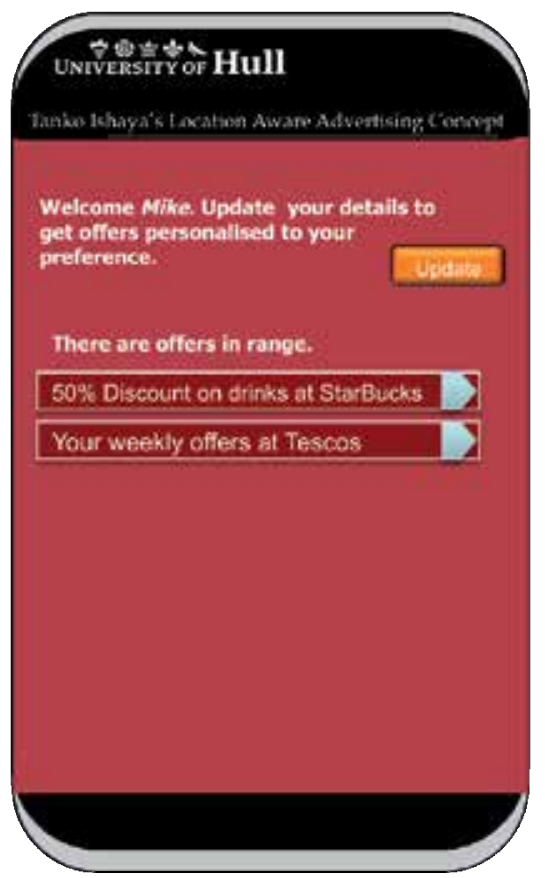

Fig. 6. ScaLaS interface with personalised offers

The user can check to see the details of each of the offer as shown in Fig.7. below.

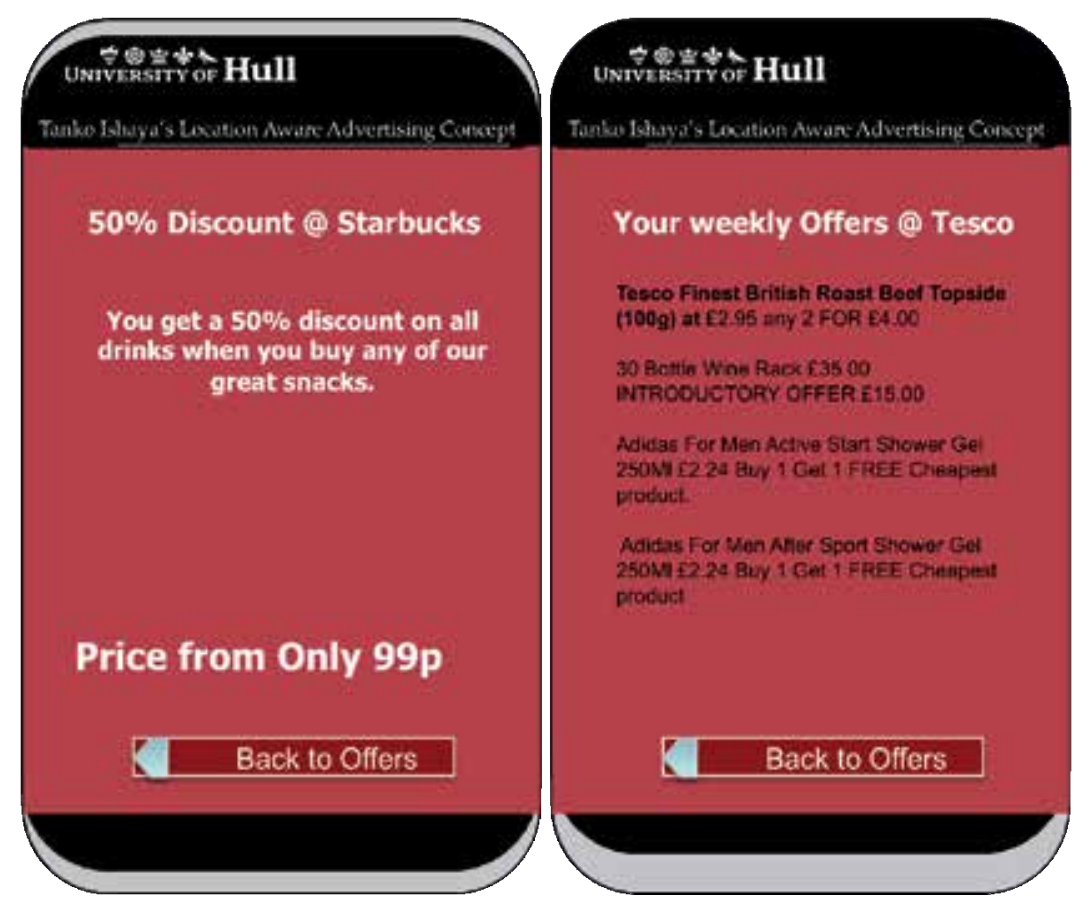

Fig. 7. ScaLaS interface with personalised offers 
Ideally, the recommendation component integrates and interacts with other internal and external systems to make logical reasoning decisions required for personalized recommendation of products and services where different data mining including classification rules such as decision tree algorithm are implemented. However, the developed prototype is limited in its ability to communicate and interact with external systems, so the data from the set of potential participating service providers were hardcoded to demonstrate the concept. Furthermore, the prototype used basic analytical techniques for personalized delivery of recommendations. In order to calculate the probability that a user may prefer certain products from certain stores, it was necessary to calculate the probability of the user profile and preferences towards those products. After calculating such a probability, the system would save the results of the predicted product in the profiles and preference database, which is to be used for delivering the next personalized products and / or services. The recommendation result is also recorded in the profile and preferences database, and the user preference will be modified through a preference adjustment algorithm in order to achieve personalized recommendation process.

\section{LAS prototype evaluation}

The evaluation of developed prototype was focused on the potential usability and adoptability of the system. Given the privacy and ethical concerns regarding the use of LAS (Casas et al, 2006), a focused group study and analysis was undertaken to investigate how users are responding and how BI can be properly utilized for effective location-aware customer relation management.

Although, main concerns raised has been with respect to privacy, data protection and appropriateness of the recommendations, it was argued that personalization approaches and personal characteristics would influence the influence the way mobile users balance between the potential usefulness gained by disclosing personal information in LAS and the adverse effects of not using the service. Privacy requirements are associated with the information gathered from the users, and ethical issues are related to use or misuse of that information. LAS technology in general allows more and more collection of information from users, and sometimes this is done simply because the technology allows it. It is therefore useful that users be properly informed on how information such as obtaining consent for location, the exact nature of which will vary depending on the user profile, data storage, and data security is being handled by the system. Recent studies on the ethics of LAS (Perusco \& Michael, 2007) posed unanswered questions about these LAS and also revealed the need for a suitable legal and ethical framework to address these concerns

Analysis from the qualitative evaluation provided some preliminary evidence to indicate that the truly personalized delivery of offers -especially on weekly grocery shopping is more likely to entice spontaneous response to LAS advertising. The evaluation suggested that users could more likely regard LAS as valuable if advertising messages are perceived to be relevant and customized to their context. Therefore an effective recommendation techniques used with LAS systems should be efficient. Furthermore, it was agreed that such systems would operate better, if participating stores within a particular town such as Scarborough were to operate a single loyalty scheme cards as a means for providing proper feedback to the system for the purpose of learning. While, the implementation of the prototype as web application was seen to have clear advantages, it was felt by most that a 
native application, which is able to use A-GPS would be more useful to some category of potential users.

The key to successful development of LAS is the ability to provide users with correct, preferred and personalized content. Furthermore, user preferences and profile adjustment is necessary for an acceptable and usable personalised LAS delivery.

\section{Conclusion and further work}

This chapter presents an investigation on the development of a LAS delivery framework, by integrating user's personal preferences, profiles, an efficient adjustment algorithms, attributes of their geographical location and the application BI processes in order to provide personalised LAS. There is clearly an increasing demand for LAS applications and while the developed retype is basic in its current stage, it is able to identify the location of an information device user, search for offers that are within a defined range and present the offers to the users, the findings of this research have provided preliminary empirical evidence about how users are willing to strike a balance between value and risk. The current research contributes to existing literature by theoretically investigating various approached for developing LAS applications and techniques for personalization. The framework developed in this study has clearly laid down groundwork for future research along various possible directions could contribute to extending the theoretical and practical implications to foster the acceptance of LAS

\section{Acknowledgements}

The author gratefully acknowledges the support provided by the University of Hull's Creative Enterprise Lab (CEL) in developing and evaluating this prototype. Many thanks to the CEL interns for their valuable contribution made in developing the proof-of-concept those far.

\section{References}

Agrawal, R., Imielinski, T., \& Swami, A. (1993). Mining association between sets of items in massive database. International Proceedings of the ACM-SIGMOD International Conference on Management of Data, 1993, pp. 207-216.

Ahn, H.J., Kang, H., Lee, J (2010). Selecting a small number of products for effective user profiling in collaborative filtering. Expert Systems with Applications 37 (2010) pp.3055-3062

Al-Bayari, O. \& Sadoun, B. (2007). Location based services using geographical information systems. Computer Communications, 30(16), 3 November 2007, pp 3154-3160

Al-Bayari, O and B. Sadoun, B (2005). New centralized automatic vehicle location communications software system under GIS environment, International Journal of Communication System 18 (9) (2005) 833-846.

Bellavista, P., Kupper, A., \& Helal, S. (2008). Location-based services: back to the future, IEEE Pervasive Computing, 7(2), 2008, pp85-89

Barnes, S. \& Scornavacca, E. (2004). Mobile Marketing: the role of permission and acceptance. International Journal of Mobile Communications, 2(2) pp128-139 
Burke, R. (2002). Hybrid recommender systems: Survey and experiments. User Modeling and User-Adapted Interaction, 12(4), pp331-370.

Cao, Y., \& Li, Y. (2007). An intelligent fuzzy-based recommendation system for consumer electronic products. Expert Systems with Applications, 33(1), pp.230-240.

Caffery, J. J. (2000) "Wireless location in CDMA Cellular Radio Systems", Kluwer Academic, Boston, 2000.

Casas, R., Marco, A., Falco, J., Artigas, J., \& Abascal, J. (2006). Ethically aware design of a location system for people with dementia, in: Proceedings of ICCHP, Lecture Notes in Computer Science, Computers Helping People with Special Needs, Linz, vol. 4061, 2006, pp. 777-784.

Chen, C. -M., Li, Y. -L., and Chen, M. -C. (2007). Personalized context-aware ubiquitous learning system for supporting effectively English vocabulary learning. In IEEE international conference on advanced learning technologies (pp. 628-630

Chen, G. (2002). Wireless location-based services - technologies, applications and management. In The Asia-Pacific network operations and management symposium

Chiaffino, S., Amandi, A.(2009). Building an expert travel agent as a software agent. Expert Systems with Applications 36, 1291-1299.

Cho, Y.H., Kim, J.K., \& Kim, S.H. (2002). A personalized recommender system based on web usage mining and decision tree induction. Expert Systems with Applications 23 (2002), pp329-342

Eze, E., Ishaya, T., \& Wood, D. (2007). Contextualizing Multimedia Semantics towards Personalised eLearning. Journal of Digital Information Management, 5(2), pp.62-69

Gauntt, J. D (2008). Mobile Advertising: After the Growing Pains. In: eMarketting

García-Crespo, A., Chamizo, J., Rivera, I., Mencke, M., Colomo-Palacios, R., Gómez-Berbís, J.M. (2009). SPETA: Social pervasive e-Tourism advisor. Telematics and Informatics 26 (3), pp. 306-315.

Goldberg, D., Nichols, D., Oki, B.M., \& Terry, D. (1992). Using collaborative filtering to weave an information tapestry. Communications of the ACM, 35(12), pp.61-70

Hazas, M., Cott,J., \& Krumm, J. (2004). Location-aware computing comes of age, IEEE Computer 37 (2) (2004), pp.95-97.

Hong, J., Suh, E., Kim, J., \&Him, S (2009). Context-aware system for proactive personalized service based on context history. Expert Systems with Applications 36 (2009) pp.7448-7457

Huang, Y., Bian, L.(2009). A Bayesian network and analytic hierarchy process based personalized recommendations for tourist attractions over the Internet. Expert Systems with Applications 36 (1), 933-943.

Kabasi, K (2010), Personalizing recommendations for tourists. Telematics and Informatics 27(2010), pp.51-66

King, N. J., \& Jessen, P. W.(2010). Profiling the mobile customer e Privacy concerns when behavioral advertisers target mobile phones. Computer law and Security review 26 (2010), pp. 455- 478

Kobsa, A. (2007). Privacy-enhanced personalisation. Communications of the ACM, 50(8), 2007, pp24-33

Leavitt, N. (2006). Recommendation technology: Will it boost E-Commerce. IEEE Computer Society, (May), pp13-16. 
Lee, J. (2009), Global Positiong/GPS. International Encyclopedia of Human Geography, 2009, pp 548-555

Liu, Y., Huang, X., An, A., 2007. Personalized recommendation with adaptive mixture of Markov models. Journal of American Society for Information Science and Technology 58 (12), pp.1851-1870

Marco, A., Casas, R., Falco, J., Gracia,H., Artigas, J.I., \& Roy, A. (2008). Location-based services for elderly and disabled people. Computer Communications 31(2008), pp1055-1066

Middleton, S. E., Shadbolt, N. R., \& De Roure, D. C. (2004). Ontological user profiling in recommender systems. ACM Transactions on Information Systems (TOIS), 22(1), pp.54-88.

Najera, P., Lopez, P., Roman, R (2011). Real-time location and inpatient care systems based on passive RFID. Journal of Network and Computer Applications 34 (2011) pp.980989

Perusco, L., \& Michael, K. (2007). Control, trust, privacy and security: evaluating locationbased services, IEEE Technology \& Society Magazine 26 (1) (2007).pp. 4-16.

Sadoun , B., Al-Bayari, O. (2007). Location based services using geographical information systems. Computer Communications 30 (16) (2007), pp3154-3160

Sheng, H., Nah, F., \& Siau, K. (2008). An experimental study on ubiquitous commerce adoption: impact of personalization and privacy concerns, Journal of the Association for Information Systems 9 (6) (2008), pp. 344-376.

Signeur, J.M., \& Jensen, C.D.(2004) "Trading Privacy for Trust", Trust Management, LNCS, vol. 2995, pp. 48-62, 2004.

Singh, S., \& Dey, L. (2005). A new customized document categorization scheme using rough membership. Applied Soft Computing, 5(4), pp.373-390.

Soroa-Joury, S. \& Yang, K. C. (2009). Factors affecting consumers' responses to mobile advertising from a social from theoretical perspective. Telematics and Informatics, 27(1), 2009, pp103-113

Son, L.T., \& Orten, P. (2007). Enhancing accuracy performance of Bluetooth positioning, in: Wireless Communications and Networking Conference, WCNC, IEEE, Hong Kong, 2007, pp. 2726-2731.

Steiniger, S., Neun, M. \& Edwardes, A.2006. Foundations of Location Based Services. Cartography 1(2006), p.1-28.

Sundar, S.S. \& Marathe, S. (2006). Is it tailoring or is it agency? Unpacking the psychological appeal of customized news, the 89th Annual Convention of the Association for Education in Journalism and Mass Communication, 2006, San Francisco, CA.

Unni, R. \& Harmon, R. (2007). Perceived effectiveness of push vs. pull mobile location-based advertising. Journal of Interactive Advertising 7(2), (August 2007. Available from http:/ / www.jiad.org/article91

W3C. (2009)). Geolocation API Specification, In: World Wide Web Consortium, Accessed 28th January, 2010), Available from http://www.w3c.org/TR/geolocation-API

Zhang, X., Edwards, J., Harding, J. (2007). Personalized online sales using web usage data mining. Computers in Industry 58 (2007), pp772-782.

Zhang, Y., \& Jiao (Roger), J. (2007). An associative classification-based recommendation system for personalization in B2C e-commerce applications. Expert Systems with Applications, 33(2), pp.357-367. 


\title{
Development of a Service Framework for Library Users from Customer Relationship Management Perspective
}

\author{
Shiow-Luan Wang \\ Department of Information Management, National Formosa University, \\ Huwei, Yunlin, Taiwan, \\ R.O.C.
}

\section{Introduction}

Libraries are service organizations that store data and function as main information resource centers for various users (Hernon and Altman, 1998; Hernon and Calvert, 2005; Huang, 2007; Raza and Nath, 2007). Traditionally, users go to the library for services, such as borrowing/returning books, accessing the reference directory, availing of interlibrary loans and document delivery, and browsing through relevant collections of resources. At present, many library service features have changed due to the recent developments in digital and networked environment technologies. The ubiquity of the Internet has been used extensively in many libraries, generating a profound effect on library users.

University library users include authorized faculty, undergraduate and graduate students, staff, and project/contract assistants. Given that there are different kinds of library users in any University setting, a barrier certainly exists in overcoming the one-to-one relationship model for each user. Library professionals confirm the difficulties involved in providing training for their students because of the large number of students, lack of suitable training rooms and equipment, and the shortage of qualified trainers (Bex and Miller, 1999). Moreover, library users are considered as customers, and taking note of their opinions may ensure the succession of a library in terms of service delivery. According to Huang (2007), library service is a kind of invisible product; thus, it is important to obtain user feedback in improving the service being provided. However, there is still no clear definition of who library users are and how to transform a library user-oriented service model to make it similar to a customer-based one.

This study aims to define users as customers and develop a conceptual framework from a customer relationship management (CRM) perspective. The inclusion of organizational capability can lead to a more successful administrative management, and this framework can be applied to academic library service in order to further improve user service. In the present work, the library organizational capability is also explored.

\subsection{Library service}

Numerous studies have reported that library service is user-oriented; thus, it is important to meet the demands and expectations of users (Ojala, 1986; Millson-Martula and Menon, 1995; 
Nitecki, 1996; Johnson and MacEwan, 1999; Flanagan and Horowitz, 2000; Cullen, 2001; Shi, et al, 2004; Huang, 2007). In recent years, the proliferation of information communication technology (ICT) has made it possible to address the needs of users for timelier as well as more convenient and rapid information delivery. In addition, the application of ICT helps libraries identify the needs of their users and provide correct information by utilizing plenty of resources. Libraries play an interactive role in encouraging users to utilize their resources, thus establishing a relationship with such users (Fig. 1).

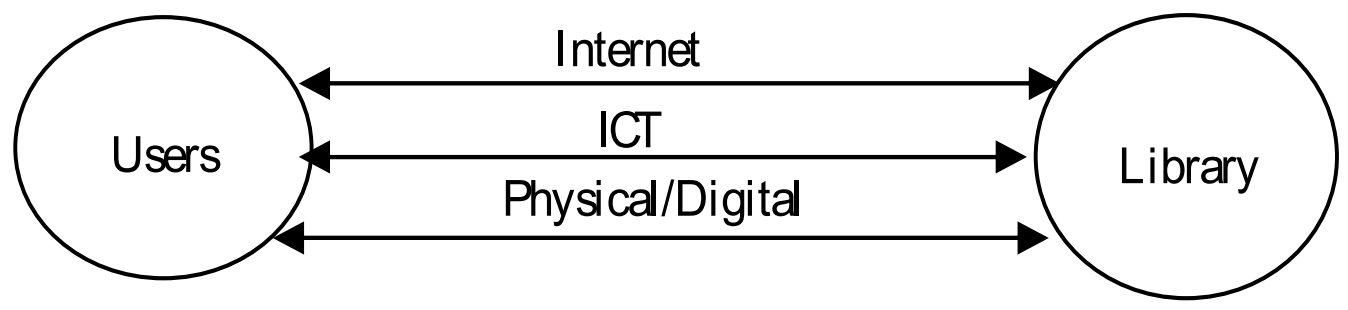

Fig. 1. Two-way connection between users and the library

Toward the goal of servicing users effectively and efficiently, many libraries provide activities, such as simultaneous remote access in multiple databases, seamless linking to database resources, selection of favorite resources and e-journals, setting up email alerts, and so on. In the information era, the Internet and ICTs have had great impact on the development of printed and electronic resource collection. To avoid existing issues on electronic resources, the proposed CRM helps library managers review their service strategies and promote the value of using the library in the university. The concept is similar to how CRM is used to generate business profits when applied in e-Commerce.

\subsection{Customer relationship management initiative}

Many library managers believe that library operation and service development is customer focused. Generally, CRM is used to analyze and utilize marketing databases as well as to leverage communication technologies in order to determine corporate practices and methods to maximize the lifetime value of each individual customer to the organization (Kumar and Reinartz, 2006). In the application of CRM in library service, library managers can focus on how they can arrange their collections and services to attract more users to the library. Thus, it has become their top priority to determine how customers expect to use a library. A relationship is a bond or connection between an organization and its customer (Mohammed et al., 2002). Researchers have used the following to emphasize the application of CRM issues in the library: data mining on book recommendation and library marketing (Yen, 2002); resource usage efficiency (Chen et al., 2004); acquisition budget allocation (Kao et al., 2003); acquisition and cataloging (Chu, 2005); improving service (Will, 2006); user service (Wang, 2006); and CRM software in e-journal access (Borchert, 2006). Without appropriate CRM, a library manager may misunderstand users' service requests and be unable to meet user expectations.

Recently, researchers have focused on the concept of personalization or personalized service (Bielema et al., 2007; Frias-Martinez et al., 2006; Fan et al., 2005; Renda \& Straccia, 2005; Giacomo et al., 2004; Hicks, 2003; Jurewicz \& Cutler, 2003). Libraries provide a 
communicational channel (i.e., Libweb), through which users can ask for a service; however, this is a passive solicitation of feedback. Personalized service focuses on being "better, faster, and cheaper" as expressed in modern management practices (Cardwell et al., 2001). Meanwhile, some libraries have established liaison outreach programs to know users better by providing greater amount of information about library programs and services (MillsonMartula and Menon, 1995).

\section{Related studies}

\subsection{Library service development}

A user is the key subject and the first to be defined due to his/her association with library operation and development. In the 1980s, library users were regarded as end-users, and Ojala was the first to propose in 1986 that libraries treat users as customers and must be able to meet their demands should. Considering the importance of users to libraries, researchers have proposed that library management consider user needs as well as customer expectation and satisfaction in setting management goals (Green, 1990; Millson-Martula and Menon, 1995; Heckart, 1999; Hernon et al., 1999; Flanagan and Horowitz, 2000; Cullen, 2001; Martensen and Gronholdt, 2003; Shi et al., 2004). Since the emergence of a network environment, libraries have to pay close attention to their customers' opinions (Cullen, 2001; Van Groenendaal, 1997; Xie, 2006; Koohang and Ondracek, 2005). Users have their own library service requirements in the same way that they make demands as consumers in the realm of business. In this context, the Internet offers an unprecedented opportunity for personalized customer services (Heckart, 1999). Additionally, a one-to-one marketing paradigm provides an organization with the opportunity to engage customers in interactive communication using ICTs as the enabling factors (Wells et al., 1999).

\subsection{User expectations and satisfaction}

The effects of satisfaction and quality improvement efforts on customer retention and market share have been studied by Payne and Frow (2005). The loyalty acquired from users represents a significant effect of library service. Previous works have also reported findings regarding user needs, customer expectations, and satisfaction (Table 1).

Satisfying customer expectations and caring for their individual needs require a thorough understanding of how they are related to CRM. Customer satisfaction represents the degree to which a library has met the user's needs and expectations (Cooper and Dempsey, 1998:33; Dlamini, 2006). User satisfaction is equal to success, although complaints may still exist (Oh, $2003 ; 2004)$. One way of ensuring satisfaction is to encourage users to utilize the resources and services offered by libraries. Libraries can also implement instruction programs to educate and guide users in browsing through the resources.

\subsection{Library instruction}

Instructional effectiveness by assessing learning outcomes includes positive cognitive, behavioral, and effective results (Julien and Boon, 2004). Nowadays, students no longer learn using the same modes during the time of printed resource materials (Wen et al., 2008). In fact, students nowadays are born in the so-called "net generation" (Zimmerman and 


\begin{tabular}{|c|c|c|}
\hline Authors and year & Main findings & Conclusions \\
\hline Phipps (2001) & $\begin{array}{l}\text { A danger in the shift of resource } \\
\text { allocation and customer loyalty }\end{array}$ & $\begin{array}{l}\text { Integrate feedback from } \\
\text { customers }\end{array}$ \\
\hline Cullen (2001) & Difficult to retain customers & Improve customer satisfaction \\
\hline $\begin{array}{l}\text { Keating and Hafner } \\
\text { (2002) }\end{array}$ & $\begin{array}{c}\text { Systems do not provide } \\
\text { sufficient information when } \\
\text { multiple patrons share the same } \\
\text { login/ password }\end{array}$ & $\begin{array}{l}\text { Develop the strategy of one-to- } \\
\text { one relationship management }\end{array}$ \\
\hline $\begin{array}{l}\text { Martensen and } \\
\text { Gronholdt (2003) }\end{array}$ & Lack of human service & $\begin{array}{l}\text { Provide friendly, helpful, and } \\
\text { professional guidance }\end{array}$ \\
\hline Keng (2003) & $\begin{array}{c}\text { Lack of appropriate interaction, } \\
\text { absence of goals and } \\
\text { communication }\end{array}$ & $\begin{array}{l}\text { Identify segments of } \\
\text { customers }\end{array}$ \\
\hline Shi et al. (2004) & $\begin{array}{l}\text { Satisfaction with the } \\
\text { information product received } \\
\text { and the information system } \\
\text { used to retrieve the product }\end{array}$ & $\begin{array}{l}\text { Provide a well-developed } \\
\text { library management method }\end{array}$ \\
\hline Dlanmini (2006) & $\begin{array}{l}\text { Lack of proper methods and } \\
\text { strategies in dealing with } \\
\text { customer care }\end{array}$ & $\begin{array}{l}\text { Develop identified customer } \\
\text { care strategies, such as } \\
\text { technology, utility call centers }\end{array}$ \\
\hline $\mathrm{Wu}(2007)$ & $\begin{array}{l}\text { Most of the users know little } \\
\text { about e-resources, } \\
\text { undergraduate students prefer } \\
\text { to obtain printed documents }\end{array}$ & $\begin{array}{c}\text { Recognize that teachers' and } \\
\text { students' needs for e-resources } \\
\text { are different }\end{array}$ \\
\hline
\end{tabular}

Table 1. Summary of previous findings on user needs, expectations, and satisfaction 
Milligan, 2007) or "Google generation" (Sykes, 2007). Wu (2007), however, reports that the overwhelming majority of the students know little about electronic resources and $49.6 \%$ of all college students in the study preferred printed periodicals. Researchers have suggested alternative methods to help users (Jiao et al., 1996; Onwuegbuzie, 1997; Jerabek, 2001). Various studies have reported that university libraries have established instruction programs in collaboration with the faculty so as to provide interactive instructions for improving the students' information search capabilities (Table 2).

\begin{tabular}{|c|c|c|}
\hline Authors and year & Main Findings & Conclusions \\
\hline Sinn (1998) & $\begin{array}{l}\text { Introduced students to the resources to } \\
\text { help them complete their assignment. }\end{array}$ & \multirow{6}{*}{$\begin{array}{l}\text { Libraries establish programs } \\
\text { in collaboration with teaching } \\
\text { faculty in the class. }\end{array}$} \\
\hline Sinn (2000) & $\begin{array}{c}\text { The use of databases and the World } \\
\text { Wide Web are differences between } \\
\text { magazines and journals. }\end{array}$ & \\
\hline Lawson (2000) & $\begin{array}{c}\text { Needs for meeting the } \\
\text { information literacy of today's college } \\
\text { students }\end{array}$ & \\
\hline Hinchliffe (2000) & $\begin{array}{l}\text { The term papers produced have been } \\
\text { improved by the guided research } \\
\text { process. }\end{array}$ & \\
\hline $\begin{array}{l}\text { Webster and Rielly } \\
\text { (2003) }\end{array}$ & $\begin{array}{l}\text { Library instruction is time- and labor- } \\
\text { intensive, especially for new courses. }\end{array}$ & \\
\hline Sanborn (2005) & $\begin{array}{l}\text { Library instruction is improved with } \\
\text { learning outcomes when combined with } \\
\text { faculty cooperation. }\end{array}$ & \\
\hline Olson (2000) & $\begin{array}{l}\text { Promote students' self-confidence and } \\
\text { encourage them to freely assess and } \\
\text { evaluate the sources of information they } \\
\text { find. }\end{array}$ & \multirow{3}{*}{$\begin{array}{l}\text { Classrooms have become } \\
\text { more interactive, one-on-one } \\
\text { instruction and information } \\
\text { search is increasing after the } \\
\text { instruction training. } \\
\text { The impact of library } \\
\text { instruction leads to user } \\
\text { satisfaction. }\end{array}$} \\
\hline Ren (2000) & $\begin{array}{l}\text { The increase has been related to } \\
\text { attitudes, emotional experiences, and } \\
\text { search performance. }\end{array}$ & \\
\hline Lapidus (2003) & $\begin{array}{l}\text { The electronic resources and online } \\
\text { bibliographic instruction for future } \\
\text { medical professionals is important. }\end{array}$ & \\
\hline Vander (2000) & $\begin{array}{l}\text { Evaluation has been conducted } \\
\text { successfully by libraries in the form of } \\
\text { focus groups, pilot-testing, tracking } \\
\text { usage of web pages, and surveys. }\end{array}$ & \multirow{2}{*}{$\begin{array}{c}\text { Enhance Web-based } \\
\text { instruction for a student } \\
\text { interacting with the library. }\end{array}$} \\
\hline Ragains (2001) & $\begin{array}{l}\text { Student response to incorporating this } \\
\text { type of Web page into library } \\
\text { instruction. }\end{array}$ & \\
\hline $\begin{array}{l}\text { Portmann and Roush } \\
\text { (2004) }\end{array}$ & $\begin{array}{l}\text { Libraries are being held increasingly } \\
\text { accountable for assessing learning } \\
\text { outcomes and addressing research } \\
\text { design issues. } \\
\end{array}$ & \multirow[t]{2}{*}{$\begin{array}{l}\text { Design valid assessment } \\
\text { programs and accurate } \\
\text { documentation of student } \\
\text { learning. }\end{array}$} \\
\hline Tag, (2004) & $\begin{array}{l}\text { Reflects positively on the library } \\
\text { instruction }\end{array}$ & \\
\hline
\end{tabular}

Table 2. Summary of library instruction programs reported in literature 
Library managers should provide a clearer strategy to develop and implement CRM-related activities in order to meet their mission and objectives. Instruction strategies are frontline tools that allow libraries to assist users and maintain relationships with them. Library managers also have to listen to the users so as to improve their customer strategy. Moreover, managers must provide communication channels, through which they can generate user feedback and understand their experiences.

\subsection{Library use}

Libraries today must find ways to optimize operations, minimize resources, enhance services, extend market penetration, and serve customers (Abram, 2007). Prior to the emergence of a digitized environment in the mid-1990, library users were regarded as patrons and library managers emphasized on the collections' development (Osiobe, 1981; Haider, 1996) and book availability (Rashid, 1990) rather than on service provision.

Viewing users as customers was first mentioned by Millson-Martula and Menon (1995). They report that gaps between the library and customers exist, such as the lack of interaction between library staff and the students and faculty. Jerabek et al. (2001) indicate that libraries should develop alternative ways to help users in utilizing their resources. Table 3 presents the anxiety, discontent information, and complaint behaviors reported by users while in the library.

\begin{tabular}{|c|c|c|}
\hline Authors and year & Main findings & Conclusions \\
\hline Onweugbuzie (1997) & Fear of interpersonal with library & Individual instruction \\
\hline Ercegovac (1997) & $\begin{array}{l}\text { Define the transition of today's } \\
\text { libraries as a storage service } \\
\text { provider }\end{array}$ & $\begin{array}{l}\text { Design a user-centered } \\
\text { information access } \\
\text { instructional program }\end{array}$ \\
\hline Jayne and Meer (1997) & $\begin{array}{l}\text { Websites are suitable in } \\
\text { demonstrating instructional } \\
\text { applications }\end{array}$ & $\begin{array}{l}\text { Develop a collaborative } \\
\text { program about the } \\
\text { instructional uses of WWW }\end{array}$ \\
\hline Jiao et al. (1998) & Lack persistence in learning & Provide visual instruction \\
\hline Jerabek et al. (2001) & $\begin{array}{l}\text { Fear of interpersonal contact, } \\
\text { computer, problem solving } \\
\text { strategies }\end{array}$ & $\begin{array}{l}\text { Develop alternative ways of } \\
\text { helping users }\end{array}$ \\
\hline Oh (2003) & Negative attitude & $\begin{array}{l}\text { Loyalty increases when users } \\
\text { have a positive attitude }\end{array}$ \\
\hline Oh (2004) & Exit to library & $\begin{array}{l}\text { View negative response as } \\
\text { valuable feedback }\end{array}$ \\
\hline Anwar et al. (2004) & $\begin{array}{l}\text { Gender of library user does not } \\
\text { have any significant relationship } \\
\text { with library anxiety }\end{array}$ & $\begin{array}{l}\text { The language of instruction } \\
\text { in library use affects library } \\
\text { anxiety }\end{array}$ \\
\hline $\begin{array}{l}\text { Mizrachi and Shoham } \\
(2004)\end{array}$ & $\begin{array}{l}\text { College library } \\
\text { instruction courses and } \\
\text { workshops should be mandatory } \\
\text { for all students at all levels from } \\
\text { beginner to advanced }\end{array}$ & $\begin{array}{l}\text { Opportunities for informal } \\
\text { and recreational } \\
\text { computer use should also be } \\
\text { provided }\end{array}$ \\
\hline
\end{tabular}

Table 3. Summary of library user feedback as reported in literature 
Providing individual instruction to users is a much needed service by graduate students; this elevates loyalty and ensures a good relationship between the library and users. Given that the needs for resources are different between users, redesigning library resources during the change from physical to electronic mode is also important. In this case, there are still gaps between library user demands and manager suppliers. This issue should be addressed in creating an instructional program.

\section{Service framework}

Peter Drucker defines marketing concepts as "the business as seen from the customer's point of view." Keating and Hafner (2002) state that business models can be applied to libraries; they also draw analogies from business by substituting "library" with "corporation and "user" with "customer." The e-Business domain has been employed extensively in governments, libraries, and diverse non-profit organizations. Constantinides (2002) proposes the Web-Marketing Mix (WMM) model, which can be used to identify the critical online marketing elements and address e-Commerce strategic, operational, organizational, and technical issues using Scope, Site, Synergy, and System (4S).

Scope identifies the strategic and operational objectives to be addressed; Site refers to a method for drafting realistic and consistent Web marketing plans in order to develop the functional platform of communication, interaction, and transaction with the Web-based customers; Synergy refers to the necessary organization, infrastructure, human resource, and knowledge required in supporting smooth online operational processes; and System identifies the main technological and administrative issues that underpin online marketing activities.

\section{$3.14 S$}

Further explanations of each component of $4 S$ are provided in this section to illustrate its implementation into our proposed conceptual framework.

Scope measures the strategic direction that managers should take to ensure that the whole staff follows the organization's predefined goals and objectives. A desire to establish benchmarking across institutions exists by identifying, understanding, and adapting external practices of other organizations in order to measure an organization's internal processes to achieve continuous improvement (Hernon, et al., 1999). To administer user profiles and sustain activities, segmentation of users is helpful in reaching the goal of setting and positioning the strategic role of the library during the service process.

Site evaluates how well a Website complies with the presetting functional requirements. A Libweb opens the collections and services (Hazard, 2003) to users, and is used as a powerful communication channel (Kuchi, 2006). It is also one of the most important communication channels between the library and its users in the digital environment. Through the Libweb, a library distinguishes the behavior and attitude of users while browsing through the sites as well as provides the newest information and recommendations at the same time.

Synergy is applied to all necessary organizational issues, such as back-end support or knowledge capability. The best customers are the loyal ones (Reinartz, and Kumar, 2002). The Internet fosters loyal customers, allowing organizations to develop close relationships with their customers (Jurewicz, and Cutler, 2003). 
System examines whether or not the library uses necessary technologies to support the technical-related services during transactional (e.g., borrowing/returning books) processes.

In order to implement the marketing concept into library service and improve effectiveness and efficiency, this study proposes an integrated service framework for users from a CRM perspective. Fig.2 illustrates the integration between library users and organizations, commencing with a detailed review of the curator's strategy. Each dimension is connected with a plus sign, which represents the correlation and feedback among these dimensions.

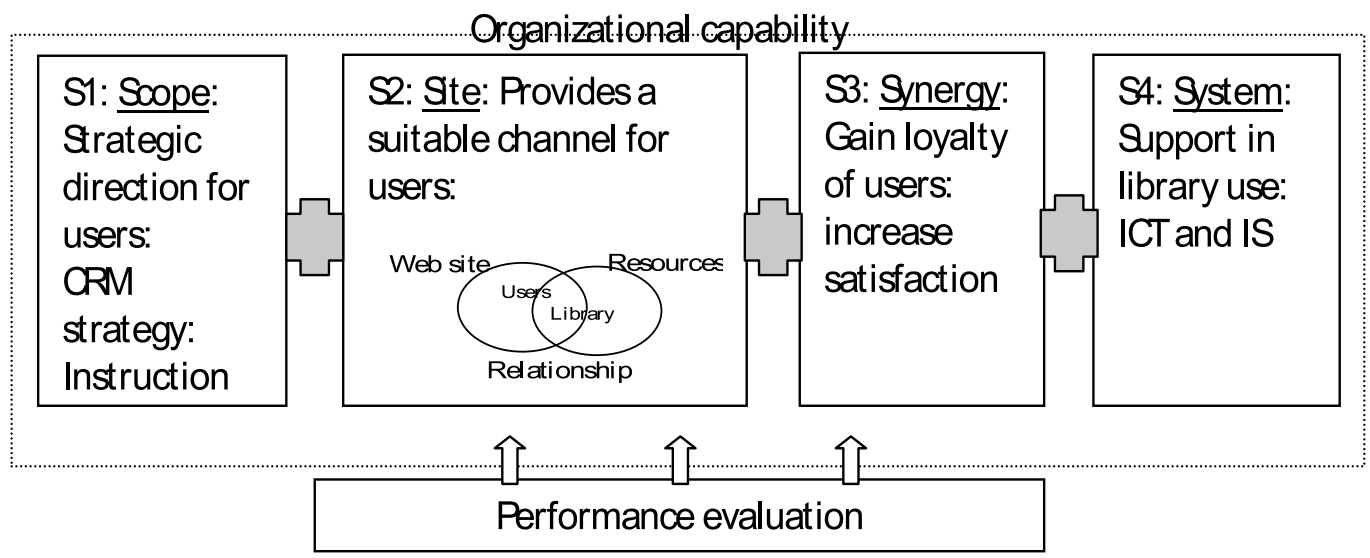

Fig. 2. Service framework for library users

\subsection{S1: Strategic direction for users: CRM strategy: Instruction}

A library must clearly understand its mission and goals to support teaching, research and learning, as well as identify the characteristics of users to provide adequate instructional programs. On the strategic stage, a library manager should create an CRM strategy focusing on the organization and customer instructional programs. Such strategy should provide the library with a clearer platform, with which to develop and implement CRM activities (Payne and Frow, 2005). Most universities have already established their library tour guides for new users; however, lack of advanced instruction for users in the class program still exists. The S1 element is a primarily strategic character, which outlines the decisions to be made in library organziations.

\subsection{S2: Provides a suitable channel for users}

Good communcation strategies are essential for the success of CRM (Broady-Preston, 2006). Users face an increased range of channel options. The effective library-users relationship managing within a multichannel environment requires efficient CRM (Payne and Frow, 2004). Nowadays, a Website is the most useful channel and a direct gateway between the library (which provides information) and the users (the ones who access resources). ICTs offer many tools in establishing the relationship between library and users, including direct mail, telephone services, facsimiles, call centers, and 3G mobile services. In the S2 element, a Website is the library-user interface and the primary source of customer experience data, making it the most important communication element of e-Commerce (Constantinides, 2002). 
Mohammed et al. (2002) provide a 7Cs framework, through which a customer interface design can achieve success. The 7Cs refer to context, content, community, customization, communication, connection, and commerce. Similar to a storefront, a good Website interace provides effective online connections. In addiiton, multichannel integration is an important process in CRM, which gathers and deploys user information and integrates it with other relevant information. This stage stipulates the output of the organizational strategy and value creation into value-added activities with users (Payne and Frow, 2005).

\subsection{S3: Gain loyalty of users: Increase satisfaction}

Synergy is defined as the integrating processes necessary for realizing the virtual ortganzation's objectives; such synergies can develop between the virtual and the physical organization (Constantinides, 2002). Organizations move from product- or brand-centric marketing to a more customer-centric approach, i.e., one-to-one communication capabilities (Reinartz, et al., 2004). Libraries view users as customers and encourage their continued patronage by increasing user satisfaction. Customer satisfaction leads to loyalty and is an important CRM tool in identifying, rewarding, and retain customers (Kumar and Reinartz, 2006). To create a sense of customer loyalty, Amazon.com offers a number of personalization features.

Libraries use ICTs to provide personalized service and generate user satisfaction (Ullen and Germain, 2002). Jeff Barry (2000) notes that advanced ways of leveraging technologies in enhancing library services generally come from library personnel. Customer retention represents a significant part of the value creation (Payne and Frow, 2005). The insights gained from this stage provides guidelines of user satisfaction and ICT; hence, information system (IS) is offered as a tool to link the resources owned or not owned by library.

\subsection{S4: Support in library use: ICT and IS}

In e-Commerce, System refers to technological capabilities and is widely considered as the main driving force behind the Internet growth (Constantinides, 2002). ICTs and IS are considered as bases that support CRM activities. ICT remains as the functional backbone of e-Commerce activities and entails the following system-related decisions (Constantinides, 2002):

- Website administration, maintenance and service;

- Web server hosting and choice of the Internet service provider;

- Site construction;

- Content management;

- $\quad$ Site security;

- Transaction functionality;

- Collection; and

- System backup.

ICT supports many activities involved in directly interfacing with customers and managing internal operations, administration, and supplier relaitonships (Greenberg, 2001). In the S4 stage, the organizational capacity to scale existing systems or plan for the migration to larger systems without disrupting business operations is critical. The information management 
process considers the collection, collation, and use of customer data from all customer contact points in order to generate customer insight and the appropriate marketing responses (Payne and Frow, 2005). Table 3.1 defines the 4 S marketing concept applied in library organization.

Using the service framework from the CRM perspective proposed in this study, the work process becoms smoother and quicker in each stage. In this system, resources are provided on-site or from remote storage locations (i.e., online or hard copy) based on the needs of the users and the objectives of the organization (Lakshmi, 2003). This integrated service framework demonstrates the interative arrangement of services that commences a strategic direction.

\section{Method}

Average scores do not exactly define performance evaluation due to the different degrees of standardization. Generally, two indicators are applied on service elements to evaluate the corresponding service quality performance, namely, importance (potential performance or PP) and satisfaction (actual performance or AP) (Hung, et al., 2003). Service quality refers to the degree of an event or experience, which meets individual needs or expectations. Customers are overwhelmed with service quality when customer perception (AP) exceeds customer expectation (PP) (AP>PP). Meanwhile, customers are moderately satisfied when customer perception (AP) is approximately equal to customer expectation ( $\mathrm{PP})(\mathrm{AP}=\mathrm{PP})$. The worse situation is when customers are dissatisfied, in which customers perception (AP) is below customer expectation (PP), resulting in satisfaction which is below expectation $(\mathrm{AP}<\mathrm{PP})$. Thus, managers are obliged to improve and enhance service quality to satisfy and retain customers (Hung et al., 2003).

\subsection{Performance evaluation}

The performance evaluation matrix (Lambert \& Sharma, 1990; Lambert \& Stock, 1999) measures customer satisfaction and expectation on each service element to provide managers with the service quality information and prioritize improvement plans for service elements that gained dissatisfied response from customers. The results of performance evaluation and customer importance are jointly determined by the location in the matrix. This location is used to evaluate service quality performance, as shown in Figure 3.

In Fig.3, the performance evaluation of customer importance is plotted against the $X$-axis (AP) and Y-axis (PP). The resulting formulation derives a score of mean and standard deviation (SD). The gap analysis depends on the actual performance compared with potential performance as well as on the viewpoint of curators regarding library service enhancement and promotions.

Library managers can identify and understand user preferences with regards the actual performance of library services through the help of ICTs and IS. However, empirical work in gap analysis shows that user preferences clearly depend on the disparity between actual performance and potential performance. To resolve this apparent discrepancy between AP and $\mathrm{PP}$, the present study shows that a simple reinterpretation of services from the CRM perspective fills the gap between the two performances. This study interprets AP as the 
current service provided and PP as user service expectations from the curator's viewpoint. Here, $\mathrm{AP}<\mathrm{PP}$ indicates poor service and dissatisfied users; $\mathrm{AP}=\mathrm{PP}$ indicates normal service and no need for specific impressions; and $\mathrm{AP}>\mathrm{PP}$ indicates good service and satisfied users.

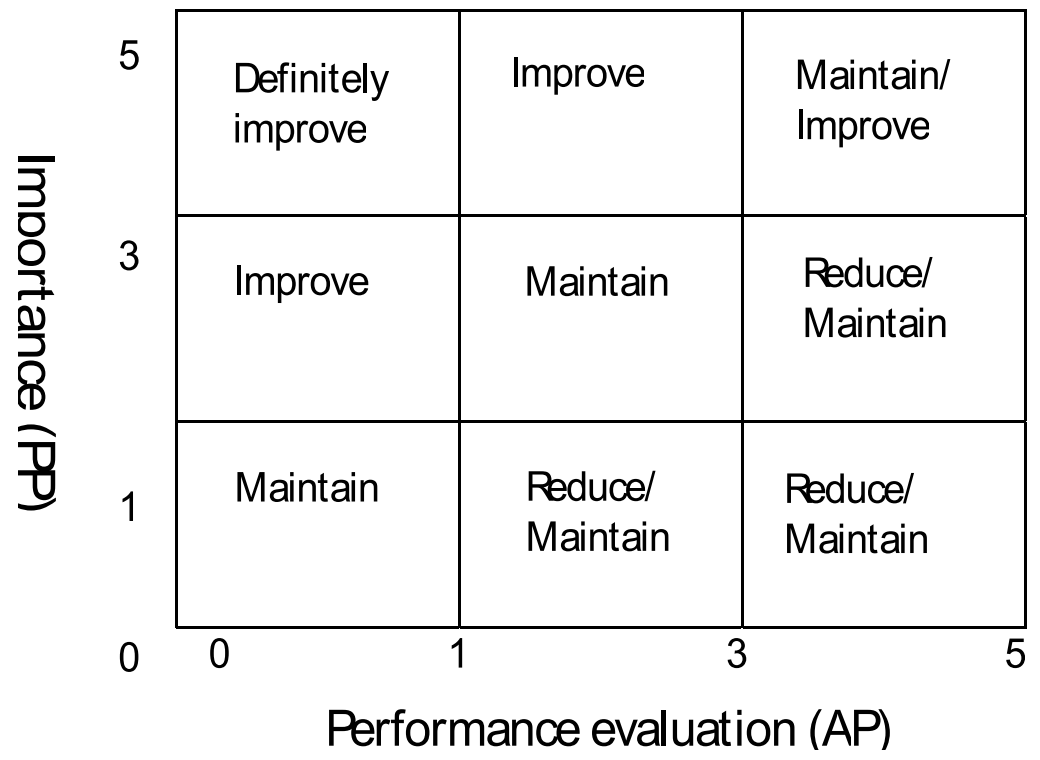

Fig. 3. Performance evaluation matrix

According to satisfaction theory, individuals are satisfied when expectations are met (Oliver, 1980, 1997; Tan and Sutherland, 2004). Statistically, this premise is expressed as: $\sum\left(D_{i}-V\right)$, where $\mathrm{D}$ is the value of $\mathrm{AP}, i$ is the value of the item, and $V$ is the value of PP. A gap is simply an expert's perception service of AP (D) minus the value of the PP (V) of factors (D$\mathrm{V})$. In this framework, an increasing gap score in each type tends to increase its user dissatisfaction if the performance is below PP and decrease if performance is above PP. Increasing user satisfaction is the core strategy of libraries.

\subsection{Participants}

The goal of the sample selection is to find comparable libraries. In the present work, we decided to include only ten public Technical and Vocational Education System (TVES) libraries of Taiwan and not other types of university libraries. These libraries offered resources to students come from another educational system other than the traditional one. In their technical and vocational senior high school years, they receive hands-on training that prepares them to be practitioners rather than theorists, and much more importance is placed on the practical than the abstract in their training. Yet nearly every one of them now receives higher education in a certain academic discipline in institutes of higher education (IHEs) and is expected to achieve college level upon entrance (Wen, 2008).

Questionnaires were mailed to 10 managers serving as the curators of TVES universities in Taiwan. All questionnaires were sent via first class mail in early May, 2009, and eight were 
returned at the end of the month. Such universities were chosen because of their public status and because they had similar budget allocations, evaluation criteria, organizational cultures, and standard processes. Moreover, student backgrounds were also the same among these universities.

Managers relate to the awareness of services and resources provided, use of services and resources offered from a user-centered perspective. Questions were formulated to ascertain the perceptions, expectations, and general information needs of the library services. The survey was conducted with efficient and effective data entry and analysis.

\section{Results}

$\mathrm{AP}$ and PP results in each level are presented in this section. The entire mean of AP is lower than PP. Table 4-7 lists each dimension of mean and SD.

The factors "Make the classroom more interactive by implementing one-on-one instruction" and "The effect of library instruction will lead to user satisfaction" show a very low mean score of 3.0000 for AP. The cooperation of the library and faculty is important for implementing instructional programs (Table 4).

\begin{tabular}{|l|c|c|c|c|}
\hline \multirow{2}{*}{$\begin{array}{c}\text { Factors } \\
\text { (S1: Strategic direction for users: CRM } \\
\text { strategy: Instruction) }\end{array}$} & \multicolumn{2}{c|}{ PP } & \multicolumn{2}{c|}{ AP } \\
\cline { 2 - 5 } & Mean & SD & Mean & SD \\
\hline $\begin{array}{l}\text { 1. Libraries must establish programs in } \\
\text { collaboration with teaching faculty in the class }\end{array}$ & 4.1250 & .6409 & 3.3750 & .5175 \\
\hline $\begin{array}{l}\text { 2. Make classrooms more interactive with } \\
\text { one-on-one instruction }\end{array}$ & 3.5000 & 1.3093 & 3.0000 & 1.1952 \\
\hline $\begin{array}{l}\text { 3. Information search is increasing after the } \\
\text { instruction training }\end{array}$ & 4.0000 & .7559 & 4.0000 & .7559 \\
\hline $\begin{array}{l}\text { 4. The effect of library instruction lead to user } \\
\text { satisfaction }\end{array}$ & 3.7500 & .4629 & 3.0000 & .5345 \\
\hline $\begin{array}{l}\text { 5. Enhance Web-based instruction } \\
\text { 6. Design valid assessment programs and } \\
\text { accurate documentation of student learning }\end{array}$ & 4.3750 & .7440 & 3.1250 & .8345 \\
\hline & \multicolumn{1}{|c|}{$\mathrm{Mp}=3.9792$} & .6409 & 3.3750 & 1.1877 \\
\hline
\end{tabular}

Table 4. Mean and SD of "Strategic direction for users: CRM strategy: Instruction"

"High-quality Internet information" and "Designers need better guidelines in building public access interfaces" obtain the highest mean score of 5.0000 for PP. The differences between AP and PP in this level are the lowest, indicating that the library is aware of the importance of building relationship with the users (Table 5). 


\begin{tabular}{|c|c|c|c|c|}
\hline \multirow{2}{*}{$\begin{array}{c}\text { Factors } \\
\text { (S2: Provide a suitable channel with users) }\end{array}$} & \multicolumn{2}{|c|}{ PP } & \multicolumn{2}{|c|}{$\mathrm{AP}$} \\
\hline & Mean & SD & Mean & SD \\
\hline $\begin{array}{l}\text { 1. Meet the goals and mission statement of } \\
\text { the library }\end{array}$ & 4.5000 & .7559 & 3.8750 & .6409 \\
\hline $\begin{array}{l}\text { 2. Integrating library service in both printed } \\
\text { and electronic resources }\end{array}$ & 4.8750 & .3536 & 4.1250 & .9910 \\
\hline 3. Ease of use & 4.8750 & .3536 & 4.1250 & 1.1260 \\
\hline $\begin{array}{l}\text { 4. Design a pleasing interface and easy to } \\
\text { use Website }\end{array}$ & 4.2500 & .7071 & 4.0000 & 1.1952 \\
\hline 5. Create a more intuitive Web interface & 4.7500 & .4629 & 4.0000 & 1.0690 \\
\hline 6. High-quality Internet information & 5.0000 & .0000 & 4.1250 & .8345 \\
\hline \multirow[t]{2}{*}{$\begin{array}{l}\text { 7. Designers need better guideline on } \\
\text { building public access interfaces }\end{array}$} & 5.0000 & .0000 & 3.8750 & 1.1260 \\
\hline & \multicolumn{2}{|c|}{$\mathrm{Md}=4.7500$} & \multicolumn{2}{|c|}{$\mathrm{Mp}=4.0179$} \\
\hline
\end{tabular}

Table 5. Mean and SD of "Provides a suitable channel for users"

Three factors resulted in a mean score of 5.0000. These include "Plan strategy that integrate digital and print collections," "Well-developed library management method," and "Develop identified user care strategies: technology, utility, and call centers." Although user satisfaction is often explored, meeting user needs and expectation is not enough; hence, these should always be the top priority of service providers (Table 6).

\begin{tabular}{|l|c|c|c|c|}
\hline \multirow{2}{*}{\begin{tabular}{|} 
Factors \\
(S3: Gain loyalty of users)
\end{tabular}} & \multicolumn{2}{c|}{ PP } & \multicolumn{2}{c|}{ AP } \\
\cline { 2 - 5 } & Mean & SD & Mean & SD \\
\hline $\begin{array}{l}\text { 1. Plan strategies that integrate digital and } \\
\text { print collections }\end{array}$ & 5.0000 & .0000 & 4.0000 & 1.1952 \\
\hline $\begin{array}{l}\text { 2. Listen to the users and encourage staff } \\
\text { involvement into organizational structure }\end{array}$ & 4.2500 & .8864 & 3.6250 & .5175 \\
\hline $\begin{array}{l}\text { 3. Establish benchmarking } \\
\text { 4. Develop the strategy of one-to-one } \\
\text { relationship management }\end{array}$ & 4.0000 & .5345 & 3.1250 & .6409 \\
\hline $\begin{array}{l}\text { 5. Friendly, helpful, and professional } \\
\text { guidance }\end{array}$ & 4.7500 & .4629 & 4.1250 & 1.3562 \\
\hline $\begin{array}{l}\text { 6. Well-developed library management } \\
\text { method }\end{array}$ & 5.0000 & .0000 & 4.0000 & 1.1952 \\
\hline $\begin{array}{l}\text { 7. Develop identified user care strategies, } \\
\text { such as technology, utility, and call centers }\end{array}$ & 5.0000 & .0000 & 4.1250 & .8345 \\
\hline \multicolumn{2}{|c|}{$\mathrm{Md}=4.482$} & \multicolumn{2}{|c|}{$\mathrm{Mp}=3.6786$} \\
\hline
\end{tabular}

Table 6. Mean and SD of "Gain loyalty of users: increase satisfaction"

The mean in this level is the lowest among all factors. The mean in AP indicates three factors, including "Instruct individually," "Designing user-centered information access instructional programs," and "Develop a collaborative program about the instructional uses of WWW," all of which show a score of less than 3. Such factors are perceived to be "not met" by the participants (Table 7). 


\begin{tabular}{|c|c|c|c|c|}
\hline \multirow{2}{*}{$\begin{array}{c}\text { Factors } \\
\text { (S4: Support in library use of users: } \\
\text { ICT, IS) }\end{array}$} & \multicolumn{2}{|c|}{ PP } & \multicolumn{2}{|c|}{$\mathrm{AP}$} \\
\hline & Mean & SD & Mean & SD \\
\hline 1. Instruct individually & 3.1250 & .8345 & 2.6250 & 1.0607 \\
\hline $\begin{array}{l}\text { 2. Designing user-centered information } \\
\text { access instructional programs }\end{array}$ & 4.0000 & 1.0690 & 2.7500 & 1.0351 \\
\hline $\begin{array}{l}\text { 3. Develop a collaborative program about } \\
\text { the instructional uses of WWW }\end{array}$ & 3.6250 & .9161 & 2.7500 & 1.0351 \\
\hline 4. Provide visual instruction & 3.2500 & 1.1650 & 2.8750 & 1.1260 \\
\hline 5. Develop alternative ways of helping users & 3.6250 & .9161 & 3.0000 & 1.0690 \\
\hline $\begin{array}{l}\text { 6. Reuse up while users are in a positive } \\
\text { attitude }\end{array}$ & 4.1250 & .6409 & 4.2500 & 1.1650 \\
\hline \multirow[t]{2}{*}{$\begin{array}{l}\text { 7. View negative response as valuable } \\
\text { feedback }\end{array}$} & 3.7500 & .7071 & 3.7500 & 1.2817 \\
\hline & \multicolumn{2}{|c|}{$\mathrm{Md}=3.7981$} & \multicolumn{2}{|c|}{$\mathrm{Mp}=3.2212$} \\
\hline
\end{tabular}

Table 7. Mean and SD of "Support in library use of users: ICT and IS"

A closer examination of the data reveals that the largest negative gap scores $(-1.125)$ are obtained for "Designers need better guideline on building public access interfaces." This demonstrates the effect of ICTs on the development of library service. Second, the gap score of "Design valid assessment programs and accurate documentation of student learning" and "Design user-centered information access instructional programs" is -1.25 , which means that user-center service should be considered.

Meanwhile, "High-quality Internet information" and "Designers need better guidelines in building public access interfaces" have a mean score of 5.000 in the PP. Thus, ICT settings and related facilities in libraries should be accessible and support the satisfaction of user needs.

As for "Develop identified user care strategies: technology, utility, and call centers" and "Plan strategy that integrate digital and print collections," these have a mean score of 5.0000 in the potential score. Hence, CRM strategy to meet user satisfaction should be considered carefully, especially the integration of electronic and printed resources. Figure 4 plots each factor in the dimensions of $\mathrm{AP}$ and $\mathrm{PP}$ values. It also shows the performance evaluation matrix diagram.

Fig.4 llustrates a diagonal line dividing the square into two parts. As can be seen, most of the dots are located in the top-right (maintain/improve cell), indicating that the importance of these levels are high. Three dots are located on the left of diagonal line, indicating that the service in this area should be maintained. Efforts must be exerted so that the dots located in the right of diagonal line showed that the service in this area should be improved. 


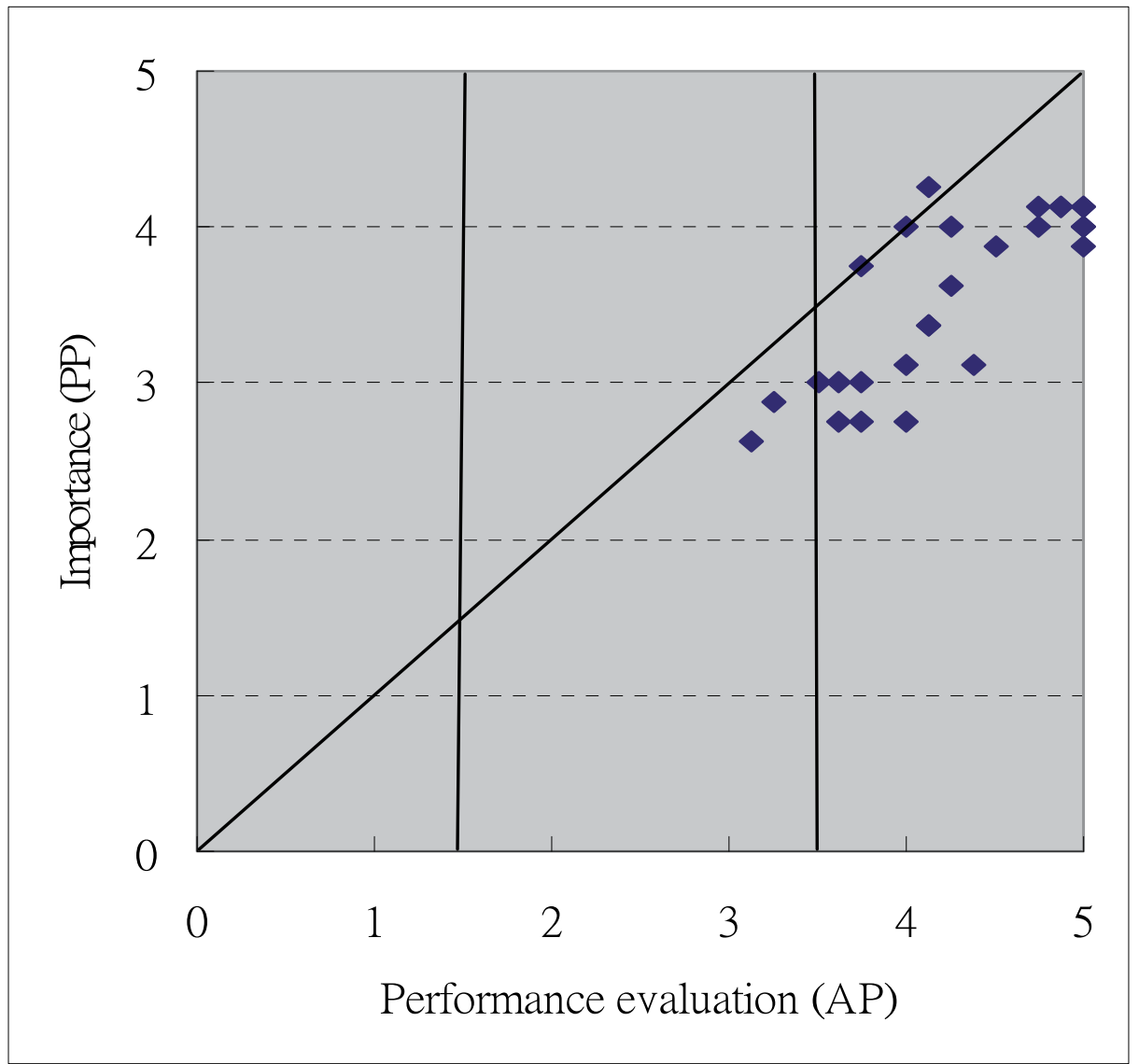

Fig. 4. The performance matrix of AP and PP values

\section{Conclusion}

Libraries often face budget deficiency and reduced resources under the operation and management style of non-profit organizations. Since their goal is to be a service organization, they must continually think of ways and strategies to attract users to utilize their resources. CRM is not a tactical or functional approach, but is a key strategic process that can achieve such a goal. A comprehensive CRM highlights the preferences and learning needs of users focused on cost-efficiency as well as enhances customer retention and loyalty. This study proposes an integrated conceptual model through a business-marketing plan and CRM perspective using literature findings, expert interviews, and a survey of library experts for the verification of the model in practice.

The present study successfully introduces the concept of the CRM perspective to the field of library and information science. The significant concepts generated from this perspective include a marketing approach intended to improve library effectiveness, instructions for increasing user satisfaction. Such notions have only been utilized in the field of business administration, but not in the target field. Thus, in our approach, wr viewed library users as "customers" who seek satisfaction from the marketplace, i.e., "library." 
More significantly, the present can be regarded as one of the few leading studies in the field, which investigates the effects of a managerial viewpoint in library services. Finally, this study can be viewed as a call for decision-makers to give more attention to university students in receiving higher education.

The proliferation of the Internet and ICTS has transformed the ways by which information is created, disseminated, stored, and accessed. Libraries must harness and utilize recent technological developments to fulfill their mission of providing access to information to meet the students' needs. Indeed, students are customers, and the libraries must establish interaction with them to identify their needs and difficulties in using library resources. "Library instruction" should not be ignored in the digital environment and ICT emergence. On the contrary, research on the instruction issues in an active and interactive way has progressed. Olson (2000), for example, addresses one-on-one instruction to promote the students' self-confidence and encourage them to freely assess and evaluate the resources of information. Keating and Hafner (2002) invite individual customers to think actively about the applicability of business concepts to academic library services. They then propose a model, which is applied for one-to-one library service.

University students include freshmen, sophomores, juniors, and seniors. A barrier certainly exists to overcome the manipulation of one-to-one relationship model for each of them. Sinn (1998) and Silver and Nickel (2007) offer library instructions to psychology and biology students and find that the instructions should be made according to characteristics of the students. Researchers focused on a composite class, in which students come from different colleges, encourage them to discuss in class their perspectives after using the library resources, thus enhancing their information literacy from this course.

\section{Appendix A}

Please tick the number from (1) to (5), ranging from extremely important (5) to not important at all (1) into the $\square$. In your own viewpoint, rate how important you believe each university library service is. Do not think about your current university; instead, think about your expectations of the quality of services in a typical university library.

\begin{tabular}{ccccc}
\hline \multicolumn{4}{|c}{$\begin{array}{c}\text { (A) You think your } \\
\text { library should } \\
\text { provide such service. }\end{array}$} \\
\hline & & & & \\
& & & & \\
1 & & 3 & & 5 \\
$\square$ & $\square$ & $\square$ & $\square$ & $\square$ \\
$\square$ & $\square$ & $\square$ & $\square$ & $\square$ \\
$\square$ & $\square$ & $\square$ & $\square$ & $\square$ \\
$\square$ & $\square$ & $\square$ & $\square$ & $\square$ \\
$\square$ & $\square$ & $\square$ & $\square$ & $\square$ \\
$\square$ & $\square$ & $\square$ & $\square$ & $\square$
\end{tabular}

1. Libraries establish programs in collaboration with teaching faculty in the class

2. Make classrooms more interactive with one-on-one instruction

3. Information search is increasing after the instruction training

4. The effect of library instruction leads to user satisfaction

5. Enhance Web-based instruction

6. Design valid assessment programs and accurate documentation of student learning
(B) You think your library actually provide such services.

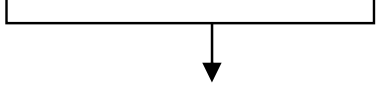

$\begin{array}{lllll}1 & & 3 & & 5 \\ \square & \square & \square & \square & \square \\ \square & \square & \square & \square & \square \\ \square & \square & \square & \square & \square \\ \square & \square & \square & \square & \square \\ \square & \square & \square & \square & \square \\ & & & & \end{array}$


Phase 2 : Provides a suitable channel for users

$\begin{array}{ccccc}1 & & 3 & & 5 \\ \square & \square & \square & \square & \square \\ \square & \square & \square & \square & \square \\ \square & \square & \square & \square & \square \\ \square & \square & \square & \square & \square \\ \square & \square & \square & \square & \square \\ \square & \square & \square & \square & \square \\ \square & \square & \square & \square & \square\end{array}$

1. Meet the goals and mission statement of the library

2. Integrating library service in both printed and electronic resources

3. Ease of use

4. Design a pleasing interface and easy to use Website

5. Oreate a more intuitive web interface

6. High-quality Internet information

7. Designers need better guidelines in building public access interfaces

Phase 3 : Reenter to use the library (Increase satisfaction)

$\begin{array}{lllll}1 & & 3 & & 5 \\ \square & \square & \square & \square & \square \\ \square & \square & \square & \square & \square \\ \square & \square & \square & \square & \square \\ \square & \square & \square & \square & \square \\ \square & \square & \square & \square & \square \\ \square & \square & \square & \square & \square \\ \square & \square & \square & \square & \square\end{array}$

1. Plan strategies that integrate digital and print collections

2. Listen to the users and encourage staff involvement in the organizational structure

3. Establish benchmarking

4. Develop the strategy of one-to-one relationship management

5. Friendly, helpful, and professional guidance

6. Well-developed library management method

7. Develop identified user care strategies, such as technology, utility, and call centers

Phase 4 : Support for use: ICT and IS

$\begin{array}{ccccc}1 & & 3 & & 5 \\ \square & \square & \square & \square & \square \\ \square & \square & \square & \square & \square \\ \square & \square & \square & \square & \square \\ \square & \square & \square & \square & \square \\ \square & \square & \square & \square & \square \\ \square & \square & \square & \square & \square \\ \square & \square & \square & \square & \square\end{array}$

1. Instruct individually

2. Designing user-centered information access instructional programs

3. Develop a collaborative program about the instructional use of WWW

4. Provide visual instruction

5. Develop alternative ways of helping users

6. Reuse up while users are in a positive attitude

7. View negative response as valuable feedback

$\begin{array}{ccccc}1 & & 3 & & 5 \\ \square & \square & \square & \square & \square \\ \square & \square & \square & \square & \square \\ \square & \square & \square & \square & \square \\ \square & \square & \square & \square & \square \\ \square & \square & \square & \square & \square \\ \square & \square & \square & \square & \square \\ & & & & \end{array}$

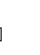


Bielema, Cheryl, Crocker, Dan, Miller, Joan, Reynolds-Moehrle, Jennifer, and Shaw, Helen, (2007), Faculty and librarian collaborations: A case study and proposal for online learning environments, Research Strategies, Vol.20, No.4, pp.334-345.

Borchert, C. A. (2006), Untangling the jungle of e-journal access issues using CRM software, Library Collections, Acquisitions, and Technical Services, 30(3-4), pp.224-237.

Broady-Preston, Felice, Joanna, and Marshall, Susan, (2006), Building better customer relationships: case studies from Malta and the UK, Library Management, 27(6/7), pp.430-445.

Cardwell, C., Furlong, K., and O'Keeffe, J. (2001), My librarian: Personalized research clinics and the academic library, Research Strategies, 18(2), pp.97-111.

Chen, T. S., Lin, M. H., and Wu, C. H. (2004), Enhancing library resources usage efficiency by data mining, Proceedings of the IEEE International Conference on Networking, Sensing \& Control, pp.382-387.

Chu, Pi. Ching, (2005), A study of library acquisition and cataloging from the viewpoint of customer relationship management, Central University Library Journal, Taoyuan: Jhongli.

Constantinides, E. (2002), The 4S Web-Marketing Mix model, Electronic Commerce Research and Applications, pp. 57-76.

Cooper, R., Dempsey P.R. (1998), Remote library users-needs and expectations, Library Trends, 47(1), pp.42-65.

Cullen, R. (2001), Perspectives on users satisfaction surveys, Library Trends, 49(4), pp.662686.

Dlamini, Petros N. (2006), Customer care services and strategies in academic libraries in KwaZulu-Natal, Journal of Library \& Information Science, 72(2), pp.119-130.

Drucker, Peter, (1973), Management: Tasks, Responsibilities, Practices. Harper and Row, New York.

Ercegovac, Zorana, (1997), The interpretations of library use in the age of digital libraries: Virtualizing the name, Library \& Information Science Research, 19(1), pp. 35-51.

Fan, Weiguo, Gordon, Michael D. and Pathak, Praveen, (2005), Effective profiling of consumer information retrieval needs: a unified framework and empirical comparison, Decision Support Systems, Vol.40, No.2, pp.213-233.

Flanagan, P. and Horowitz, R. (2000), Exploring new service models: can consolidating public service points improve response to customer needs? Journal of Academic Librarianship, 26(5), pp.329-338.

Frias-Martinez, E. Magoulas, G., Chen, S. and Macredie, R., (2006), Automated user modeling for personalized digital libraries, International Journal of Information Management, Vol.26, No.3, pp.234-248.

Giacomo, Mariella Di \& Knudson, 2004, MyLibrary @LANL, a Personalized and Collaborative Digital Library Portal for Facilitating Scientific Research, Los Alamos National Laboratory Research Library.

Green, Andrew, (1990), What do we mean by user needs? British Journal of Academic Librarianship. 5(2), pp.65-78.

Haider, Syed Jalaluddin, (1996), Acquisitions and collections development in Pakistan, Library Acquisitions: Practice \& Theory, 20(2), pp.147-156.

Hazard, B. (2003), Online fundraising at ARL libraries, The Journal of Academic Librarianship, 29(1), pp.8-15. 
Heckart, Ronald J. (1999), Imagining the digital library in a commercialized internet, The Journal of Academic Librarianship, 25(4), pp.274-280.

Hernon, Peter and Altman, Ellen, (1998), Assessing service quality: satisfying the expectations of library customers, Chicago: American Library Association.

Hernon, Peter and Calvert, Philip, (2005), E-service quality in libraries: exploring its features and dimensions, Library \& Information Science Research, Vol. 27, pp.377-404

Hernon, Peter, Nitecki, Danuta A., and Altman, Ellen, (1999), Service quality and customer satisfaction: An assessment and future directions, The Journal of Academic Librarianship, Vol.25, No.1, pp.9-17.

Hicks, David, (2003), Supporting personalization and customization in a collaborative setting , Computers in Industry, Vol.52, No.1, pp.71-79.

Hinchliffe, J. (2000), Faculty-directed library use instruction: A single class, retrospective study, Research Strategies, 17(4), pp.281-289.

Huang, R. (2007), Study and analysis of information on the reader's potential discontent in an academic library, Library Management, 28(1/2), pp.27-35.

Hung, Y.H., Huang, M. L., and Chen, K. S., (2003), Service quality evaluation by service quality performance matrix, Total Quality Management, Vol. 14, No.1, pp.79-89.

Jayne, Elaine, and Meer, Vander, (1997), The library's role in academic instructional use of the World Wide Web, Research Strategies, 15(3), pp.123-150.

Jerabek, J. N., Meyer, L. S., and Kordinak, T. (2001), "Library anxiety" and "computer anxiety:" Measures, validity, and research implications, Library \& Information Science Research, 23(3), pp.277-289.

Jiao, Q. G., Onwuegbuzie, A. J., and Lichtenstein, A.. (1996). Library anxiety: Characteristics of at-risk college students. Library \& Information Science Research, 18, 151- 163.

Jiao, Q. G. and Onwuegbuzie, A. J. (1998), Perfectionism and library anxiety among graduate students, The Journal of Academic Librarianship, 24(5), pp.365-371.

Johnson, Peggy, and MacEwan, Bonnie, (1999), Virtually Yours: Models for Managing Electronic Resources and Services. Chicago: American Library Association.

Julien, Heidi, and Boon, Stuart, (2004), Assessing instructional outcomes in Canadian academic libraries, Library \& Information Science Research, 26(2), pp.121-139.

Jurewicz, Lynn, and Cutler, Todd, (2003), High Tech, High Touch: Library Customer Service Through Technology, Chicago: American Library Association, p.7. [e-Book].

Kao, S. C. Chang, H. C. and Lin, C. H. (2003), Decision support for the academic library acquisition budget allocation via circulation database mining, Information Processing and Management, 39(1), pp.133-147.

Keating, III, John J. and Hafner, Arthur W. (2002), Perspective on ...Supporting individual library patrons with information technologies: emerging one-to-one library services on the college or university campus, The Journal of Academic Librarianship, Vol.38, No.6, pp.426-429.

Keng, K. A., Kwon, J., and Wirtz, J. (2003), Segmentation of library visitors in Singapore, Learning and reading related lifestyles, Library Management, 24(1/2), pp.20-33.

Koohang, Alex and Ondracek, James, (2005), Users' views about the usability of digital libraries, British Journal of Educational Technology, 36(3), pp.407-423.

Kuchi, T. (2006), Communicating mission: an analysis of academic library Web sites, The Journal of Academic Librarianship, 32(2), pp.148-154. 
Kumar, V. and Reinartz, Werner J., (2006), Customer Relationship Management: a databased approach, N.J.: John Wiley \& Sons.

Lambert, D.M. and Sharma, A. (1990), A customer-based competitive analysis for logistics decisions, International Journal of Physical Distribution and Logistics Management, 20, p.23.

Lambert, D.M. and Sharma, A. (1999), Strategic Logistics Management, (Irwin).

Lapidus, Mariana, (2003), Library services for pharmacy and health sciences students: results of a survey, The Journal of Academic Librarianship, 29(4), pp. 237-244.

Lawson, M. D. (2000), Reaching the masses: marketing a library instruction course to incoming freshmen, Research Strategies, 17(1), pp.45-49.

Martensen, Anne and Gronholdt, Lars, (2003), Improving library users' perceived quality, satisfaction and loyalty: an integrated measurement and management system, Journal of Academic librarianship, 29(3), pp.140-147.

Millson-Martula, Christopher and Menon, Vanaja, (1995), Customer Expectations: Concepts and Reality for Academic Library Services. College \& Research Libraries, Vol.56, No.1, pp.33-47.

Mizrachi, D. and Shoham, S. (2004), Computer attitudes and library anxiety among undergraduates: a study of Israeli B.Ed students, The International Information \& Library Review, 36(1), pp.29-38.

Mohammed, R. F., Rpbert, J., Jaworski, J., and Cahill, A. M. (2002), Internet Marketing: Building Advantage in the Networked Economy, Boston: McGraw-Hill/Irwin, p.623.

Nitecki, D. A. (1996), Changing the concept and measure of service quality in academic libraries, The Journal of Academic Librarianship, pp.181-190.

Oh, D. G. (2003), Complaining behavior of public library users in South Korea, Library \& Information Science Research, 25(1), pp.43-62.

Oh, Dong-Geun, (2004), Complaining behavior of academic library users in South Korea, The Journal of Acadecmi Librarianship, 30(2), pp.136-144.

Ojala, M. (1986), Views on end-user searching, The American Society for information Science, 37(4), pp.197-203.

Oliver, Richard L., (1997), Satisfaction: A Behavioral Perspective on the Consumer. New York: McGraw-Hill.

Oliver, Richard L., (1980), “A Cognitive Model of the Antecedents and Consequences of Satisfaction Decisions," Journal of Marketing Research, 17 (November), 460-9.

Olson, John A. (2000), How to encourage students in a library instruction session to use critical and creative-thinking skills: a pilot study, Research Strategies, 16(4), pp.309-314.

Onwuegbuzie, A. J. (1997), Writing a research proposal: the role of library anxiety, statistics anxiety, and composition anxiety, Library \& Information Science Research, 19(1), pp.5-33.

Osiobe, S. A., 1981, The Faculty versus librarians in the acquisitions process: a comparative analysis, Library Acquisitions: Practice \& Theory, 5, pp.9-13.

Payne,A, and Frow, P. (2005), "A strategic framework for customer relationship management", Journal of Marketing", 69 (4), pp.167-176.

Phipps, Shelley, (2001), Beyond measuring service quality: learning from the voices of the customers, the staff, the processes, and the organization, Library Trends, 49(4), pp.635-661. 
Portmann, Chris A. and Roush, Adrienne Julius (2004), Assessing the Effects of Library Instruction, The Journal of Academic Librarianship, 30(6), pp. 461-465.

Ragains, P. (2001), A primer on developing and using course-related library Web pages, Research Strategies, 18(1), pp.85-93.

Rashid, Haseeb F., (1990), Book availability as a performance measure of a library: an analysis of the effectiveness of a health sciences library, Journal of the American Society for Information Science, 41(7), pp.501-507.

Raza, M. Masoom and Nath, Amar, (2007), Use of IT in university libraries of Punjab, Chandigarh and Himachal Pradesh: a comparative study, The International Information \& Library Review, 39(3-4), pp.211-227.

Reinartz, Werner, and Kumar V. (2002), The Mismanagement of customer loyalty, Harvard Business Review, pp.86-94.

Ren, Wen-Hua, (2000), Library instruction and college student self-efficacy in electronic information searching, The Journal of Academic Librarianship, 26(5), pp.323-328.

Renda, M. Elena and Straccia, Umberto, (2005), A personalized collaborative Digital Library environment: a model and an application, Information Processing \& Management, Vol41, No.1, pp.5-21.

Sanborn, L. "Improving library instruction: faculty collaboration", The Journal of Academic Librarianship, 31(5), 2005, pp.477-481.

Shi, X, Holahan, P. J., and Jurkat, M. P. (2004), Satisfaction formation processes in library users: understanding multisource effects, The Journal of Academic Librarianship, 30(2), pp.123-131.

Sinn, R. N. (1998), Library instruction for biology courses: a literature review and survey, Research Strategies, 16(2), pp. 103-115.

Sinn, R. N. (2000), A comparison of library instruction content by biology faculty and librarians, Research Strategies, 17(1), pp.23-34.

Silver, S.L. and Nickel, L.T. "Are online tutorials effective? A comparison of online and classroom library instruction methods," Research Strategies, vol.20, pp.389-396, 2007.

Sykes, Jean, (2007), Improving the student experience-how can the library help?, New Review of Information Networking, Vol.13, No.1, pp.23 - 30.

Tag, Sylvia G. (2004), A Library Instruction Survey for Transfer Students: Implications for Library Services, The Journal of Academic Librarianship, 30(2), pp. 102-108.

Tan, F. B. and Sutherland, P. (2004). Online Consumer Trust: A Multi-Dimensional Model. Journal of Electronic in Organizations, 2(3):40-58.

Van Groenendaal, Willem J.H. (1997), A user's view on the electronic library, Library Acquisitions: Practice \& Theory Vol.21, Issue 3, pp.337-345.

Vander Meer, (2000), Pushing the limits: creative web use in libraries related to instruction, Research Strategies, 17(4), pp.237-256.

Wang, Mei, Yu, (2006), CRM and Library Reader Service, Taipei: Showwe.

Webster, L., and Rielly, L. (2003), A library instruction case study: measuring success from multiple perspectives, Research Strategies,19(1), pp. 16-32.

Wells, John D., Fuerst, William, and Choobineh, Joobin, (1999), Managing information technology (IT) for one-to-one customer interaction, Information \& Management, $35(53-62)$. 
Wen, Yvonne Ying-Ya, Wang, Shiow-Luan, and Thomson, Gavin, (2008), Enhancing Cultural Literacy through E-Learning: A Case Study in the TVES of Taiwan, The 2008 International Joint Conference on e-Commerce, e-Administration, e-Society, and e-Education (e-CASE 2008), March 27-29, Bangkok, Thailand. (ISBN 978-98683038-2-9).

Will, Nicole, (2006), Data-mining: Improvement of university library services, Technological Forecasting and Social Change, Vol.73, No.8, pp.1045-1050.

$\mathrm{Wu}$, Shuling, (2007), Investigation and analysis of current use of electronic resources in university libraries, Library Management, 28(1/2), pp.72-88.

Xie, Hong, (2006), Evaluation of digital libraries: criteria and problems from users' perspectives, Library \& Information Science Research, 28, pp.433-452.

Yen, Chia-Hui, (2002), The Application of data mining in library marketing and customer relationship management, Bulletin of Library and Information Science, 42, pp.58-68.

Zimmerman, L. and Milligan, A. T. (2007). Perspectives on communicating with the Net Generation. Innovate 4(2).

http://www.innovateonline.info/index.php?view=artical\&id=338. 


\title{
Dual Approach to the Modelling Single Product Demand Curves in the Next Best Offer CRM Problem
}

\author{
Džulijana Popović \\ Zagrebačka Banka d.d., UniCredit Group \\ Croatia
}

\section{Introduction}

Customer Relationship Management (CRM) is a comprehensive approach for creating, maintaining and expanding customer relationships (Anderson \& Kerr, 2002). The definition tells that CRM has to be a comprehensive way of doing business that touches all areas and does not belong to one department of an organization, such IT, Marketing or Sales. CRM is also a way of thinking and dealing with different aspects of relationship with customers and involves having a clear strategy and plan. In modern economy that relationship between a company and customer has various forms, from personal to completely virtual contacts with frequent customers who have never spoken to anyone from the company. Therefore, CRM also takes care about creating the idea and strategy of high touch in a high tech environment. Technology must not stay on the way of applying CRM strategy and must not be confused with it.

There are a number of important CRM questions and problems and the most common are:

- $\quad$ customer acquisition (problem of attracting new customers);

- customer retention (problem of preventing attrition of existing customers, especially the most profitable ones);

- cross-sell and up-sell (problem of making existing customers more profitable);

- risk approval and underwriting tools (problem of avoiding high-risk customers);

- lifetime value modelling (problem of recognizing new profitable customers);

- improved targeting and campaign response rates (problem of expense reduction and increasing sales and revenues);

- $\quad$ customer segmentation (problem of profiling customer database), etc.

Customers want to do business with organizations that know them, that understand what they want and need, and that continue to fill those needs (Anderson \& Kerr, 2002) in changing environment. Modern companies collect various data about their customers, but these data rarely answer the direct questions such as "what will each of our customers need in the next future?" or "which are the product attributes that satisfy his/her needs in the way that results in product purchase?". The way to answer such questions is deep diving into available data, with strong understanding what the analyst is searching for, which 
conclusions are valid syllogisms, and how to translate business goals mentioned above into analytical problems. The learning process about customers has to be an adaptive, flexible and feedback supplied process, in order to build dynamic knowledge about customers. In order to have the right proposal for each customer in each contact occasion, a company needs to solve the next best offer problem as well. The proposal has to be in form and content which meets both customer's and company's goals. While the company's business goals are well defined within the organization, the source of uncertainty in the next best offer problem are unknown product demand curves at the individual customer level, not only in their snapshot form, but rather in their dynamical form. Finally, the companies have to remember that data mining and statistical models only suggest, but business decides and supports the solution implementation. There is no much gain of having high tech tools and excellent predictive models, if the business environment and decision makers do not support and ensure their application.

\section{Methodology}

The chapter presents dual approach to the problem of offering the single product to the right customer at the right time and through the right channel, instead of trying to model the next best offer generally. The duality of the approach lies in the combination of product and customer perspective, as well as in the combination of classical statistical methods and modern methodologies. The model for the probabilities of buying the single product was built as the logistic regression model and interpreted as the single product demand curve. The model for customer clustering according to their channel usage and communication history was built with fuzzy c-means clustering algorithm and interpreted as the natural grouping of the customers that reveals their propensity to buy the product when reached through preferred channel. From the expert systems and knowledge discovery perspective the models are divided into two groups: predictive models and classification models. Regression model is a predictive model which gives the predicted values of the dependent (target) variable as output. Clustering is a classification model, since it gives the group flag or group membership function value to each observation. From the pattern recognition perspective regression model is supervised learning technique, since it uses the dependent variable for solution generation. Clustering is unsupervised learning technique, since it does not use the dependent variable for cluster detection and definition. But, discovered clusters can help in classifying new observations and in that way clustering becomes also predictive model (Cox, 2005). The flexibility of the final model is achieved in the second iteration, when the membership functions' values from the fuzzy c-means clustering algorithm enter the logistic regression model as additional input variables, improving the predictions of individual probabilities of product purchase. In that way all the information on the individual customer level that is comprised in the clusters' definition also enters the first model. The goal of the fuzzy clustering process is not to obtain another kind of general customer segmentation, but focuses on discovering the clusters according to their channel usage and communication history. In that way the model for the purchase probabilities is influenced by the membership functions that contain the information about communication channel that leads to the purchase. Since the clustering is not crisp, but fuzzy, it provides additional information on the extent to which the customer belongs to each of the channel fuzzy clusters. That information can be monitored over time, helping the company to recognize the changes in customer channel preferences before customer actually fall in 
another cluster. The combination of the two underlying models can lead to more accurate predictions of sales (product perspective), to more responsive target of customers (marketing perspective), more predictive costs and revenues (budget perspective) and/or to the greater level in satisfying the customers' needs and loyalty (customer perspective). Generally, the dual approach can help the company to develop operationally possible and sustainable models to meet customer needs on time, to dynamically learn about them not only from their purchasing history, but from their feedback to every CRM intervention and still to reach financial and business goals.

\subsection{Logistic regression analysis}

The logistic regression model is a mathematical model used for the categorical data analysis and belongs to the class of generalized linear models (GLM). The class of generalized linear models extends the theory and methods of linear models to data with nonnormal responses. Differently from other extensions of linear modelling to nonnormal data, which all relied on transformations of the data, generalized linear models apply a transformation to the mean of the data. In that way the systematic component is a linear predictor $\eta=X^{\prime} \beta$, where $\eta$, in contrast to linear models, does not represent the mean function of the data. The transformation called link function $g(\cdot)$ relates that linear predictor to the mean, $g(\mu)=\eta$. The link function is a monotonic and invertible function, so the mean can be expressed as the inversely linked linear predictor $\mu=\mathrm{g}^{-1}(\mathrm{\eta})$. Generalized linear models allow the data to come from a distribution that is a member of the exponential family of distributions and link function provides a mapping between the linear predictor and the mean of the data.

Suppose $x$ is a vector of independent or explanatory variables and $\Pi=p(Y=1 \mid x)$ is the response probability to be modelled. The linear model is not an appropriate model since the predicted values from a linear model can assume any value and probabilities are by definition bounded between 0 and 1 . The other shortcoming of linear probability model is that the relationship between the probability of an outcome and independent variables is usually nonlinear. The one-unit change in an independent variable may have less impact when the probability is near 0 or 1 than when the probability is about 0,5 . (Hosmer \& Lemeshow, 2000). The appropriate model is a logistic model, which is based on the logistic function

$$
f(z)=\frac{1}{1+e^{-z}}
$$

Equations (2) and (3) show that logistic function has the range of values between 0 and 1, regardless of the value of $\mathrm{z}$ (Kleinbaum \& Klein, 2010):

$$
\begin{aligned}
& f(-\infty)=\frac{1}{1+e^{-(-\infty)}}=\frac{1}{1+e^{\infty}}=0 \\
& f(+\infty)=\frac{1}{1+e^{-(+\infty)}}=\frac{1}{1+e^{-\infty}}=1
\end{aligned}
$$

To obtain the logistic model from the logistic function, $\mathrm{z}$ is substituted by the expression 


$$
z=\beta_{0}+\beta_{1} X_{1 i}+\cdots+\beta_{k} X_{k i}
$$

and the equation that directly refers to the probability of the outcome is

$$
p_{i}=\frac{1}{1+e^{-\left(\beta_{0}+\beta_{1} X_{1 i}+\cdots+\beta_{k} X_{k i}\right)}}
$$

Equation (5) is logistic regression model and is equivalent to the logit link transformation expressed as natural log of the odds, which is the ratio of the probability of the outcome to the probability of no outcome:

$$
\log i t\left(p_{i}\right)=\ln \left(\frac{p_{i}}{1-p_{i}}\right)=\beta_{0}+\beta_{1} X_{1 i}+\cdots+\beta_{k} X_{k i}
$$

where $\beta_{0}$ is the intercept parameter and $\beta_{1}, \ldots, \beta_{\mathrm{k}}$ are the slope parameters.

As mentioned earlier, logistic model is used for categorical data analysis, which is concerned with categorical responses, regardless of whether the predictor variables are categorical or continuous. If the set of response consists of only two values, then the response is dichotomous or binary and the appropriate model is binary logistic model. Therefore, the binary logistic regression model characterizes the relationship of several independent variables to a dichotomous dependent variable (Kleinbaum \& Klein, 2010). It uses the categorical and/or continuous input variables to predict the probability of specific outcomes. Since the dependent variable in logistic regression is not continuous, but discrete or categorical, that makes logistic regression very useful in predicting discrete customer's actions such as a response to a buying offer (Parr Rud, 2001). The logistic regression model provides the estimates that lie in the range between zero and one and an appealing S-shape description of the combined effect of several independent variables (factors) on the probability of the dependent outcome (Kleinbaum \& Klein, 2010). The methods employed in logistic regression analysis follow the same general principles used in linear regression analysis (Hosmer \& Lemeshow, 2000) and are out of the scope of this chapter.

\subsection{Fuzzy c-means clustering algorithm}

Cluster analysis is a family of mathematical techniques that find groups of observations with similar characteristics (Parr Rud, 2001). The goal of clustering is to divide (in crisp clustering to partition) the input dataset into groups called clusters, according to observed characteristics, in the way that the observations within the same cluster are as much similar to each other as possible, while as much dissimilar to the observations in other clusters.

Classical clustering, also known as hard or crisp clustering assigns each observation to a single cluster, without information how far or near the observation is from all the other possible decisions. Fuzzy clustering, based on the concept of fuzzy membership functions and the fuzzy set theory, allows entities to belong to many clusters with different degrees of membership (Theodoridis \& Koutroumbas, 2006). The basic steps in a cluster analysis are feature selection, proximity measure choice, clustering criterion, clustering algorithm, validation and interpretation of the clustering results. Different choices in these steps lead to completely different clustering results and the final answer to these questions is often 
influenced by the expert knowledge. As stated in (Theodoridis \& Koutroumbas, 2006), cluster analysis can be used for both hypothesis testing and prediction based on groups, which are the ideas used in this chapter. In context of the next best offer problem, one of the hypothesis is that the company can predict the individual customer probability of buying the product and the other one is that the company can influence the probability by choosing the most appropriate communication channel. Therefore, the cluster analysis should support the assumption that customers can be successfully clustered according to their purchase behaviour and channel usage, regardless other factors that influence their product demand curve. The clustering algorithm chosen for that purpose is fuzzy c-means clustering (FCM), which is the most known method of fuzzy clustering. Generally, fuzzy clustering of $\mathrm{X}$ into $p$ clusters is characterized by $p$ membership functions $\mu_{\mathrm{j}}$, where

$$
\begin{gathered}
\mu_{j}: X \rightarrow[0,1], j=1, \ldots, p \\
\sum_{j=1}^{p} \mu_{j}\left(x_{i}\right)=1, \quad i=1,2, \ldots, n
\end{gathered}
$$

and

$$
0<\sum_{i=1}^{n} \mu_{j}\left(x_{i}\right)<n, \quad j=1,2, \ldots, p
$$

Membership functions are based on a distance function, such that membership degrees express proximities of entities to cluster centres, called cluster prototypes. Fuzzy c-means algorithm, initially proposed by Dunn and generalized by Bezdek (Cox, 2005), involves two iterative processes: the calculation of cluster centres and the assignment of the observations to these centres using some form of distance. Fuzzy c-means is attempting to minimize a standard loss function

$$
l=\sum_{k=1}^{p} \sum_{i=1}^{n}\left[\mu_{k}\left(x_{i}\right)\right]^{m}\left\|x_{i}-c_{k}\right\|^{2}
$$

from which two fundamental equations necessary to implement fuzzy c-means are derived. A new cluster centre value is calculated using the expression (11):

$$
c_{j}=\frac{\sum_{i}\left(\left[\mu_{j}\left(x_{i}\right)\right]^{m} x_{i}\right)}{\sum_{i}\left[\mu_{j}\left(x_{i}\right)\right]^{m}}
$$

and expression (12) is used to calculate the membership in the j-th cluster:

$$
\mu_{j}\left(x_{i}\right)=\frac{\left(\frac{1}{d_{j i}}\right)^{\frac{1}{m-1}}}{\sum_{k=1}^{p}\left(\frac{1}{d_{k i}}\right)^{\frac{1}{m-1}}}
$$


The symbols in the equations (10), (11) and (12) denote:

1 is the minimized loss value;

$\mathrm{p} \quad$ is the number of fuzzy clusters;

$\mathrm{n} \quad$ is the number of observations in the data set;

$\mu_{\mathrm{k}}\left(\right.$ ) is a function that returns the membership of $x_{i}$ in the k-th cluster;

$\mathrm{m} \quad$ is the fuzzification parameter;

$\mathrm{c}_{\mathrm{k}} \quad$ is the centre of the $\mathrm{k}$-th cluster;

$\mathrm{d}_{\mathrm{ji}} \quad$ is the distance metric for $\mathrm{x}_{\mathrm{i}}$ in cluster $\mathrm{c}_{\mathrm{j}}$;

$\mathrm{d}_{\mathrm{ki}} \quad$ is the distance metric for $\mathrm{x}_{\mathrm{i}}$ in cluster $\mathrm{c}_{\mathrm{k}}$.

\section{Next best offer problem in the CRM}

In CRM literature and practice there are two well-known problems, oriented primarily to the sales and revenues increase: up-sell and cross-sell. Cross-sell is the event of a current customer buying a different product or service from the same company. Up-sell is the event of a current customer buying more of the same products and services of the company. Both events aim to reach product budget goals and increase the profitability of product lines. In the customer-centric strategy, the optimization of the value of each customer relationship and increase of the customer profitability comes to the first priority. In that situation, companies have to manage their offers more carefully to avoid over-soliciting their existing customers, while at the same time optimizing their product lines goals. Instead of answering the question: "to whom we can offer and sell product X in order to reach the budget?", the company tries to answer more complex and multi-criteria question: "which of my products will the customer need in the next future and how we have to offer it to him/her in order to reach the financial goals?". Therefore, the next best offer problem in CRM is the decision problem of what to offer, when to offer and how to offer to each customer, in order to improve customer retention and loyalty, increase up-sell and cross-sell, reach customer profitability and product lines profitability goals. To cross the way from the next best offer problem to the next best action, companies develop models and integrate expert knowledge with technology. Solving the general problem of the next best offer on the individual level is very challenging, because the complete CRM process does not finish with recognition of the product sequence for each customer. The complete solution should lead to the desired event of product purchase and revenue increase. It means that the company has also to decide which channel, what kind of message, which price and what timing to apply for each customer recognized by the model as the customer with high probability of buying the product. Failure to correctly define the goal can result in wasted money and lost opportunity (Parr Rud, 2001). These are the reasons why the company should know well the demand for each of its major products, as well as its dominant customer profile.

\subsection{Purpose of the model}

The main purpose of elaborated hybrid model is recognition of the customers who have high probability of buying the target product if contacted through the preferred channel. The first part is solved by modelling the single product purchase probabilities as the logistic regression curves, getting the independent customers' probabilities for each of the products. The second part is done by customers' clustering into the channels fuzzy clusters, according to their channels' usage data and communication history. The goals of these two models 
differ substantially, since the goal of the first model is predictive and the goal of the second is descriptive. The goal of the complete dual approach model is predictive.

It is important to note that the purpose of the statistical models in CRM is different from the purpose of CRM campaigns. The goal of a CRM campaign is to change behaviour and reaching an individual who is going to purchase the product anyway is only slightly more effective than reaching an individual who will not purchase despite having received the offer. Building the model which will recognize likely responders to the offer differs from the model which recognizes likely buyers of the product anyway. Therefore, the goal of CRM campaign is reaching individuals who are more likely to purchase because of having been contacted through the right channel. This kind of analysis is known as differential response analysis and compares the results from a treated group with results from a control group. The object of differential response analysis is to find segments with the greatest difference in response between the treated and untreated groups. Dual approach proposed here uses some ideas from differential response analysis, such as the idea of recognizing the customers with higher propensity to purchase if approached through their preferred channel.

\subsection{General structure of the modelling database}

After having defined the goal, the next step in model building is wide data selection and further data preparation. The questions in the process of data selection include, but are not limited to these: what is available in company's data warehouse and data marts, how much data will be enough and how much history is required, what these data must contain for the specific goal and/or problem, how many variables to include into initial database. Patterns in customer behaviour need time to become evident. Data warehouses need to support accurate historical data so that data mining process can pick up these critical trends (Berry \& Linoff, 2004). After the initial data selection, the next step is getting to know the data, by examining distributions, validating initial assumptions, asking a lot of questions and ensuring very good preliminary data analysis before even starting to model. The steps surrounding the model processing can be more critical to the overall success of the project than the technique used to build the model. The organization of the input data here proposed is shown in the Figure 1.

The first modelling database is constructed by joining together the data from the four separate databases: customer data, product data, customer behaviour about the products data and channel usage data. Each of the input data tables contains the time variable and appropriate primary and foreign key used for joining. Customer data table contains the variables on the customer level and some of them are demographic, socio, economic and financial data. Product data table contains the variables on the each product level, for example the position of the product in the general product scheme of the company, product indicators for the time period such as product price, indicator whether the product was on promotion in that time period, total volume sold in the period, percentages of the volume sold in the regular sale and in the promotion campaigns, total revenues in the time period, etc. Customer behaviour about the products gives customer purchase history for each time period and each product. It contains the indicators whether the purchase of the concrete individual product happened, but also whether the purchase of any product from that product category happened, according to the company's product scheme. Finally, channel 
usage data is a database that contains channel usage flags for each customer and each time period, number of contacts during the period by the channel, ideally number of purchase events resulting from the contact, total amount of consumption in the time period, etc.

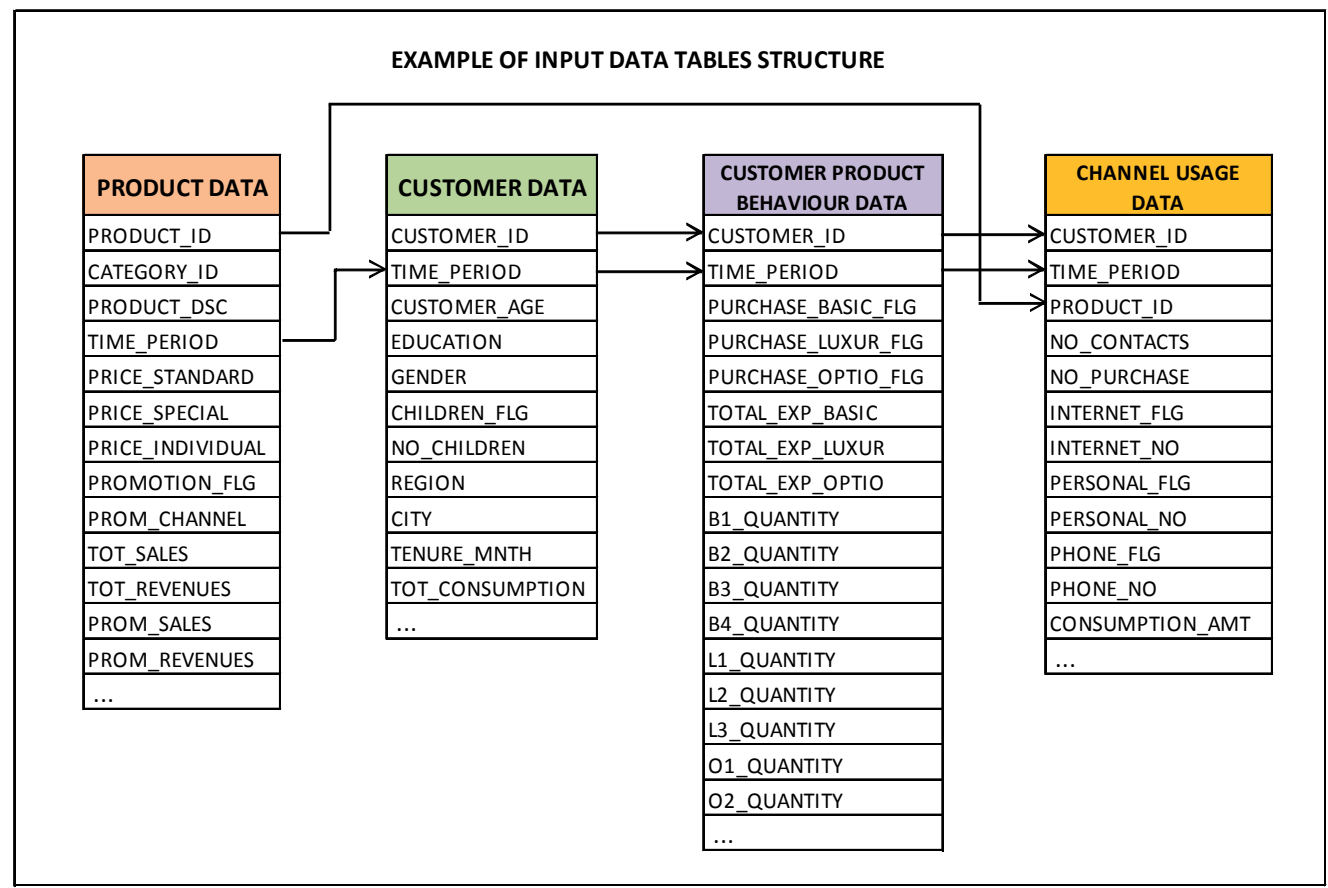

Fig. 1. Example of input data tables structure and data organization

Depending on the modelled event, these separate databases are joined together and outcome (target or dependent) variable is derived according to the event definition. In this study, the first modelled event is purchase of the chosen single product from the product scheme in the period $\mathrm{T}$ and comes in two versions. In the first version it is allowed to use all other data from the period T-1 as the independent input variables, apart from the data about the chosen product. This approach is testing the hypothesis that the probability for the purchase of the chosen product in period T can be derived from the customer's purchase history about other products. In the second version of the same event the history data about the chosen product are also allowed to enter the model as the predictors. This makes sense if the repetitive customer's need is being modelled and that is industrydependent possibility. The second modelled event is purchase of the chosen product from the company's product scheme if customer was contacted in the same period through his/her preferred channel. The information about the preferred channel enters the model either in the form of original variables from channels' usage history or in the form of the fuzzy membership functions obtained from fuzzy clustering of the customer behaviour about channels and about products in the period T-1. One of our hypotheses is that the fuzzy membership functions can be better and more stable choice. The event is defined as the combination of the purchase and the decision of the company to contact the customer through the certain channel. The transformations that add target variable into the database are provided under the section 4 . From the definition of the events it is obvious 
that the modelling database must contain the data from at least three successive time periods. More available history leads to more accurate predictions. After joining input data tables into one modelling database, the process of initial data selection is finished and the process of data quality checks and data preparation process can start.

\subsection{Data quality and data preparation}

Data quality generally refers to the degree of excellence with which the data in the modelling database correctly represent the situation in the core company's information systems for each time period and satisfy relational integrities. The data are of good quality if they are complete, consistent, accurate, time-stamped and industry standard-based. If, in addition to that, the data satisfy special business need, the data are of high quality. For any model development the quality of the input data is crucial. The monitoring of data quality should become the integral part of the modelling processes and can include even development of data quality protocols. The data quality issues differ from the data adequacy for modelling defined event. Even when the initial data selection ensures appropriate variables for modelling target event and when the data are of high quality, further data preparation is needed. The process of data preparation for modelling consists of data cleaning, missing value treatment and imputation, outlier removal and preliminary variable selection. The realization of this process is problem-based and requires the decisions with regard to the modelling purpose for which the data are being prepared.

\subsubsection{Data cleaning}

Data cleaning, also known as data scrubbing, is a multiple steps process of maintaining the database clean, accurate, consistent and free of errors, mismatched or invalid information. There are various techniques of data cleaning, but generally all of them include following steps: error identification, error reporting, new data values check and data merging. The first step is identification of the errors and their classification into critical and non-critical errors. The critical errors must be fixed, not only because the dirty data can not be used for modelling purposes, but also because the critical errors can not remain in the database due to the regulatory reporting or other industry-dependent reasons. Non-critical errors do not cause operational problems and can be fixed periodically. After the errors were identified, whether using an automated system or a manual system, the errors must be verified. It means that humans need to look at the information and make a judgement whether it is truly an error or not, and whether the classification of the error as critical or non-critical is correct. This step is unavoidable before errors deleting, good data values identification and bad values replacement. After the cleaning process, error check must be repeated in order to verify that in the process of cleaning some new errors did not occur and that all bad data were correctly replaced by good data. The final step is data merging, since the data cleaning never takes place on actual working data in the production environment. What is being cleaned is the generated identical copy of the original dataset, which prevents unrepairable damage or loss of the original data. When audit verifies successful cleaning of the copy, the cleaned data can be used to replace original dataset. 


\subsubsection{Missing values treatment}

Missing data occurs in a data set when at least one observation is missing a value on at least one variable. There are usually discovered during data cleaning process, when basic statistic for each variable is computed, showing the count and percentage of missing versus nonmissing values and zero versus non-zero values. There can be a number of different reasons why the data are missing, from human's errors in entering the data correctly, to the equipment malfunctioning. The important issue on missing values is whether they can be characterized as missing completely at random or missing not at random. Data is missing completely at random when the probability that an observation $X_{i}$ is missing is unrelated to the value of $X_{i}$ or to the value of any other variable, otherwise data is not missing at random. The randomness of missing data is important for the later choice of missing values treatment. Generally, there are two approaches for dealing with missing values: missing value elimination and missing value imputation. The choice of the approach and the method within each approach depends not only on the randomness of the missing data, but also on the initial database size, the minimal number of observations needed for valid analysis of the concrete problem, occurrence of the missing values across all input variables in the dataset. In the elimination approach, if a missing value occurs on any of the variables the entire observation is eliminated. The consequence of this rigid approach is that even a dataset with modest total number of missing values suffers from substantial reduction in size, which can make the sample size insufficient for the later modelling purpose. Still, if data is missing completely at random this approach is the best solution, since the analysis and parameters estimates are unbiased by the absence of the data. When the data is not missing completely at random, exclusion of the incomplete observations leads to biased results. The only way to obtain unbiased parameters estimates is to model missingness and to incorporate that model into the model for estimation. This can be very complex task and belongs more to the research then to the business application field. The missing value imputation is the process of filling in the missing values of a variable, using one of the common imputation methods: substitution with a measure of central tendency, distribution based imputation, tree imputation, regression imputation, imputation using the expectationmaximization algorithm, multiple imputation. Substitution with a measure of central tendency is the simplest method and uses mean, median, midrange or mode value of the variable, estimated by the robust estimators, to substitute missing values. Better solution is distribution based imputation, which seeks to preserve the empirical distribution of the data and replacement values are calculated based on the random percentiles of the variable's distribution. Tree imputation and regression imputation replace missing values with the predicted values obtained from the decision tree and regression model, respectively. The expectation-maximization algorithm and multiple imputation are the finer methods, but based on the same ideas as the regression imputation which is appropriate for the most of the real datasets.

\subsubsection{Removal of outliers}

Many proposed definitions of outlier share the common idea that outlier is an observation which deviates so much from other observations as to arouse suspicion that it was generated by a different mechanism (Ben-Gal, 2010). Although outliers are often considered as an error, here we distinguish the errors in the database records elaborated under the data 
cleaning section from the observations that deviate markedly from other observations in the database. Since the outliers may lead to model misspecification, biased parameter estimates and incorrect results, it is important to identify them prior to analysis and modelling phase. Methods for detecting outliers can be divided into univariate methods, specific for the earlier researches and multivariate methods that belong to more recent works. Another taxonomy is between parametric (statistical) and nonparametric methods that are modelfree. The difference between two is that statistical parametric methods assume a known distribution of the observations, which is often a violated assumption in the real-world data. According to parametric methods, those observations that deviate from the model assumption, such as normal distribution for example, are flagged as outliers. Within the class of non-parametric outlier detection methods there is a set of so called distance-based methods, which are based on local distance measures and can handle large databases. In that respect, outliers are defined as observations whose distance to the location estimate exceeds some multiple of the scale estimate. Location estimate can be, for example mean, median and trimmed mean, while scale estimate can be standard deviation, median absolute deviation, interquartile range or Gini's mean difference. These methods require no prior knowledge of the underlying data distribution and are used in this study. Outliers can be detected for each input variable and the intersection of these sets can be used to determine the final set of the observation considered and removed from the dataset as serious outliers. Although considered as errors, outliers can reveal some key information in the data generation mechanism or underlying behaviour that the analyst tries to model. These worthy case-studies can be afterwards incorporated into the research conclusions, even if the outliers were excluded from the modelling database since they lead the algorithms to incorrect or biased results.

\subsection{Preliminary analysis and variables selection}

Having a cleaned and prepared modelling customer database is still far away from having a problem solution. The preliminary analysis should take a place before modelling phase, since it helps in choosing appropriate methodology, speeds up the learning process and improves final model interpretability. When the modelling problem definition assumes the underlying differences between groups of observation, then canonical discriminant analysis (CDA) can be used as an auxiliary method for testing the separability of the groups. In the problem of predicting the probabilities for single product purchase, built as the binary logistic regression, there are at least two underlying groups of customers: the group of non-buyers and the group of product buyers. Therefore, canonical discriminant analysis can help in testing the separability between these two groups of customers, using different input variables combinations. Canonical discriminant analysis is a multivariate, dimension-reduction statistical technique related to principal component analysis and canonical correlation. It requires a nominal classification variable, for two or more groups of observations and several interval input variables. In our case the classification variable is derived in the way analogue to derivation of the target variable for the logistic regression. All other available interval variables can enter the canonical discriminant analysis, which then derives canonical variables as linear combinations of the interval variables with the scope to obtain the highest possible multiple correlation with the groups. The highest correlation is called the first canonical correlation, the coefficients of that linear combination are the canonical coefficients and the variable defined by that linear combination is the first canonical variable. The second canonical correlation is 
obtained by finding the linear combination uncorrelated with the first canonical variable that has the highest possible multiple correlation with the groups. The process of extracting canonical variables is iterative and stops when the number of canonical variables reaches the number of original variables or the number of classes minus one, whichever is smaller. In the case of binary class variable only the first canonical variable would be of practical usage and in the case of defining several classes, according to the company's product scheme for example, k1 canonical variables make sense, where $k$ denotes the number of product categories. Generally, CDA helps not only in better understanding of the groups separability, but also in better recognition of input variables that mostly contribute in predicting the probabilities of buying the single product, which can be afterwards compared with the selection of the most powerful variables suggested by the logistic regression iterations. The preliminary analysis is not the substitution for the modelling, but is its complementary part in knowledge discovery process. Variable selection, also known as feature selection, can be done during the preliminary analysis or during the modelling phase, depending on the problem definition. Variable selection is a technique of selecting a subset of relevant features for building robust learning models, with many potential benefits such as: facilitating data visualization and data understanding, reducing storage requirements, reducing training time, avoiding the effects of the curse of dimensionality and improving prediction performance (Guyon \& Elisseeff, 2003). Feature selection algorithms typically fall into two categories: feature ranking and subset selection. The first category algorithms rank the features by a metric and eliminate all features that do not achieve an adequate score. Algorithms for subset selection search the set of possible features for the optimal subset, according to the target problem. Both approaches can have their shortfalls. Selecting the most relevant variables is usually suboptimal for building a good predictor, particularly if the variables are redundant. At the other side, a subset selection may exclude many redundant, but still relevant variables and, since the approach searches for the optimal subset, the memory and processing time requirements may become unacceptable. The importance of the proper feature selection is especially visible in the problems where hundreds and even thousands of raw input variables are available as potential predictors. In the real business environment providing faster and more cost-effective predictors often becomes the objective itself and can determine the success of the modelling phase. Therefore, having a strategy for coming to the set of good predictors is highly recommended. In this study the most popular form of feature selection in statistics, called stepwise regression is used. Stepwise regression is a natural choice for the problems solved by the logistic regression. It is a greedy algorithm that adds the best feature and/or deletes the worst feature at each round, where the best and the worst are defined in terms of the variable contribution to the model significance. Therefore, the analyst chooses two p-values for the stepwise algorithm: $p$-value for the variable entrance into the model and p-value for the variable exclusion from the model. The process terminates when no significant improvement can be obtained by adding or by subtracting another variable. The subset of the variables already in the model at that moment is the best subset chosen by the stepwise procedure.

\section{Dual approach model setup}

The demand schedule represents the amount of some good that buyers are willing and able to purchase at various prices, assuming all other determinants of demand, such as income, tastes and preferences, the price of substitute goods, the price of complementary goods, the number of buyers etc., remain the same. It is graphically depicted as the two-dimensional 
downward sloping demand curve. The negative slope of the demand curve reflects the law of demand, which says that as price of the good decreases, consumers will buy more of the good, ceteris paribus (Samuelson \& Nordhaus, 2000). The theory recognizes hypothetical types of the goods that have upward-sloping demand curves, such as Giffen goods and Veblen goods, where this general price rule is violated. The demanded quantity of good $\mathrm{X}$ for individual customer $i$ is the function $\mathrm{f}_{\mathrm{i}}$ :

$$
Q_{i}(x)=f_{i}\left(p_{x}, p_{s}, p_{c}, I_{i}, T_{i}, P_{i}\right)
$$

where $p_{x}$ is the price of good $X$ (it is not customer indexed, if the same price is applied to each buyer), $p_{s}$ is the price of substitute goods, $p_{c}$ is the price of complementary goods, $I_{i}, T_{i}$ and $P_{i}$ are the income, tastes and preferences of the buyer i respectively. Such a pure mathematical model, in which the relationships between inputs and outputs are captured entirely in deterministic fashion, is important theoretical tool, but is rather impractical for describing observational, experimental, or survey data. For such purpose, we need to allow the model to draw on stochastic as well as deterministic elements, changing it from the deterministic into the stochastic model. Since the final goal in this study is to estimate the form of the single product demand curves, that stochastic model will contain estimated parameters and becomes so statistical model. For these reasons, the equation (13) is transformed into:

$$
Q_{i}(x)=f_{i}\left(p_{x}, \text { wap }_{s}, \text { wap }_{c}, I_{i}, P N_{i}, \sigma_{i}\right)
$$

where wap $\mathrm{p}_{\mathrm{s}}$ represents weighted average of the most important substitutes in the market, rather than the price of one substitute or each of the substitutes exactly, wap $\mathrm{p}_{\mathrm{c}}$ represents weighted average of the most important complementary goods in the market, $\mathrm{PN}_{\mathrm{i}}$ stands for the recognized and predicted needs of the customer $\mathrm{i}$ and replaces his/her practically unknown tastes and preferences, and $\sigma_{i}$ represents stochastic effect on the demand of customer i. Note that the word "customer" replaced the word "buyer" as we move from theoretical framework to more practical demand function form.

If the equation (14) is accepted as the description of the purchased quantity of the product $X$ by the customer $i$, then the following transformation introduces the first modelling event:

$$
\text { Purchase }_{X(i)}=\left\{\begin{array}{lll}
1, & \text { for } & Q_{X(i)}>0 \\
0, & \text { otherwise. }
\end{array}\right.
$$

The modelled event becomes a dichotomous event, represented by the binary variable Purchase $_{(\mathrm{i})}$ and logistic regression model becomes the appropriate modelling method. In this phase the input dataset still does not include the information about customers' channel preferences, contained in the fuzzy membership functions. When this information enters the model in the second phase, the modelled event changes into the combined event, introduced by another transformation:

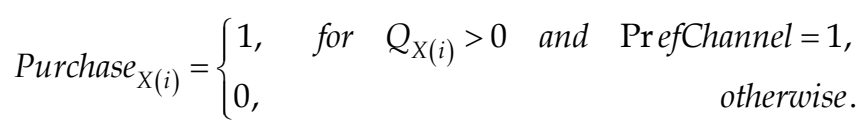


where PrefChannel is the variable having the value 1 if the customer was contacted through his preferred channel and the value 0 if not. The preferred channel is recognized as the fuzzy cluster for which the membership function reaches the maximum in the second submodel. The final model consists of two sub-models: the first sub-model is logistic regression model for assessment of the single product demand curves and the second sub-model is fuzzy clustering model of the customers' behaviour on the channels. The next sections present the results obtained through the data analysis process, parameters' estimation and validation of the fuzzy membership functions contribution to the model. The results were obtained following the methodology described throughout the chapter, from the data cleaning phase to the logistic regression and fuzzy clustering part. The small portion of the real purchase data was collected in the inquiry and the rest of the data were simulated based on the collected sample, under the controlled conditions.

\subsection{Data analysis review}

Before modelling, the input data quality, missing values existence and outliers' presence were checked. Variable CSI, which stands for Customer Satisfaction Index, had missing values on $37 \%$ of the customers. Therefore, the substitution with two different measures of central tendency, mean and median, were tried and both of them significantly changed the measures of the central tendency and the variable distribution after the imputation. The significantly high correlation between the variable TENURE_MNTH, which denotes the length of the relationship of the customer with the company, and CSI was discovered during the input variables analysis, showing that these missing CSI values were predominantly distributed among the customers with the shortest relationship with the company. That is a situation of the data not missing completely at random, therefore the better solution was to substitute missing values with the smallest value from the CSI variable domain, which was treated as the default value in research of customer satisfaction and correlated with the shorter tenure. That method affected much less the non-missing values distribution and was preserved as the best solution. The most serious outliers were detected for each input variable and each time period separately, using the standard deviation method. The intersection of these separate outliers' sets was found. The number of the occurrences of the CUSTOMER_ID as an outlier, the maximum multiple of the standard deviation obtained by CUSTOMER_ID and presence of the customer in the set of the most serious outliers for each time period was considered for the decision about their removal from the modelling dataset. The outliers occurred mostly on the variables describing their expenditure on luxury goods and seven customers showed up with maximum deviance in both time periods.

The outliers from the second time period are shown in the Table 1. The circled customers were found in the both outlier sets and were excluded from the modelling of single demand curves, as well as from the fuzzy clustering.

The complete correlation matrix of Pearson product-moment correlations was calculated for both time periods separately and for all the data together. The comparison of the correlation matrices showed time-consistent correlations between variables. The extraction from the correlation matrix for the first time period is given in the Table 2 . The corresponding $\mathrm{p}$-values of the correlations were used to test the null hypothesis that the correlation is 0 , assuming independent and identically distributed observations from a bivariate distribution with at least one variable normally distributed. Table 2 shows that 
the correlation between Customer Satisfaction Index and Tenure in Months is positive and significant, which leads to conclusion that the customers with longer relationship with the company show higher satisfaction and are more likely to participate in the satisfaction inquiries, since the missing values of CSI were predominantly distributed among the customers with the shortest tenure. Correlations help not only in recognizing relationships among the variables, but also help in removing redundant variables from the later logistic model. For instance, discovered high and significant correlation between Customer Satisfaction Index and Tenure in Months means that we have to delete one of them from the final logistic regression model. Wald chi-square together with business experience helps in identifying which one to delete. Since these two variables are highly correlated, their correlations with other variables and with target variable bring similar information value to the model. However, it is more sensible to leave Tenure in Months and delete CSI, due to the fact that Tenure can be calculated for each customer and has no missing values, while CSI value depends on the customer's willingness to participate in the satisfaction measurements and is often missing.

\begin{tabular}{|c|c|c|c|c|}
\hline $\begin{array}{c}\text { TIME } \\
\text { PERIOD }\end{array}$ & $\begin{array}{c}\text { CUSTOMER } \\
\text { ID }\end{array}$ & $\begin{array}{c}\text { NUMBER OF } \\
\text { OCCURRENCES AS AN } \\
\text { OUTLIER }\end{array}$ & $\begin{array}{c}\text { MAX MULTIPLE OF } \\
\text { STD DISTANCE }\end{array}$ & \multicolumn{1}{c|}{$\begin{array}{c}\text { VARIABLES WITH MAX } \\
\text { DIFFERENCE }\end{array}$} \\
\hline $2 Q$ & 99 & 5 & 2,82 & O4_EXP (O4_QUANTITY) \\
$2 Q$ & $\mathbf{9 1}$ & 4 & 3,16 & L1_EXP (L1_QUANTITY) \\
$2 Q$ & 3 & 3 & 3,16 & L1_EXP (L1_QUANTITY) \\
$2 Q$ & $\mathbf{6 4}$ & 3 & 3,29 & L3_EXP (L3_QUANTITY) \\
$2 Q$ & $\mathbf{7 8}$ & 3 & 3,77 & LUXURY_ACTIVITY \\
$2 Q$ & $\mathbf{3 5}$ & 2 & 2,99 & NO_CONTACTS \\
$2 Q$ & $\mathbf{4 1}$ & 2 & 3,35 & O5_EXP (O5_QUANTITY) \\
$2 Q$ & $\mathbf{4 7}$ & 2 & 2,88 & O5_EXP (O5_QUANTITY) \\
$2 Q$ & $\mathbf{9 3}$ & 2 & 3,29 & L3_EXP (L3_QUANTITY) \\
$2 Q$ & 15 & 1 & 2,51 & NO_CONTACTS \\
$2 Q$ & 65 & 1 & 2,64 & LUXURY_ACTIVITY \\
\hline
\end{tabular}

Table 1. Outliers in the second time period according to the standard deviation method

\begin{tabular}{|l|c|c|c|c|}
\hline CSI vs. & NO_CHILDREN & TENURE_MNTH & EXP_LUXUR & NO_CONTACTS \\
\hline PCC & 0.13983 & 0.97974 & 0.45132 & 0.18264 \\
\hline p-value & 0.18130 & $<0.0001$ & $<0.0001$ & 0.07970 \\
\hline
\end{tabular}

Table 2. Extraction of Pearson Correlation Coefficients matrix for Customer Satisfaction Index 


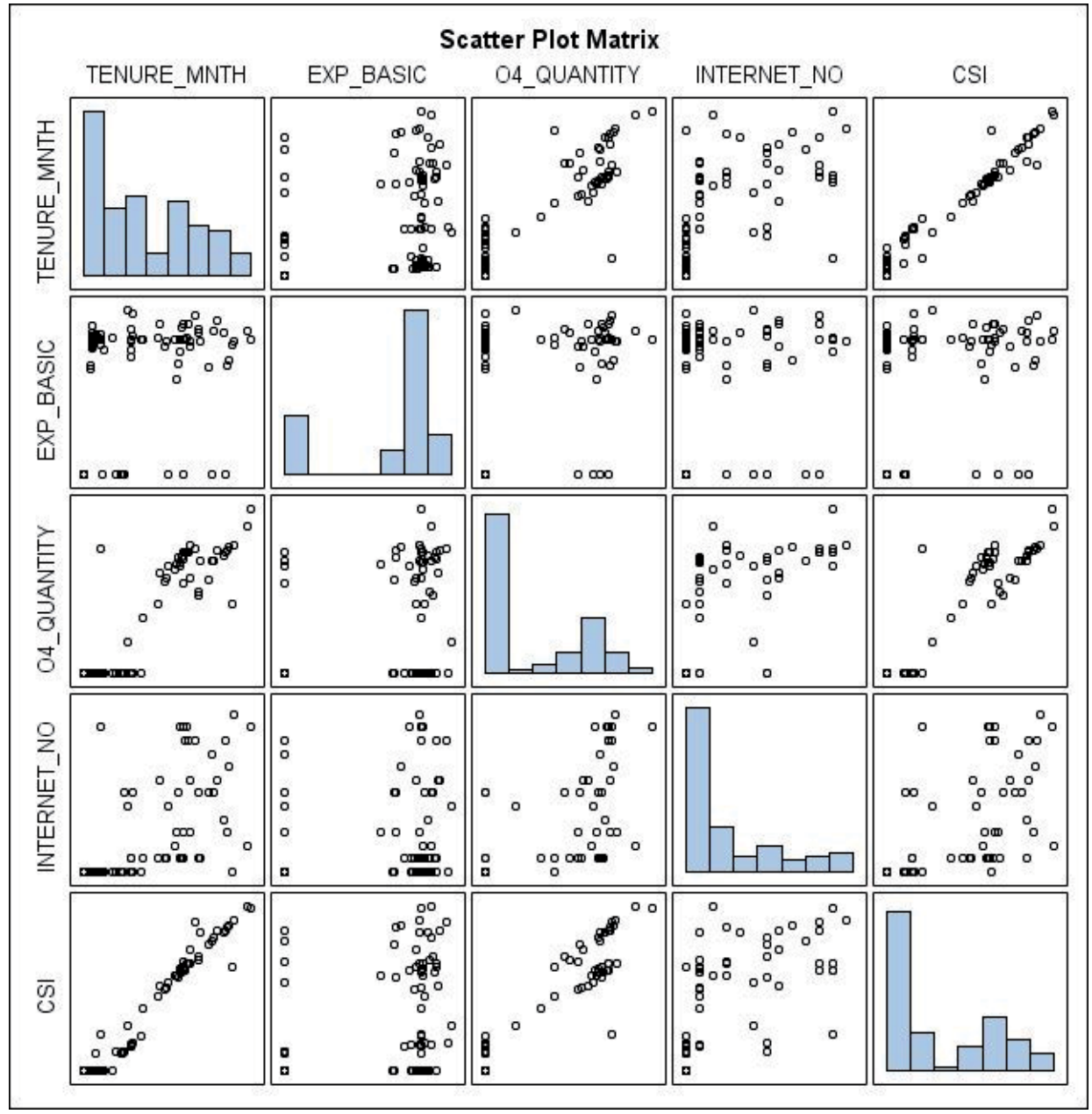

Fig. 2. Scatter plot matrix as an auxiliary tool in preliminary analysis

The correlation matrix is usually accompanied by the scatter plots matrix, which presents the relationship between each pair of the input variables graphically and is helpful tool in initial exploration of the input data. Figure 2 gives the scatter plots matrix of five variables of our interest for predicting the probabilities of product $\mathrm{O} 4$ purchase.

\subsection{Single product demand curves}

There were two products chosen for the demand modelling: product denoted as B1, belonging to the BASIC product category and product denoted as $\mathrm{O} 4$, belonging to the OPTIONAL product category according to the product scheme of the company. In order to prepare the data for the binary logistic regression, the target variables B1_FLG and O4_FLG were calculated using the transformation (15). In the first stage of the modelling only restricted number of variables were used and no data about the communication history or channels' usage were available. The stepwise regression method was used, with p-value for the variable entrance in the model set at the level of 0,3 and $p$-value for the variable to stay 
in the model set at the level of 0,35. The Figure 3 shows Receiver Operator Characteristics (ROC) curves of the model for B1 product, obtained without data about channels' usage. ROC curve is also known as Lift Curve and summarizes the performance of a diagnostic test with a positive/negative outcome. The final model was assessed in the nine steps.

The input variables chosen by the stepwise algorithm in the last step contained both Customer Satisfaction Index and Tenure in Months, recognized during the preliminary analysis as highly correlated variables. They satisfied the conditions for entrance and for stay in the model, improved fit statistics and obtained percent concordant pairs of $83,3 \%$, percent discordant of $16,7 \%$, percent tied of $0,00 \%$ and Somers' $\mathrm{D}$ of 0,66 . The modeller, not the algorithm, brings the final decision whether to preserve both variables or to delete one of them and which one.

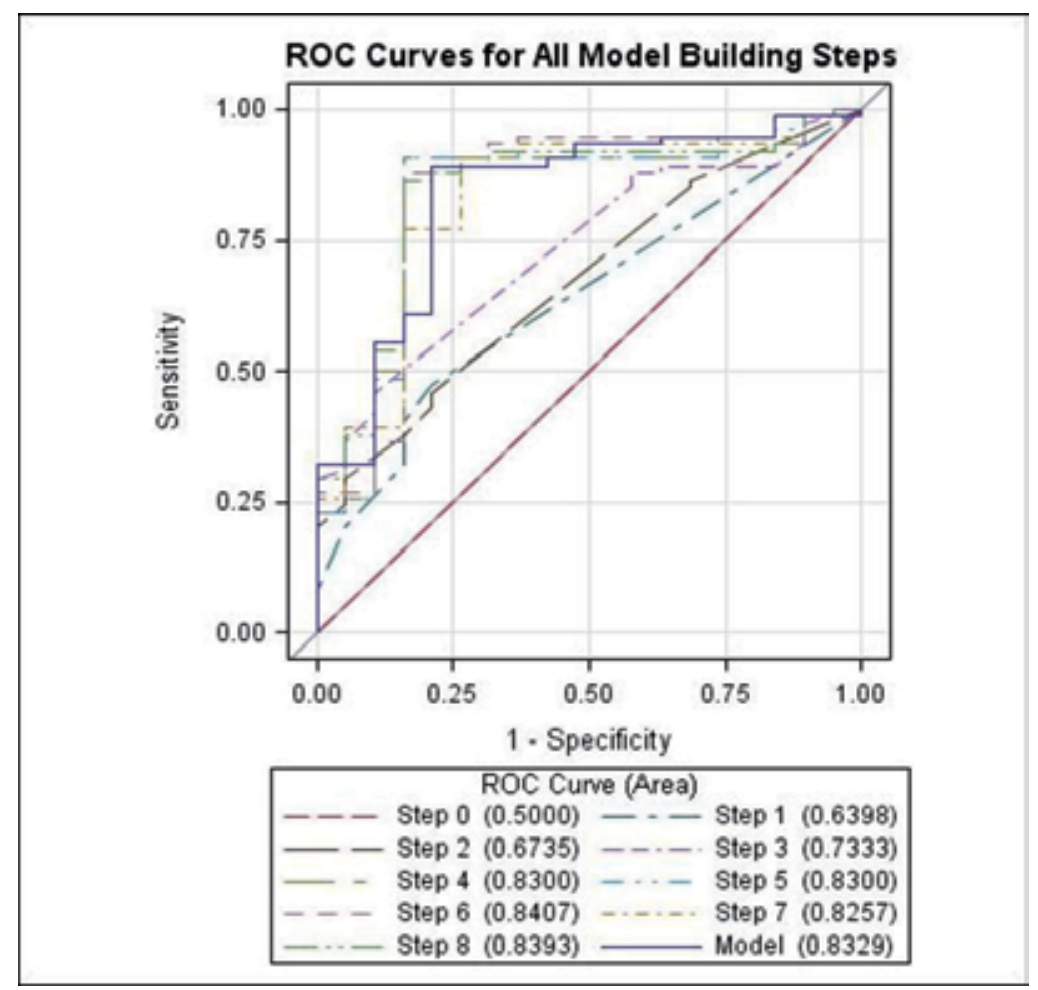

Fig. 3. Receiver Operator Characteristics (ROC) curves for the logistic regression on B1_FLG without channels data 


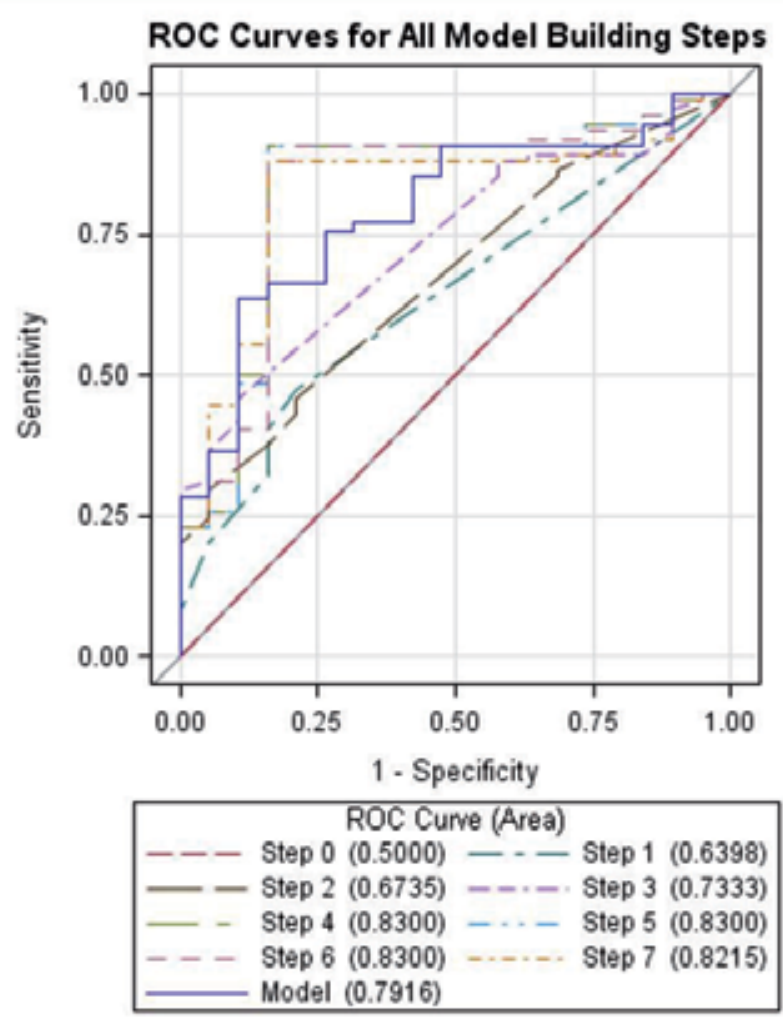

Fig. 4. Receiver Operator Characteristics (ROC) curves for the logistic regression on B1_FLG without channels data and CSI variable

Therefore, we run another logistic regression omitting Customer Satisfaction Index from the input dataset, which lowered Area Under the Curve (AUC) from 83,29\% to 79,16\% on the modelling data. Percent concordant dropped to $79,2 \%$, percent discordant increased to $20,8 \%$, percent tied remained $0,00 \%$ and Somers' D decreased to the value of 0,583 , all showing lower fit on the modelling data. Figure 4 shows ROC curve for the logistic regression without channels data and Customer Satisfaction Index and Table 3 gives the variables, parameter estimates and p-values of the new model.

\begin{tabular}{|l|l|l|l|}
\hline PARAMETER & VARIABLE DESCRIPTION & ESTIMATE & Pr > ChiSq \\
\hline Intercept & - & 1.3690 & 0.0238 \\
\hline L4_EXP & Expenditure on luxury product L4 & -0.00916 & 0.0135 \\
\hline NO_CHILDREN & Number of children & -0.4044 & 0.2471 \\
\hline O1_EXP & Expenditure on optional product O1 & -0.0137 & 0.0821 \\
\hline O5_EXP & Expenditure on optional product O5 & 0.0330 & 0.1863 \\
\hline Q_LUXUR & Total purchase of all luxury products & 0.4287 & 0.0396 \\
\hline TENURE_MNTH & Relationship with the company in months & 0.0167 & 0.0236 \\
\hline
\end{tabular}

Table 3. Parameter Estimates for the logistic model on B1_FLG without channels data and CSI variable 
Another trial to increase the model fit was to introduce the variables from the customers' communication history with the company, in their original form. When these variables entered the modelling database, they significantly influenced the stepwise process and lead to almost perfect predictions, with unreliable AUC of 0,9822. This happened mostly because the modelling sample was too small, the channels usage variables were mostly binary variables and some of them were highly correlated with already existing input variables describing customers' purchase history. Binary variables (flags) often bring a strong impact on the modelled event, but also lead to model over-fitting and questionable model validity. Three of five variables that remained in the model in the last iteration were number of internet contacts, number of total purchases and flag for phone contacts, which are correlated among each other rather significantly and therefore should not be in the model at the same time. In practice, although available, such discrete variables have to be avoided or substituted whenever possible, since the resulting model does not generalize well and can not be used for obtaining reasonable predictions. At the other side, the significant correlation between channel variables and purchase variables is desired for the final purpose of offering the right product through the right channel. The open question here is: "How to include valuable channels' usage information into the model, without corrupting its validity?" In the next step, the channel variables were used for the fuzzy clustering of the customers and the channels' usage information re-enter the logistic regression model in the form of the fuzzy membership functions.

\subsection{Fuzzy clusters of the customers}

In order to improve predictions for the purchase probabilities and to obtain model that generalizes well at the same time, we developed fuzzy clustering sub-models, one for each of chosen products $\mathrm{B} 1$ and $\mathrm{O} 4$. In development process, fuzzy c-means algorithm was applied only on the data about channels usage and communication history, testing different combinations of input parameters $\mathrm{p}, \mathrm{m}$ and number of iterations. The final choice of FCM for product $\mathrm{B} 1$ was the combination of $\mathrm{p}=3, \mathrm{~m}=1,30$ and number of iterations $=100$ and the release is named FCM-p3. For product $\mathrm{O} 4$ the combination of $\mathrm{p}=2, \mathrm{~m}=1,25$ and number of iterations $=20$ was chosen and named FCM-p2. Informally, a combination of clustering parameters performs better than some other combination if the resulting clusters less overlap, if they are of similar size and obtain good separability of the clustered observations. If the resulting clusters are of very different size, and especially if one of them contains only a few observations, the number of clusters should be set to lower value (lower parameter $p$ ) and small clusters should be checked for outliers. All these steps were done in order to get the final releases FCM-p2 and FCM-p3. The standard performance metrics was calculated from confusion matrix of each release, according to the same criteria (variables). The following tables show why these releases were chosen and how their results enter the logistic models, leading to the final next best offer model. Table 4 gives the confusion matrices of the release FCM-p2 on the sample data, according to variables INTERNET_FLG and PHONE_FLG.

The fuzzy algorithm divided customers into two fuzzy clusters, as it was determined with parameter $\mathrm{p}=2$. In cluster profiling, which means discovering what makes the customers in one cluster similar to each other, on two variables performance metrics was good: INTERNET_FLG and PHONE_FLG. The algorithm correctly put the majority of internet users $(73,9 \%)$ into the FUZCLUS_1 and the majority of non-users $(89,4 \%)$ into the cluster FUZCLUS_2, according to calculated fuzzy membership functions $\mu_{\text {FUZCLUS_1 }}$ and $\mu_{\text {FUZCLUS_2. }}$ 


\begin{tabular}{|l|c|c|c|}
\hline CRITERION & \multicolumn{3}{|c|}{ FUZZY CLUSTER } \\
\hline INTERNET_FLG & FUZCLUS_1 & FUZCLUS_2 & TOTAL \\
\hline YES & 34 & 12 & 46 \\
\hline NO & 5 & 42 & 47 \\
\hline TOTAL & $\mathbf{3 9}$ & $\mathbf{5 4}$ & $\mathbf{9 3}$ \\
\hline PHONE_FLG & FUZCLUS_1 & FUZCLUS_2 & TOTAL \\
\hline YES & 29 & 42 & 71 \\
\hline NO & 10 & 12 & 22 \\
\hline TOTAL & $\mathbf{3 9}$ & $\mathbf{5 4}$ & $\mathbf{9 3}$ \\
\hline
\end{tabular}

Table 4. Confusion matrices of FCM-p2 according to INTERNET_FLG and PHONE_FLG

If we validate the same fuzzy clusters according to phone usage criterion, we see that FUZCLUS_1 which mostly contains internet users at the same time contains significant number of phone non-users (45,5\%) and analogously FUZCLUS_2 which contains internet non-users at the same time contains the majority of phone users $(59,2 \%)$. The performance metrics, given in the Table 5, shows that FCM-p2 performs very well in separating users and non-users on both channels, with more success for the internet channel. Therefore, the values of $\mu_{\text {FUZCLUS_1 }}$ and $\mu_{\text {FUZCLUS_2 }}$ calculated for each customer contain the information whether the customer prefers and uses more frequently internet or phone communication with the company. The advantage of fuzzy clustering over crisp clustering is that fuzzy membership functions enter the logistic regression as continuous input variables and not as class or binary variable and they change over time smoothly and not in discrete way. The next step is to recognize for which product this information is most useful, especially when focusing on the internet communication.

\begin{tabular}{|l|c|c|c|c|}
\hline \multicolumn{1}{|c|}{ Metrics of FCM-p2 on } & Hit Rate & False Alarm Rate & Accuracy & Specificity \\
\hline INTERNET_FLG & $73,91 \%$ & $10,64 \%$ & $81,72 \%$ & $89,36 \%$ \\
\hline PHONE_FLG & $59,15 \%$ & $54,55 \%$ & $55,91 \%$ & $45,45 \%$ \\
\hline
\end{tabular}

Table 5. Standard performance metrics of FCM-p2

FCM-p3 divided customers into three clusters of similar size, as it is shown in the Table 6. This release gives the advantage to discovering the phone users over the internet users, what can be seen from the performance metrics in the Table 7.

\begin{tabular}{|l|c|c|c|c|}
\hline \multicolumn{1}{|c|}{ CRITERION } & \multicolumn{4}{c|}{ FUZZY CLUSTER } \\
\hline INTERNET_FLG & FUZCLUS_1 & FUZCLUS_2 & FUZCLUS_3 & TOTAL \\
\hline YES & 27 & 14 & 5 & 46 \\
\hline NO & 2 & 15 & 30 & 47 \\
\hline TOTAL & $\mathbf{2 9}$ & $\mathbf{2 9}$ & $\mathbf{3 5}$ & $\mathbf{9 3}$ \\
\hline PHONE_FLG & FUZCLUS_1 & FUZCLUS_2 & FUZCLUS_3 & TOTAL \\
\hline YES & 23 & 19 & 29 & 71 \\
\hline NO & 6 & 10 & 6 & 22 \\
\hline TOTAL & $\mathbf{2 9}$ & $\mathbf{2 9}$ & $\mathbf{3 5}$ & $\mathbf{9 3}$ \\
\hline
\end{tabular}

Table 6. Confusion matrices of FCM-p3 according to INTERNET_FLG and PHONE_FLG 


\begin{tabular}{|l|c|c|c|c|}
\hline \multicolumn{1}{|c|}{ Metrics of FCM-p3 on } & Hit Rate & False Alarm Rate & Accuracy & Specificity \\
\hline INTERNET_FLG & $58,70 \%$ & $4,26 \%$ & $77,42 \%$ & $95,74 \%$ \\
\hline PHONE_FLG & $67,61 \%$ & $72,73 \%$ & $58,06 \%$ & $27,27 \%$ \\
\hline
\end{tabular}

Table 7. Standard performance metrics of FCM-p3

Since the product $\mathrm{O} 4$ has stronger correlation with INTERNET_NO (number of internet contacts in time period) then product B1, the resulting fuzzy membership functions from FCM-p2 enter the logistic model for O4, while the membership functions from FCM-p3 enter the logistic regression model for B1. In case of O4 variable $\mu_{\text {FUZCLUS_1 }}$ enters the logistic model as significant variable, while in the case of B1 variable $\mu_{\text {FUZCLUS_2 }}$ enters the model. Since the B1 model was elaborated previously in more detail, Table 8 gives parameter estimates for the logistic model on B1_FLG with fuzzy membership functions from FCM-p3. Figure 5 shows ROC curve for the new hybrid model, with improved AUC of $85,06 \%$ in comparison to the model without information on channels usage.

\begin{tabular}{|l|l|r|r|}
\hline \multicolumn{1}{|c|}{ PARAMETER } & \multicolumn{1}{|c|}{ VARIABLE DESCRIPTION } & ESTIMATE & Pr > ChiSq \\
\hline Intercept & - & 0.3974 & 0.3716 \\
\hline L4_EXP & Expenditure on luxury product L4 & -0.0129 & 0.0077 \\
\hline O2_EXP & Expenditure on optional product O2 & -0.0392 & 0.1579 \\
\hline O3_EXP & Expenditure on optional product O1 & -0.0877 & 0.2547 \\
\hline O5_EXP & Expenditure on optional product O5 & 0.0944 & 0.0215 \\
\hline Q_LUXUR & Total purchase of all luxury products & 0.4602 & 0.0563 \\
\hline TENURE_MNTH & $\begin{array}{l}\text { Relationship with the company in } \\
\text { months }\end{array}$ & 0.0298 & 0.0095 \\
\hline $\boldsymbol{\mu F U Z C L U S \_ 2 ~}$ & $\begin{array}{l}\text { Fuzzy membership function for fuzzy } \\
\text { cluster 2 obtained by FCM-p3 }\end{array}$ & 3.2878 & 0.0233 \\
\hline
\end{tabular}

Table 8. Parameter Estimates for the logistic model on B1_FLG with fuzzy membership functions from FCM-p3

The percent concordant is $85,1 \%$, percent discordant $14,9 \%$, percent tied $0,00 \%$ and Somers' $\mathrm{D}$ is 0,701 . The Table 9 gives the final variable list and parameter estimates. According to $\mathrm{p}$ values the most significant variables are now Expenditure on Product L4, Tenure in Months, Expenditure on Product O5, $\mu$ FUZCLUS_2 fuzzy membership function and Total Purchased Quantity of Luxury Products, while Expenditure on Products O2 and O3 can be omitted. It is interesting that expenditure variables entered the model and not the purchased quantities of these products, although the both types of variables were in the modelling dataset. Since the expenditure on product in one time period equals purchased quantity multiplied by the product price at the moment of each purchase, this could potentially signalize that the prices of these products are in fact the factors that influence the probabilities of purchase of product $\mathrm{B} 1$, and not the general attributes of other products. 


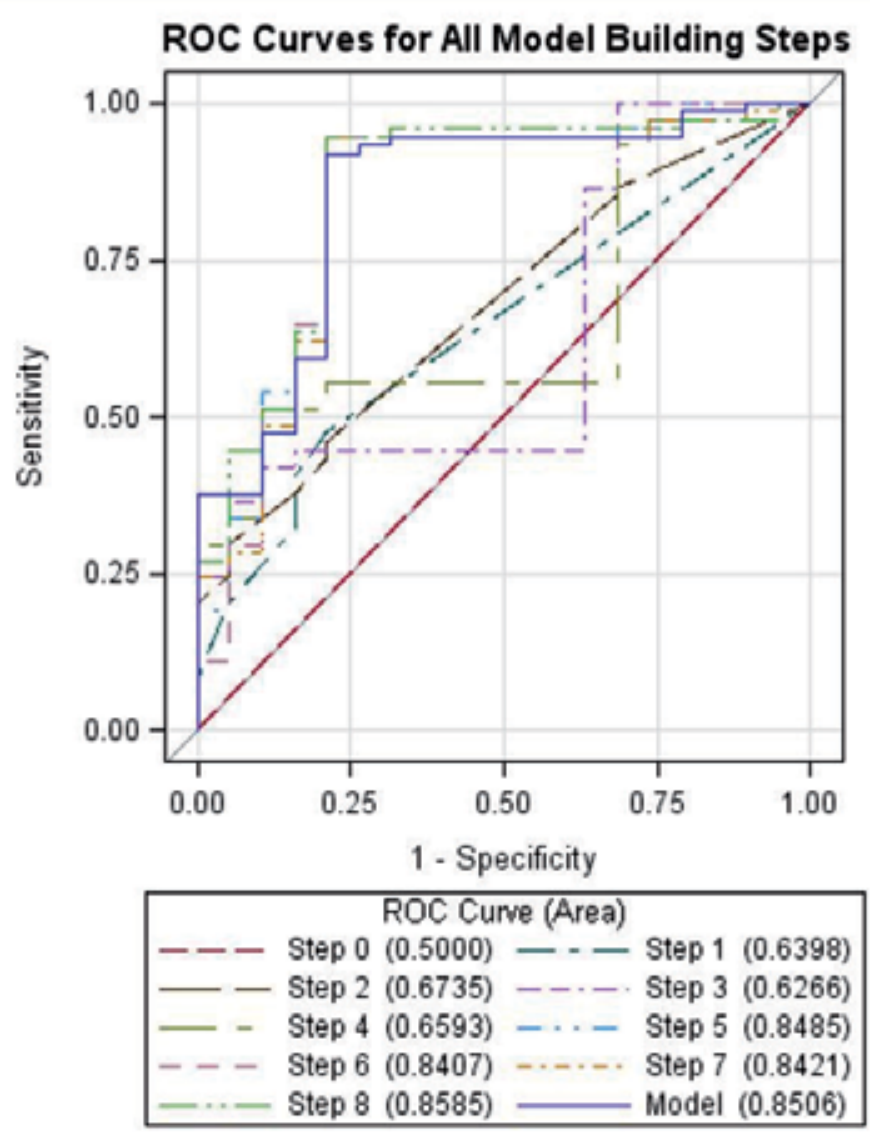

Fig. 5. Receiver Operator Characteristics (ROC) curves for the logistic regression on B1_FLG with fuzzy membership functions from FCM-p3

\subsection{Dual approach solution to the next best offer problem}

The steps described in sections 4.2 and 4.3 are ideally repeated for all $k$ products of interest, resulting in $k$ hybrid models. Each model gives not only the predicted purchase probabilities, but also the information through which channel the customers should be contacted in order to increase those purchase probabilities. The final solution which product to offer to individual customer and through which channel to contact her/him is obtained by descending sort of all single hybrid models' outcomes for each customer, where the first remaining (or highest remaining) outcome wins, after eventual hard filters and business rules were applied to the sorted queue. In our study only two products were compared and resulting offers consisted of product O4 offered via internet and product B1 offered by phone calls, depending on combination that resulted in higher probability of purchase for concrete customer. The future changes in customers' product preferences and purchase behaviour will affect the model through the logistic regression sub-model, while the changes in communication preferences and channels' usage will affect the fuzzy membership functions in fuzzy clustering sub- 
model. Such a dual approach to modelling the problem of next best offer should raise the flexibility of the entire proposed model.

\section{Conclusions and further work}

The next best offer problem is well known problem in CRM community and there exist theoretical and practical solutions to this problem. Still, the literature describing in detail the methodology or new applicable scientific insights to the problem is scarce. The problem solutions are mostly spread as built-in solutions within software tools for statistical modelling and campaign management. The majority of them applies either the logistic regression or GLM to modelling the product demand curves and uses the sort algorithm as default method for choice of the product to be offered. Since the real business data does not behave nicely as artificial or simulated data, the improvement of the final solution is limited by the possibility of improvement of the underlying logistic regression model. The decision engine is too simplistic for growing business complexity, where the next best problem has already evolved into the next best action problem. The next best action is wider problem in the sense that it consist of several decisions: which product or service to offer to the customer, when ideally to offer, through which channel(s) to make the offer, at which price level and with which individualized message for each single customer. The growth of available software tools and IT applications for solving CRM problems is an advantage of modern world only if used in proper manner. Therefore, it becomes necessary to raise the level of deep understanding of such built-in solutions, to avoid misuse and to manage the expectations that companies have from the software itself. The level of specific statistical and business knowledge, required for modelling such complex problems, has to be recognized and constantly upgraded, if striving for better CRM solutions. The dual approach solution to the next best offer proposed in this chapter had and achieved the following goals: it explained in concise way the overall process of solving a general CRM problem, presented concrete statistical method (logistic regression) and knowledge discovery method (fuzzy clustering) with application to the next best offer problem, confirmed the hypothesis that fuzzy clustering on channels' data could result in fuzzy membership functions that are significant input variables for logistic regression and lead to better model performance. Finally, it gave an example of successful combining different methodologies into one hybrid solution. The further work on the topic might include extension of the solution to the cost-benefit analysis related to the elements of performance metrics of fuzzy clustering, applying different alpha-cuts on the membership functions in order to recognize the customers during their transition from one preferred channel to another preferred channel and testing the possibility of influencing such a transition by the company's actions. The greatest challenge in such CRM research remains the availability of real industry data. The pure researches rarely have access to real and fresh business data and analysts within the companies rarely have the possibility to devote their time to research, in order to shift the modelling horizon at the higher level. This chapter might give an idea how to sustainably introduce new methods into the already existing modelling framework, instead of forcing better results with exhausted possibilities or by buying new software. The CRM relies on knowledge discovery and knowledge discovery requires time to get know the data, to feel the data, to understand industry context and to acquire needed business wisdom. 


\section{References}

Anderson, K. \& Kerr, C. (2002). Customer Relationship Management, McGraw-Hill, ISBN 0-07137954-1, New York, USA

Ben-Gal, I. (2010). Outlier Detection, In: Data Mining and Knowledge Discovery Handbook: A Complete Guide for Practitioners and Researchers, O. Maimon \& L. Rokach, (Eds.), 117128, Springer, ISBN 978-0-387-09822-7, New York, USA

Berry, M. J. A. \& Linoff, G. (2004). Data mining techniques: for marketing, sales, and customer relationship management, Wiley Publishing, Inc., ISBN 0-471-47064-3, Indianapolis, USA

Cox, E. (2005). Fuzzy Modeling and Genetic Algorithms for Data Mining and Exploration, Morgan Kaufmann Publishers, ISBN 0-12-194275-9, San Francisco, USA

Guyon, I. \& Elisseeff, A. (2003). An Introduction to Variable and Feature Selection. Journal of Machine Learning Research, Vol.3, (March 2003), pp. 1157-1182, ISSN 1532-4435

Hosmer, D. W. \& Lemeshow, S. (2000). Applied logistic regression, John Wiley \& Sons, Inc., ISBN 0-471-35632-8, New Jersey, USA

Kleinbaum, D. G. \& Klein, M. (2010). Logistic Regression: A Self-Learning Text, Springer, ISBN 978-1-4419-1741-6, New York, USA

Parr Rud, O. (2001). Data Mining Cookbook Modeling Data for Marketing, Risk, and Customer Relationship Management, John Wiley \& Sons, Inc., ISBN 0-471-38564-6, New York, USA

Samuelson, P. A. \& Nordhaus, W. D. (2000). Ekonomija, MATE d.o.o., ISBN 953-6070-10-3, Zagreb, Croatia

Theodoridis, S. \& Koutroumbas, K. (2006). Pattern Recognition, Academic Press Elsevier, ISBN 0-12-369531-7, San Diego, USA 


\title{
Business Intelligence in Telecoms Industry: A Service Oriented Approach
}

\author{
Tanko Ishaya and Musiliudeen Folarin \\ The University of Hull, Scarborough Campus \\ United Kingdom
}

\section{Introduction}

Mobile market is becoming saturated and competitive in telecoms industry. As a result, these organizations are becoming more and more conscious about the advantages of data and information kept in their organization, the need to integrate these large volumes of data and to utilize these information to support the quality of their decision-making, in order to stay at a competitive advantage and to increase profit (Wu et al, 2007; Pareek, 2006). The profitability of these industry is clearly linked to its subscriber base which again depends on number of active customers, duration of calls made by customers, quality of service, price as compare to others, and ability to satisfy customers (Pareek, 2006). To properly utilize the relationships between all the profitability attributes, there is a clear demand for quality Business Intelligence (BI) (Wu et al, 2007; Pareek, 2006). BI is the combination of business processes with the use of IT Systems such as DWs, Data Marts, Metadata Data Mining, ETL, Query and Reporting Software, OLAP, and Visualization (Kudyba and Hoptroff, 2001; Pareek,2006) to support decision-making in an organization.

However, studies have shown that many researchers view BI from different perspectives. For example, Power (2003) considers BI as a data driven decision support system while others such as Rus and Toader (2008), and Kulkarni et al (2010) considered BI as strategic information system capable of providing actionable information through a centralized data repository, sourced from numerous sources, transformed into meaningful information via BI analytical tools, to facilitate business insights leading to informed decisions. Ishaya et al. (2007) shared similar view with Rus and Toader (2008) and further classified Information System in an organization into two broad categories: Operational Support Systems (OSS) which are systems that supports day-to-day business operational data and Decision Support Systems (DSS) which are systems that support decision-making. Ranjan (2009) defined BI as a way and method of improving business performance by making actionable information available for decision makers in an organization. BI is also defined as "the communication facility serving the conduct of a business, the notion of intelligence is the ability to apprehend the interrelationship of presented facts in such a way as to guide action towards a desired goal" (Rus and Toader, 2008). Hence, BI can be define as a process and methods of improving decision-making through a combination of business processes and effective utilization of IT to integrate data and information from various OSS into DWs, using data mining to analyze the data, and generating high-level report in a timely and user friendly manner for the decision makers in an organization. 
BI assists corporate managers and decision makers to make relevant, accurate, timely and smart decision in an organization and thus lead to increase in productivity and profitability of an organization (Gordon et al, 2006; Ranjan, 2009). BI is a field of building "information that is conclusive, fact-based, and actionable"(Pareek, 2006). Therefore, BI expose the importance of data and information kept by various organizations, which can be used to help in accurate and efficient decision-making based on the facts rather than human reasons (Ishaya et al, 2007). The competitive forces common in the world of business today require a business organization to operate efficiently and productively in order to maintain and support market share, profitability and shareholder values (Atre, 2003; Madnick et al, 2009). BI use traditional Extracts, Transform and Load (ETL) for data integration from Operational Support System (OSS) such as CRM, Decision Support System (DSS), Supply Chain Management (SCM), Enterprise Resource Planning (ERP), and E-business application (Pareek, 2006), which involve complex rule and long-running business processes during business downtime and which may span days as emphased in Gordon et al(2006). Current implementation of BI in telecoms organization is still based on traditional approach to data integration, which is static in nature. This approach may not meet up with constantly changing analysis required to support decision-making due to its static nature and direct end-to-end BI tools (Wu et al, 2007). Million of Call Details Record (CDR) are being generated daily and as services providers add new services to ensures customer satisfaction, customer's data will continue to grow exponentially, which can be difficult to analyze at a reasonable time and cost (Gordon et al, 2006; Ranjan, 2009). Therefore, there is need for a Service Oriented (SO) approach to BI in order to provide real-time data analysis. The SO approach will also provide an open, interoperable and potentially collaborative means of proving BI (Berthold et al, 2010).

This chapter presents an investigation into the integration and analysis of data from CRM and CDR of Telecoms operators using SO approach to assist the organization in making real-time and accurate decision about the customer tariff plan to ensure customer satisfaction which in return can lead to increase in profit.

The research has investigated the use of SO approach to BI in Telecoms organizations towards providing real-time and accurate decision support about customer tariff plan in order to ensure customer satisfaction. The chapter presents:

- A thorough review of current approaches/technologies to BI with telecoms industry and data sources -such as CDR, Billing system and CRM

- The development of Service Oriented Business Intelligence (SOBI) architecture based on an analysis of existing architectures/models and customer requirements that were captured through questionnaires. The architecture integrates integrate data from heterogeneous data sources of these organizations.

- Development of a SOBI prototype system that simulates the basic operation of a typical telecoms organization.

- An evaluation of the architecture and potential effectiveness using the implemented prototype

\section{A background to $B I$ within telecoms}

Advancement in the use of information technology (IT) over the past 50 years to collect, keep, extract, analyze and communicate data and information (Kudyba and Hoptroff, 2001) 
has lead business organizations through an era of OSS (Pareek, 2006). With these OSS, business organizations are able to keep lots of data about customers and daily operation and they now want to turn these data into actionable information. Since there are different perspectives to BI, there are also differing challenges of BI applications between organisations. The table below presents an analysis of some of the challenges that different industries face in implementing BI applications.

\begin{tabular}{|c|c|c|}
\hline Industry & Application & Challenge \\
\hline Telecommunication & CRM, DSS & $\begin{array}{l}\text { Legal Issues (Griffin, 2003; Kudyba and } \\
\text { Hoptroff 2001). } \\
\text { Ethical Issues (Griffin, 2003). } \\
\text { Collaboration Business Platforms (Griffin, } \\
\text { 2003; Atre, 2003; Johnstone and Wong, 2008). } \\
\text { Improper Implementation (Ishaya and } \\
\text { Rigneau, 2007; Levine, 2002). } \\
\text { Minimization of time (Griffin, 2003). }\end{array}$ \\
\hline Construction & DSS & $\begin{array}{l}\text { Data Quality (Madnick et al, 2009; Ishaya and } \\
\text { Julian 2007; Ishaya and Rigneau, 2007) }\end{array}$ \\
\hline Retail Sale & CRM, DSS & $\begin{array}{l}\text { Collaboration Business Platforms (Griffin, } \\
\text { 2003; Atre, 2003). }\end{array}$ \\
\hline E-Commerce & CRM & $\begin{array}{l}\text { Data Quality (Madnick et al, 2009; Ishaya and } \\
\text { Julian 2007; Ishaya and Rigneau, 2007). } \\
\text { Improper Implementation (Ishaya and } \\
\text { Rigneau, 2007; Levine, 2002) }\end{array}$ \\
\hline Insurance & DSS & $\begin{array}{l}\text { Ethical Issues (Witten and Frank, 2005) } \\
\text { Legal Issues (Witten and Frank, 2005) }\end{array}$ \\
\hline
\end{tabular}

Table 1. BI Challenges in various Industries

As can be seen from Table 1 above, collaborative business platforms is a fundamental challenge as also identified in Bethold et al(2010) that require investigating within telecoms industry. This section presents a review of BI, implementation of BI within Telecoms industry, and data sources use for data warehouses (DWs) and BI in Telecoms industry and an analysis of the data sources within the industry.

\subsection{A review of current approaches to $B I$ in telecoms industry}

Application of BI in Telecoms Industry has been focused mainly on customer management, fraud management, knowledge discovery and key performance indicators (Christine normile 2006). Each application has its own process and the processes are often automated in the Telecoms industry. BI combines business processes with IT systems to support decision-making in an organization. The IT systems used in BI such as DWs, OLAP, and Reporting have their own processes and combination of these processes made up the processes of BI. Business processes in $\mathrm{BI}$ are business rules defined by each Telecoms organization base on the business requirement and objectives. If for instance, the objective of Telecoms Company is to manage customers, then customer satisfaction becomes the business requirement and as a result, a set of rules are developed to define the processes required to achieve the requirement. 
The process of CRM in Telecoms industry involves three steps, which are customer identification, understanding, and interaction as shown in Figure 1 below.

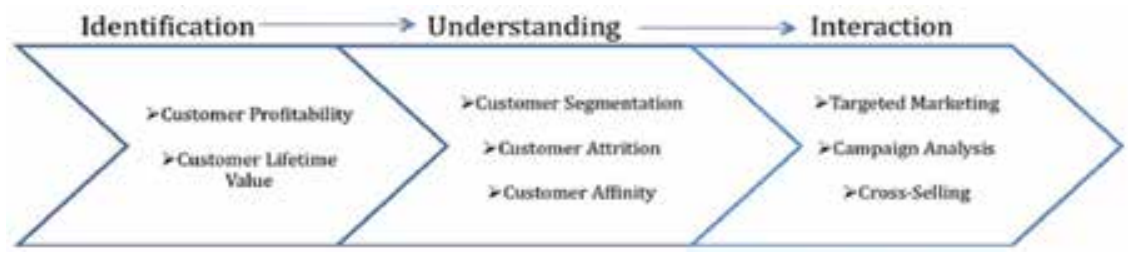

Fig. 1. Process of CRM in telecoms (Normile, 2006)

The following sections provides a brief description of the main components:

\subsubsection{Identification}

Customer identification is very important to Telecom operators and it starts from counting the number of subscriber base via a unique identification MSISDN and to identify the most profitable and potential profitable customers in the future. In the past, Telecom operators were more concerned about the number of subscribers with a simple view that the more the subscribers the more their turn over until recently when the telecoms operators started applying BI before they discover many unknowns such as the differences in the contribution of each subscriber (Normile, 2006). Hence, they need to define business rule to identify customers who are the most profitable among their customer base and who are the less profitable. These set of business rules help the company to keep the profitable customer to ensure stable income while the less profitable one can also give an insight about the reasons why they are not profitable, which may be due to wrong offerings, low income or bad network in their location and so on. To determine the overall customer profitability, the operators need to calculate the costs of serving customers over a period of time and revenue realized over the same period of time (Normile, 2006).

The second attribute in the identification component is the Customer Lifetime Value (CLV), which is the value in terms of money that a telecoms operator can realize from the customer over long-term (Cunningham et al, 2004). Analysis of CLV could tell if a customer is likely to be more profitable in the future or not and a customer may also serve as reference to a profitable customer (Normile, 2006). CLV is also used to justify the cost of customer acquisition. For example, if it will cost $£ 20$ to acquire a customer and CLV is about $£ 50$, then the cost may be considered justifiable.

\subsubsection{Understanding}

In order for services or products offering to be successful, there is need for proper understanding of the needs and wants of customers. Due to large number of customers, it is always good to divide them into groups for close observation before drilling down to individual customer. Segmentation is used to segment customers with common relationships. These segments now become a unique entities and the future relationship with the segments can be tailored accordingly. Through segmentation we can identify market potential relationship between products and each customer in the segments and decisions can be made about which product is likely to be interested to the segments (Lee and Park, 2005). 
Customer affinity is also referred to as market-basket analysis and this analysis tells what segments of customer are likely to buy from a group of products. Affinity analysis is usually done using association techniques to predict the right combination of products and services for a customer or segment of customer (Normile, 2006). The last in the process of CRM is customer interaction, after identifying the type of customers and understand their usage pattern; the next step is to start interacting with the customers. Targeted Marketing, Campaign Analysis, and Cross-selling are ways of interacting with the customer (Normile, 2006).

\subsubsection{Interaction}

In targeted marketing, particular group of customer segmentation are the target and once the customer segments are identified, BI tools can be used to develop a predictive model to determine buying propensity of the segment towards both new and existing products (Normile, 2006). Campaign analysis is the analysis of impact of a promotion or marketing advertisement on a particular service or product. Market affinity and market target and knowledge of past success or failure are the prerequisites of campaign analysis (Normile, 2006). Cross-selling is way of using existing data via BI tools to gain quick insight into what could be the new products that may be requested or required by the customers so that the right offer can be made to the customers when interacting or making contact with them. Cross-selling also make used of association technique to achieve it aim (Normile, 2006). However, for this to be more effective, it is important to ensure that the data captured about customers is of quality in nature. The importance of data quality for data mining has been well discussed in Ishaya and Rigneau (2007), and Griffin (2003).

\subsection{Implementation of $\mathrm{BI}$ in telecoms industry}

The processes of BI in Telecoms Industry are usually implemented using traditional BI approaches as shown in figure 2 below.

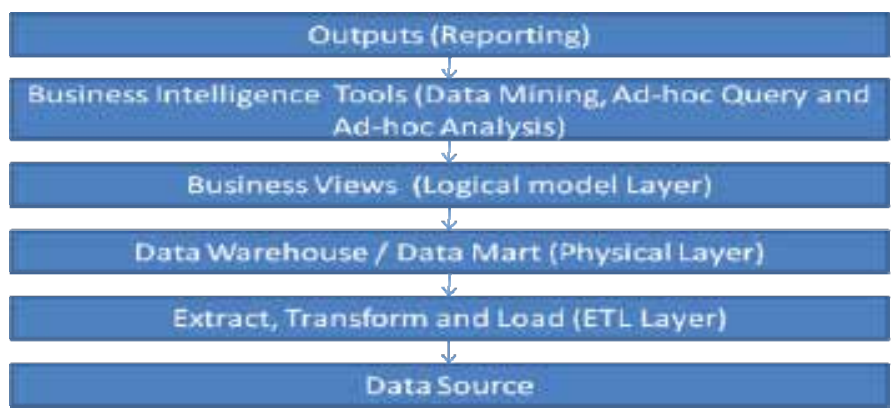

Fig. 2. Traditional Approach to BI (Wu et al, 2007)

As shown in figure 2 above, BI integrates data and information from various sdata source using the ETL process to extract transactional data, transform and upload data into DWs. After loading the data into DWs, Data mining tools such as OLAP and ad-hoc query operate on the vast amount of information stored in the DWs or Datamarts to produce business related report in a timely (near real-time) and friendly format. However, traditional approach to BI takes much longer time to process and as competition increases among 
business organizations, this approach to data integration may not meet up with constantly changing analysis needed to support decision-making due to the static and time dependent nature of DWs and direct end to end BI tools. Millions of CDRs data are being generated daily and as service providers add new services to ensures customer satisfaction, customer's data will continue to grow exponentially and it can be difficult to analyze these vast amounts of data at a reasonable time and cost (Cunningham el al, 2004). Therefore, there is the need for $\mathrm{SO}$ and dynamic approach to $\mathrm{BI}$ that would allow for flexibility, collaboration and both real-time and historic data processing and analysis of the vast amount of data and information keep in Telecoms Industry.

\subsection{An analysis of telecoms data sources}

Data sources for BI can be from OOS, external source, archived data, and information from other DWs (Ranjan, 2009). Weiss (2004) described three major data keep by telecoms organizations as CDR, Network Data, and CRM. Also Johnstone et al (2008) recognized Network Switches, Billing System and Service Records as part of data sources in telecoms organizations. The data sources for BI in Telecoms industry can be grouped into internal and external data sources as discussed in section 2.3.1 and 2.3.2 respectively. Data sources can also be classified into structure and unstructured data. The structure data referred to as data from structured databases such as relational and $\mathrm{xml}$ while unstructured data are data from text file, PDF, Web pages, and so on.

\subsubsection{Internal data sources}

The Internal data sources are data generate from OSS and examples include CDR, CRM, Billing Systems, and Service Records. CDR is generated directly from the telco's network switch. Billing System extract part of CDR, CRM and Service Records for billing purpose and merge the bill to customer via the mobile number after calculating the bill.

CDR is a computer record containing details of calls such as the number making the call, number receiving the call, date and time of call, call duration, call route, call type, the number charged for the call, telephone switch identity, record identity, and fault condition encountered during the call usually generated by charging system of the telephone switch. The sending telephone switches keep the CDR progressively until the end of the call, after which the Telecoms billing support system can retrieve and process the CDR for billing. Mobile CDR may contain information on more than one call type or traffic such as voice calls, Short Message Service (SMS), and other data services traffic (Johnstone and Wong, 2008). Due to valuable information contain in the CDR, Telecom operators can utilize CDR information as a data source for DWs and BI. The mediation module prepares CDR data for billing by cleaning and transforming CDRs into format that is accessible by the billing system (Johnstone and Wong, 2008). Figure 3 below shows a simple billing process and explanation on how the billing system work is provided.

All mobile calls passes through Mobile Switch Centre (MSC) for the purpose of routing and to generate, collect, and store CDR records. If the call is a local call, the call traffic is connected through MSC to a public-switched telephone network (PSTN) for a fixed-line network or directly to MSC of another mobile operator network. But in the case of International Direct Dialling (IDD) call, the traffic is routed from MSC to an international 
toll gateway (ITG) or other IDD services providers (Johnstone and Wong, 2008). The SMS CDR is being generated and recorded by Short Message Service Centre (SMSC). SMSC provides a store and forward function delivering SMS messages to the users' destination when they are available while destination mobile operator has a SMSC designated to the respective SMS message partners or SMS clearinghouse for further delivery (Johnstone and Wong, 2008). Global System for Mobile Communication (GSM), 2G General Packet Radio Service (GPRS), 2.5G GPRS and 3G GPRS offers data services and the usage of data services are recorded by GPRS Support Note (SGSN) and Gateway GPRS (GGSN). Data collected from the SGSN and the GGSN is first sent to a dedicated charging gateway (CG) before being forwarded to the mediation module. The major function of a CG is to collect CDRs from both the SSGN and GGSN, buffering and transferring CDRs to the mediation module of the billing system (Johnstone and Wong, 2008). The mediation module also contains a filtering rule algorithm. The filtering rules are a programming conditions base on the business requirements. It is very important to ensure that appropriate and complete information is delivered to the billing system for rating and necessary calculation, and the service type must be mapped accurately against the corresponding rate for accurate billing (Johnstone and Wong, 2008).

The main reasons for developing CRM is to manage customer by identifying who the customer is, understanding what customer needs and value of each customer, and interacting with them base on the information at hand. CRM also combine data from CDR, Billing System, and Customer profile and Service Record (Weiss, 2004) to give more information about the customer in order to make more accurate and stronger decision to be able to make right offer to the right customer at the right time.

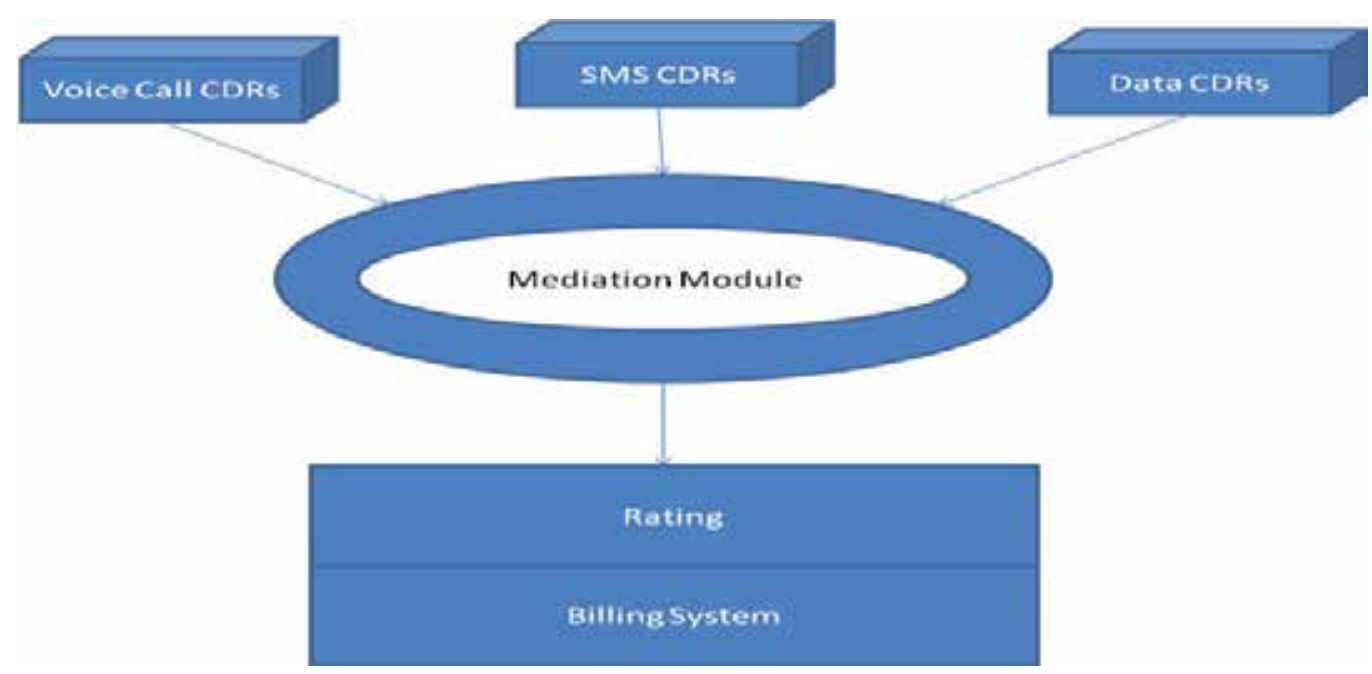

Fig. 3. Simple billing process (Johnstone and Wong, 2008) 


\subsubsection{External data sources}

The external data sources are data retrieved from external network domain such as Telecoms regulatory body and specialist vendor in the public or social network domain. Among the information retrieved from external source are customer profile information such as income, age, habits and gender and competitor's products, prices, and sales. External data sources are very expenses due to unstructured format, which need to undergo extra and complex transformation before loading into the DWs.

This section has presented a review of BI in Telecoms industry by a way of justifying a need for SOBI approach to BI in order to ensure flexible, collaborative and both real-time and historic data analysis of vast amount of data and information available within the industry. In the next section, a proposed SOBI architecture is presented and discussed.

\section{A proposed service oriented business intelligence (SOBI) architecture}

Based on the review presented in the previous section, it is clear that telecoms industries need BI that is capable of performing real-time analysis on vast amount of CDR data generated and able to analyze historical data of CDR to identify customer value and make strategic decision to retain, attract new customer, and to ensure their satisfaction towards increasing profitability. A service-oriented-architecture (SOA) is an architecture upon which different standalone services can be loosely coupled over distributed systems ( $\mathrm{Hu}$ et al, 2011). They are business-centric IT architectural approach that supports the integration of business as connected and repeatable business services. A fundamental advantage of these services is that they can communicate with each other even though each service has different underlying implementation platforms. It is therefore clear that a Service Oriented (SO) approach will provide a common, open, and interoperable solution to the problem encountered in traditional BI. While, SO approach is being used within many industries, its advantages are yet to be fully harnessed within the telecoms industry. SO can be adopted for agile and flexible applications, application-application integration, high-frequency events, real-time data analysis, reusable of services components, proper data formats and structures, and encapsulates and abstracts functionality (Gordon et al, 2006). This section presents the development of Service Oriented Business Intelligence (SOBI) architecture based on an analysis of existing architectures/models and customer requirements that were captured through questionnaires. The architecture integrates data from heterogeneous data sources of the organization.

The SOBI architectural framework intends to leverages the strengths of BI and SO while defining guiding principle to ensure that the fundamental tenets of each of the component architectures are not broken. SO allows distributed application development through interfaces capable of exchange messages through. In SOBI paradigms, BI is seen as a collection of Services such as Data Services, Transformation Services and so on, while SO is seen as a collection of data sources and event source. A service can promptly be opened "as a data source with the introduction of a simple facade layer that provides a mapping between the BI interface and interface exposed by the service" (Gordon et al, 2006). The facade layer also transforms the results set of the call from data schema used on the service bus to data format expected by the BI platform and returns the result to the caller. The section is organised as follows: Section 3.1 describes the general approach used in the 
development of the proposed architecture. Section 3.2 presents an analysis and discussion of the customer satisfaction surveys and interviews undertaken to help capture a set of user requirements for SOBI. Section 3.3 presents a review of current BI architectures, which was also used in analysing the SOBI requirements presented in Section 3.4. Section 3.5 finally presents the proposed architecture.

\subsection{Methodology}

A mixed methods approach was used in developing the SOBI Architecture. First we conducted a customer satisfaction survey via a questionnaire to capture customer requirements, and business requirement by interviewing a few Telecoms operators. Second, the requirements were used in the context of existing models. A phone simulator was developed to generate and store CDR data in OSS database since we couldn't not lay our hands on the CRM and CDR dataset from the telecoms operator that promised to provide us with such data. Samples of other data such as customer profile, tariff plan, route, rate, algorithm, route, location, and services are provided in the OOS database. A DW was developed and data and information was extracted from OSS databases to populate the DW. The customer questionnaire survey data was collected to capture requirements required for the development of the SOBI architecture. The interview was conducted with Telecoms operator to understand business rules and requirements, which form the business processes towards development of SOBI architecture.

\subsection{Customer satisfaction surveys and interviews}

An interview was conducted with two Telecoms analysts who are making use of BI report for decision-making and BI application developer analyst. One of the Telecoms analysts works with Vodafone as Online Services Senior Executive and the second works with Etisalat Nigeria as Product Specialist- Post-paid/Corporate Solutions. The first interview with Vodafone BI analyst was carried out face to face while the subsequent interview was conducted via email. Interview with Etisalat Nigeria Analyst was through email and interview with BI application developer was through online blog. During the interview, we were able to understand the type of data kept in Telecoms industry and the necessary reports needed to support decision-making process. Also, we were able to capture business rule and processes to ensure customer satisfaction, which eventually form the Telecoms operator requirement to develop SOBI architecture.

The interview conducted with Telecoms analyst also assisted in understanding the processes, which helped in the design of the questionnaire that was administered to customers. The interview with BI application developer gave us more details on how Telecoms operator system works. A questionnaire was developed and administered online by sending a link of the survey to a list of postgraduate students of the University of Hull and other individuals across UK that have volunteered to participate in the study. The questionnaire was made anonymous by making sure that personal information - such as name, telephone number, and address were not been included. This is in order to ensure that we conform to privacy law. The questionnaire was divided into sections. Section one captured some of the generic participant's personal details such as gender, age group, region and country of residence, education level, industry sector, and current position. 
Section two covers customer mobile information such as how long a customer has been using their provider's SIMcard, the name of the provider, the reasons and name of second provider for those using multiple SIMcards. Section three covers the customer usage information such as services and tariff plan used by the customer, reasons for choosing particular tariff plan and the level of their satisfaction with services, tariff plan and quality of network.

A total number of 42 customers participated in the survey with results presented in Table 2 below. A number of responses for each question in the questionnaire vary due to the option given to customers to skip or even opt out of the survey at any time, which was one of the stated conditions in the letter of consent. The analysis of the result showed that $47.6 \%$ and $52.4 \%$ are male and female who participated in the survey respectively. $66 \%$ are within the age of 18 and 30 and $90.5 \%$ are currently residing in UK and $9.5 \%$ residing in other countries. 17 out of 38 responses equivalent to $44.7 \%$ have been using their provider SIMcards for less than one year, 39.5\% have been using provider SIMcard for one to five years and $15.8 \%$ have maintained their SIMcard providers for more than five years. O2 happened to be the preferred provide for most of the participants followed by Vodafone and Orange. $20.0 \%$ used two SIMcards due to lack of variation of services, and $70.0 \%$ leave the previous provide for the current one because the current provider offer competitive tariff. 23 out of 27 responses equivalent to $85.2 \%$ of customer used their current SIMcard. $66.7 \%$ make local call every day, $25.0 \%$ make international calls every day, $46.9 \%$ make long duration call of $5 \mathrm{~min}$ and above every day, $78.1 \%$ send text messages every day, $25.0 \%$ used the internet every day, and $37.5 \%$ send or check email every day while none of them send video messages, download music and video at all on a daily basis.

\begin{tabular}{|l|c|c|c|c|c|c|}
\hline \multicolumn{1}{|c|}{ Services } & Daily & Weekly & Monthly & Yearly & Never & $\begin{array}{c}\text { No of } \\
\text { Response }\end{array}$ \\
\hline Local call & $66.7 \%$ & $15.2 \%$ & $15.2 \%$ & - & $3.0 \%$ & 33 \\
\hline International call & $25.0 \%$ & $25.0 \%$ & $12.5 \%$ & $15.6 \%$ & $21.9 \%$ & 32 \\
\hline $\begin{array}{l}\text { Make 5 min call and } \\
\text { above }\end{array}$ & $46.9 \%$ & $25.0 \%$ & $18.8 \%$ & - & $9.4 \%$ & 32 \\
\hline Text messages & $78.1 \%$ & $15.6 \%$ & $3.1 \%$ & $3.1 \%$ & - & 32 \\
\hline Video messages & - & $6.5 \%$ & $9.7 \%$ & $3.2 \%$ & $80.6 \%$ & 31 \\
\hline Internet browsing & $25.0 \%$ & $12.5 \%$ & $12.5 \%$ & - & $50.0 \%$ & 32 \\
\hline Check and send email & $37.5 \%$ & $3.1 \%$ & $12.5 \%$ & - & $46.9 \%$ & 32 \\
\hline Download music & - & $3.1 \%$ & $25.0 \%$ & $3.1 \%$ & $68.8 \%$ & 32 \\
\hline Download video & - & $3.1 \%$ & $25.0 \%$ & - & $71.9 \%$ & 32 \\
\hline
\end{tabular}

Table 2. Customer usage habit over time on various services

Customer tariff plan was also captured during the survey, with results presented in Table 3 below. 18 out of 32 responses equivalent to $56.3 \%$ of the customers are using Pas As You Go tariff plan also known as pre-paid package, $43.8 \%$ are using Contract Package also known as post-paid package while none of them were using a roaming tariff plan. The reason for choosing a particular tariff plan varies among the customers. 21 out of 28 responses equivalent to $75 \%$ choose tariff plan because they were more cheaper them, $14.3 \%$ choose a particular tariff plan because they were not aware of others, $10.7 \%$ choose tariff plan because 
of the availability of free international call, $3.67 \%$ choose a particular tariff plan because of more number of free international text, $14.3 \%$ choose tariff plan because of more number of free local call, and $10.7 \%$ choose tariff plan because of more number of free local text. The survey also captured the level of customer satisfaction on some charges and promotional offers.

\begin{tabular}{|l|c|c|c|c|c|c|}
\hline & $\begin{array}{l}\text { Strongly } \\
\text { Satisfied }\end{array}$ & Satisfied & Neutral & Dissatisfied & $\begin{array}{c}\text { Strongly } \\
\text { Dissatisfied }\end{array}$ & $\begin{array}{c}\text { No of } \\
\text { Response }\end{array}$ \\
\hline $\begin{array}{l}\text { Charges on } \\
\text { Pay As You } \\
\text { Go }\end{array}$ & $16.7 \%$ & $33.3 \%$ & $26.7 \%$ & $3.3 \%$ & $20.0 \%$ & 30 \\
\hline $\begin{array}{l}\text { Promo offer } \\
\text { on Pay As } \\
\text { You Go }\end{array}$ & $10.3 \%$ & $24.1 \%$ & $51.7 \%$ & $10.3 \%$ & $3.4 \%$ & 29 \\
\hline $\begin{array}{l}\text { Charges on } \\
\text { Contract } \\
\text { Package }\end{array}$ & - & $39.3 \%$ & $35.7 \%$ & $10.7 \%$ & $14.3 \%$ & 28 \\
\hline $\begin{array}{l}\text { Free call on } \\
\text { Contract } \\
\text { Package }\end{array}$ & $11.1 \%$ & $40.7 \%$ & $40.7 \%$ & - & $7.4 \%$ & 27 \\
\hline $\begin{array}{l}\text { Free text on } \\
\text { Contract } \\
\text { Package }\end{array}$ & $18.5 \%$ & $37.0 \%$ & $37.0 \%$ & - & $7.4 \%$ & 27 \\
\hline
\end{tabular}

Table 3. Customer satisfaction surveys

From the table above, customers are satisfied except on promotional offer where customers are neutral. These levels of satisfaction indicate where Telecom operators' analysis needs to concentrate in order to know if a customer is satisfied or not. Hence tariff plan and associated benefit need to meet the preference of the customer especially on Pay AS You Go tariff plan.

The survey further captured what will be customer next step if Telecoms operator want to use business rule of $£ 20$ usage in a month to identify loyal customer by getting the monthly usage and call of $5 \mathrm{~min}$ and above before and after asking customers how likely they are likely to make more call and used $£ 20$ in a month. 17 out of 33 responses equivalent to $51.5 \%$ of customers used $£ 20$ and above while $24.2 \%$ used less than $£ 20$ in a month. $18.8 \%$ of customers make 5 min call and above in a month as shown in table 1000 above. But after asking the question, the customers responses show that 14 out of 32 equivalents to $43.8 \%$ of customers are very likely to make more call, $18.8 \%$ are likely to make more call, $6.3 \%$ are not likely to make more call, and $9.4 \%$ are very unlikely to make more call if Telecoms operator is ready to reduce price on long duration call. Also, 6 out of 31 equivalents to $19.4 \%$ of customer are very likely to used $£ 20,25.8 \%$ are likely to used $£ 20,32.3 \%$ say nothing, $12.9 \%$ are unlikely to used $£ 20$, and $9.7 \%$ are very unlikely to used $£ 20$ in a month. This show that customer are willing to make more call but $£ 20$ average set by the Telecoms operator is too much for them and hence majority of customer may not be satisfied with promotional offer targeting customer with $£ 20$ usage in a month and can also be the reason why customer are not satisfied with promo offer on Pay As You Go as the case of this survey. 


\subsection{Analysis of current $\mathrm{BI}$ architecture}

As discussed, traditional BI has been designed with focus on historical data usually provided by DWs and used for strategic decision which may span days but as business activities continue to evolve there is need for multi-tier data analytics application and leverage analytics of data, event, and content (Atre, 2008; Berthold, 2010). Current approach to $\mathrm{BI}$ has changed beyond traditional approach (as previously discussed) in other industries such as E-commerce and a good example is Amazon.com, but Telecom Operators are just on the way to follow this trend. Telecoms Operators are now structuring OSS towards SO which in return will aid SOBI. Figure 4 below shows the component of SOBI architecture proposed by $\mathrm{Wu}$ et al. (2007).

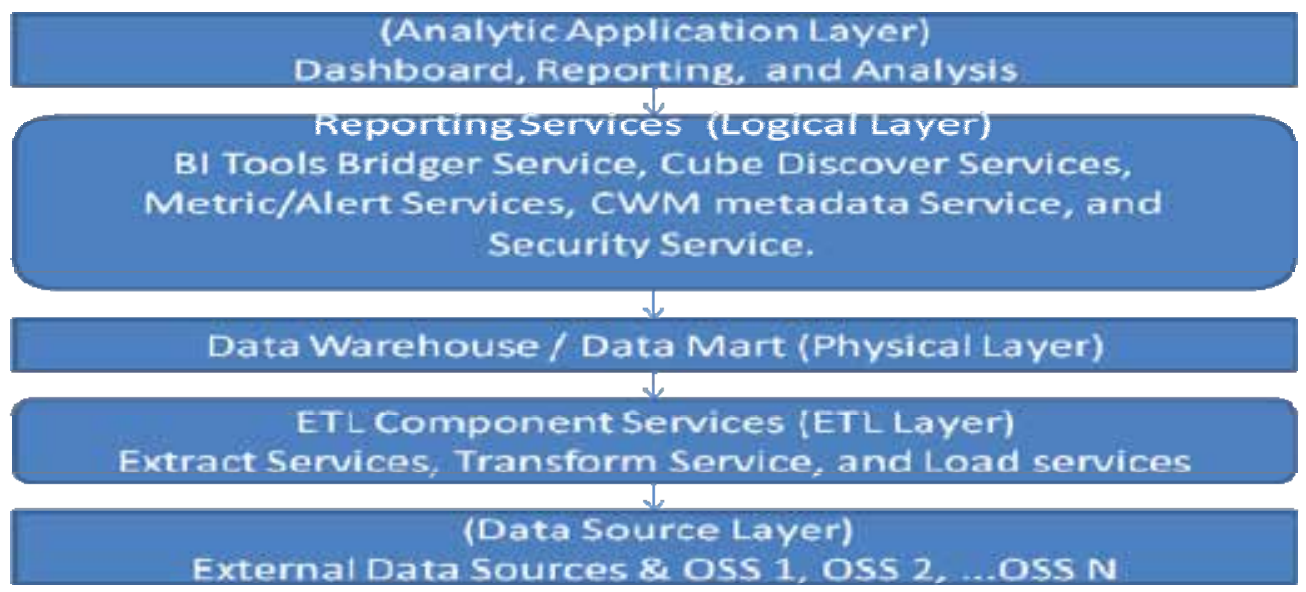

Fig. 4. Current BI Architecture (Wu et al, 2007)

$\mathrm{Wu}$ et al. (2007), described SO architecture as an improvement on the traditional BI architecture by implementing ETL Layer and Logical Layer as web component services and thus leverage $\mathrm{SO}$ and $\mathrm{BI}$ architecture.

\subsection{Requirements analysis for SOBI architecture}

Based on survey analysis, interviews and a review of related models, the following requirements were identified as fundamental in the development of SOBI architecture.

- Telecoms operators need to analyze both real-time and historical data. Real-time analysis such as registering an event on CDR record to identifying customer making long duration call and automatically billing them base on predefined tariff plan to such transactions and inform the customer about it. This can speed up decision-making process and communication. Analysis of historical data can provide adequate review of what tariff plan need to be set up, and other required services by which category or individual customer.

- Telecoms operator managers need to have a quick summary of customer satisfaction. While it is important to go through in-depth customer satisfaction analysis by the managers or the analyst, it also important to have a quick overview customer satisfaction levels. 
- Telecoms operators need to analyze customer usage pattern in various dimensions. This is important in order to understand why customers have behaved in a particular way at a particular time. For example, customers may have different calling habits depending on tariff plan, available service, time of the day, and so on. These analyses also enable the discovery of hidden behaviour, which has not been noticed in the past.

- Telecoms operators need to be able to drill down and drill up while analysing the customer usage pattern. This is also supporting requirement No. 3 mentioned above.

- Telecoms operators need BI architecture that is flexible to change in the business activities, which usually lead to changes in business requirement. Change is inevitable in business activities, therefore the more flexible to adapt to change, the more Telecoms operator will be able to survive the competitive environment.

- Telecoms operators need to ensure security of data stored in the OSS and DWs and during analysis. Security of operational data and customer information is very important to prevent loss, stolen, damage and authorise person from accessing the information while in storage or during analysis.

- Telecoms operators need to combine call details with customer profile and demographic for more accurate decision making about customer satisfaction. For example customer that is 60 years of age and above may make less calls but there may be an issue of customer dissatisfaction when customer within the age of $20-40$ is making less call.

From the customer's point of view, the following requirements were identified:

- Customers need reasonable tariffs and would wish that the tariffs were dynamically adjustable to suite individual demands, which clearly suggest a need for a personalised plan where possible.

- The customers need to be aware of current promotion and contract packages.

- Customers need quality of service

There are also a number of technical and non-technical requirements

\subsection{The proposed SOBI architecture}

The SOBI architecture was developed based on the general requirements presented in Section 3.4. The architecture is an extension of the one developed in $\mathrm{Wu}$ et al. (2007). Main extension is the clear emphasis on the analysis of events that should be performed on CDR data. Figure 5 below shows the developed SOBI architecture.

The SOBI architecture consists of five layers, which are Data Source Layer, ETL Layer, Physical Layer, Logical Layer, and Application Layer. Each of these layers defines a set of business processes to ensure a successful BI project. Each of the layers has been briefly described below, with a more technical insight provided in the implementation of the SOBI prototype simulator.

- Data Source Layer is the OSS database where day-to-day business transaction data are stored. Data Source Layer can also be an external source such as data from a survey company. SOBI architecture had been designed to allow analytics of events on the CDR data source in order to provide more real time analysis. The Data Source Layer stored day-to-day business activities of Telecoms operators in OOS database. In order to 
design OSS database, we need data modelling using ERM or Normalization approach to ensure that the entities in OSS database are normalized to the third normal form. This is very essential to prevent data inconsistency, data redundancy, and anomalies, which reduce the quality of data and thus make ETL process very complex and can even result into poor quality BI.

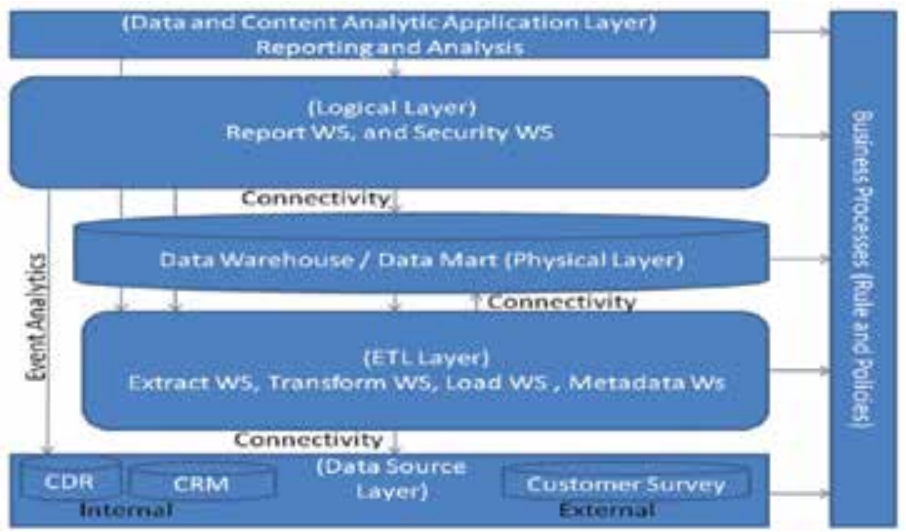

Fig. 5. SOBI Architecture

- ETL Layer consists of Extract, Transform, and Loading Services. The extract service extract all the required data from the OSS databases, transform service transform the data into a format required by the DWs while the function of loading service is to load the data and information into the DWs. The design of ETL Layer starts with the identification of the exact data that need to be extracted, the quality of the data and additional information necessary to provide complete and meaningful information. Business processes must be followed during ETL Layer design. Business processes determine when operational data is available for ETL, reformatting of OSS into a unified format, reconciling the data redundancy, and cleansing the dirty data found in the source system.

- The Physical Layer is the data repository centre of SOBI architecture and this is the layer where DWs are required to be developed. DWs have processes and architecture have been discussed in section 2. Before designing DWs, it is important to have DWs specific technical and functional requirements from the general requirements performed in section 3 .

- The Logical Layer of SOBI architecture focuses on the development of business logic. This includes appropriate activities that are required to be monitored, those that trigger other events/services, design of variable billing algorithms, tariffs, etc. This layer represents the logical view of the entire Telecoms operator data Business logic and rules regarding security, privacy, etc also falls within this layer.

- The Application Layer is the presentation layer where data are display in form of reporting tools using tables, charts, etc to aid visualization. This layer is where reporting and complex analysis are performed and rendered to the BI end user. OLAP and data mining technique will be adopted for reporting and forecasting respectively. OLAP provide summary data and information, which can also be drill down, roll up, slice and dice. Appropriate data mining techniques such as segmentation and 
exponential smoothing can be applied for specific objectives, such as the ability to predict customer satisfaction level and forecast the average usage of customer respectively.

The developed SOBI architecture will be evaluated by the prototype application, which will be discussed in the next section

\section{Development of a SOBI prototype simulator}

According to Atre and Moss (2003), BI applications require a dynamic system development approach. Since it was not possible to have access to some telecoms data, it became necessary to design a simulator to demonstrate and further reflect on the developed SOBI architecture presented in Section 3. The design of the simulator was done according to the five layers of the architecture - Data Source Layer, ETL Layer, Physical Layer, Logical Layer and Application Layer. The focus of the prototype was on the generation of CDR and CRM data, extraction, transformation and loading of the data into developed DWs. The prototype also covered report generation to demonstrate how such reports could assist Telecoms operator to analyze the customer call details over time and able to identify the relationship between tariff plan and customer usage. The prototype is limited to only call service categorise by local and international call.

\subsection{Prototype requirement analysis}

After reviewing service oriented development technologies, the prototype was design and implemented using PHP WS technology at the server side, JavaScript at the client side, and Ajax to provide dynamic interaction between the client and the server. The data source and DWs was designed and implemented using MySQL RDBMS running on Apache server with PHP installed on the server. WS was configured with SOAP extensions in the PHP library. The prototype also required sample data of CDR and CRM from Telecoms operator but a call simulator will be developed since samples data are not available.

1. The prototype is expected to allow user to simulate a call and generate the CDR data set.

2. Extract data from OSS, transform data and load into DWs.

3. Analyze customer call details to know the customer satisfaction level.

4. Identify relationship between customer usage and tariff plan.

5. Provide details information about customer in segment of the tariff plan.

The overall design of the simulator is shown in Figure 6 below.

The simulator also required the design of the data source layer in order to provide the OSS data required for the development of other layers. The entities necessary for Telecoms operator to store customer call details included Mediation, TariffPlan, TariffAlgorithm, Rate, Billing, Route, Location, Service, ServiceType, Customer, CDR, etc.

At the physical layer, a DW has been design to provide the required data repository for the SOBI prototype simulator. Before designing the DW, it was important to have the DW specific technical and functional requirements. A star schema of the DW containing a customer fact table and the associated dimensions were designed as shown in Figure 7. 


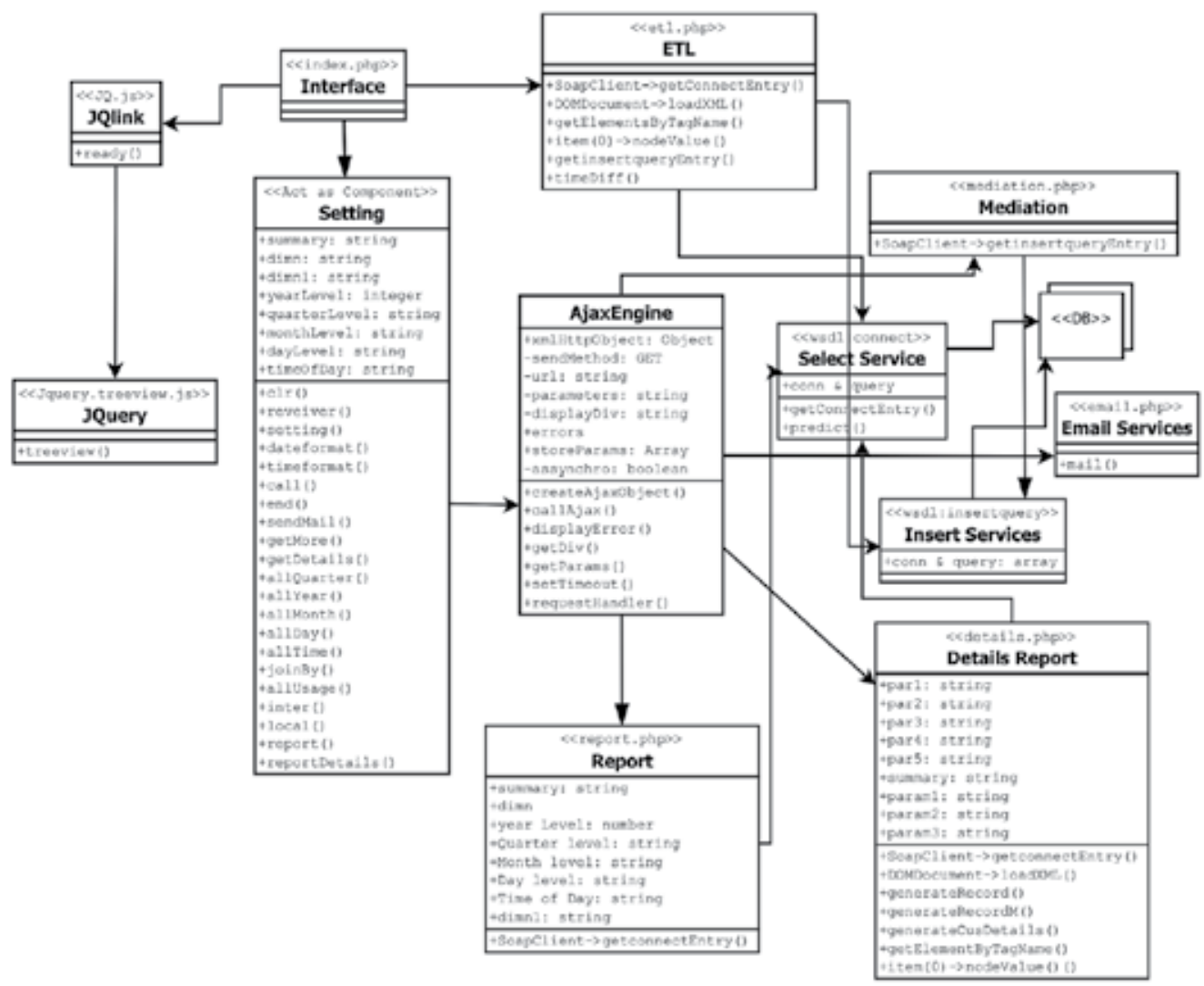

Fig. 6. Class diagram of the SOBI prototype simulator 


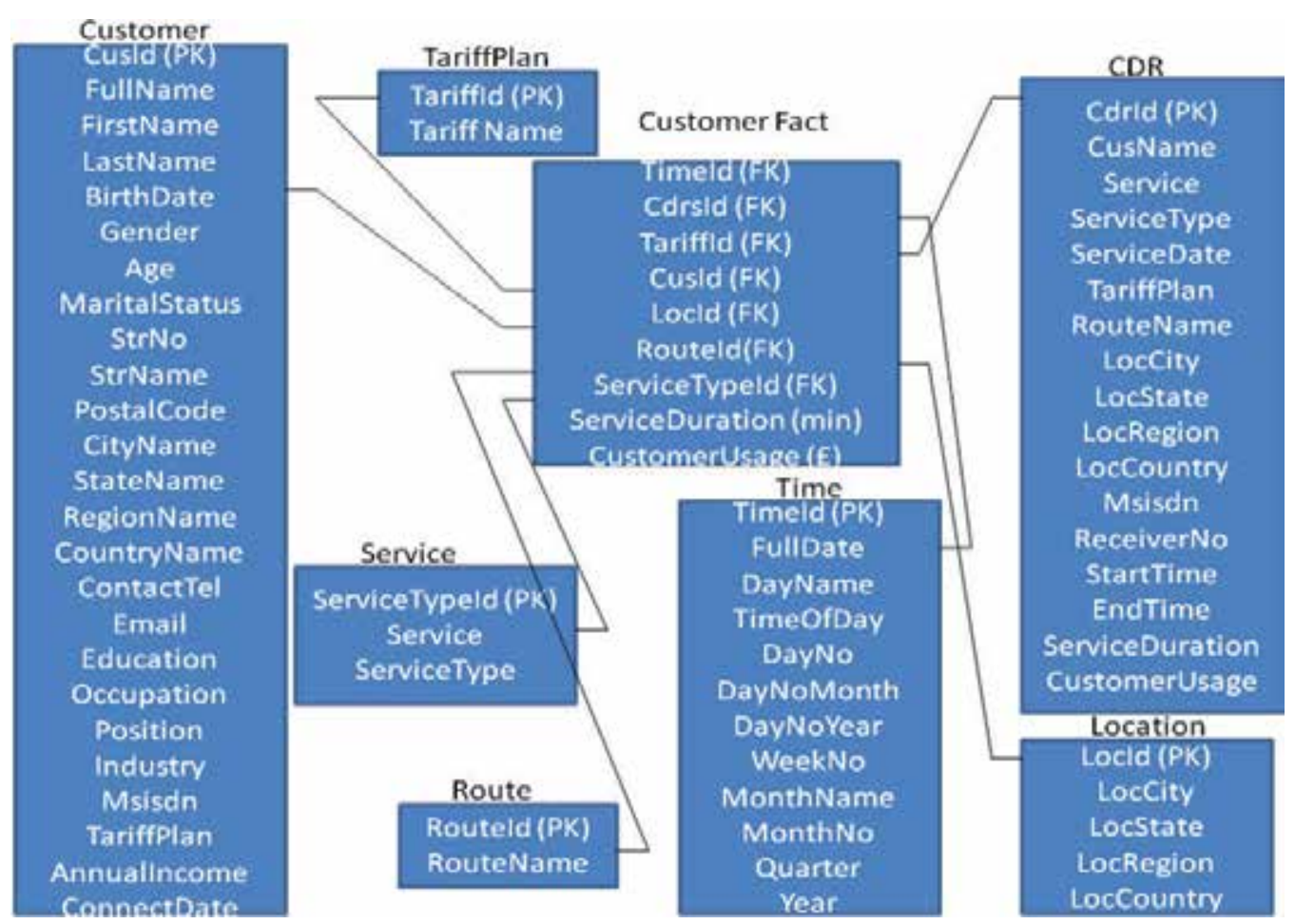

Fig. 7. Star Schema of Customer Fact.

As shown from Figure 7 above, the Customer Fact is in the centre surrounded by the dimension table. The time dimension will make it easy to view ServiceDuration and CustomerUsage on daily, weekly, monthly, quarterly and yearly basis. Other physical layer designs included data marts, metadata, backup and recovery, data aggregation, etc.

\subsection{Prototype implementation}

The implementation of SOBI prototype is divided into Data Source, DWs, analytical and presentation tools.

The simulator prototype was implemented using service-oriented technologies. As shown in Figure 6, the prototype has a single interface using JavaScript at the client side to capture the request of the user and pass it to the Ajax Engine which then send the request to the server where the WS class component are located. The ETL processes are being handled by etl.php. The index.php is the interface to invoke the ETL process and the interface will refresh to reflect the newly loaded data. The interface has a tree view menu list elements that is dynamically handled using the JQuery class. Setting.js acts as a listener to every change that occurs and passes the necessary parameter to the Ajax.class.js, which sends the request to the server and handles the response, which is display on the client side. Other components of the class diagram are discussed below. 
The Insert Service has a WSDL, which specified the input and output parameter operations. The array of input parameter contains the host, username, password, database, table, and query. This service is used to insert CDR data generated by the call simulator into the OSS database on MySQL server and is also used to load the transformed data into DW in another MySQL database on the same server. This class has also been developed to connect with PostgreSQL. This is the usefulness of SOBI, the interoperability and the reusability and flexibility that WS brings.

The select service also has WSDL and WS server class that perform the requested operation. The select service has input parameter as an array, which contains the same content as insert service and another additional parameter, which specified what type of string to be returned by the service. The service can return XML or HTML string depending on the expected result output. The HTML string has been specially developed to generate html table of any column and row without knowing the structure of the table. What is requires is the correct query. Similarly, XML file is generated using DOMDocument object class. The select service also has a function that calculates single exponential smoothing technique. This function takes the row of average usage query result accordingly and applies the formula to forecast the next average usage.

The report has been implemented using the select service to select from the database and send the return HTML string from the select service to Ajax Engine which passes it to JavaScript which is using DOM Objects to display the table in a specified div (cont) in the index.php corresponding to the specified of the interface report area. The report service contain series of next if statement which determines what query to be executed before invoking the select service. The details report could have been part of Report Service discussed above but it has been move to another PHP file for simplicity, readability and to avoid confusion as a result of the complexity of the if statement involved in both reports. Parameters sent by the Ajax is also examined to determine which query is required and responses returned from Select Service is handle using DOMDocument to load the XML string and generate html table which is sent back to the Ajax Engine.

Mediation Service get all the call simulator parameter sent by setting.js through Ajax Engine and invoke Select Service to get other information such as customer id of the caller and tariff plan. It has functions that calculate the duration and bill the customer before invoking Insert Service to insert the CDR data into the OOS database.

The extract, transform, and load services, which have been design separately during the SOBI system design, are now implemented together as a single service. The Select Service was invoked to select the current data from the source system and transformation process was carried out before invoking the Insert Service to load into the DW. During data transformation, the content of DW table was compare with sources in order to select the current information. PK and FK relationships are used to get the actual data from the sources system. The dimension and fact table was loaded during the ETL.

The Email Service gets the necessary parameter such as message, receiver email and name from client side through JavaScript and Ajax Engine. Email Service used PHP mail function to sent mail and returns nothing back to the Ajax Engine. 
The prototype was evaluated by developing a set of tasks that will enable telecoms analysts to perform customer call usage analysis through simulated calls and whether or not they could make informed decisions about specific customer. The evaluation was carried out by the telecom analysts were interviewed during the requirements gathering stage. Evaluation results clearly indicates a great potential of using SOBI in telecoms industry.

\section{Conclusion}

This chapter presents an investigation into the integration and analysis of data from CRM and CDR of Telecoms operators using SO approach to assist the organization in making real-time and accurate decision about the customer tariff plan to ensure customer satisfaction which in return can lead to increase in profit.

The prototype was evaluated against the potential outcome of the research study. The SOBI architecture and design was able to achieve all but the prototype has not been able to achieve everything. Analytic events on CDR, ability to offer the right product to the right customer, and security of WS have not been achieved. This is due to limitation of the prototype scope and it is expected that the prototype will have to go through next iteration of the software engineering process.

Telecoms operator cannot do without SOBI in the competitive market and ability to analyze, make decision, and act on the decision in time could be an advantage to exploit market opportunity. SOBI architecture have been developed and designed to achieve this but the prototype have not been able to evaluate everything about SOBI. Therefore, we need to implement other aspect and re-evaluate the SOBI architecture and design.

\section{References}

Atre, S. (2008), Successful Business Intelligence: Secrets to Making BI a Killer App, the McGraw-Hill Companies, ISBN: 978-0-07-149851-7, Available at http:/ / books.google.co.uk/ accessed [19 July 2010].

Atre, S. (2003), The Top 10 Critical Challenges for Business Intelligence Success, White Paper Article, Available at

http://www.computerworld.com/computerworld/records/images/pdf/BusIntel lWPonline.pdf accessed [19 July 2010].

Berthold, H., Rosch P., Zoller S., Wortmann F., Carenini A., Campbell S., Bisson P., and Strohmaier F. (2010), An Architecture for Ad-Hoc and Collaborative Business Intelligence, ACM Conference Proceeding Series Vol. 426, Proceeding of the 2010 EDBT/ICDT Workshops, Lausanne, Switzerland, ISBN:978-1-60558-990-9, Article No. 13, Available at http:/ / portal.acm.org/citation.cfm accessed [28 June 2010].

Christensen, E., Curbera, F., Meredith, G., and Weerawarana, S. (2001), Web Services Description Language (WSDL) 1.1, W3C, Available at http://www.w3.org/TR/wsdl, accessed [5th August 2010].

Chung, W. and Chen, H. (2009), Handbooks in Information Systems Series: Business Computing, Volume 3, Edited by Gediminas, A. and Alok, G.,Emerald Group Publishing Limited, ISBN:978-1-84855-264-7, Available at 
http:/ / books.google.co.uk/books accessed [14 June 2010] , pp. 373-396.

Cunningham, C., Song, L., and Chen, P.P. (2004), Data Warehouse Design to support Customer Relationship Management Analyses, Data Warehousing and OLAP, Proceedings of the 7th ACM international workshop on Data warehousing and OLAP, Washington DC, USA, ISBN: 1-58113-977-2, pp. 14-22, Available at http:// portal.acm.org accessed [8th July 2010].

Gordon, S., Grigg, R., Horne, M., and Thurman, S. (2006), Service-Oriented Business Intelligence, Microsoft, Available at http://msdn.microsoft.com/enus/library/bb245659.aspx accessed[18 June 2010].

Griffin, J. (2003), A Challenge for the Telecom Industry: Converging Enterprise Portals and Business Intelligence to Produce a Collaborative Business Platform, Information Management Magazine, August 2003, Available at http://www.informationmanagement.com/issues/20030801/7154-1.html accessed [6th July 2010].

Hadden, J., Tiwari, A., Roy, R., and Ruta, D. (2007), Computer assisted customer churn management: State-of-the-art and Future Trends, Computers and Operations Research vol.34, No.10, pp2902-2917

Han, J., and Kamber, M. (2006), Data Mining : Concepts and Techniques, Morgan Kaufmann, Second Edition, ISBN:1-55860-901-6.

$\mathrm{Hu}$, J., Khalil, I., Han, S., and Mahmood, A (2011). Seamless integration of dependability and security concepts in SOA: A feedback control system based framework and taxonomy. Journal of Network and Computer Applications Vol 34(4), July 2011, pp1150-1159

Hung, S.Y, Yen, D.C, and Wang, H.Y. (2006), Applying Data Mining to Telecom Churn Management, Expert Systems with Application Vol.31, Issue 3, pp. 515-524, available at linkinghub.elsevier.com/retrieve/pii/S0957417405002654, accessed [2nd July 2010].

Hwang, H., Jung, T., and Suh, E.(2004), An LTV model and customer segmentation based on customer value: a case study on the wireless telecommunication industry, Expert Systems with Application Vol.26, Issue 2, pp.181-188, Available at http://www.sciencedirect.com/science accessed[8th July 2010].

Ishaya, T., Chadband, J., and Grierson, L. (2007), Integrating Enterprise Data for Decision Support in Construction Organisations, Proceedings of the 9th International Conference Organisations Systems , Funchal, Madeira, Portugal, ICEIS(1) : 534-539.

Ishaya, T., and Rigneau, J. (2007), Data Quality for Effective E-Commerce Customer Relationship Management, Proceedings of the 9th International Conference on Enterprise Information Systems, Funchal, Madeira, Portugal, ICEIS (4): 92-100.

Johnstone, D., and Wong, C.Y. (2008), Billing Audit on a Mobile Operator-Call Detail Record, Information Systems Control Journal, Vol. 3.

Kudyba, S. and Hoptroff, R. (2001), Business Intelligence A Guide to Productivity, Idea Group Publishing, ISBN: 1-930708-03-3, Available at http://www.igi-global.com accessed [14 June 2010].

Kleinbaum, D.G, Kupper, L.L, Nizam, and Muller, K.E. (2008), Applied regression analysis and other multivariable methods, Fourth Edition, ISBN: 13:978-0-495-38496-0. Available at http:/ / books.google.co.uk/ accessed [12 July 2010]. 
Kulkarni, U., Power, D. J. and Sharda, R. (2007), Decision Support for Global Enterprises: Annals of Information Systems, Vol. 1, Springer, Available at http://www.springerlink.com/content/g02v70027227648u/fulltext.pdf accessed [15 June 2010].

Lee, J.H., and Park, S.C.(2005), Intelligent profitable customers segmentation system based on business on business intelligence tools, Expert Systems with Application Vol.29, pp.145-152, Available at

http://www.sci.brooklyn.cuny.edu/ kopec/cis718/fall_2005/sdarticle2.pdf accessed[5th July 2010].

Levin, S. (2002), Lessons in CRM: when it comes to caring for customers, telecom firms need to wise up. Here's a primer of best practices, complied from a roster of CRM experts - Telecom Corporate, Telecom Asia, Available at http://findarticles.com/p/articles/mi_m0FGI/is_10_13/ai_94010195/, accessed [8th July 2010].

Madnick, S.E, Lee, Y.W, and Zhu H. (2009), Overview and Framework for data and Information quality research, ACM Journal, Data Information Quality 1(1)

MetaGroup, (2004), Data Mining Tools: METAspectrunSM Evaluation, Available at http://www.oracle.com/technology/products/bi/odm/pdf/odm_metaspectrum _1004.pdf accessed [30 July 2010].

Moss, L.T., and Atre, S. (2003), Business Intelligence Roadmap: The Complete Project Lifecycle for Decision-Support Applications, Addison-Wesley, ISBN: 0-201-784203.

Pareek, D. (2006), Business Intelligence for telecommunications, Auerbach Publications, ISBN: 0-8493-8792-2.

Patrick, P. (2005), Impact of SOA on Enterprise Information Architectures, International Conference on Management of Data archive, Proceedings of the 2005 ACM SIGMOD International Conference on Management of Data, pp. 844-848.

Power, D., J. (2003), A Brief History of Decision Support Systems, version 2.8, DSSResources.COM, Available at

http:/ / dssresources.com/history/dsshistoryv28.html accessed [15 June 2010].

Ranjan, J. (2009), Business Intelligence: Concepts, Components, Technique and Benefits ,Journal of Theoretical and Applied Information Technology, Vol.9, No.1, Available at http://www.jatit.org/volumes/research-papers/Vol9No1/9Vol9No1.pdf accessed on [26 July 2010].

Rus, V.R., and Toader, V. (2008), Business Intelligence for hotels' Management Performance, International Journal of Business Research, FindArticles.com, Available at http://findarticles.com/p/articles/mi_6773/is_4_8/ai_n31136506/ accessed [14 June 2010].

Schnjakin, M., Menzel M., and Meinel C. (2009) , A pattern-driven security for serviceoriented architectures, Conference on Computer and Communications Security, Proceeding of the 2009 ACM workshop on Secure web services, Chicago, Illinios, USA, ISBN:978-60558-789-9, pp. 13-20, Available at http://portal.acm.org/citation.cfm accessed [28 June 2010]. 
Watson, H.J. (2005), Real Time: The Next Generation of Decision Support Data Management, Business Intelligence Journal, Vol. 10, No.3, pp. 4-6.

Weiss, G.M. (2004), Data Mining in Telecommunications, kluwer, 2004.

Witten, I.H, and Frank, E. (2005), Data Mining: Practical Machine Learning Tools and Techniques, Second Edition, ISBN: 0-12-088407-0, Available at http://books.google.co.uk/ accessed [12 July 2010].

Wu, L., Barash, G. And Bartolini, C. (2007), A Service Oriented Architecture for Business Intelligence, IEEE International Conference on Service-Oriented Computing and Application (SOCA'07), Newport, Beach. 



\section{Edited by Daniel Catalán-Matamoros}

Customer relationship management (CRM) strategies have become increasingly important worldwide due to changes in expectations from customers as well as changes in the nature of markets. This book puts forth a conceptualization that attempts to not only outline CRM's domain but also to reconcile the divergent perspectives found in the academic and popular literature. Readers can see through measurable data-containing examples how the theory is applied with great success by various real-life examples. This book presents innovative proven methods for determining whether a CRM strategy for changing the way a company provides service (by adding new technology, processes, and procedures) will realize the return on the investment projected. It could be a great help to CRM personnel, student, managers and any one that works directly or indirectly with customers. 